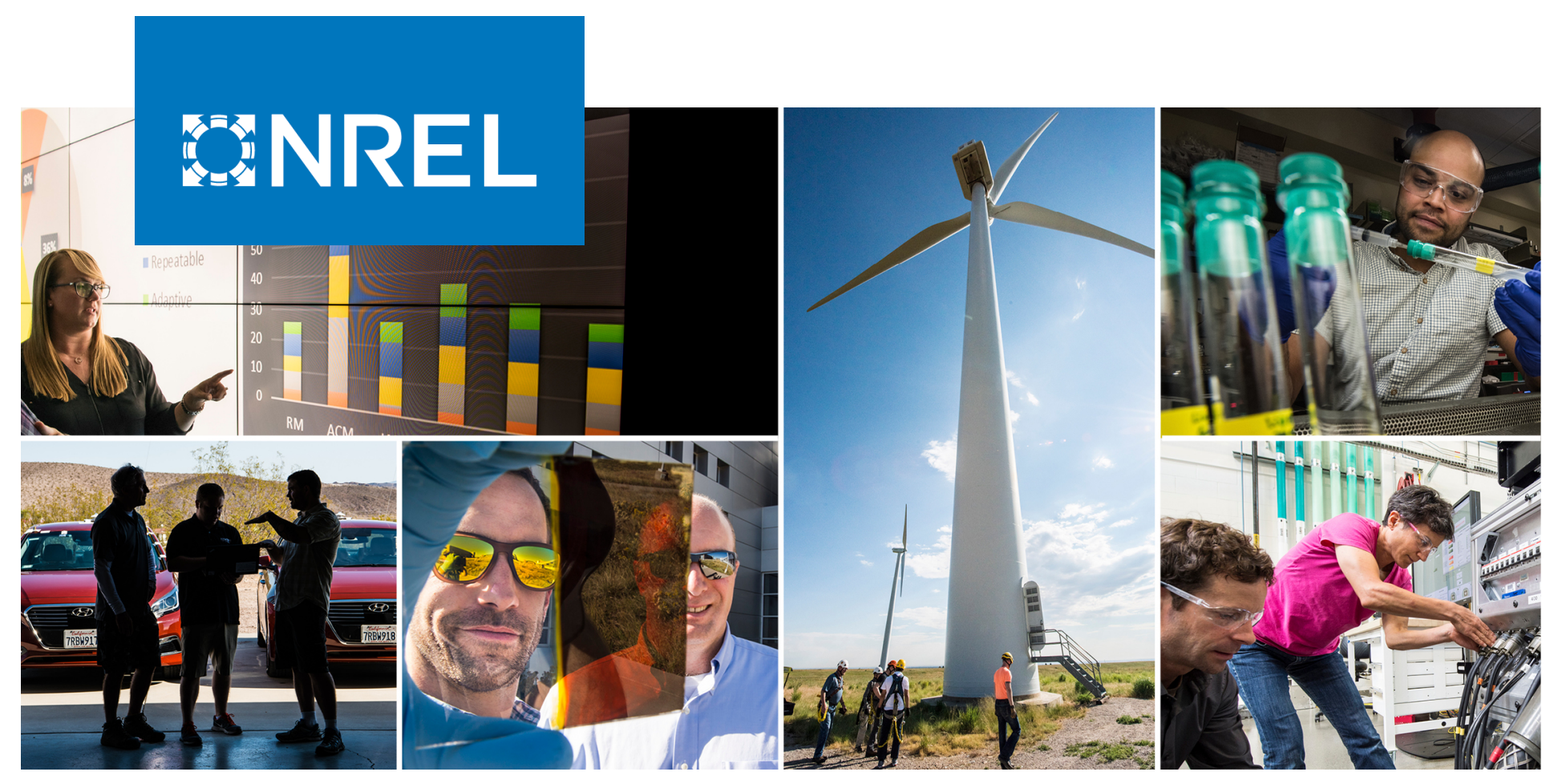

\title{
Molten Chloride Thermophysical Properties, Chemical Optimization, and Purification
}

Youyang Zhao

National Renewable Energy Laboratory

NREL is a national laboratory of the U.S. Department of Energy

Office of Energy Efficiency \& Renewable Energy

Operated by the Alliance for Sustainable Energy, LLC

This report is available at no cost from the National Renewable Energy Laboratory (NREL) at www.nrel.gov/publications.

\section{Technical Report}

NREL/TP- 5500-78047

November 2020 


\section{GNREL}

\section{Molten Chloride Thermophysical Properties, Chemical Optimization, and Purification}

Youyang Zhao

National Renewable Energy Laboratory

\section{Suggested Citation}

Zhao, Youyang. 2020. Molten Chloride Thermophysical Properties, Chemical

Optimization, and Purification. Golden, CO: National Renewable Energy Laboratory.

NREL/TP-5500-78047. https://www.nrel.gov/docs/fy21osti/78047.pdf.

NREL is a national laboratory of the U.S. Department of Energy Office of Energy Efficiency \& Renewable Energy Operated by the Alliance for Sustainable Energy, LLC

This report is available at no cost from the National Renewable Energy Laboratory (NREL) at www.nrel.gov/publications.

Contract No. DE-AC36-08GO28308
Technical Report NREL/TP-5500-78047 November 2020

National Renewable Energy Laboratory 15013 Denver West Parkway Golden, CO 80401 303-275-3000 • www.nrel.gov 


\section{NOTICE}

This work was authored by the National Renewable Energy Laboratory, operated by Alliance for Sustainable Energy, LLC, for the U.S. Department of Energy (DOE) under Contract No. DE-AC36-08GO28308. Funding provided by the Office of Energy Efficiency and Renewable Energy, Solar Energy Technologies Office (Award number DE-EE00033870). The views expressed herein do not necessarily represent the views of the DOE or the U.S. Government.

This report is available at no cost from the National Renewable Energy Laboratory (NREL) at www.nrel.gov/publications.

U.S. Department of Energy (DOE) reports produced after 1991 and a growing number of pre-1991 documents are available free via www.OSTI.gov.

Cover Photos by Dennis Schroeder: (clockwise, left to right) NREL 51934, NREL 45897, NREL 42160, NREL 45891, NREL 48097, NREL 46526.

NREL prints on paper that contains recycled content. 


\section{Final Technical Report}

Project Title:

Project Period:

Submission Date:

Recipient:

Address:

Website:

Award Number:

Project Team:

Principal Investigator:

\begin{abstract}
Business Contact:
\end{abstract}

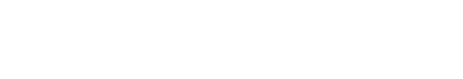

Technology Manager:

Project Officer:
Molten Chloride Thermophysical Properties, Chemical Optimization, and Purification

$2 / 1 / 18-8 / 31 / 20$

$10 / 5 / 2020$

National Renewable Energy Laboratory (NREL)

15013 Denver West Parkway

Golden, CO 80401-3305

www.nrel.gov/csp

DE-EE00033870

Savannah River National Laboratory (SRNL)

Sandia National Laboratories (SNL)

Argonne National Laboratory (ANL)

University of Wisconsin-Madison (UW)

University of Arizona (UA)

ICL Innovation, Ltd. (ICLIN), Israel Chemicals Ltd. (ICL)

Albemarle (in Chile)

SolarReserve

Youyang Zhao, Ph.D.

Phone: (303) 275-4398

Email: Youyang.Zhao@nrel.gov

Mark Mehos

Phone: (303) 384-7458

Email: Mark.Mehos@nrel.gov

Levi Irwin

Christine Bing 


\section{Executive Summary}

Next-generation concentrating solar power (CSP) technology requires high-temperature heattransfer fluids and thermal energy storage that can operate in the temperature range of $500^{\circ}-$ $720^{\circ} \mathrm{C}$. This high temperature demands a new chemistry for the heat-transfer fluids that must have high-temperature thermal and chemical stabilities, high energy density, and low corrosion rate on metallic materials used in the heat exchangers, piping, and thermal energy storage tanks. A ternary $\mathrm{MgCl}_{2}-\mathrm{KCl}-\mathrm{NaCl}$ chloride-salt system has been proposed to achieve such goals, given its high-temperature thermal stability. The chloride-salt-based systems have been used by the metallurgy industry as the electrolyte to electrolytically extract metallic magnesium. They have also attracted attentions from the nuclear industry for developing the molten salt fast reactors that can operate at close to atmospheric pressure and at higher temperature than traditional lightwater reactors.

However, the corrosion properties of the ternary salt are not well known. The corrosion mechanism is believed to be correlated to the presence of $\mathrm{MgOHCl}$ impurity at the operation temperature. $\mathrm{MgOHCl}$ is fundamentally caused by the hygroscopic nature of the $\mathrm{MgCl}_{2}$ component. Therefore, the first key objective of this project is to understand the nature of the corrosiveness of the ternary chloride-salt system and its prevention by designing new lab-scale purification processes. Because of its importance, a working group called the Chloride Salt Collective across multiple U.S. Department of Energy national laboratories is established to gain experimental agreement on the corrosion behaviors. In addition, water generation during salt dehydration could lead to highly corrosive $\mathrm{HCl} /$ water mixture via a hydrolysis process between water and anhydrous $\mathrm{MgCl}_{2}$ or $\mathrm{MgCl}_{2}$ hydrates. $\mathrm{MgOHCl}$ will eventually be converted to $\mathrm{MgO}$ particulates regardless of the chemical path chosen (i.e., by thermal decomposition, chemical purification with an active metal, or electrochemical purification utilizing the reduction power of electron flows). Large $\mathrm{MgO}$ particles with high hardness can wear out bearing and bushing and even clog the delicate channels in the primary heat exchanger. Because of this, a second objective is to understand the chemistry behind salt purification and transfer the scientific understanding to a set of engineering know-how for large-scale salt melter design. Because there is limited information on the thermophysical properties and the sensitivity of these properties around the targeted salt composition, a third objective is to measure thermophysical properties relevant to system and component design and support Topic 1 Liquid Pathway development. For example, composition shift due to salt reaction with water can be a potential issue because it can lead to changes of thermophysical properties, such as (1) melting point (or freeze point), which can jeopardize safe operation of the supercritical $\mathrm{CO}_{2}$ power cycle proposed for next-generation CSP, and (2) heat capacity and density, which can decrease the overall power-generation capability of the plants. The value of the thermal conductivity of the selected salt composition is also a critical criterion for the solar receiver design.

NREL's strategy is to: (1) benchmark the corrosion behavior of a commercially available salt and improve the corrosion properties by designing thermal, chemical, and/or electrochemical purification processes given our past expertise in the field of corrosion mitigation; (2) keep track of any shift in salt composition and impurity concentration during purification in order to locate the true salt composition and, more importantly, to understand the route toward maintaining desirable composition in case composition shift is inevitable during salt handling, purification, 
and operation; and (3) accurately and reliably measure relevant thermophysical properties that will be used to down-select the optimal salt composition to achieve highest per-cost energy density and provide key design parameters for Topic 1 Liquid Pathway system and component design. Because of the uncertain nature of any materials property measurements, statistics and uncertainties based on multiple measurements from different salt batches are provided to Topic 1 Liquid Pathway system and component designers in order to have the best representation of the inherent variations of the salt and its processing procedures. The statistics and uncertainties are later manifested into design considerations. The success in all three aspects of NREL's strategy can help assure long lifespan to next-generation CSP plants and does not present huge cost associated with plant maintenance due to corrosion. The knowledge of accurate and reliable thermophysical properties of the fluid will also provide guidance to downstream equipment manufacturers to better design their products.

After extensive experimental effort, NREL is able to use 1000-2500 ppm of elemental magnesium to produce up to $1 \mathrm{~kg}$ of purified salt with (1) low impurity levels (i.e., $\sim 0.1 \mathrm{wt} \%$ of $\mathrm{MgOHCl},{ }^{1}<100 \mathrm{ppm}$ of $\mathrm{S}$ and $<50 \mathrm{ppm}$ of $\mathrm{Fe}$ ), (2) consistent thermophysical properties (i.e., the standard-deviation-to-average-value ratio is 5-10\% for most properties), and (3) small $\mathrm{MgO}$ particulates using an effective particle settling step following salt purification. The recommended salt purification procedure has been verified by the Chloride Salt Collective, University of Wisconsin-Madison and MIT at up to $10 \mathrm{~kg}$. The $\mathrm{MgO}$ particle settling step in the lab-scale purification process is effective at reducing particulate mass loading from about $1 \mathrm{wt} . \%$ to less than $0.05 \mathrm{wt} . \%$. With an additional particle filtration process at $550^{\circ}-600^{\circ} \mathrm{C}$ with filters of $10-25$ $\mu \mathrm{m}$ pore size, the purification/settling process can produce a molten salt free of large $\mathrm{MgO}$ particles (i.e., $>20 \mu \mathrm{m} \mathrm{size}{ }^{2}$ ). The low particulate mass loading and small particle size can significantly reduce the risks of pump damage in the salt loop.

The experimental effort also reveals that salt degradation after short-term exposure (up to 3 hours) to oxygen (up to 21 vol.\%) and moisture (up to $400 \mathrm{ppm}$ ) is not as extensive as expected. Although the results seem encouraging, a similar longer-term investigation must be conducted with corrosion evaluations included in order to fully understand the consequences of impurity gas ingress during salt loop operation.

Static corrosion tests with Haynes 230 coupons suggest that the corrosion rates of Haynes 230 at $800^{\circ} \mathrm{C}$ in the purified baseline salt, based on mass measurements, are $259 \pm 28 \mu \mathrm{m} /$ year without corrosion inhibitors and can be significantly improved to $<30 \mu \mathrm{m} /$ year with extra $\mathrm{Mg}$ addition. However, the spread of corrosion data from the three national labs in the Chloride Salt Collective indicates that corrosion is sensitive to salt handling, melting and purification. Additional investigations with strictly controlled salt handling procedure must be conducted if highly quantitative corrosion rates are needed. More information under a flowing-salt condition at different corrosion time and temperatures is also needed for extrapolation to long-term corrosion behaviors.

\footnotetext{
${ }^{1}$ The real concentration might be lower. $0.1 \mathrm{wt} . \%$ is close to the limit of the analytical titration method.

2 The true particle size can be much smaller despite some disagreement between different particle size analysis techniques. Therefore, $>20 \mu \mathrm{m}$ is a conservative estimate.
} 


\section{Table of Contents}

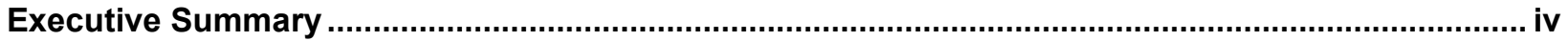

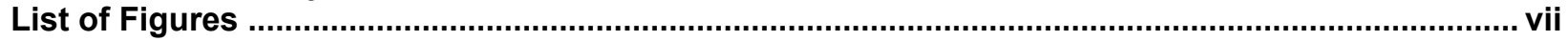

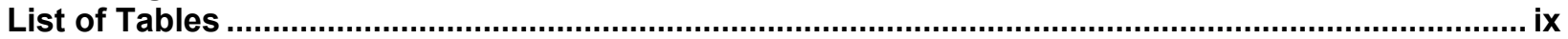

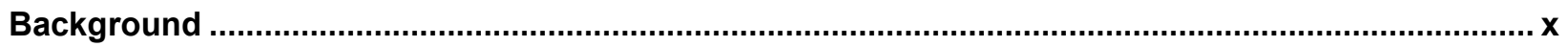

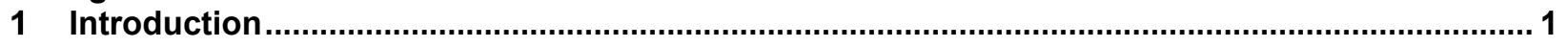

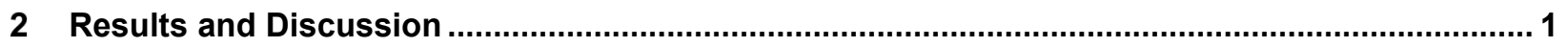

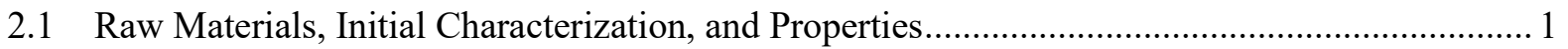

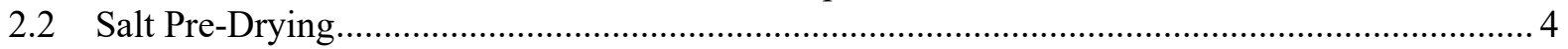

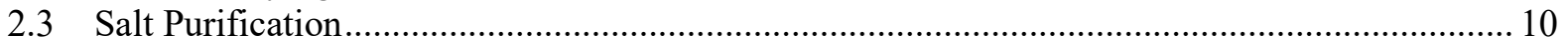

2.4 Purified Salt Composition and Thermophysical Properties .................................................... 30

2.5 Salt Degradation During Exposure to Moisture and/or Oxygen at High Temperature ............... 51

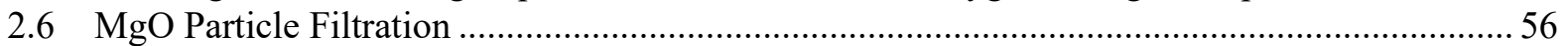

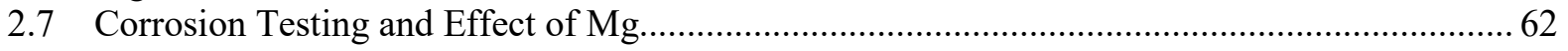

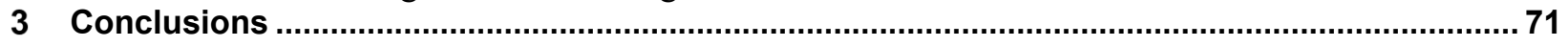

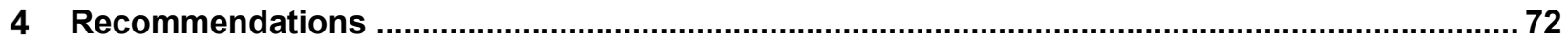

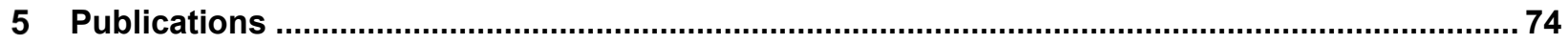

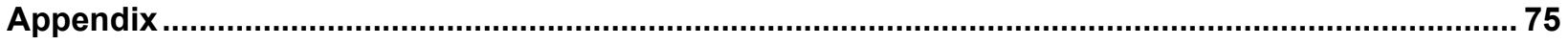

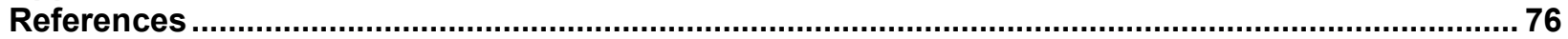




\section{List of Figures}

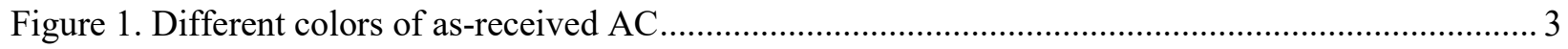

Figure 2. Weight change of purified carnallite during exposure to ambient atmosphere .......................... 4

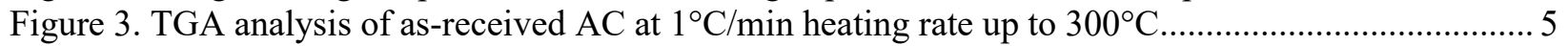

Figure 4. (a) Color comparison between raw AC and pre-dried AC; (b) Changes of pre-dried AC resting

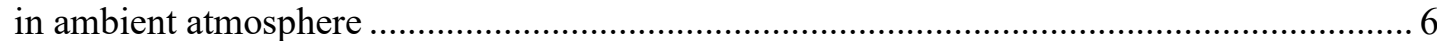

Figure 5. Variation of water release time during salt pre-drying as a function of total gas flow rate........... 8

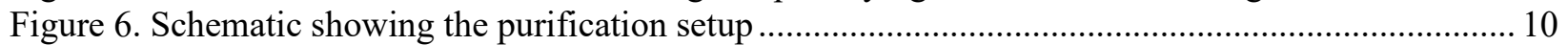

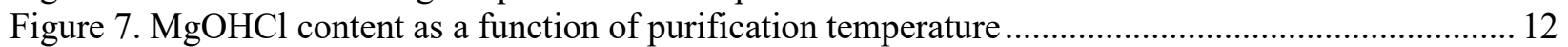

Figure 8. The effect of $\mathrm{Mg}$ addition on $\mathrm{MgOHCl}$ content after salt purification at $650^{\circ} \mathrm{C} \ldots \ldots \ldots \ldots \ldots \ldots \ldots . . . . . . .13$

Figure 9. Top: $\mathrm{pH}$ and sample temperature monitoring during salt purification; Bottom: calculated rate of

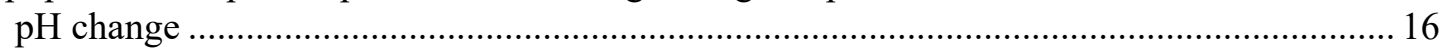

Figure 10. Flammability diagram for $\mathrm{H}_{2}-\mathrm{N}_{2}-\mathrm{O}_{2}$ mixture at room temperature ..................................... 18

Figure 11. Flammability diagram of $\mathrm{N}_{2}-$ rich $\mathrm{H}_{2}-\mathrm{N}_{2}-\mathrm{O}_{2}$ mixture at elevated temperatures ...................... 19

Figure 12. Hydrogen gas sensing during salt purification with $\mathrm{Mg}$ piece added at the beginning ............ 21

Figure 13. Variation of $\mathrm{HCl}$ release time during purification as a function of inert gas sparging rate ....... 23

Figure 14. Variation of post-purification $\mathrm{MgOHCl}$ content as a function of inert gas sparging rate ......... 24

Figure 15. Calculated unit distance settling time of $\mathrm{MgO}$ particles at $500^{\circ} \mathrm{C}$.......................................... 29

Figure 16. NaCl-KCl- $\mathrm{MgCl}_{2}$ phase diagram calculated by FactSage showing the compositions of the

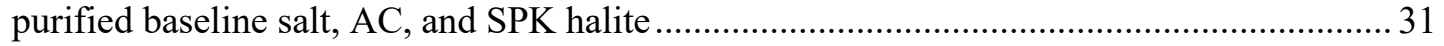

Figure 17. DSC heating and cooling traces for purified AC and baseline composition .......................... 32

Figure 18. (a) DSC heating and cooling traces for baseline +5 wt. $\% \mathrm{MgCl}_{2}$; (b) DSC heating and cooling traces for baseline $+10 \mathrm{wt} . \% \mathrm{MgCl}_{2}$ 34

Figure 19. (a) DSC heating and cooling traces for baseline $+5 \mathrm{wt} . \% \mathrm{NaCl}$; (b) DSC heating and cooling

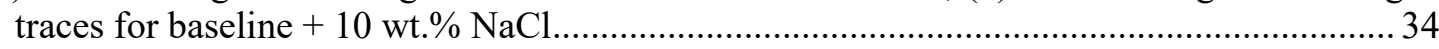

Figure 20. NaCl-KCl- $\mathrm{MgCl}_{2}$ phase diagram showing the locations of the baseline salt and the six offbaseline compositions with their approximate liquidus temperature ................................... 35

Figure 21. Molten-state heat capacity of the baseline salt .................................................................... 36

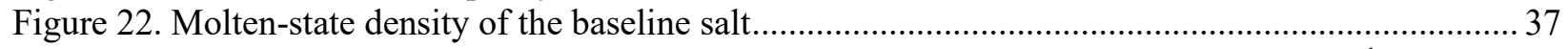

Figure 23. (a) Temperature variation of viscosity (b) Re-plot of $\ln$ (viscosity) vs. temperature ${ }^{-1}$.............. 39

Figure 24. Viscosity as a function of temperature for different $\mathrm{MgO}$ mass loading................................. 40

Figure 25. (a) Temperature variation of total vapor pressure (b) Re-plot of $\ln$ (vapor pressure) vs.

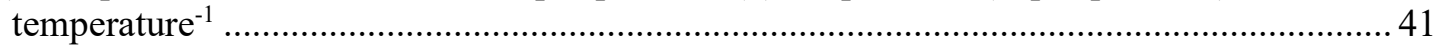

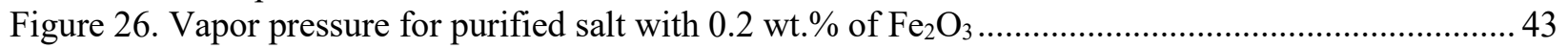

Figure 27. Vapor pressure of salts with different levels of $\mathrm{Fe}_{2} \mathrm{O}_{3}$ addition............................................. 44

Figure 28. (a) Temperature variation of the experimental thermal diffusivity (b) Temperature variation of

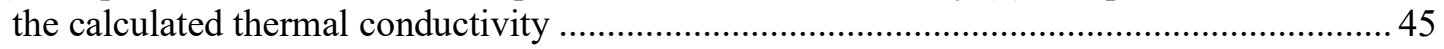

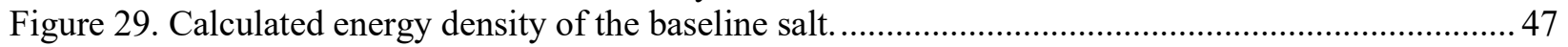

Figure 30. Calculated total vapor pressure of $40 \mathrm{MgCl}_{2} / 40 \mathrm{KCl} / 20 \mathrm{NaCl}(\mathrm{mol} \%)$ and individual gaseous

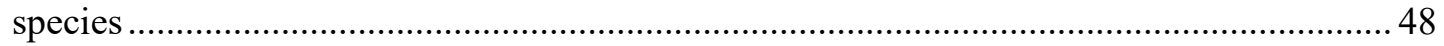

Figure 31. DSC heating and cooling traces for purified salt's vapor condensate ................................... 50

Figure 32. Particle size and distribution of salts after impurity gas ingress experiments ........................ 54

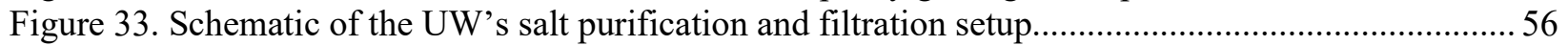

Figure 34. Stainless-steel filters used in UW's filtration experiment ................................................ 57

Figure 35. Schematic of the stainless-steel filters used during UW's filtration experiment......................57

Figure 36. Salt flow rate and pressure differential during UW's salt transfer/filtration .......................... 58

Figure 37. Pictures of particles collected on UW's stainless-steel filters .................................................59

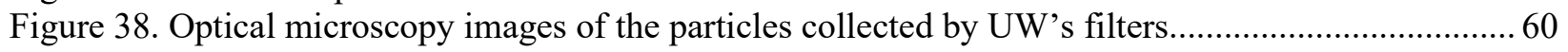

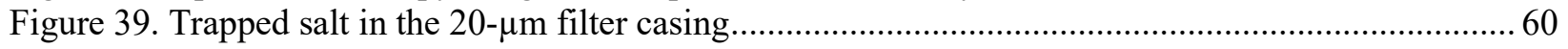


Figure 40. Optical microscopy images of UW's filtered salt............................................................ 61

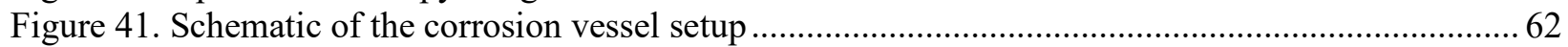

Figure 42. Corrosion rates of Haynes 230 with dehydrated carnallite (DC) and AC salts subject to different treatments

Figure 43. Corrosion rates of Haynes 230 in purified baseline salt and baseline salt with additional 0.1

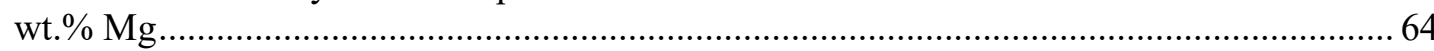

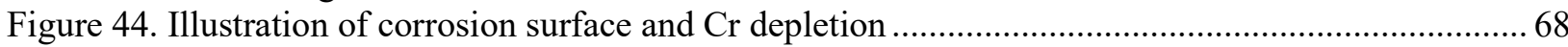

Figure 45. Cr profile across the corrosion interface of a H230 sample corroded in the baseline salt with

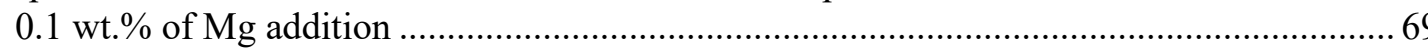

Figure 46. SEM image of the corrosion interface of a Haynes 230 coupon corroded in baseline salt ....... 70

Figure 47. SEM image of the corrosion interface of a Haynes 230 coupon corroded in baseline salt with

0.1 wt. $\%$ of $\mathrm{Mg}$ addition

Figure 48. (a) Variation of water release time during salt pre-drying at $275^{\circ}-285^{\circ} \mathrm{C}$ as a function of sparging gas flow rate. (b) Variation of water release time during salt pre-drying at $275^{\circ}-$ $285^{\circ} \mathrm{C}$ as a function of cover gas flow rate.

Figure 49. (Left) Vapor pressure for purified salt with 1 wt.\% of $\mathrm{Fe}_{2} \mathrm{O}_{3}$ (Right) Vapor pressure for purified salt with 3 wt. $\%$ of $\mathrm{Fe}_{2} \mathrm{O}_{3}$ 


\section{List of Tables}

Table 1. Chemical Analysis of AC and SPK Halite Provided by ICL and Albemarle .............................. 2

Table 2. Composition of Raw AC Measured by ICL and NREL ….................................................. 2

Table 3. Composition of SPK Halite Measured by Albemarle and NREL ................................................ 3

Table 4. $\mathrm{MgOHCl}$ Content by Analytical Titration on AC in the As-Received Condition ......................... 4

Table 5. Weight Loss During Pre-Drying Experiments Under Different Sparging Conditions .................. 7

Table 6. Recommended Heating Schedule and Gas Flow Rates for the Purification Process.................... 11

Table 7. Summary of Purifications With Different Parameters ................................................................ 23

Table 8. ICP Analysis of Salts Purified With Different Levels of Mg Addition ..................................... 25

Table 9. Average Composition and Standard Deviation of Purified AC + Halite Based on ICP-AES ...... 31

Table 10. Summary of Phase Transition Temperatures During Heating for Six Salt Compositions.......... 33

Table 11. Second-Order Polynomial Fit for the Heat Capacity ............................................................... 37

Table 12. Summary of Measured Thermophysical Properties of the Baseline Salt Composition .............. 46

Table 13. Elemental Analysis Results of Collected Vapor Condensate ................................................... 49

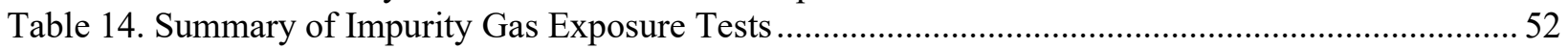

Table 15. Summary of the Measured Particle Mass Fraction, $\mathrm{MgOHCl}$ Content, and Salt Composition

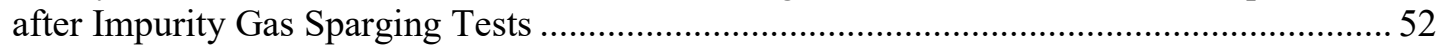

Table 16. Weight estimation of the Collected Particles on Stainless-Steel Filters after Filtration ............. 59

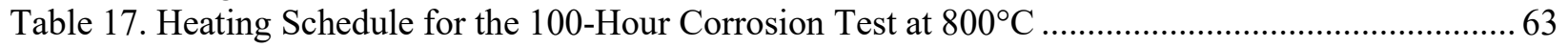

Table 18. Summary of Corrosion Results in the Salt Collective. ......................................................... 65

Table 19. ICP Analysis of Pre-Corrosion Salt Purified with 400 ppm Mg, Top Portion of the Post-

Corrosion Salt and Bottom Sludge of the Post-Corrosion Salt .............................................. 67

Table 20. Cr Depletion Depth for Hayne 230 Samples Corroded in Baseline Salt and Baseline Salt with

0.1 wt. $\%$ of $\mathrm{Mg}$ Addition 


\section{Background}

Solar Salt, $\mathrm{NaNO}_{3}-\mathrm{KNO}_{3}(60-40 \mathrm{wt} . \%)$, has been deployed as the heat-transfer fluid (HTF) and thermal energy storage (TES) medium for Gen2 CSP power tower technology. The designed operating temperature range is from $294^{\circ} \mathrm{C}$ to $565^{\circ} \mathrm{C}$ with a steam Rankine power cycle. To enable the use of a higher-efficiency super-critical $\mathrm{CO}_{2}\left(\mathrm{sCO}_{2}\right)$ power cycle, a new HTF chemistry needs to be discovered because Solar Salt is not stable above the maximum operating temperature of $565^{\circ} \mathrm{C}$, which forms $\mathrm{NO}_{\mathrm{x}}$ (e.g., $\mathrm{NO}$ and $\mathrm{NO}_{2}$ ). Molten chloride salts have been proposed as an alternative HTF chemistry for the next generation (Gen3) CSP technology operating at higher temperatures in order to maximize the benefit of using the $\mathrm{SCO}_{2}$ power cycle $[1,2]$. A significant number of research efforts [3,4,13-22,5,23-28,6-12] have been devoted to investigating molten chlorides' chemistry, thermodynamics, corrosion, and properties, especially the ternary system of $\mathrm{NaCl}-\mathrm{KCl}-\mathrm{MgCl}_{2}$ due to its availability and low cost.

The primary corrosion mechanism is believed to be correlated to the presence of magnesium hydroxychloride, $\mathrm{MgOHCl}$, impurity at the operation temperature [2,19,28-30]. This corrosive impurity is fundamentally caused by the hygroscopic nature of the $\mathrm{MgCl}_{2}$ component in the ternary salt (i.e., $\mathrm{MgCl}_{2}$ takes various forms of hydrates, such as $\mathrm{MgCl}_{2} \cdot \mathrm{H}_{2} \mathrm{O}, \mathrm{MgCl}_{2} \cdot 2 \mathrm{H}_{2} \mathrm{O}$, $\mathrm{MgCl}_{2} \cdot 4 \mathrm{H}_{2} \mathrm{O}$, and $\mathrm{MgCl}_{2} \cdot 6 \mathrm{H}_{2} \mathrm{O}$ ). Very similar behaviors to produce hydroxychloride during salt dehydration had been found in $\mathrm{CaCl}_{2}$ salt as well [16,17,31-35]. To mitigate the risks of the corrosive hydroxychloride species, multiple methods for salt dehydration and purification have been proposed, such as thermal treatment by controlled heating [26,29,43,31,36-42], reduction by elemental $\mathrm{Mg}$ [19,22,23,25], dehydration with ammonium chloride [14,29,42,44,45], and carbochlorination with $\mathrm{CO}, \mathrm{Cl}_{2}$, and/or $\mathrm{CCl}_{4}$ to remove oxide species $[13,14,46,47]$. Because the targeting CSP industry needs a significant amount of salt inventory $(>10,000 \mathrm{Mt})$ for each power plant, it is our intent to investigate the most cost-effective and scalable salt purification process. The ammonium chloride dehydration and carbochlorination processes are either not readily scalable or require handling toxic gases. Therefore, the present work is mostly motivated by the relative ease of thermal dehydration of $\mathrm{MgCl}_{2}$ hydrates and $\mathrm{Mg}$ reduction to remove impurities. The dehydration of these hydrates (Eqs. 1-4) and hydrolysis of anhydrous $\mathrm{MgCl}_{2}$ with the released $\mathrm{H}_{2} \mathrm{O}$ (Eqs. 5 and 6) form $\mathrm{MgOHCl}$ which have been reported by the literature [3,15,49$51,16,17,29,31,39,41,42,48]$. The temperature range after each reaction is a compilation of various reported values from the literature.

$$
\begin{gathered}
\mathrm{MgCl}_{2} \cdot 6 \mathrm{H}_{2} \mathrm{O}=\mathrm{MgCl}_{2} \cdot 4 \mathrm{H}_{2} \mathrm{O}+2 \mathrm{H}_{2} \mathrm{O} \text { at } 96^{\circ}-117^{\circ} \mathrm{C} \\
\mathrm{MgCl}_{2} \cdot 4 \mathrm{H}_{2} \mathrm{O}=\mathrm{MgCl}_{2} \cdot 2 \mathrm{H}_{2} \mathrm{O}+2 \mathrm{H}_{2} \mathrm{O} \text { at } 107^{\circ}-180^{\circ} \mathrm{C} \\
\mathrm{MgCl}_{2} \cdot 2 \mathrm{H}_{2} \mathrm{O}=\mathrm{MgCl}_{2} \cdot \mathrm{H}_{2} \mathrm{O}+\mathrm{H}_{2} \mathrm{O} \text { at } 153^{\circ}-242^{\circ} \mathrm{C} \\
\mathrm{MgCl}_{2} \cdot \mathrm{H}_{2} \mathrm{O}=\mathrm{MgCl}_{2}+\mathrm{H}_{2} \mathrm{O} \text { at } 304^{\circ}-400^{\circ} \mathrm{C} \\
\mathrm{MgCl}_{2} \cdot 2 \mathrm{H}_{2} \mathrm{O}=\mathbf{M g O H C l}+\mathrm{HCl}(\mathrm{g})+\mathrm{H}_{2} \mathrm{O} \text { at } 193^{\circ}-240^{\circ} \mathrm{C} \\
\mathrm{MgCl}_{2}+\mathrm{H}_{2} \mathrm{O}=\mathrm{MgOHCl}+\mathrm{HCl}(\mathrm{g}) \text { at } 210^{\circ}-445^{\circ} \mathrm{C}
\end{gathered}
$$

These reactions, combined with the thermal decomposition of $\mathrm{MgOHCl}[29,40,52]$,

$$
\operatorname{MgOHCl}=\boldsymbol{M g O}+\boldsymbol{H C l}(\boldsymbol{g}) \text { at } 500^{\circ}-568^{\circ} \mathrm{C},
$$


will produce a corrosive $\mathrm{HCl} / \mathrm{H}_{2} \mathrm{O}$ mixture, irreversibly shift the overall salt composition, and eventually form one mole of $\mathrm{MgO}$ for each mole of $\mathrm{MgCl}_{2}$ involved, as shown below [48,51].

$$
\boldsymbol{M g C l}_{2}+\boldsymbol{H}_{2} \boldsymbol{O}=\boldsymbol{M g O}+\mathbf{2 H C l}(\boldsymbol{g}) \text { at } 455^{\circ}-468^{\circ} \mathrm{C}
$$

This outcome can be a serious issue because it may lead to changes of thermophysical properties such as (1) melting point (or freezing point), which can jeopardize the safe operation of the CSP plants, and (2) heat capacity and density, which can decrease the overall power-generation capability of the CSP plants when integrated to the supercritical $\mathrm{CO}_{2}$ Brayton power cycle. The production of $\mathrm{MgO}$ in the form of fine particulates can also risk clogging the delicate channels in the primary heat exchanger and the bushing and bearings used in the salt pumps. Therefore, proper purification of $\mathrm{MgCl}_{2}$-containing chloride salt is needed.

Some efforts have been dedicated to understanding the reversibility of the aforementioned reactions in an attempt to find a means to suppress the formation of $\mathrm{HCl}$ and $\mathrm{MgOHCl}$. Chlorination of $\mathrm{MgOHCl}$ with $\mathrm{HCl}$ or $\mathrm{Cl}_{2}$ to form $\mathrm{MgCl}_{2}$ and $\mathrm{H}_{2} \mathrm{O}$ (e.g., the reverse reaction of Eq. 6) was investigated by $[53,54]$. However, the kinetics of chlorination gradually diminish as chlorination time increases, which seems independent of chlorination temperature, possibly due to the back reaction when $\mathrm{H}_{2} \mathrm{O}$ is generated. Similarly, the reverse reaction of Eq. 7 was also investigated between $450^{\circ}$ and $650^{\circ} \mathrm{C}$ [55]. The reaction kinetics slow down as diffusion of $\mathrm{HCl}$ through the layer of $\mathrm{MgCl}$, the reaction product, dominates over the chemical reaction between $\mathrm{MgO}$ and $\mathrm{HCl}$. At the industrial scale, using $\mathrm{HCl}$ or $\mathrm{Cl}_{2}$ requires corrosion-resistant hardware and gas scrubbing systems for environmental, health, and safety reasons. Hence, this type of method is not practical for the cost-sensitive CSP industry, where the targeting TES cost is $\$ 15 / \mathrm{kWh}$ thermal (set by the U.S. Department of Energy), which includes materials cost, processing cost, and all relevant hardware cost (e.g., TES tanks). Therefore, the purification method utilizing the reduction power of an active metal such as $\mathrm{Mg}[19,22,23,25]$ according to Eq. 9 seems most promising.

$$
2 \mathrm{MgOHCl}+\mathrm{Mg}=2 \mathrm{MgO}+\mathrm{MgCl}_{2}+\mathrm{H}_{2}
$$




\section{Introduction}

The first year of the project was designed for performing initial investigation on the candidate salts and sharing information with two partner national labs, Oak Ridge National Laboratory (ORNL) and Savannah River National Laboratory (SRNL). The results were used to inform the second year to optimize the purification process and final salt composition, measure thermophysical properties, and understand salt degradation as a function of impurity gas ingress.

\section{Project Objectives:}

- Use state-of-the-art capabilities to optimize and control purification of salts to completely remove oxygen and water-containing compounds.

- Optimize purification and chemical procedures to obtain real eutectic compositions of mixtures containing $\mathrm{MgCl}_{2}$ or hygroscopic salts that will provide the required minimum congruent melting point.

- Develop, validate, and publish in the open literature the purification procedures of mixtures containing $\mathrm{MgCl}_{2}$ or hygroscopic salts.

- Develop, validate, and publish protocols and national/international guidelines for handling, preparing, and testing hygroscopic molten salts.

- Determine, validate, and publish in the open literature reliable and accurate thermophysical data necessary to support the design and development of CSP components.

- Using developed procedures, determine reliable and accurate thermophysical data of purified commercial salts, including the chemical composition of tested samples before and after analyses.

\section{Results and Discussion}

\subsection{Raw Materials, Initial Characterization, and Properties}

\section{Compositions of As-Received Materials}

The primary raw materials used in the project are anhydrous carnallite (AC) from Israel Chemicals Ltd (ICL) and Silver Peak (SPK) halite from Albemarle Corporation. The approximate compositions for $\mathrm{AC}$ and $\mathrm{SPK}$ halite reported by the suppliers are $45.3 \mathrm{MgCl}_{2}-$ $40.6 \mathrm{KCl}-13.9 \mathrm{NaCl}$ (wt.\%) and $92.5 \mathrm{NaCl}-6.0 \mathrm{KCl}-1.4 \mathrm{CaSO}_{4} \cdot 2 \mathrm{H}_{2} \mathrm{O}$ (wt.\%), respectively. The elemental makeup, including other minor salt components, is summarized in Table 1. 
Table 1. Chemical Analysis of AC and SPK Halite Provided by ICL and Albemarle, Respectively

Empty cells indicate that the element or ion is not detected.

\begin{tabular}{|c|c|c|c|}
\hline & Unit & ICL AC & SPK Halite \\
\hline $\mathrm{Mg}$ & \multirow{3}{*}{ wt. $\%$} & 11.4 & 0.125 \\
\hline $\mathrm{K}$ & & 20.8 & 1.80 \\
\hline $\mathrm{Na}$ & & 4.9 & 23.5 \\
\hline $\mathrm{Ca}$ & \multirow{8}{*}{ ppm } & & 3,848 \\
\hline $\mathrm{Br}$ & & 3,900 & \\
\hline $\mathrm{Fe}$ & & 46.2 & \\
\hline $\mathrm{Mn}$ & & 3.36 & \\
\hline $\mathrm{Li}$ & & & 378 \\
\hline $\mathrm{SO}_{4}{ }^{2-}$ & & 203 & \\
\hline $\mathrm{S}$ & & & 3,425 \\
\hline $\mathrm{Zn}$ & & $<1$ & \\
\hline
\end{tabular}

Tables 2 and 3 show the compositions measured by the suppliers and NREL. Batch-to-batch variation of salt composition as well as measurement inconsistency are observed:

- In Table 2, the $\mathrm{NaCl}$ content in the Jan 2019 batch measured by NREL is more than two standard deviations away from the yearly average of 2018 measured by ICL. The $\mathrm{MgCl}_{2}$ content in the Jan 2019 batch measured by NREL is more than one standard deviation away from the yearly average of 2018 measured by ICL. Similar composition discrepancy is observed between the same salt batch (Jan 2019) measured by ICL and NREL.

- No statistical data are available regarding the SPK halite composition. The composition discrepancy in Table 3 is on the similar order of magnitude (i.e., 1-2 wt.\%).

Although variations of industrial-grade materials produced at Mt-scale are not unexpected, we must: (1) acknowledge and understand the potential risks, (2) perform regular quality check on as-received materials, and (3) deploy correction measures accordingly (e.g., by adjusting salt purification recipe).

Table 2. Composition of Raw AC Measured by ICL and NREL

\begin{tabular}{|c|c|c|c|c|c|}
\hline \multirow{2}{*}{ Salt Batch } & \multirow{2}{*}{$\begin{array}{c}\text { Measurement } \\
\text { by }\end{array}$} & \multirow{2}{*}{ Data } & $\mathrm{KCl}$ & $\mathrm{NaCl}$ & $\mathrm{MgCl}_{2}$ \\
\hline & & & \multicolumn{3}{|c|}{$w t \%$} \\
\hline \multirow{2}{*}{ Jan-Dec 2018* } & \multirow{2}{*}{$\mathrm{ICL}$} & Average & 40.6 & 13.9 & 45.3 \\
\hline & & Stdev & 0.69 & 0.43 & 0.63 \\
\hline Jan 2019 & ICL & $\begin{array}{c}\text { Average } \\
\text { only }\end{array}$ & 40.8 & 13.0 & 46.2 \\
\hline Aug 2019 & ICL & $\begin{array}{c}\text { Average } \\
\text { only }\end{array}$ & 41.4 & 12.8 & 45.9 \\
\hline \multirow{2}{*}{ Jan 2019** } & \multirow{2}{*}{ NREL } & Average & 38.6 & 12.3 & 49.1 \\
\hline & & Stdev & 0.97 & 0.43 & 0.68 \\
\hline
\end{tabular}

* Based on multiple measurements on a monthly basis

** Based on three measurements 
Molten Chloride Thermophysical Properties, Chemical Optimization, and Purification National Renewable Energy Laboratory

Table 3. Composition of SPK Halite Measured by Albemarle and NREL

\begin{tabular}{|c|c|c|c|c|c|}
\hline \multirow{2}{*}{ Salt Batch } & \multirow{2}{*}{$\begin{array}{l}\text { Measurement } \\
\text { by }\end{array}$} & \multirow{2}{*}{ Data } & $\mathrm{KCl}$ & $\mathrm{NaCl}$ & $\mathrm{CaSO}_{4} \cdot 2 \mathrm{H}_{2} \mathrm{O}$ \\
\hline & & & \multicolumn{3}{|c|}{$w t \%$} \\
\hline Jan 2019 & Albemarle & $\begin{array}{c}\text { Average } \\
\text { only }\end{array}$ & 5.96 & 92.5 & 1.41 \\
\hline Jan 2019 & NREL & $\begin{array}{c}\text { Average } \\
\text { only }\end{array}$ & 8.57 & 90.7 & 0.70 \\
\hline
\end{tabular}

MgOHCI Impurities in As-Received AC

At ICL, the raw materials for AC were melted after a drying process and a chlorination process.

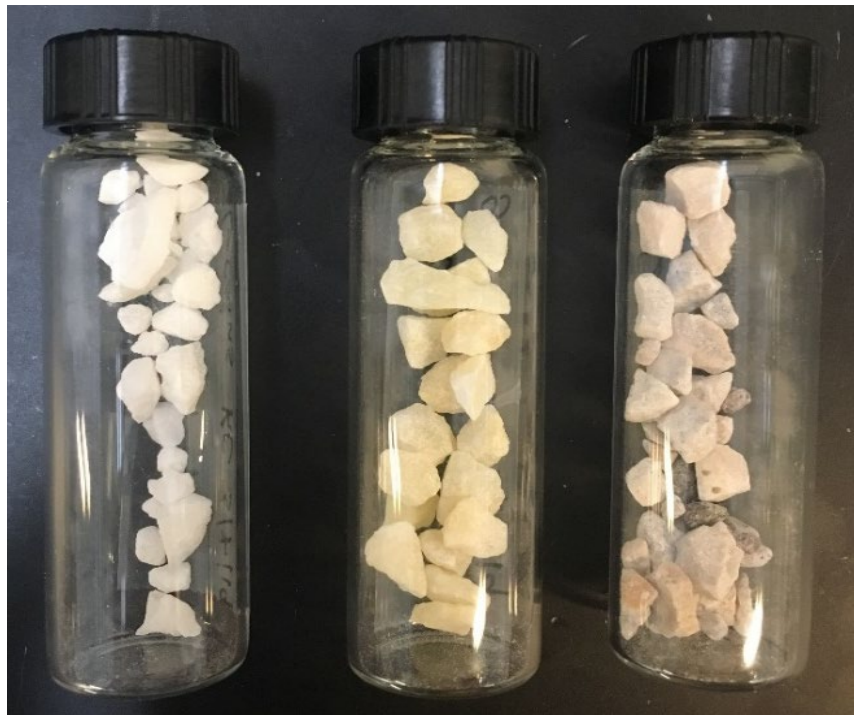

Figure 1. Three colored phases (white, yellow, and gray from left to right) of AC. Slow solidification and cooling at Dead Sea Magneiusm (DSM) may have resulted in phase separation. Yellow is the primary phase in $A C$ in terms of quantity.
Because the raw materials (i.e., salts extracted from the Dead Sea) had significant amounts of water, the melting process produced $\mathrm{MgOHCl}$ as suggested by Eqs. 1 to 6. The chlorination process with $\mathrm{Cl}_{2}$ gas was implemented to suppress the formation of $\mathrm{MgOHCl}$, but it was not expected that chlorination would completely avoid formation of $\mathrm{MgOHCl}$.

Salt grains of three distinct colors were observed in as-received AC (Figure 1); yellow is the dominant color. ${ }^{3}$ Two hypotheses were given regarding the colors:

1. Given the complexity of the $\mathrm{MgCl}_{2}$ $\mathrm{NaCl}-\mathrm{KCl}$ phase diagram in the solid state, the melting and solidification processes could have introduced phase transformation in the solidified AC because of slow cooling at industrial scale (instead of quenching).

2. Because the production process of $\mathrm{AC}$ produced significant amounts of $\mathrm{MgO}$, but there were no strict measures to separate the $\mathrm{MgO}$ particles and/or there was short-circuiting of the salt flow, ${ }^{4}$ the gray phase is likely the salt near the $\mathrm{MgO}$ sludge in the chlorination chamber that is richer in $\mathrm{MgO}$. The yellow color is hypothesized to be due to higher water absorption during storage or during transportation ${ }^{5}$ or higher $\mathrm{FeCl}_{3}$ content (as claimed by ICL).

A titration method [56] was used to determine the initial $\mathrm{MgOHCl}$ content in all three phases of salt shown in Figure 1. The results are summarized in Table 4. Note that the multiple titrations

\footnotetext{
${ }^{3}$ It must be acknowledged that color variation from batch to batch has been observed. For example, an AC batch received by NREL around June 2020 (produced in early 2018 and stored in steel drums at ICL) exhibits a more orange color. Therefore, it is recommended to use salt colors as a qualitative tool only.

${ }^{4}$ Short-circuiting means some salts flow to the outlet of the chlorinator chamber without spending enough time chlorinating with $\mathrm{Cl}_{2}$ and/or allowing $\mathrm{MgO}$ particles to settle down.

5 The hypothesis was inspired by a salt pre-drying experiment when the as-received AC salt was exposed to $250^{\circ}-$ $300^{\circ} \mathrm{C}$, after which the yellow salt changed to off-white.
} 
were performed on each salt sample by two individuals to minimize human errors. Because the yellow salt is the dominant type, the average $\mathrm{MgOHCl}$ content is expected to be on the order of 1 wt.\%.

A salt pre-drying experiment at 500-g scale in a furnace with ultra-high-purity $\mathrm{N}_{2}$ cover gas (heating up from room temperature to $\sim 285^{\circ} \mathrm{C}$ at $5^{\circ} \mathrm{C} / \mathrm{min}$ and holding until no water or $\mathrm{HCl}$ was detected in the off-gas) and a thermogravimetric analysis (TGA) experiment under ultra-highpurity $\mathrm{Ar}$ (heating up from room temperature to $300^{\circ} \mathrm{C}$ at $1{ }^{\circ} \mathrm{C} / \mathrm{min}$ ) were performed with the intention of removing absorbed moisture in the as-received AC. Post-drying inspection showed that most of the yellow color disappeared after both experiments. Post-drying weight measurement showed that the weight loss was about $1.9 \mathrm{wt} . \%$ in the 500 -g scale furnace experiment and about $2.5 \mathrm{wt} . \%$ in the $10 \mathrm{mg}$ scale TGA experiment. The higher weight loss after the TGA experiment is most likely due to higher surface-area-to-volume ratio of a small salt grain.

\section{Table 4. MgOHCl Content by Analytical Titration on Three Colored Phases of AC in the As- Received Condition}

Titration was performed by two intern students using the same salt sampled in the exact same fashion.

\begin{tabular}{|c|c|}
\hline Salt Phase & MgOHCl wt. $\%$ \\
\hline White & 0.596 \\
\hline Yellow & 1.156 \\
\hline Gray & 1.074 \\
\hline
\end{tabular}

In conclusion, the color difference will not be of primary concern for future re-melting and purification at Mt-scale, because local variations in color (or moisture content) will be averaged out by (1) simple mixing of metric tons of raw materials and (2) a dedicated pre-drying process to remove moisture.

\subsection{Salt Pre-Drying}

ICL reported 0.575 wt. $\%$ and 0.76 wt. $\%$ of loss on drying ${ }^{6}$ for the January 2019 AC salt batch, which was used during the second year of the project. Communication with ICL revealed that the AC salt after production was stockpiled in ambient atmosphere. To understand the potential impact of moisture absorption, NREL monitored the weight change of a purified

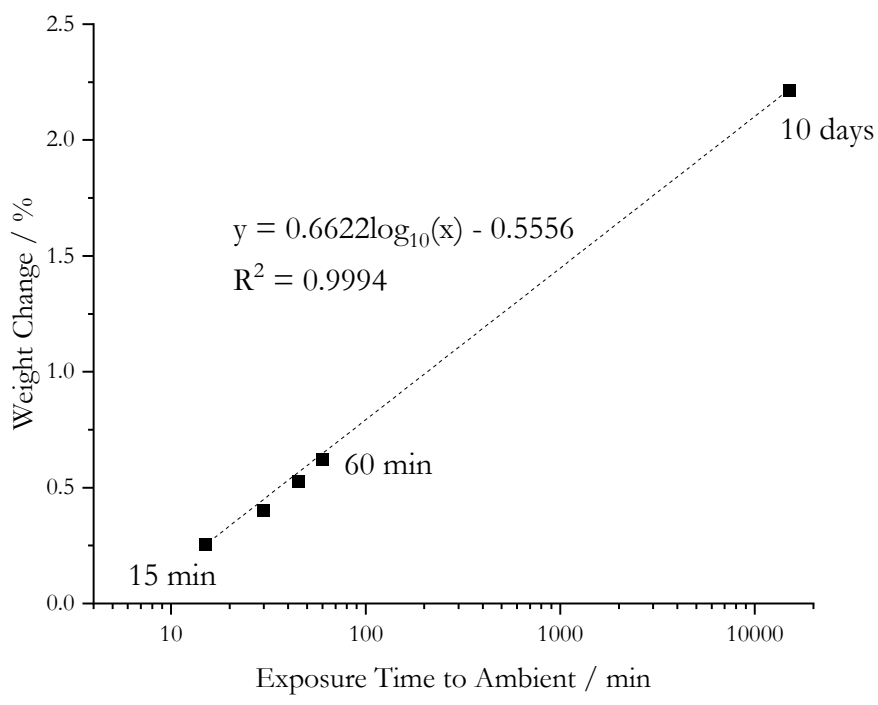

Figure 2. Weight change of purified carnallite during exposure to ambient atmosphere in the laboratory; note that the time axis is in logarithmic scale

\footnotetext{
${ }^{6}$ Drying temperature was not reported.
} 
carnallite salt ${ }^{7}$ that was crushed into salt grains of $\sim 1 \mathrm{~mm}$ size during exposure to ambient atmospheres. ${ }^{8}$ Figure 2 reveals a weight gain (most likely due to moisture absorption) at $\sim 2$ wt. $\%$ over 10 days of exposure. Therefore, it is very reasonable to assume that similar or greater moisture absorption had happened in the as-received AC due to storage in ambient at ICL. ${ }^{9}$ Note that a logarithmic fit is best at describing the moisture absorption vs. time relation in Figure 2 with a $\mathrm{R}^{2}$ value very close to 1 . However, the specific form of the logarithmic fit does not have the best physical meaning for moisture absorption because, mathematically, it never crosses the origin (i.e., no moisture

absorption at $\mathrm{t}=0 \mathrm{~min}) .{ }^{10}$

Figure 3 shows a typical TGA study on $\sim 10 \mathrm{mg}$ of as-received $\mathrm{AC}$ (as mentioned in the previous section) with a weight loss around 2.75 wt. $\%$ below $\sim 120^{\circ} \mathrm{C}$.

Similarly, a few 450-900-g predrying experiments were conducted by heating up the salt from room temperature to $200^{\circ}-$ $300^{\circ} \mathrm{C}$ at $5^{\circ} \mathrm{C} / \mathrm{min}$ and holding until water release stopped, as measured by a moisture sensor connected to the off-gas line. Table 5 shows the results from these pre-drying experiments. After the pre-drying experiments, the salt turned from yellow to offwhite (Figure 4a).

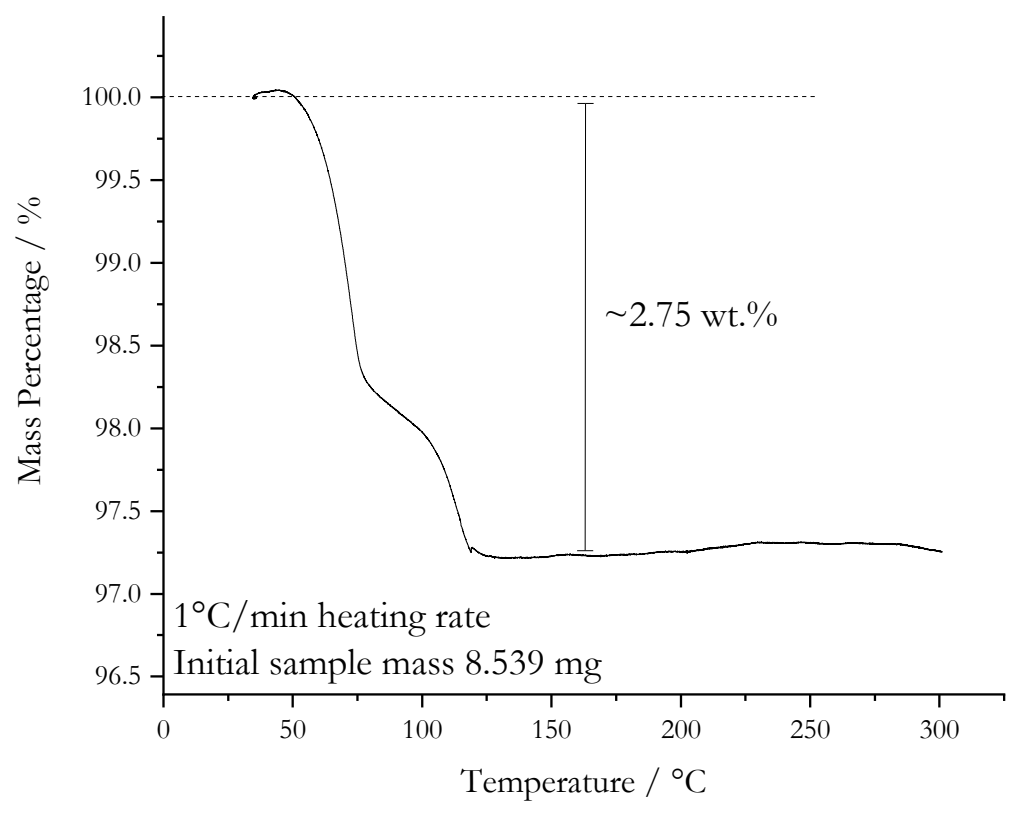

Figure 3. TGA analysis of $8.539 \mathrm{mg}$ of as-received $\mathrm{AC}$ at $1^{\circ} \mathrm{C} / \mathrm{min}$ heating rate up to $300^{\circ} \mathrm{C}$

Figure 4 shows a few important findings:

1. There is a strong correlation between the color change and water release during pre-drying. Previous understanding was that the light yellow color of the raw AC is characteristic of carnallite. However, the off-white color after pre-drying - where the pre-drying temperature is likely not high enough to cause composition shift in terms of the content $\mathrm{Mg}, \mathrm{K}, \mathrm{Na}$, and other minor salt components - proves that the color change is more correlated to change in salt's crystal structure due to removal of hydrates. Color change has been observed in the literature for salt hydrates during dehydration [57-59]. To our best knowledge, there is no

\footnotetext{
${ }^{7}$ The purification process was slightly different than the purification procedure recommended in this report. But the results should serve as a reasonable indicator for moisture absorption.

${ }^{8}$ The temperature and relative humidity in the lab were $22.69^{\circ} \pm 0.35^{\circ} \mathrm{C}$ and $30.25 \% \pm 4.28 \%$, recorded over 7 days at 15-min intervals.

${ }^{9}$ According to ICL, the salt was stored in closed barrels after mechanical crushing under open atmospheres without special precautions.

${ }^{10}$ For example, if moisture absorption is limited by mass diffusion, then absorption/mass gain proportional to time ${ }^{1 / 2}$ is expected given the Fick's Laws of Diffusion.
} 
known correlation between dehydration of physically absorbed moisture and color change in a salt system. Alternatively, ICL suggests that the color change is due to the removal of $\mathrm{FeCl}_{3}$ during pre-drying around $250^{\circ}-300^{\circ} \mathrm{C} .{ }^{11} \mathrm{FeCl}_{3}$ is originally introduced in the chlorinator with Fe electrodes.
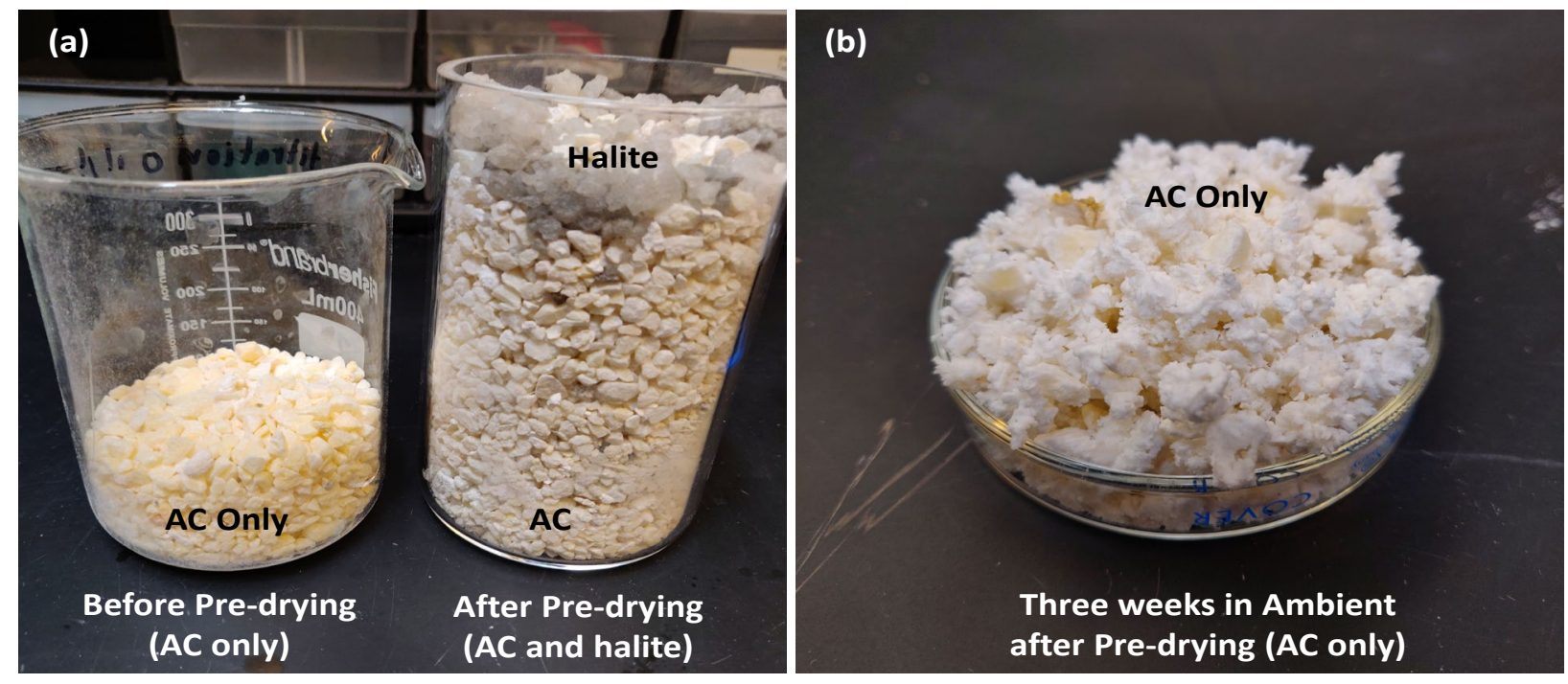

Figure 4. (a) Color comparison between raw AC and pre-dried AC; (b) Change of pre-dried AC resting in ambient atmosphere three weeks after pre-drying

2. Comparison between the raw AC (Figure 4a) and the pre-dried AC that has been resting in ambient for over three weeks after pre-drying (Figure $4 \mathrm{~b}$ ) also suggests that the pre-drying not only removes physically absorbed moisture but also certain hydrates. The reason is that the raw $\mathrm{AC}$ has been resting in ambient for over 12 months since delivery at NREL. During this long period, during which raw $\mathrm{AC}$ can absorb atmospheric moisture, we did not observe noticeable appearance change (i.e., the AC stayed yellow and granular). The pre-dried AC resting in ambient, however, slowly grew and had a visible volume increase (or a popping behavior) above its original height (about the height of the petri dish shown in Figure 4b) because of the formation of the snowflake-like "arms" on the surface of the salt grains. Although we didn't characterize these "arms," this behavior seems to closely resemble the growth of salt hydrates by nucleation $[60,61]$. $\mathrm{HCl}$ release data (discussed below) also corroborate the hypothesis that pre-drying does remove some hydrates (which makes rehydration a possibility).

A few observations and possible explanations regarding water release and weight loss are summarized next:

- Unfortunately, the TGA was not equipped with a mass spectroscopy at the time to identify the released species when weight loss started. However, we can reasonably assume that water is the most likely species, based on literature information. There is a significant difference in temperature between the onset of weight loss in TGA (as low as $50^{\circ} \mathrm{C}$ ) and the onset of water release in pre-drying (from $104^{\circ} \mathrm{C}$ to $230^{\circ}$ ). The discrepancy in temperature can be partially

\footnotetext{
11 The melting point and boiling point of solid $\mathrm{FeCl}_{3}$ are $306^{\circ} \mathrm{C}$ and $315^{\circ} \mathrm{C}$, respectively, meaning removal of $\mathrm{FeCl}_{3}$ via evaporation is possible with direct heating at $250-300^{\circ} \mathrm{C}$.
} 
explained by the temperature measurement accuracy in each setup. TGA usually uses $<10 \mathrm{mg}$ of salt, and the control thermocouple is located right below the crucible holding the salt sample. On the other hand, temperature is measured by a thermocouple inserted into the loosely packed salt in the pre-drying experiments. Loosely packed salt (made of 2- to 5-mm grains) is considered a bad thermal conductor because of solid-solid heat transfer between salt grains and the air trapped in the free spaces. Therefore, there could be a significantly non-uniform temperature distribution in the salt. When multiple thermocouples were inserted into different locations in the salt, ${ }^{12}$ a temperature difference as large as $50^{\circ} \mathrm{C}$ was observed. This temperature difference usually diminishes as furnace temperature increases to above $350^{\circ}-400^{\circ} \mathrm{C}$.

- Weight losses of $1.927 \pm 0.143 \mathrm{wt} . \%$ after pre-drying and $\sim 2.75 \mathrm{wt} . \%$ after TGA are also different. This is most likely due to a combination of reasons: (1) different surface-area-tovolume ratio at different scale, (2) effective flow rate of cover gas, ${ }^{13}$ and (3) the effective depth of drying (deeper for smaller salt grains if normalized by particle size).

Table 5. Weight Loss During Pre-Drying Experiments Under Different Sparging Conditions

\begin{tabular}{|c|c|c|c|c|c|c|c|c|c|c|}
\hline \multirow[t]{2}{*}{$\begin{array}{l}\text { Exp. } \\
\text { ID }\end{array}$} & $\begin{array}{c}\text { Sparging } \\
\text { Gas } \\
\text { Flow } \\
\text { Rate }\end{array}$ & $\begin{array}{l}\text { Cover } \\
\text { Gas } \\
\text { Flow } \\
\text { Rate }\end{array}$ & \multirow[t]{2}{*}{$\begin{array}{l}\text { Gas } \\
\text { Type }\end{array}$} & \multirow[t]{2}{*}{$\begin{array}{c}\text { \# of } \\
\text { Sparging } \\
\text { Tubes }\end{array}$} & $\begin{array}{l}\text { Max } \\
\text { Pre- } \\
\text { Drying } \\
\text { Temp.* }\end{array}$ & $\begin{array}{c}\text { Salt } \\
\text { Weight } \\
\text { Before } \\
\text { Pre- } \\
\text { Drying } \\
\end{array}$ & $\begin{array}{l}\text { Water } \\
\text { Release } \\
\text { Temp. }\end{array}$ & $\begin{array}{l}\text { Water } \\
\text { Release } \\
\text { Time }\end{array}$ & $\begin{array}{l}\text { Weight } \\
\text { Loss }\end{array}$ & $\begin{array}{c}\text { Estimated } \\
\mathrm{HCl} \\
\text { Release }\end{array}$ \\
\hline & sccm & $\mathrm{sccm}$ & & & ${ }^{\circ} \mathrm{C}$ & $g$ & ${ }^{\circ} \mathrm{C}$ & $\min$ & wt. $\%$ & wt. $\%$ \\
\hline 1 & 0 & 690 & Dry $\mathrm{N}_{2}$ & 0 & $275-285$ & 493.04 & 148 & 67 & $1.846 \%$ & $0.139 \%$ \\
\hline 2 & 50 & 690 & Dry $\mathrm{N}_{2}$ & 1 & $275-285$ & 495.7 & 140 & 100 & $2.070 \%$ & $0.148 \%$ \\
\hline 3 & 200 & 690 & Dry $\mathrm{N}_{2}$ & 1 & 275-285 & 497.06 & 175 & 70.2 & $1.859 \%$ & \multirow{4}{*}{$\mathrm{N} / \mathrm{A}$} \\
\hline 4 & 200 & 690 & Dry $\mathrm{N}_{2}$ & 1 & $275-285$ & 471.57 & 104 & 52.1 & $1.906 \%$ & \\
\hline 5 & 200 & 690 & Dry Air & 1 & $275-285$ & 462.92 & 172 & 77.9 & $1.888 \%$ & \\
\hline 6 & 200 & 690 & Dry $\mathrm{N}_{2}$ & 2 & $275-285$ & 486.94 & 230 & 39 & $1.809 \%$ & \\
\hline 7 & 200 & 690 & Dry $\mathrm{N}_{2}$ & 2 & $275-285$ & 491.84 & 165 & 61.1 & $1.903 \%$ & $0.067 \%$ \\
\hline 8 & 200 & 200 & Dry $\mathrm{N}_{2}$ & 1 & $275-285$ & 495.55 & $\mathrm{~N} / \mathrm{A}$ & 150 & $1.957 \%$ & $0.120 \%$ \\
\hline 9 & 460 & 690 & Dry $\mathrm{N}_{2}$ & 1 & $275-285$ & 464.98 & 171 & $40^{* *}$ & $1.774 \%$ & $\mathrm{~N} / \mathrm{A}$ \\
\hline 10 & 690 & 200 & Dry $\mathrm{N}_{2}$ & 1 & $275-285$ & 496.02 & 135 & 60 & $2.262 \%$ & $0.073 \%$ \\
\hline & & & & & & Average & 160 & 72 & $1.927 \%$ & $0.109 \%$ \\
\hline & & & & & & Stdev & 35 & 33 & $0.143 \%$ & $0.037 \%$ \\
\hline
\end{tabular}

${ }^{*}$ The experiment was carried out by heating up the salt mixture from room temperature to the max pre-drying temperature at $5^{\circ} \mathrm{C} / \mathrm{min}$. Given our experimental setup, it was not possible to load salt samples directly into a hot furnace at the temperature of interest. A gradual heating program was necessary. Note that this is the furnace control temperature, which is not subject to the inaccurate temperature measurement discussed below.

** This is an estimate only. The real measured time is $50.8 \mathrm{~min}$. But the actual time should be shorter because sparging gas was not turned on until $20 \mathrm{~min}$ after water release was detected.

\footnotetext{
12 The thermocouples are only $3-5 \mathrm{~cm}$ apart.

${ }^{13}$ Cover gas flow rate is about $10 \mathrm{sccm}$ in TGA for $<10 \mathrm{mg}$ of salt and about $700-900 \mathrm{sccm}$ in pre-drying for $\sim 500 \mathrm{~g}$ of salt. So, the gas flow rate normalized by salt mass is much higher in the TGA experiment.
} 
Table 5 also reveals the effects of gas flowing (as cover gas and sparging gas) and pre-drying temperature on total time/effectiveness of water release. The following information can be used as design basis for a large-scale furnace/dryer that dries the raw $\mathrm{AC} /$ halite before transporting the dried mixture to the salt melter for subsequent purification.

1. Gas flowing effect on pre-drying time: A relatively easy method to understand the gas flowing effect is to plot the observed drying time ${ }^{14}$ as a function of gas flow rate (i.e., sparging gas, cover gas, or the sum of sparging and cover gas). Figure 5 shows that the water release time is most correlated to the total gas flow rate (i.e., the sum of sparging gas and cover gas) during pre-drying. ${ }^{15}$ Figure 48 in the Appendix shows the same plots for sparging gas flow rate and cover gas flow rate where there is no clear correlation. Comparison between results from Experiment 3, 4, and 5 and the results from Experiment 10 in Table 5 also support the argument that it is the total gas flow

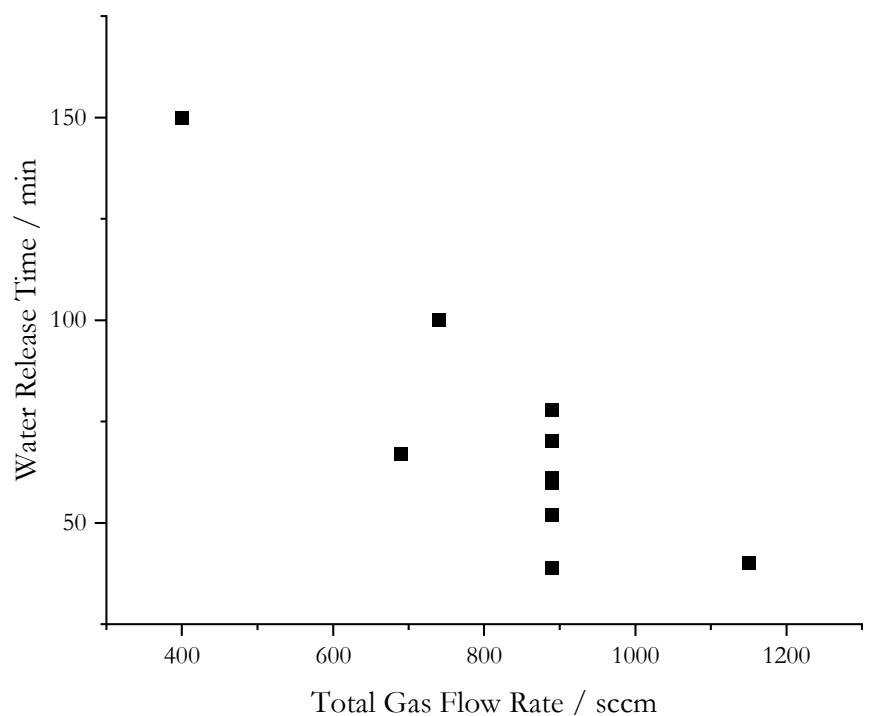

Figure 5. Variation of water release time during salt pre-drying at $275^{\circ}-285^{\circ} \mathrm{C}$ as a function of total gas flow rate (i.e., sum of sparging gas and cover gas) rate that dictates the water release time (i.e., the exact distribution of sparging gas and cover gas is less relevant as long as the sum is the same). Results from Experiment 1 where no sparging was used, again, support the argument. In addition, distribution of gas through multiple sparging tubes (Experiments 6 and 7) does not play an important role either, or at least the results are inconclusive. In conclusion, the results in Table 5 suggest that water removal from a loosely packed solid salt pile may not be the limiting factor during the predrying process (i.e., water release can readily move through the solid network by itself and is not easily trapped by this loose and porous structure). This is different from the subsequent higher-temperature purification process where sparging gas through the molten salt is much more important compared to cover gas (discussed later). Therefore, when designing a largescale dryer, the key is to ensure that there is sufficient overall gas flow to help remove released water; whether the gas needs to flow through the packed salt does not appear to be critical.

2. Effect of pre-drying temperature: All experiments shown in Table 5 were performed at $275^{\circ}$ $285^{\circ} \mathrm{C}$. We did one pre-drying at $200^{\circ} \mathrm{C}$ with a total gas flow rate of $890 \mathrm{sccm}$. It had a water release time of over $105 \mathrm{~min}$, but the overall weight loss on pre-drying is comparable at

\footnotetext{
${ }^{14}$ Onset and end of drying is determined by the moisture sensor connected to the gas outlet of the pre-drying setup.

15 The significant variation at $890 \mathrm{sccm}$ of total gas flow is most likely due to 1) larger number of tests performed compared to other gas flow rates, and 2) the data points are not for the exact same test condition (i.e., with different distribution of cover gas and sparging gas, with different numbers of sparging tubes, etc.). Therefore, we only intend to show that, qualitatively, water release time is most correlated to total gas flow rate.
} 
1.854 wt.\%, not statistically different from the weight losses of other experiments with 890 $\mathrm{sccm}$ of total gas flow. Although there is only one data point, it seems to suggest that drying at a higher temperature such as $275^{\circ} \mathrm{C}$ is more time efficient but not necessarily more efficient in terms of the extent/quality of dehydration (as reflected by the total weight loss). For this reason, we do not have a strong opinion regarding the exact recommended predrying temperature. Likely any temperature in the range of $200^{\circ}-300^{\circ} \mathrm{C}$ should serve the purpose.

3. Effect of pre-drying atmosphere: There is no significant difference between using dry $\mathrm{N}_{2}$ and dry air (by comparing Experiment 5 with the rest). Using dry air can be a viable lower-cost choice at large scale.

The measured moisture content (or weight loss) in the as-received AC is much higher than the value reported by ICL. The most likely explanation is water absorption during storage in ambient atmosphere at both ICL and NREL. It is clear from the salt chemistry perspective that water absorption can lead to hydrolysis and $\mathrm{HCl}$ formation during dehydration. For this reason, potential $\mathrm{HCl}$ release in Experiments $1,2,7,8$, and $10^{16}$ was tracked by monitoring the $\mathrm{pH}$ of a buffer solution connected to the off-gas line, which was then used to estimate HCl generation (as a fraction of the total salt weight before pre-drying). The accuracy of the $\mathrm{HCl}$ estimate depends on the accuracy of the $\mathrm{pH}$ meter, extent of the reaction between $\mathrm{HCl}$ and the hardware, ${ }^{17}$ escaped $\mathrm{HCl}$ through potential leaks in the system, etc. Hence, the number of $0.109 \pm 0.037 \mathrm{wt} \%$ is considered a rough estimate only. Regardless, this estimate shows that most weight loss during pre-drying is from water release, which is indeed the intention of pre-drying (i.e., removing water, either physically absorbed moisture or chemical hydrates, without generating a significant amount of $\mathrm{HCl}$ via hydrolysis). We can also estimate the fraction of water that participated in hydrolysis. Eq. 6 shows that each mole of $\mathrm{HCl}$ generation requires 1 mole of $\mathrm{H}_{2} \mathrm{O}$ (from dehydration of either physically absorbed moisture or chemical hydrates). ${ }^{18}$ Assuming an average $\mathrm{HCl}$ generation of $0.1 \mathrm{wt} . \%$ during pre-drying, the amount of water responsible for this portion of $\mathrm{HCl}$ generation is $\sim 0.049 \mathrm{wt} . \%$. In the worst-case scenario, all $0.049 \mathrm{wt} . \%$ of water will come from chemical hydrates formed during oversea shipping and storage.

Temperature and $\mathrm{pH}$ are both monitored during the pre-drying process which, in theory, could provide information about the temperature at which $\mathrm{HCl}$ release starts. However, because of the large discrepancy of temperature measurement in the loosely packed solid salt at a relatively low temperature of $<300^{\circ} \mathrm{C}$, the statistic scatter is too large for us to reach a conclusion.

Now, it is possible to have a better understanding of water absorption during shipping and storage. Assume $0.5 \mathrm{wt} . \%$ is the water content of a fresh AC batch directly from ICL's production line (as claimed by ICL). After overseas shipping from ICL and $>12$ months of storage in ambient at NREL, the water content increases by $\sim 1.5 \mathrm{wt} . \%$ to $2 \mathrm{wt} . \%$ (based on the total loss on pre-drying). Out of the $1.5 \mathrm{wt} . \%$ of water content increase, roughly $0.05 \mathrm{wt} . \%$ is in the form of hydrates (in the worst-case scenario as stated above), which means most water

\footnotetext{
${ }^{16}$ For clarification, Table 5 is not ordered chronologically.

17 Thermodynamically $\mathrm{HCl}$ gas can react with $\mathrm{Ni}$-alloys at $250^{\circ}-300^{\circ} \mathrm{C}$. Inconel 600 was the material for the purification vessel.

18 This $1: 1$ ratio is based on the fact that the dehydration temperature is much lower than where $\mathrm{MgOHCl}$ can thermally decompose, which can form another mole of $\mathrm{HCl}$.
} 
content increase is due to absorption of physical water. In theory, these water molecules should be removed much more easily at $\sim 100^{\circ} \mathrm{C}$ compared to hydrates. If fresh $\mathrm{AC}$ with $0.5 \mathrm{wt} . \%$ of water content can be used for pilot-scale testing, we expect a lower $\mathrm{HCl}$ production upon predrying.

\subsection{Salt Purification}

\section{Experimental}

Materials: Raw materials used were AC from ICL, SPK halite from Albemarle, and elemental Mg (chips, 6-35 mesh size, 99.98\% trace metals basis, part\# 254118, Sigma Aldrich).

Purification setup: Figure 6 gives the schematic of the purification setup showing the crucible (fused quartz crucible, part\# FQ-2500 or FQ-2800, AdValue Technology), gas sparger (alumina single-bore tube, part\# AL-T-N1/4-N3/16-12, AdValue Technology), stainless-steel SS316 or Inconel 625 test vessel (150-mm inner diameter, 350-mm height), SS316 gas inlet and outlet, type-K thermocouple (part\# CAIN-18G-18, Omega Engineering), and nickel crucible cover/cap (part\# Z246700-1EA, Sigma Aldrich). About 500-800 g of AC was used for each purification batch, where $6.5 \mathrm{wt} \%$ of SPK halite and 0-0.25 wt.\% of elemental Mg (chips, 6-35 mesh size, 99.98\% trace metals basis, part\# 254118, Sigma Aldrich) were added to achieve desired salt

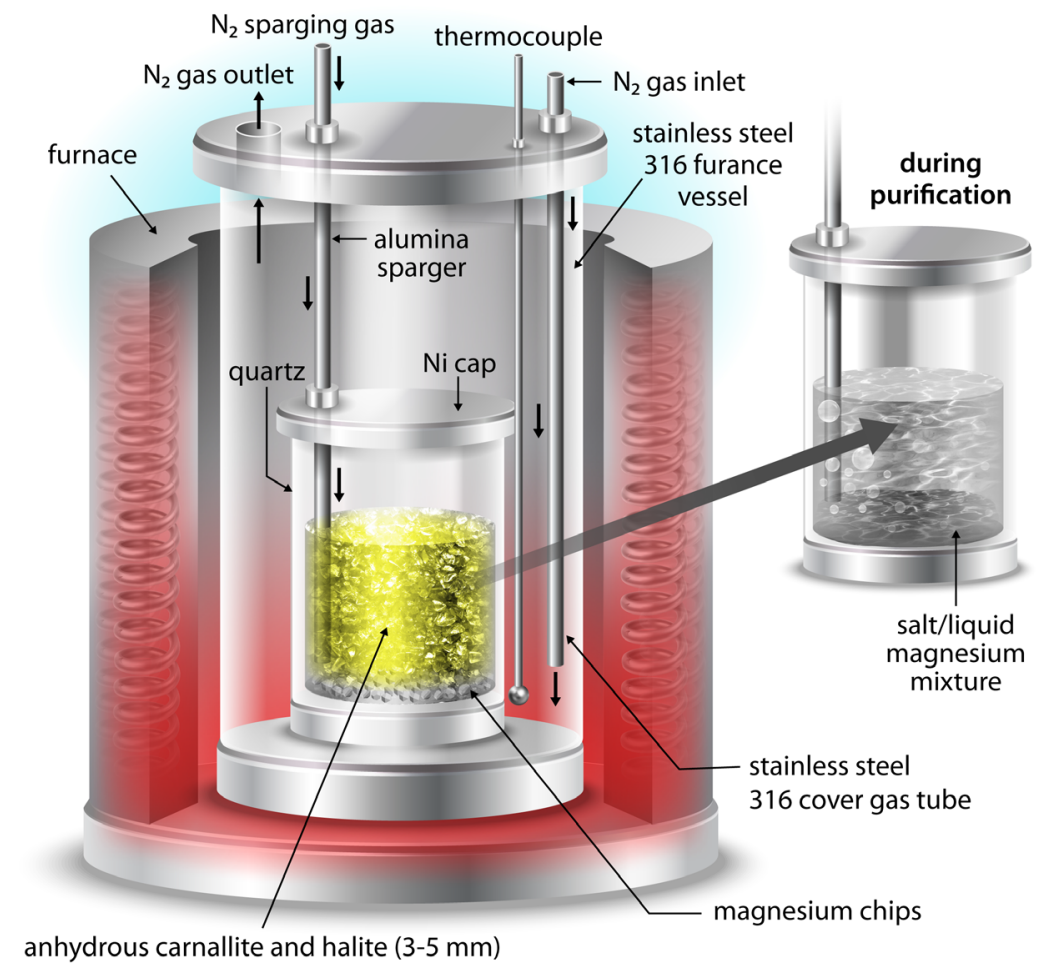

Figure 6. Schematic showing the purification setup. Note that $\mathrm{HCl}$ and $\mathrm{H}_{2} \mathrm{O}$ will be generated from the salt inside the quartz crucible during salt predrying/purification and then contact the Ni cap, SS316 (or In625) furnace vessel and SS316 $\mathrm{N}_{2}$ gas outlet. These are the locations where $\mathrm{HCl}$ corrosion and potential $\mathrm{H}_{2}$ generation could occur (discussed later). 
composition and perform chemical purification, respectively. Dry nitrogen $\left(\mathrm{N}_{2}\right)$ gas $(<10 \mathrm{ppm}$ oxygen, $<1$ ppm moisture) was used as the sparging and cover gas.

Purification schedule: Table 6 summarizes the finalized recommended heating schedule and gas flow rates for the purification process (including pre-drying). The experimental efforts and theoretical calculations are given in the next a few sections to explain the rationale behind the recommended heating schedule.

Table 6. Recommended Heating Schedule and Gas Flow Rates for the Purification Process Including Pre-Drying at 500- to 1,000-g Scale

\begin{tabular}{|c|c|c|c|c|}
\hline \multicolumn{5}{|c|}{ Recipe: $6.5 \mathrm{~g}$ of SPK Halite and $\sim 0.1 \mathrm{~g}$ of $\mathrm{Mg}$ per $100 \mathrm{~g}$ of ICL AC } \\
\hline Step & $\begin{array}{c}\text { Furnace } \\
\text { Temperature }\end{array}$ & Ramp Rate & Hold Time & $\begin{array}{l}\text { Dry Nitrogen Gas Flow } \\
\text { Rate }\end{array}$ \\
\hline $\begin{array}{c}\text { Pre- } \\
\text { Drying* }\end{array}$ & R.T. to $250^{\circ} \mathrm{C}$ & \multirow{3}{*}{$\leq 1^{\circ} \mathrm{C} / \mathrm{min}$} & $\begin{array}{l}\text { Until moisture } \\
\text { release stops }\end{array}$ & \multirow{2}{*}{$\begin{array}{c}200-400 \text { sccm for } \\
\text { sparging gas } \\
>500 \text { sccm for cover gas }\end{array}$} \\
\hline Purification & $\begin{array}{l}250^{\circ} \mathrm{C} \text { to } \\
670^{\circ} \mathrm{C}\end{array}$ & & $\begin{array}{l}\text { Until } \mathrm{HCl} \text { release } \\
\text { stops or } \mathrm{MgOHCl} \\
\text { content }^{* *} \text { is low }\end{array}$ & \\
\hline $\begin{array}{l}\text { Cool-Down } \\
\text { and Sludge } \\
\text { Settling }\end{array}$ & $670^{\circ} \mathrm{C}$ to R.T. & & $\mathrm{N} / \mathrm{A}$ & $\begin{array}{c}\text { No active sparging } \\
>500 \text { sccm for cover gas }\end{array}$ \\
\hline
\end{tabular}

* Both dry nitrogen and dry air can be used during pre-drying.

** $\mathrm{MgOHCl}$ content can be monitored by an in-situ electrochemical sensor.

\section{Effect of Mg Purification Temperature}

Figure 7 shows the effect of purification temperature during a single-step purification of asreceived AC only (no halite addition). We determined $\mathrm{MgOHCl}$ content with titration [56] at three purification temperatures in salt mixtures with $0.5 \mathrm{wt} . \%$ and $0.75 \mathrm{wt} . \%$ of $\mathrm{Mg}$ added. The salt mixture was held at the purification temperature for 2 hours. We observed a clear decrease of $\mathrm{MgOHCl}$ content with increasing purification temperature.

Results in Figure 7 suggest that $>650^{\circ} \mathrm{C}$ (i.e., when $\mathrm{Mg}$ is molten) is the most desirable temperature for reduction of $\mathrm{MgOHCl}$. To exclude the possibility that kinetic barriers at $500^{\circ} \mathrm{C}$ and $575^{\circ} \mathrm{C}$ limited the reaction between $\mathrm{MgOHCl}$ and $\mathrm{Mg}$ (Eq. 9), we used FactSage to calculate the Gibb's free energy of the reaction [62]. A Gibb's free energy of reaction of around $-150 \mathrm{~kJ}$ per mole of $\mathrm{MgOHCl}$ at both temperatures suggests that such a highly spontaneous reaction, from the thermodynamic perspective, at moderately high temperatures of $500^{\circ}-600^{\circ} \mathrm{C}$ cannot be severely limited by reaction kinetics. A plausible explanation lies in the solubility of $\mathrm{Mg}$ in the ternary molten chloride salt. Although literature information on (1) Mg solubility in chloride salt with composition close to that of the purified salt or (2) solid Mg solubility in molten chloride salt is lacking, there is literature on liquid $\mathrm{Mg}$ solubility in some pure or binary chloride salts. The solubility of liquid $\mathrm{Mg}$ is about $0.1-0.5 \mathrm{~mol} \%$ and generally increases with temperature and with decreasing amount of alkali chlorides [63-68].

Without sufficient literature support or experimental evidence, we could only speculate a low solubility of $\mathrm{Mg}$, especially when it is not molten, given limited literature understanding. The lower $\mathrm{Mg}$ solubility may have caused the lower efficiency of $\mathrm{MgOHCl}$ reduction seen at $500^{\circ} \mathrm{C}$ 
and $575^{\circ} \mathrm{C}$. Another possible reason that molten $\mathrm{Mg}$ seems better at reducing $\mathrm{MgOHCl}$ is that $\mathrm{MgO}$, one of the reaction products shown in Eq. 9, can potentially passivate the solid $\mathrm{Mg}$ surface. Post-experiment inspection showed that the remaining $\mathrm{Mg}$ chips after purification experiments at lower temperatures than $650^{\circ} \mathrm{C}$ exhibited a black surface layer. When dissolved in deionized water, these remaining $\mathrm{Mg}$ chips with the black surface clearly showed a much slower reaction with water which released gas bubbles (i.e., $\mathrm{H}_{2}$ ) compared to native $\mathrm{Mg}$ chips. On the contrary, $\mathrm{MgO}$ formation on molten $\mathrm{Mg}$ may be more easily broken off because of the turbulence created by inert gas sparging and the flexible/flowing nature of liquids. However, caution must be taken when interpreting these hypotheses before confirming the chemical makeup of the surface layer and whether $\mathrm{MgO}$ can indeed passivate the reaction. In addition, we hypothesize that not all soluble $\mathrm{MgOHCl}$ (e.g., at $0.02 \mathrm{~mol} / \mathrm{kg}$ as reported by [69] in similar molten chlorides) can equally access $\mathrm{Mg}$, either soluble or insoluble $\mathrm{Mg}$. It should be noted that the scatter of data at $500^{\circ} \mathrm{C}$ and $575^{\circ} \mathrm{C}$ is much larger than that at $650^{\circ} \mathrm{C}$ - which seems to support the aforementioned hypotheses that intend to explain the observed inconsistency of the $\mathrm{Mg}$ purification power below its melting point.

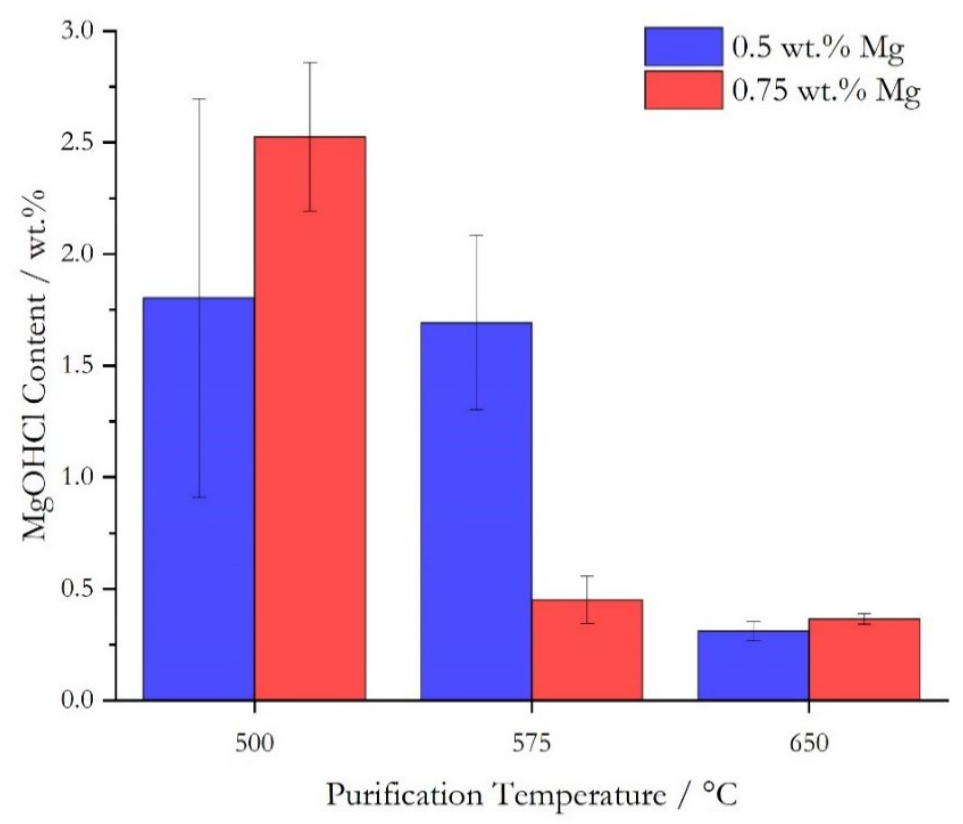

Figure 7. $\mathrm{MgOHCl}$ content determined by titration as a function of purification temperature for 0.5 wt. $\%$ and 0.75 wt. $\%$ of $\mathrm{Mg}$ addition to the $\mathrm{AC}$

To be rigorous, we acknowledge that the results in Figure 7 do not completely exclude the possibility of using solid $\mathrm{Mg}$ as primary purification species because solid $\mathrm{Mg}$ does have a finite, non-zero solubility. Because the reaction kinetics is fast (as suggested by Ding et al. [12] using cyclic voltammetry technique and inferred by the large negative Gibb's free energy of reaction), the foreseen downside of using solid $\mathrm{Mg}$ (i.e., below $650^{\circ} \mathrm{C}$ ) is simply a longer purification dwell time. However, the objective of the work is to find a cost-effective commercially scalable purification procedure in terms of purification effectiveness. Given that (1) Mg solubility increases with temperature, which should improve reaction rate of Eq. 5; (2) higher temperature should increase reaction rate of Eq. 3; and (3) salt vapor pressure increases exponentially with temperature (to be discussed later), which can lead to excessive salt evaporation and deposition 
and eventual clogging of the experimental purification apparatus or even future real-scale purification tank, we chose $670^{\circ} \mathrm{C}$ (i.e., slightly above $650^{\circ} \mathrm{C}$ in order to mitigate potential inhomogeneous temperature distribution inside the molten salt) as a practical compromise and did not further investigate purification at other temperatures.

\section{Effect of Mg Addition}

Figure 8 shows the effect of $\mathrm{Mg}$ addition (0-0.75 wt.\%) during the single-step purification of asreceived AC only (no halite addition). All experiments with $\mathrm{Mg}$ addition (0.25-0.75 wt.\%)

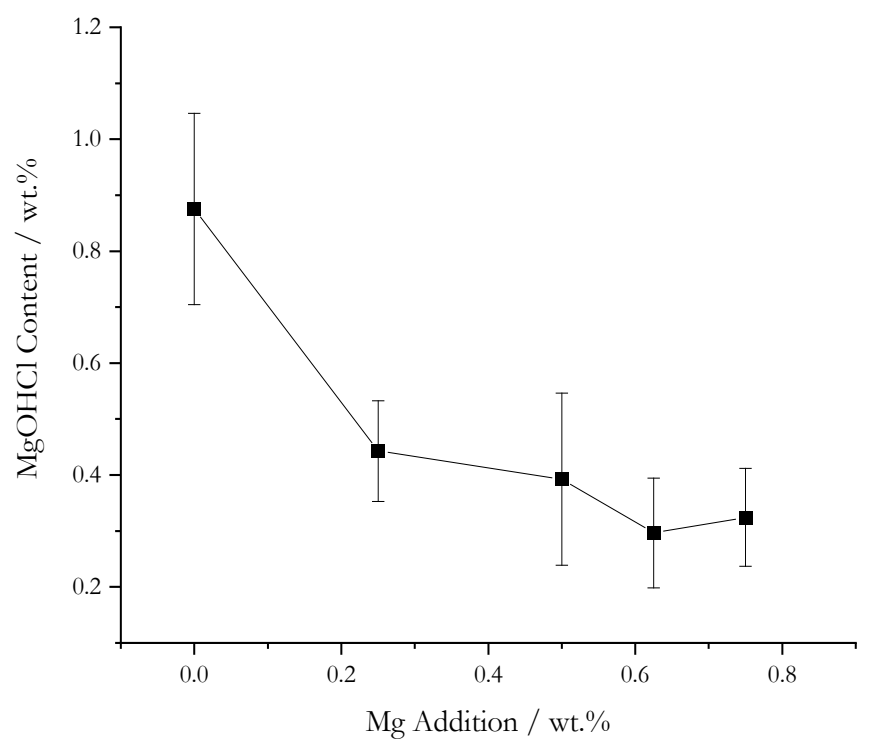

Figure 8. The effect of $\mathrm{Mg}$ addition on $\mathrm{MgOHCl}$ content measured after salt purification at $650^{\circ} \mathrm{C}$ showed signs of excess $\mathrm{Mg}$ droplets at the bottom of the salt sample by visual post-purification inspection. Similar behavior had been observed in [28]. Therefore, $0.25 \mathrm{wt} . \%$ was the least amount of $\mathrm{Mg}$ that provided the best balance between effective reduction of $\mathrm{MgOHCl}$ and minimum excess of $\mathrm{Mg}$ after purification. To confirm this experimentally observed value, we give an order-of-magnitude calculation below based on $\mathrm{H}_{2} \mathrm{O}$ and $\mathrm{MgOHCl}$ content to estimate the maximum amount of $\mathrm{Mg}$ needed.

1. The initial $\mathrm{MgOHCl}$ content in nontreated raw $\mathrm{AC}$ is on the order of 0.75 wt. $\%{ }^{19}$ (as measured by multiple titrations on $\mathrm{AC}$ after crushing and mixing), which equals 0.00977 mole of $\mathrm{MgOHCl}$ per $100 \mathrm{~g}$ of $\mathrm{AC}$.

2. The $\mathrm{H}_{2} \mathrm{O}$ content (including both physical moisture and chemical hydrates) in non-treated $\mathrm{AC}$ is assumed to be around $0.5 \mathrm{wt} . \%$ (according to the salt specification provided by ICL), which equals 0.0278 mole of $\mathrm{H}_{2} \mathrm{O}$ per $100 \mathrm{~g}$ of $\mathrm{AC}$. Assuming $100 \%$ of $_{2} \mathrm{O}$ is used for the hydrolysis of $\mathrm{MgCl}_{2}$, an additional 0.0278 mole of $\mathrm{MgOHCl}$ will be formed given the stoichiometry in Eq. 6.

3. Therefore, the maximum $\mathrm{MgOHCl}$ that can occur in the entire course of purification is $0.00977+0.0278=0.0376$ mole per $100 \mathrm{~g}$ of $\mathrm{AC}$. This amount assumes that thermal purification does not reduce $\mathrm{MgOHCl}$ amount.

Based on Eq. 9, each mole of $\mathrm{MgOHCl}$ consumes 0.5 mole of $\mathrm{Mg}$ for complete reduction. Therefore, the amount of $\mathrm{Mg}$ needed is $(0.00977$ mole $+0.0278 \mathrm{~mole}) \div 2 \times 24.305 \mathrm{~g} / \mathrm{mole}=$ $0.457 \mathrm{~g}$ per $100 \mathrm{~g}$ of $\mathrm{AC}$, or $0.457 \mathrm{wt} \%$.

\footnotetext{
${ }^{19}$ This amount in reasonable agreement with the values reported in Table 4, which were measured in different phases of $\mathrm{AC}$ without crushing and mixing.
} 
The actual $\mathrm{MgOHCl}$ produced during purification and the needed $\mathrm{Mg}$ amount should be lower because:

1. The assumption in \#2 above is not accurate because (1) physically absorbed moisture can be removed at the pre-drying step, ${ }^{20}$ and (2) not all $\mathrm{H}_{2} \mathrm{O}$ released from dehydration of $\mathrm{MgCl}_{2}$ hydrates can react with $\mathrm{MgCl}_{2}$ to form $\mathrm{MgOHCl}$ at $100 \%$ efficiency.

2. The assumption in \#3 above is not accurate because thermal purification does show the ability to reduce $\mathrm{MgOHCl}$ content by at least $50 \%$ if an isothermal step at $600^{\circ} \mathrm{C}$ for 1 hour is used. In addition, reference [40] found that the decomposition rate constant increases with temperature following an Arrhenius-type relation.

Therefore, if we make some relaxed assumptions that (1) $50 \%$ of the initial water content is physically absorbed moisture, (2) $\mathrm{H}_{2} \mathrm{O}$ released from dehydration reacts with anhydrous $\mathrm{MgCl}_{2}$ with $50 \%$ efficiency, and (3) thermal decomposition can reduce $50 \%$ of $\mathrm{MgOHCl}$ produced, then a more realistic estimation of $\mathrm{Mg}$ needed is $(0.00977$ mole +0.0278 mole $\times 50 \% \times 50 \%) \times 50 \%$ $\div 2 \times 24.305 \mathrm{~g} / \mathrm{mole}=0.102 \mathrm{~g}$ per $100 \mathrm{~g}$ of $\mathrm{AC}$, or $0.102 \mathrm{wt} . \%$. Our experimental observation of excess $\mathrm{Mg}$ after purification using $0.25 \mathrm{wt} . \%$ of $\mathrm{Mg}$ also corroborates this calculation, which suggests that the most efficient amount of $\mathrm{Mg}$ needed should be less than $0.25 \mathrm{wt} . \%$, or even less than $0.102 \mathrm{wt} . \%$ if the assumptions are too conservative. Ideally, the excess $\mathrm{Mg}$ remaining in the salt after purification should be quantified to provide the exact consumption of $\mathrm{Mg}$. However, the separation of excess $\mathrm{Mg}$ from the chloride salt presents a technical challenge - namely, manual collection of solid $\mathrm{Mg}$ droplets is time-consuming and unreliable, and dissolution of chloride salts is not feasible because the solvents that dissolve chloride salts usually react with $\mathrm{Mg}$. Although the exact recipe for $\mathrm{Mg}$ purification is not clear at lab scale, $0.1 \mathrm{wt} \% \%$ should serve as a practical estimate for future large-scale purification experiments if the true moisture content in the raw salt material is about $0.5 \mathrm{wt} . \% .^{21}$

Concerns with larger variation of industrial salt quality can be addressed first by performing similar order-of-magnitude estimation shown above to establish an upper bound for $\mathrm{Mg}$. $\mathrm{A}$ $\mathrm{MgOHCl}$ sensor currently under development at Argonne National Laboratory that can directly and quickly measure $\mathrm{MgOHCl}$ content in the molten salt could be used to provide feedback and then control the feed rate of raw materials and/or the residence time of the salt in the purification reactors (i.e., effectively adjusting the $\mathrm{Mg}$ recipe). In addition, the effectiveness of purification may also be affected by the level of mixing in the molten salt, which can be highly dependent on the specific design of a purification reactor. For these reasons, we settled on $0.1 \mathrm{wt} . \% \mathrm{of} \mathrm{Mg}$ addition $^{22}$ for lab-scale purification of freshly produced AC with $0.5-1 \mathrm{wt} . \%$ of initial moisture content, and no further optimization of $\mathrm{Mg}$ addition was conducted.

It should be noted that $\mathrm{Mg}$ purification and $\mathrm{MgOHCl}$ thermal decomposition both can reduce $\mathrm{MgOHCl}$ concentration. Also, $\mathrm{MgOHCl}$ thermal decomposition kinetics increases with temperature [40]. When $\mathrm{MgOHCl}$ concentration is high, the ability to have both mechanisms is

\footnotetext{
${ }^{20}$ The pre-drying step is able to remove up to $1.9 \mathrm{wt} . \%$ of moisture in as-received AC where the actual moisture content is believed to be much higher than the claimed value of $0.5-0.75$ wt. $\%$.

${ }^{21}$ If the true moisture content is higher, more $\mathrm{Mg}$ must be used.

${ }^{22}$ Multiple experiments at 500-g scale with $0.1 \mathrm{wt} . \%$ of $\mathrm{Mg}$ addition showed some excess $\mathrm{Mg}$ droplets after purification.
} 
beneficial, and $\mathrm{MgOHCl}$ can be removed in the shortest time possible. When $\mathrm{MgOHCl}$ content is low, the exact amount of $\mathrm{Mg}$ addition may be lower than $0.1 \mathrm{wt} . \%$ because $\mathrm{MgOHCl}$ thermal decomposition might be sufficient to reduce this small amount of $\mathrm{MgOHCl}$ (to be discussed later).

The final decision on $\mathrm{Mg}$ addition at industrial scale should be made based on the actual moisture content of the raw $\mathrm{MgCl}_{2}$-containing salt as well as the considerations of the added equipment/cost to deal with the safety hazard of handing $\mathrm{Mg}$ addition at high temperature and treating potentially explosive $\mathrm{H}_{2}$ in the off-gas (Eq. 9), because $\mathrm{HCl} / \mathrm{H}_{2} \mathrm{O}$ can react with $\mathrm{Mg}$ and produce $\mathrm{H}_{2}$. When initial $\mathrm{MgOHCl}$ content in the raw material is low and hydrolysis to generate additional $\mathrm{MgOHCl}$ can be minimized by careful pre-drying and dehydration, or when the largescale melter design can handle $\mathrm{HCl}$ in the off-gas by having the off-gas lines made of corrosion resistant composite materials, it seems that using low $\mathrm{Mg}$ to reduce $\mathrm{MgOHCl}$ can be feasible. In this case, $\mathrm{Mg}$ addition is still recommended (but at a smaller amount) to reduce other impurities such as $\mathrm{Fe}$ (at $\sim 100 \mathrm{ppm}$ ). For example, to reduce Fe impurity from $100 \mathrm{ppm}$ to $0 \mathrm{ppm}$, approximately $65 \mathrm{ppm}$ of $\mathrm{Mg}$ is needed, assuming the reaction is $\mathrm{Fe}^{3+}+\mathrm{Mg} \rightarrow \mathrm{Fe}+\mathrm{Mg}^{2+}$. Additional $\mathrm{Mg}$ should be added to (1) account for some $\mathrm{MgOHCl}$ reduction given by Eq. 9, (2) compensate some $\mathrm{Mg}$ loss via reaction with $\mathrm{HCl}$ and/or $\mathrm{H}_{2} \mathrm{O}$, and (3) provide corrosion resistance by having dissolved $\mathrm{Mg}$ in the salt melt. In addition to having $\mathrm{Mg}$ as purification agent and corrosion inhibitor, the exact amount of $\mathrm{Mg}$ addition should also be decided based on its solubility in the ternary chlorides at $650^{\circ}-700^{\circ} \mathrm{C}$. If excess $\mathrm{Mg}$ is present and keeps accumulating at $650^{\circ}-700^{\circ} \mathrm{C}$, it can float on top of the salt melt, which may present a risk of shorting the electrodes of the immersion heater in the melter design. The Mg solubility is estimated to be 300-1,000 ppm given limited literature information on specific salt composition and temperatures $[63,65,66]$. Hence, a conservative recommendation on $\mathrm{Mg}$ addition for industrial scale salt purification is still 1,000 ppm.

A practical design is that $\mathrm{Mg}$ can be added only during the $\mathrm{MgO}$ particle settling stage. The rationale is that no $\mathrm{Mg}$ will be added during the purification stage, which can prevent $\mathrm{H}_{2}$ hazard via (1) $\mathrm{MgOHCl}$ reduction by $\mathrm{Mg}$ (Eq. 9) and (2) $\mathrm{Mg}$ reaction with $\mathrm{HCl}$ and $\mathrm{H}_{2} \mathrm{O}$. Once purification is complete (i.e., $\mathrm{HCl}$ and $\mathrm{H}_{2} \mathrm{O}$ generation is completed), the appropriate amount of $\mathrm{Mg}$ will be added to reduce other cationic impurities such as Fe and provide dissolved $\mathrm{Mg}$ for the purpose of corrosion control. This should serve as the best balance among achieving good salt quality with low $\mathrm{MgOHCl}$ content, avoiding $\mathrm{H}_{2}$ hazard (a major concern from the industry), providing dissolved $\mathrm{Mg}$ for continued corrosion resistance, and minimizing handling of $\mathrm{Mg}$ at high temperature.

\section{Effect of Mg Purification Time}

Figure 9 shows the typical $\mathrm{pH}$ change of the acetic acid aqueous buffer solution connected to the gas outlet of the furnace vessel during purification at $\sim 670^{\circ}-680^{\circ} \mathrm{C}$. As indicated by the first dashed vertical line (at around $110 \mathrm{~min}$ ), the $\mathrm{pH}$ drop starts at $535^{\circ} \mathrm{C}$. $^{23}$ This onset is defined as the intercept between a horizontal baseline before $\mathrm{pH}$ drop and a tangent line after the $\mathrm{pH}$ drop, similar to the definition of the onset of a thermal phenomenon in a differential scanning calorimetry (DSC) experiment. The end of $\mathrm{pH}$ change is defined as when the $\mathrm{pH}$ change rate is

\footnotetext{
${ }^{23}$ Other purification experiments had similar temperatures in the range of $530^{\circ}-550^{\circ} \mathrm{C}$.
} 
close to zero $\mathrm{min}^{-1}$. We acknowledge that this definition may not be perfect, but the purpose is to have a consistent definition so we can compare the effects of other purification parameters such as $\mathrm{Mg}$ addition and gas sparging rates (discussed in the next few sections). We can see that although the mathematical definition shows the onset at around $535^{\circ} \mathrm{C}$, there is a noticeable $\mathrm{pH}$ drop as early as about $400^{\circ} \mathrm{C}$, which coincides with salt melting. ${ }^{24}$ Therefore, we tend to conservatively conclude that the onset of $\mathrm{pH}$ drop and $\mathrm{HCl}$ release is about $400^{\circ} \mathrm{C}$.

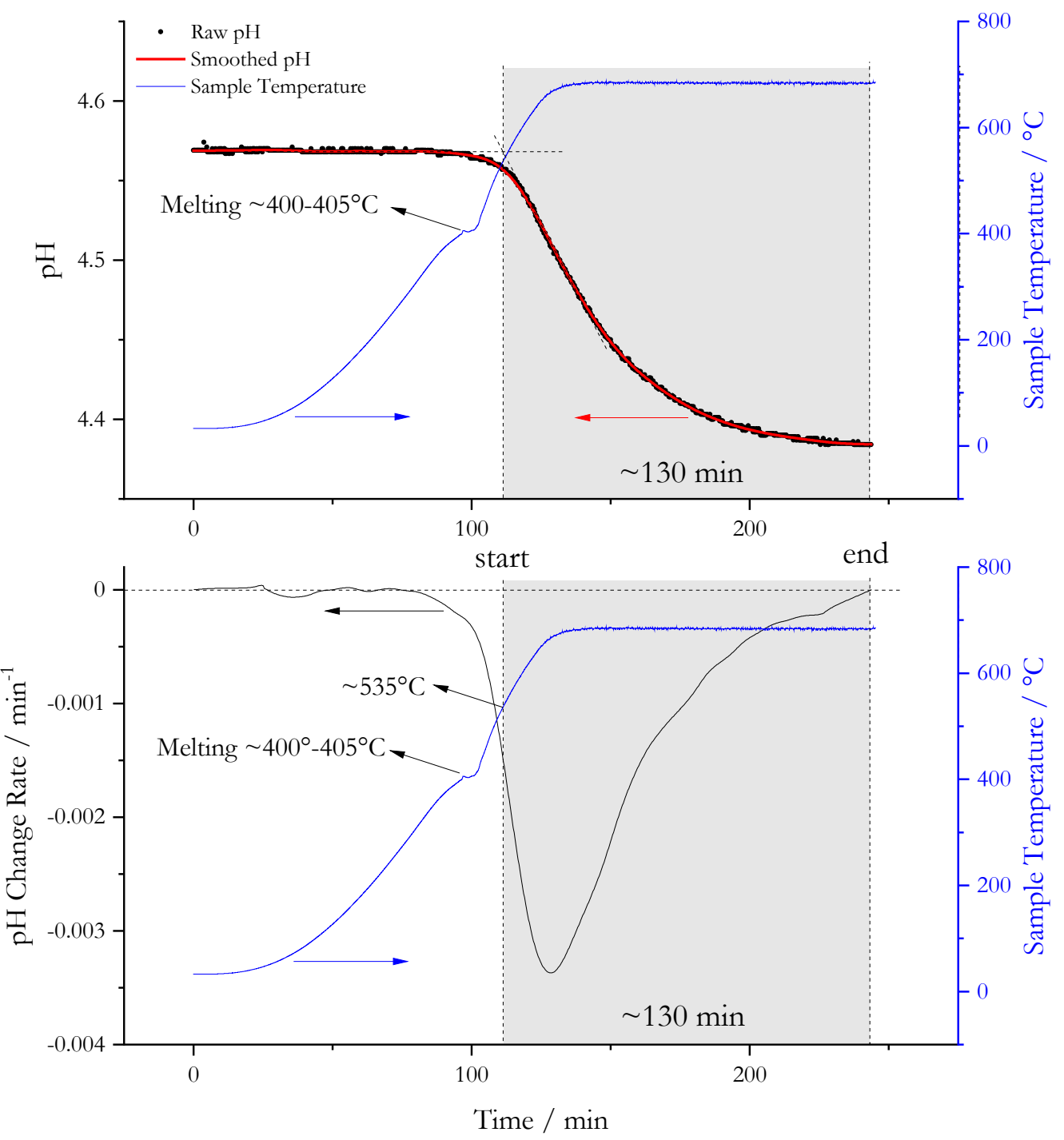

Figure 9. Top: $\mathrm{pH}$ and sample temperature monitoring during a typical Mg purification; Bottom: calculated rate of $\mathrm{pH}$ change

There are several important observations to note:

\footnotetext{
${ }^{24}$ The melting point of the raw $\mathrm{AC}$ is reportedly $>450^{\circ} \mathrm{C}$, whereas the melting point of halite is much higher. Observation of salt melting at $\sim 400^{\circ}-405^{\circ} \mathrm{C}$ shows that the mixing of halite and $\mathrm{AC}$ following the recipe is very effective at suppressing the melting point of the mixture even during initial melting. This melting point is consistent with our DSC experiments.
} 
1. There is no noticeable $\mathrm{pH}$ drop below $400^{\circ} \mathrm{C}$. This indicates that the pre-drying process at $<300^{\circ} \mathrm{C}$ is effective at removing most moisture via dehydration and most $\mathrm{HCl}$ molecules via hydrolysis. Even after cooling down the pre-dried salt, taking mass measurement, storing in the glove box, and reheating the salt to the purification temperature in the next day, there is no noticeable $\mathrm{HCl}$ release until $\sim 400^{\circ} \mathrm{C}$.

2. The release of $\mathrm{HCl}$ is fundamentally caused by dehydration of certain $\mathrm{MgCl}_{2}$ hydrates and hydrolysis with anhydrous $\mathrm{MgCl}_{2}$. If all available hydrates and possible $\mathrm{HCl}$ formation have been removed by pre-drying, the next $\mathrm{HCl}$ formation must be due to dehydration of additional $\mathrm{MgCl}_{2}$ hydrates that are not accessible at the pre-drying temperature of $<300^{\circ} \mathrm{C}$. $\mathrm{MgCl}_{2}$ monohydrate $\left(\mathrm{MgCl}_{2} \cdot \mathrm{H}_{2} \mathrm{O}\right)$ is the only one with reported dehydration temperature above this range (see Eq. 4 and its references). Therefore, this seems to prove that the predrying process is able to remove all higher hydrates except the monohydrates in the raw AC. Note that the raw AC had been stored in ambient atmosphere for over 12 months before some of these experiments, during which the salt could absorb additional moisture and rehydrate to form these higher hydrates. ${ }^{25}$

3. Results from multiple salt purification experiments show that the noticeable $\mathrm{pH}$ drop coincides with salt melting. The exact reason for the coincidence is not clear. A potential explanation is that the dehydration of $\mathrm{MgCl}_{2}$ monohydrate may have been hindered by the mass transfer in the solid state (i.e., $\mathrm{H}_{2} \mathrm{O}$ molecules need to first diffuse through the solid salt gains). Salt melting facilitates easier mass transfer, which suddenly accelerates the dehydration and hydrolysis processes, making a noticeable $\mathrm{pH}$ change after $\sim 400^{\circ} \mathrm{C}$ due to $\mathrm{HCl}$ production via hydrolysis.

4. The $\mathrm{pH}$ change is accelerating in the range of $550^{\circ}-650^{\circ} \mathrm{C}$. One of the $\mathrm{HCl}$ production mechanisms is the thermal decomposition of $\mathrm{MgOHCl}$ (Eq. 7). The thermodynamic decomposition temperature is calculated to be around $555^{\circ} \mathrm{C}$ [29] and is experimentally observed at as low as $500^{\circ} \mathrm{C}[40,52]$. Therefore, $\mathrm{MgOHCl}$ thermal decomposition can be responsible for the $\mathrm{HCl}$ production in this temperature range. The intriguing part of the $\mathrm{pH}$ change is that it reaches its peak at about $650^{\circ}-660^{\circ} \mathrm{C}$, followed by a clear slow-down (as shown by the $\mathrm{pH}$ change rate in the bottom plot of Figure 9). The temperature at the peak coincides with the melting point of $\mathrm{Mg}$. This seems to hint at the effectiveness of $\mathrm{Mg}$ purification, which suppresses $\mathrm{HCl}$ formation by forming $\mathrm{H}_{2}$ (Eq. 9). However, we know from the literature that (1) $\mathrm{MgOHCl}$ decomposition kinetics is fast (i.e., over $75 \%$ reduction in $\mathrm{MgOHCl}$ in less than $20 \mathrm{~min}$ at $600^{\circ} \mathrm{C}$ ) and increases with temperature following the kinetics of thermal activation, and (2) $\mathrm{MgOHCl}$ decomposition is eventually limited by mass transfer of produced $\mathrm{HCl}$. There is a chance that the acceleration of $\mathrm{pH}$ drop and $\mathrm{HCl}$ release is a result of fast $\mathrm{MgOHCl}$ decomposition during the first 10-20 min of thermal decomposition and the slow-down is indicative of mass transfer limitation, when produced $\mathrm{HCl}$ can no longer be effectively removed from the reaction site. To confirm the hypothesis, purification without $\mathrm{Mg}$ is performed (discussed later).

\footnotetext{
${ }^{25}$ ICL claims that the moisture/hydrate content of a freshly produced AC batch should be less than $0.5 \mathrm{wt} . \%$ (mostly in the form of $\mathrm{MgCl}_{2}$ monohydrate). However, an $\mathrm{AC}$ batch stored in ambient atmospheres could have 3-4 times higher moisture content as reported by ICL and NREL's measurement upon pre-drying and purification. The higher moisture content can very likely be due to rehydration that forms higher hydrates.
} 
If the $\mathrm{HCl}$ release is indeed mostly due to $\mathrm{MgOHCl}$ thermal decomposition, and $\mathrm{Mg}$ purification serves a supplemental role (i.e., not a major driver), then the $\mathrm{HCl}$ release time should be affected by the gas sparging rate if its kinetics are indeed limited by mass transfer. Therefore, the effect of gas sparging is investigated (discussed later).

$\mathrm{HCl}$ will be generated during the purification because of hydrolysis (Eq. 6) and $\mathrm{MgOHCl}$ thermal decomposition (Eq. 7). Rough calculation of $\mathrm{HCl}$ generation based on the $\mathrm{pH}$ drop of the buffer solution indicates that $\mathrm{HCl}$ generation is about $0.165 \pm 0.062 \mathrm{wt} . \%$ of the total weight of salt $+\mathrm{Mg}$. This range is believed to be an estimation only because (1) the calculation is very sensitive to $\mathrm{pH}$ changes because $\mathrm{pH}$ is defined as the logarithmic of $\mathrm{H}^{+}$ions and the specified resolution of $\mathrm{pH}$ probe is only $0.01^{26}$, and (2) some $\mathrm{HCl}$ molecules may not be captured by the buffer if they react with the furnace vessel hardware and outlet gas tubing ${ }^{27}$ and/or escape the vessel hardware through leaks. ${ }^{28}$ In addition, the total weight loss during the purification step is $0.578 \pm 0.098 \mathrm{wt} . \%,{ }^{29}$ higher than the estimated weight fraction of $\mathrm{HCl}$. Such discrepancy in mass balance again suggests that not all mass loss is from $\mathrm{HCl}$ release and moisture can be responsible for the rest of the mass loss, which corroborates the assumption used by the calculation in the previous section that not all released $\mathrm{H}_{2} \mathrm{O}$ participates in hydrolysis to form $\mathrm{HCl}$.

\section{$\mathrm{H}_{2}$ Generation and Safety Hazard}

As discussed previously, we recommend $\mathrm{Mg}$ addition for industrial-scale purification. Communication with the industry partner reveals that there is a bigger concern with $\mathrm{H}_{2}$ generation than $\mathrm{HCl}$ generation, because $\mathrm{H}_{2}$ gas can be generated during $\mathrm{Mg}$ purification via $\mathrm{Mg}$ reaction with $\mathrm{MgOHCl}, \mathrm{HCl}$, and/or $\mathrm{H}_{2} \mathrm{O}$. Regardless of which reaction occurs, the stoichiometry between $\mathrm{Mg}$ and the $\mathrm{H}_{2}$ generated is fixed at a $1: 1$ molar ratio. The maximum level of $\mathrm{H}_{2}$ generation can be estimated as following. At 1,000 ppm of $\mathrm{Mg}$ addition, each Mt of processed salt has $1,000 \mathrm{~g}$ of $\mathrm{Mg}$, which is available to form $82.3 \mathrm{~g}$ of $\mathrm{H}_{2}$. Assuming $\mathrm{H}_{2}$ is ideal at the purification temperature $\left(\sim 670^{\circ} \mathrm{C}\right)$ and

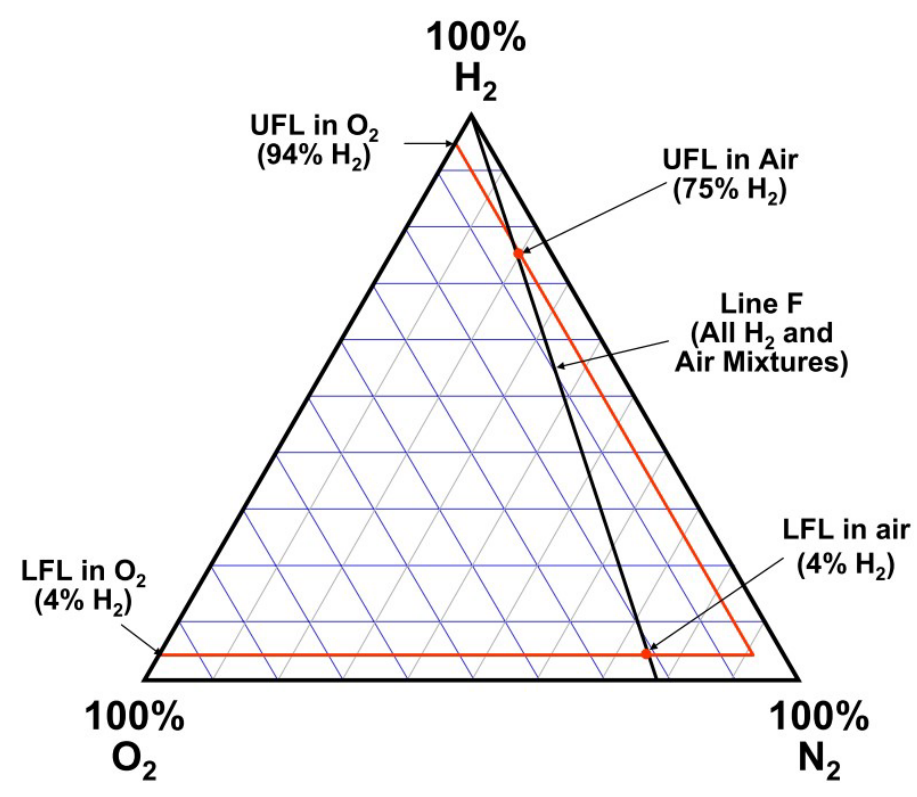

Figure 10. Flammability diagram for $\mathrm{H}_{2}-\mathrm{N}_{2}-\mathrm{O}_{2}$ mixture at room temperature [71] pressure $(\sim 1 \mathrm{~atm})$, the total volume is

\footnotetext{
${ }^{26}$ The finer resolution shown in Figure 9 is from interpolation by the $\mathrm{pH}$ meter when the user selects an output resolution of 0.001 .

${ }^{27}$ Inconel vessel can indeed react with $\mathrm{HCl}$ at high temperatures.

${ }^{28}$ The purification is always performed with a slight positive pressure (up to a few psig) in the furnace vessel.

${ }^{29}$ Based on multiple purifications with different $\mathrm{Mg}$ addition and gas sparging rate. Details will be discussed later.
} 
$3.2 \mathrm{~m}^{3}$. Although this is a very conservative upper bound because not all $\mathrm{Mg}$ will find $\mathrm{MgOHCl}$, $\mathrm{HCl}$, and/or $\mathrm{H}_{2} \mathrm{O}$ to form $\mathrm{H}_{2}$ gas, the hazard of $\mathrm{H}_{2}$ generation at high temperature is present.

Figure 10 shows the flammability of the $\mathrm{H}_{2}-\mathrm{N}_{2}-\mathrm{O}_{2}$ mixture at room temperature. The gas mixture compositions within the envelope bound by the red lines are flammable if there is an external source of ignition. The envelope for self-ignition (i.e., the gas mixture is flammable even without an external source of ignition because the temperature is high enough to overcome the reaction barrier of $\mathrm{H}_{2}+\mathrm{O}_{2}$ ) is smaller [70]. Because the melting process is under a dry- $\mathrm{N}_{2}$ environment with potentially minor $\mathrm{O}_{2}$ content, we should be more concerned with the flammability limits around the bottom right corner (i.e., close to $100 \% \mathrm{~N}_{2}$ ) AND at high temperature of $650^{\circ}-720^{\circ} \mathrm{C}$, which the melter is operating at. Figure 11 shows the $\mathrm{N}_{2}$-rich corner of the $\mathrm{H}_{2}-\mathrm{N}_{2}-\mathrm{O}_{2}$ flammability diagram with additional flammability envelopes at higher temperatures [71]. Because the flammability envelope expands linearly with temperature [70,72], the flammability envelope at $1,300^{\circ} \mathrm{C}$ ( or $704^{\circ} \mathrm{C}$ ) can be linearly extrapolated from those at lower temperatures, as shown by the area bounded by the red lines. This flammability envelope suggests that at about $700^{\circ} \mathrm{C}$, there is no minimum amount of $\mathrm{H}_{2}$ below which the gas mixture is non-flammable (at the presence of an external ignition source) as defined by the lower flammability limit. The only way to make the gas mixture non-flammable (at the presence of an external source of ignition) is to ensure $<1 \mathrm{vol} \%$ of $\mathrm{O}_{2}$. The amount of $\mathrm{H}_{2}$ is not the dominating factor (i.e., a mixture of $99 \mathrm{vol} \%$ $\mathrm{H}_{2}, 0.5 \mathrm{vol} \% \mathrm{~N}_{2}$, and $0.5 \mathrm{vol}^{\circ} \mathrm{O}_{2}$ is non-flammable even at the presence of an external source of ignition). The implications of Figure 11 are that (1) sufficient $\mathrm{N}_{2}$ should be used in the design to

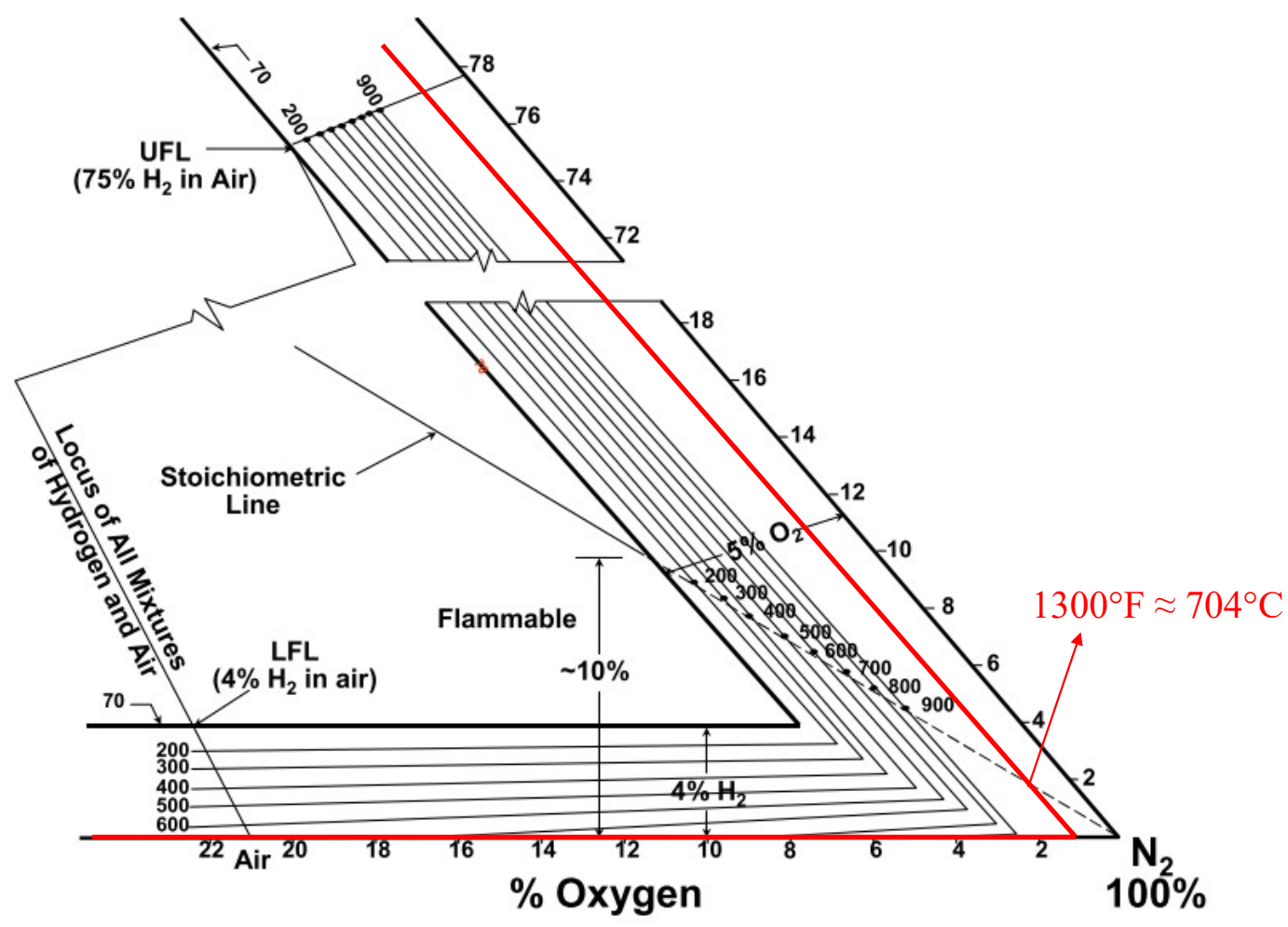

Figure 11. Flammability diagram of $\mathrm{N}_{2}$-rich $\mathrm{H}_{2}-\mathrm{N}_{2}-\mathrm{O}_{2}$ mixture at elevated temperatures [71]. Note that the temperatures in the diagram are in Fahrenheit. The area bounded by the red lines is the flammability at about $704^{\circ} \mathrm{C}$. 
ensure that $\mathrm{O}_{2}$ content is below $\approx 1$ vol\% during normal operation, ${ }^{30}$ (2) extra $\mathrm{N}_{2}$ purge must be implemented to dilute any possible $\mathrm{H}_{2}$ accumulation before opening the melter for service and maintenance (meaning $\mathrm{O}_{2}$ ingress is inevitable) even at low temperatures but an external source of ignition might be present by accident, and (3) maximum allowable rates of $\mathrm{H}_{2}$ generation and/or $\mathrm{O}_{2}$ ingress can be determined ${ }^{31}$ (i.e., how fast the gas composition moves from $100 \% \mathrm{~N}_{2}$ to cross into the flammability envelope given the purge rate of $\mathrm{N}_{2}$ ).

Experimentally, a hydrogen gas sensor (0-1,000 ppm) was used to detect hydrogen gas in the off-gas during the salt pre-drying process at $250^{\circ}-300^{\circ} \mathrm{C}$. The off-gas was bubbled through (1) a $1 \mathrm{M} \mathrm{NaOH}$ aqueous solution to remove any acidic gas such as $\mathrm{HCl}$ and $\mathrm{H}_{2} \mathrm{~S},{ }^{32}$ and (2) a drierite desiccator to remove moisture. Cross-sensitivity of $\mathrm{H}_{2} \mathrm{~S}$ is reported by the hydrogen sensor manufacturer and a high relative humidity above $90 \%$ can affect the sensor too. In an experiment with Inconel furnace vessel and stainless off-gas tubing, $\mathrm{H}_{2}$ was detected with and without $\mathrm{Mg}$ addition. The temperature at which $\mathrm{H}_{2}$ was detected and the duration of detection agreed reasonably well with the water $/ \mathrm{HCl}$ release in Table 5 . The reason is that $\mathrm{Ni}$ and Ni-based alloys can react with $\mathrm{HCl}$ to form $\mathrm{H}_{2}$ at almost any elevated temperature. This is an important finding because it suggests that a non-metal interface with the gas phases is needed for the salt dryer/melter.

Two more salt pre-drying experiments with a zero-metal setup were conducted with 2,500 ppm $\mathrm{Mg}$ addition (as Mg chips) and without any $\mathrm{Mg}$. Neither showed any $\mathrm{H}_{2}$ detection within the capability of the hydrogen sensor. The observation of no $\mathrm{H}_{2}$ was slightly surprising because, thermodynamically, $\mathrm{Mg}$ should easily react with $\mathrm{H}_{2} \mathrm{O}$ and $\mathrm{HCl}$ at elevated temperatures. It was most likely that the solid reaction product, e.g., $\mathrm{MgCl}_{2}$ from $\mathrm{Mg}$ and $\mathrm{HCl}$, was not easily removed which might have slowed down or even passivated further reactions. ${ }^{33}$ The result is encouraging because it helps eliminate the concerns with $\mathrm{H}_{2}$ generation in the salt dryer (for predrying purposes). Even if solid $\mathrm{Mg}$ is mixed in the feed with the salt, we do not expect significant $\mathrm{H}_{2}$ generation either.

A similar experiment was conducted at $550^{\circ}-570^{\circ} \mathrm{C}$ where $\sim 400$-g batch of pre-dried AC + halite salt was melted in a pyrex furnace vessel (to exclude $\mathrm{H}_{2}$ generation due to any $\mathrm{HCL}$ reaction with metals) with a $\sim 10-\mathrm{g} \mathrm{Mg}$ piece added to the salt mixture from the beginning $(\mathrm{Mg}$ remained solid at $550^{\circ}-570^{\circ} \mathrm{C}$ ) while the off-gas was bubbled through a $1 \mathrm{M} \mathrm{NaOH}$ aqueous solution and a drierite desiccator before entering the same $\mathrm{H}_{2}$ sensor. In this case, a clear $\mathrm{H}_{2}$ signal up to $1000 \mathrm{ppm}$ was detected by the sensor (Figure 12). Because of the pyrex vessel setup, direct visual observation of gas generation within the molten salt was possible (e.g., liquid surface movement and gas bubbling). The duration of the gas bubbling behavior corresponded

\footnotetext{
${ }^{30}$ The maximum tolerable $\mathrm{O}_{2}$ content will be higher if designed to prevent auto-ignition only (i.e., flammable without an external source of ignition).

31 This is beyond the scope of this project but should serve as a guideline for the calculation.

${ }^{32} \mathrm{H}_{2} \mathrm{~S}$ formation was a possibility because (1) the characteristic rotten egg odor was present during pre-drying, and (2) alkaline and alkaline-earth sulfides can easily react with $\mathrm{H}_{2} \mathrm{O}$ and $\mathrm{HCl}$ to form $\mathrm{H}_{2} \mathrm{~S}$ gas. S was reported by the salt supplier in the form of sulfates in the raw salt materials. However, it was based on ICP results, which should only give information about elemental makeup. So, we are cautious and want to assume that sulfides can also be present.

$33 \mathrm{This}$ is very different from common reaction between $\mathrm{Mg}$ and aqueous $\mathrm{HCl}$ solution. The reaction product $\mathrm{MgCl}_{2}$ is highly soluble in the aqueous solution thus making it impossible to form any reaction barrier.
} 
reasonably well to the duration of $\mathrm{H}_{2}$ detection (80-90 $\mathrm{min}$ ). This time duration was shorter than the duration of $\mathrm{HCl}$ generation (based on experiences of purification, see Figure 9). Nevertheless,

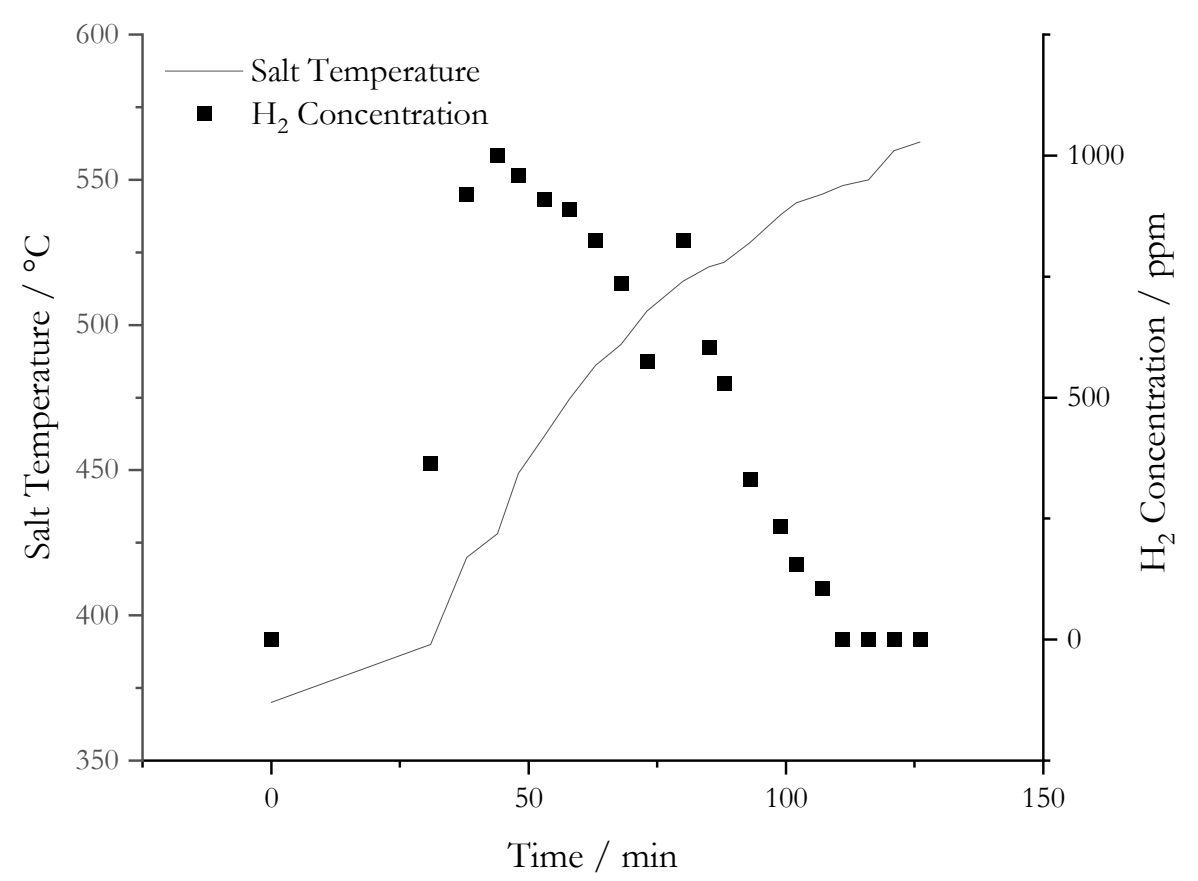

Figure 12. Hydrogen gas sensing during salt purification with a 10-g Mg piece added at the beginning. The data was collected manually

we tend to believe that $\mathrm{H}_{2}$ was indeed generated and was correlated to $\mathrm{HCl}$ generation.

Another experiment was conducted at $550^{\circ}-570^{\circ} \mathrm{C}$ where the salt was purified without $\mathrm{Mg}$ for $~$ 5 hours to release as much $\mathrm{HCl}$ and $\mathrm{H}_{2} \mathrm{O}$ as possible. ${ }^{34} \mathrm{~A} \mathrm{Mg}$ piece was then added into the molten salt. After about 5-8 minutes, a maximum of $150 \mathrm{ppm}$ of $\mathrm{H}_{2}$ was detected for less than 4 minutes. No $\mathrm{H}_{2}$ was detected afterwards for at least 60 minutes. This is encouraging because it suggests that holding the molten salt at $550^{\circ}-570^{\circ} \mathrm{C}$ for 5 hours successfully removed large amount of $\mathrm{HCl}$ and $\mathrm{H}_{2} \mathrm{O} .{ }^{35}$ The $\mathrm{H}_{2}$ detection was significantly reduced in terms of both magnitude and duration.

Unfortunately, the pyrex-based experimental setup is not capable of operating at the recommended purification temperature of $650^{\circ}-700^{\circ} \mathrm{C}$ because of concerns of pyrex's thermal stability. But we believe, given the success of the experiments at $550^{\circ}-570^{\circ} \mathrm{C}$, holding the molten salt at $650^{\circ}-700^{\circ} \mathrm{C}$ with sufficient gas sparging for $\sim 2$ hours (i.e., enough to remove most $\mathrm{HCl}$ based on results in Figure 9) should significantly reduce or even eliminate $\mathrm{H}_{2}$ generation.

\footnotetext{
${ }^{34}$ Because the experimental setup, $\mathrm{HCl}$ monitoring was not used. At $550^{\circ}-570^{\circ} \mathrm{C}, 5$ hours of holding without gas sparging (due to time constraints, longer holding was not performed) is not sufficient to remove all $\mathrm{HCl}$ based on results in Table 7.

${ }^{35}$ Due to time constraint, we could only run for 5 hours before introduction of $\mathrm{Mg}$. Before $\mathrm{Mg}$ addition, the off-gas was still acidic at $\mathrm{pH}$ 2-3 measured by $\mathrm{pH}$ papers.
} 
In conclusion, the literature on the topic of $\mathrm{H}_{2}$ flammability has been developed for over 50 years and engineering knowledge is also available. Although there is evidence at a lower purification temperature of $550^{\circ}-570^{\circ} \mathrm{C}$ that $\mathrm{H}_{2}$ risk could be mitigated by strategically adding $\mathrm{Mg}$ after $\mathrm{HCl}$ and $\mathrm{H}_{2} \mathrm{O}$ release, we cannot overlook such potential danger. Therefore, the possibility of salt purification without elemental $\mathrm{Mg}$ at all, which should eliminate the concerns with $\mathrm{H}_{2}$ generation, is discussed in the next sections.

\section{Gas Sparging Effect and Evaluation of Purification Without Mg}

Inert gas sparging during purification was investigated because Kashani-Nejad et al. [40] found that mass transfer of the reaction product, $\mathrm{HCl}$, is likely the rate-limiting step of $\mathrm{MgOHCl}$ thermal decomposition (Eq. 7) and there are no other intermediate steps. It was also found that at least $20 \mathrm{~min}$ is needed to complete the $\mathrm{MgOHCl}$ thermal decomposition at $600^{\circ} \pm 50^{\circ} \mathrm{C}$ in a TGA study. Because [40] used small amount of synthesized $\mathrm{MgOHCl}(100 \mathrm{mg}$ to $1 \mathrm{~g}$ without any chloride components), we believe that in our salt purification, the condition is more complicated and the thermal decomposition time can be longer, because (1) the absolute amount of $\mathrm{MgOHCl}$ is $>10$ times higher in our $\sim 500$-g salt batch but (2) the relative fraction of $\mathrm{MgOHCl}$ is much lower at $1 \mathrm{wt} . \%$ (with $99 \mathrm{wt} . \%$ of salt components) which might further slow-down the thermal decomposition reaction if the reaction rate is assumed, at first order, to be proportional to the concentration of the reactant. Similarly, the Mg purification kinetics (Eq. 9) can also be limited by mass transfer of $\mathrm{H}_{2}$ and/or $\mathrm{MgO}$ formation. Given the relatively long $\mathrm{HCl}$ release time during purification (Figure 9) and noticeable $\mathrm{pH}$ drop of the buffer solution, clearly neither of two competing reactions was dominating: if thermal decomposition were dominant and fast, the purification time would be shorter; if $\mathrm{Mg}$ purification were dominant and fast, the $\mathrm{pH}$ change would be much smaller. This might be the reason why there was still $\mathrm{HCl}$ release even when we believe $\mathrm{Mg}$ purification should greatly reduce $\mathrm{HCl}$ formation.

Table 7 summarizes all purification experiments with different purification parameters (i.e., sparging gas rate and amount of $\mathrm{Mg}$ addition). It shows that there is no noticeable difference in post-purification salts treated with $0.1 \mathrm{wt} . \%, 0.04 \mathrm{wt} . \%$, and $0 \mathrm{wt} . \% \mathrm{Mg}$ in terms of $\mathrm{HCl}$ release time, final $\mathrm{MgOHCl}$ content (except one sample with $0.1 \mathrm{wt} . \%$ of $\mathrm{Mg}$ and $50 \mathrm{sccm}$ gas sparging), sludge weight, and weight loss during purification as long as the purifications use the same gas sparging rate.

The results of $\mathrm{HCl}$ estimation based on $\mathrm{pH}$ monitoring are inconclusive, with reasons similar to the $\mathrm{HCl}$ estimation for pre-drying. The bottom line is that $\mathrm{HCl}$ release during high-temperature purification (with or without $\mathrm{Mg}$ ) is about 1.5-2.5 times higher than that during pre-drying. Using the average weight percent of $\mathrm{HCl}$ generation and assuming each $\mathrm{HCl}$ molecule generation is only related to thermal decomposition of one molecule of $\mathrm{MgOHCl}$, we can show that the estimated amount of $\mathrm{MgOHCl}$ prior to salt purification but after pre-drying is $0.33 \mathrm{wt} . \%$. The average $\mathrm{MgOHCl}$ content of an $\mathrm{AC}$ salt after a series of isothermal drying up to $400^{\circ} \mathrm{C}$ is at least $0.8 \mathrm{wt} . \%$ based on titration, much higher than the estimation of $0.33 \mathrm{wt} . \%$ based on $\mathrm{HCl}$ tracking. Therefore, it again shows that $\mathrm{pH}$ monitoring is a qualitative tool to track the release of $\mathrm{HCl}$, but not a quantitative tool to determine absolute amount of $\mathrm{HCl}$ generation. 
DE-EE00033870

Molten Chloride Thermophysical Properties, Chemical Optimization, and Purification National Renewable Energy Laboratory

Table 7. Summary of Purifications With Different Parameters

\begin{tabular}{|c|c|c|c|c|c|c|c|c|c|c|}
\hline \multirow[t]{2}{*}{$\begin{array}{l}\text { Exp. } \\
\text { ID }\end{array}$} & $\begin{array}{c}\text { Sparging } \\
\text { Gas } \\
\text { Flow } \\
\text { Rate }\end{array}$ & Mg & $\begin{array}{l}\text { Cover } \\
\text { Gas } \\
\text { Flow } \\
\text { Rate }\end{array}$ & \multirow[t]{2}{*}{$\begin{array}{l}\text { Gas } \\
\text { Type }\end{array}$} & $\begin{array}{c}\text { Initial } \\
\text { Salt } \\
\text { Weight }\end{array}$ & $\begin{array}{c}\mathrm{HCl} \\
\text { Release } \\
\text { Time }\end{array}$ & $\begin{array}{l}\mathrm{MgOHCl} \\
\text { Content }\end{array}$ & $\begin{array}{l}\text { Sludge } \\
\text { Weight }\end{array}$ & $\begin{array}{c}\text { Weight } \\
\text { Loss } \\
\text { during } \\
\text { Purification }\end{array}$ & $\begin{array}{c}\text { Estimated } \\
\mathrm{HCl} \\
\text { Release }\end{array}$ \\
\hline & $\mathrm{sccm}$ & wt. $\%$ & $\mathrm{sccm}$ & & g & $\min$ & wt.\% & wt. $\%$ & wt. $\%$ & wt.\% \\
\hline 1 & \multirow{2}{*}{0} & $0.00 \%$ & \multirow{8}{*}{690} & \multirow{8}{*}{$\begin{array}{l}\text { Dry } \\
\mathrm{N}_{2}\end{array}$} & 456.73 & 590 & $0.218 \pm 0.101$ & $0.952 \%$ & $0.528 \%$ & $0.090 \%$ \\
\hline 2 & & $0.04 \%$ & & & 452.31 & 570 & $0.284 \pm 0.127$ & $1.053 \%$ & $0.639 \%$ & $0.259 \%$ \\
\hline 3 & \multirow{3}{*}{50} & $0.00 \%$ & & & 485.45 & 200 & $0.146 \pm 0.017$ & $1.050 \%$ & $0.515 \%$ & $0.221 \%$ \\
\hline 4 & & $0.04 \%$ & & & 486.06 & 220 & $0.150 \pm 0.016$ & $1.007 \%$ & $0.548 \%$ & $0.172 \%$ \\
\hline 5 & & $0.10 \%$ & & & 488.31 & 195 & $0.578 \pm 0.203^{*}$ & $0.921 \%$ & $0.663 \%$ & $0.094 \%$ \\
\hline 6 & \multirow{2}{*}{200} & $0.00 \%$ & & & 454.18 & 130 & $0.125 \pm 0.025$ & $1.071 \%$ & $0.438 \%$ & $0.159 \%$ \\
\hline 7 & & $0.04 \%$ & & & 482.48 & 115 & $0.151 \pm 0.009$ & $1.133 \%$ & $0.717 \%$ & $0.162 \%$ \\
\hline 8 & 300 & $0.04 \%$ & & & 484.82 & 128 & $0.155 \pm 0.027$ & $1.011 \%$ & $0.615 \%$ & $0.161 \%$ \\
\hline & & & & & & & Average & $1.025 \%$ & $0.578 \%$ & $0.165 \%$ \\
\hline & & & & & & & Stdev & $0.068 \%$ & $0.098 \%$ & $0.057 \%$ \\
\hline
\end{tabular}

* There is no clear explanation why this value is much higher than the rest. This could be an outlier due to experimental errors.

Figure 13 plots the total $\mathrm{HCl}$ release time (or purification time needed) at the purification temperature of $\sim 670^{\circ}-680^{\circ} \mathrm{C}$ as a function of sparging gas flow rate at different $\mathrm{Mg}$ addition levels. It shows that there is a strong correlation between $\mathrm{HCl}$ release time (or purification time needed) and sparging gas flow rate. The amount of $\mathrm{Mg}$ does not play an important role in determining the $\mathrm{HCl}$ release time. The effectiveness of reducing purification time by increasing gas sparging rate diminishes quickly at higher sparging rate with the single 1/4-inch sparging tube

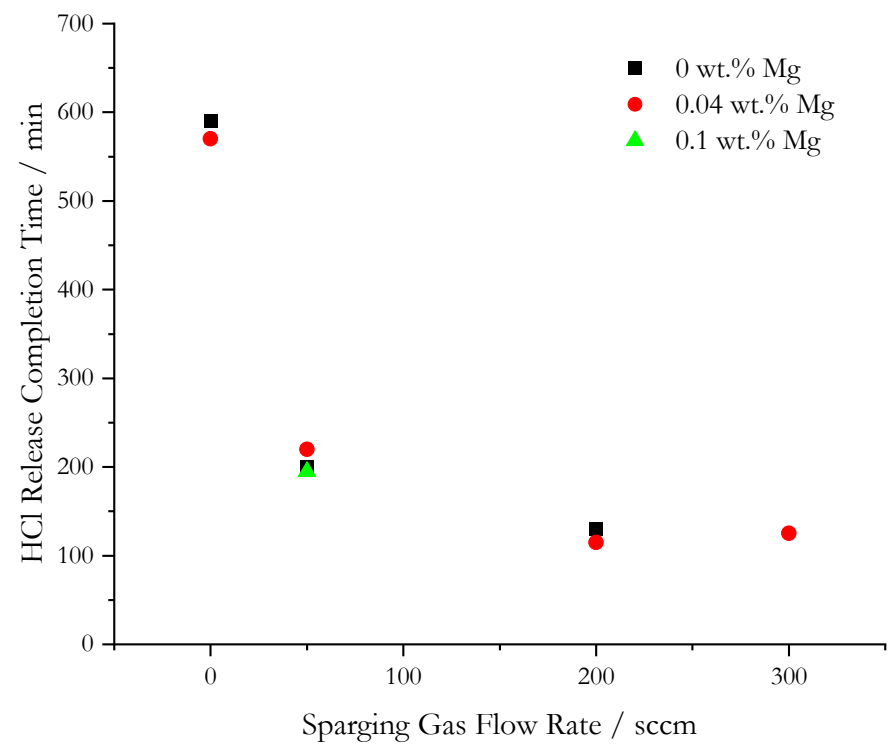

Figure 13. Variation of $\mathrm{HCl}$ release time (or purification time needed) at $670^{\circ} \mathrm{C}$ as a function of inert gas sparging rate with different levels of $\mathrm{Mg}$ addition 
setup. ${ }^{36}$ Figure 14 plots the post-purification $\mathrm{MgOHCl}$ content as a function of sparging gas flow rate at different $\mathrm{Mg}$ addition level. Except the possible outliers at $50 \mathrm{sccm}$ with $0.1 \mathrm{wt} . \% \mathrm{Mg},{ }^{37}$ there is generally a lower $\mathrm{MgOHCl}$ content if sparging is used, but there is no significant difference between $50 \mathrm{sccm}$ and $200 \mathrm{sccm}$ of sparging. The role of $\mathrm{Mg}$ seems inconclusive. In addition, besides the higher $\mathrm{MgOHCl}$ content when there is no sparging, the statistical scatter is

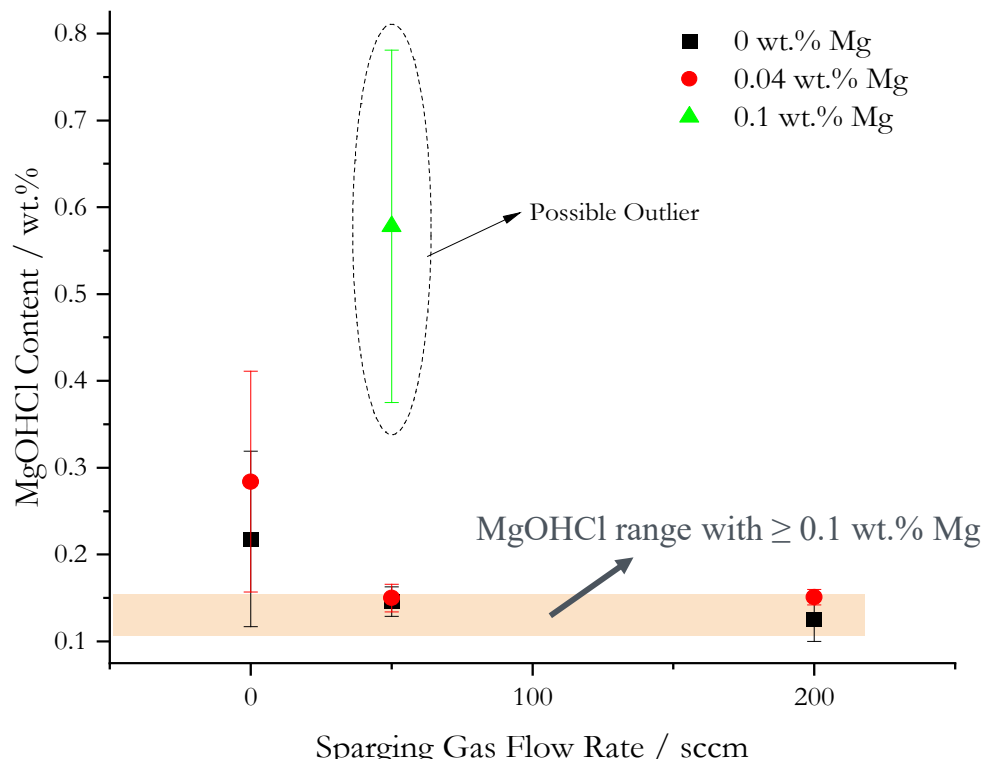

Figure 14. Variation of post-purification $\mathrm{MgOHCl}$ content as a function of inert gas sparging rate with different levels of Mg addition

also much larger. It indicates that gas sparging is indeed important at removing $\mathrm{HCl}$ from $\mathrm{MgOHCl}$ thermal decomposition and ensuring a homogenous salt with consistent quality. Note that cover gas at $690 \mathrm{sccm}$ was present even when there was no sparging gas. This suggests that the phenomenon of $\mathrm{HCl}$ gas release depends much more on gas going into the salt melt (sparging gas) than gas flowing in the head space (cover gas), which agrees with the hypothesis that $\mathrm{HCl}$ release kinetics is eventually limited by its own removal from the reaction site. Obviously, the information in Table 7 is only the very first data point and cannot be directly translated to a larger-scale melter. A careful up-scaling study will be needed. For example, the design certainly will not adopt the single-tube sparging design; instead, the sparging tube can be perforated or some industrial standard design/geometry can be used to improve efficiency.

\footnotetext{
${ }^{36}$ We have attempted using a quartz sparging tube with a fritted end (pore size of 150-200 $\mu \mathrm{m}$ ) at similar sparging gas flow rate. The intention is to better disperse the sparging gas bubbles and increase efficiency. However, the fritted end is clogged shortly after the salt is molten. The fritted end can be unclogged with ultra-sonication in deionized water after which it shows a slight color change compared to clean quartz, suggesting that some chemical attack may have resulted in the clogging. Or additionally, the pore size is too small such that some salt freezing may have clogged the pores due to the cooling effect from the sparging gas. However, this is a speculation only. But, both possibilities suggest that clogging must be considered in the melter design.

37 The outliers are possibly due to an expired chemical used for titration. The range of $\mathrm{MgOHCl}$ in more than 10 batches of salts purified with $\geq 1000 \mathrm{ppm}$ of $\mathrm{Mg}$ across the project period is given in the plot to show that the data points at $50 \mathrm{sccm}$ with $0.1 \mathrm{wt} \% \mathrm{Mg}$ should be considered outliers.
} 
Besides the experimental observations shown in Figure 13 and Figure 14, salt purification without $\mathrm{Mg}$ (at least at low initial $\mathrm{MgOHCl}$ content) is also considered feasible based on a few experimental studies by de Bakker et al. [38], Kashani-Nejad and Harris [40], and the electrochemical sensor work by Argonne National Laboratory. All measured the kinetics of the $\mathrm{MgOHCl}$ thermal decomposition at elevated temperatures. The results indicate that $\mathrm{MgOHCl}$ thermal decomposition at a high temperature of $700^{\circ} \mathrm{C}$ could potentially be faster than $\mathrm{MgOHCl}$ reduction by elemental $\mathrm{Mg}$. It is, therefore, possible that $\mathrm{MgOHCl}$ can be the major mechanism to reduce $\mathrm{MgOHCl}$ content during purification (i.e., one of the major objectives of purification).

Table 8 shows the post-purification compositions by inductively coupled plasma (ICP)-atomic emission spectroscopy (AES) of salts purified with 0 ppm, $400 \mathrm{ppm}, 1,000 \mathrm{ppm}$ and 2,500 ppm of Mg. It should be noted that, after May 2020, the ICP analysis service (at Colorado School of Mines) switched to a different testing standard/procedure. The new standard/procedure may have caused some systematic errors between the salt purified before May 2020 (salt purified with 2,500 ppm Mg) and after May 2020 (salt purified with 0 ppm, $400 \mathrm{ppm} \mathrm{Mg}$ and 1,000 ppm). Two salt samples were analyzed from the same purification batch with $0 \mathrm{ppm}, 400 \mathrm{ppm} \mathrm{Mg}$ and $1,000 \mathrm{ppm}$, and four salt samples were analyzed from four different purification batches with 2,500 ppm $\mathrm{Mg}$, which should be taken into account when interpreting the standard deviations values.

\section{Table 8. ICP Analysis of Salts Purified With Different Levels of Mg Addition (0 ppm, 400 ppm, 1,000 ppm, and 2,500 ppm)}

Empty cells indicate that the measurement is below detection limit. The lack of standard deviation indicates that only one data point is available. The notation " $A$ " or " $R$ " after the name of the element means different spectrum standard used.

\begin{tabular}{|c|c|c|c|c|}
\hline \multirow{3}{*}{ Element } & \multicolumn{4}{|c|}{ Purification With Different Mg Addition } \\
\hline & 0 ppm Mg & 400 ppm Mg & 1,000 ppm Mg & 2,500 ppm Mg \\
\hline & \multicolumn{4}{|c|}{ Average \pm Stdev in ppm } \\
\hline Al 396.153 - A & 3.7 & & $2.8 \pm 0.8$ & \\
\hline As $188.979-\mathrm{A}$ & $13.7 \pm 0.6$ & $12.9 \pm 3.3$ & $13.2 \pm 0.1$ & \\
\hline \multicolumn{5}{|l|}{ B 249.677 - R } \\
\hline Ba $233.527-A$ & $1.3 \pm 0.3$ & $0.8 \pm 0.1$ & & $1.0 \pm 0.2$ \\
\hline \multicolumn{5}{|l|}{ Be $313.107-\mathrm{R}$} \\
\hline Ca $317.933-\mathrm{A}$ & $1157.8 \pm 61.8$ & $1419.6 \pm 24.2$ & $1148.1 \pm 1.6$ & $1011.3 \pm 59.8$ \\
\hline Cd $214.440-\mathrm{A}$ & 0.2 & 0.1 & 0.1 & \\
\hline \multicolumn{5}{|l|}{ Cu $324.752-A$} \\
\hline Cr $205.560-A$ & $4.8 \pm 4.2$ & & $2.0 \pm 0.6$ & \\
\hline Fe $238.204-A$ & $149.9 \pm 5.3$ & $47.3 \pm 11.3$ & $126.3 \pm 56.8$ & $7.4 \pm 3.1$ \\
\hline K $766.490-\mathrm{R}$ & $171923.5 \pm 6987.1$ & $179826.2 \pm 3733.0$ & $170326.3 \pm 1709.1$ & $176108.0 \pm 8394.3$ \\
\hline Li $670.784-\mathrm{R}$ & $7.2 \pm 3.9$ & $6.4 \pm 6.4$ & $7.5 \pm 0.0$ & \\
\hline $\mathrm{Mg} 285.213-\mathrm{R}$ & $97950.4 \pm 1791.8$ & $101115.6 \pm 32.3$ & $96553.4 \pm 636.5$ & $102474.0 \pm 3718.8$ \\
\hline Mg $279.077-\mathrm{R}$ & $98167.2 \pm 727.5$ & $100503.5 \pm 164.5$ & $95440.4 \pm 1186.4$ & $100903.0 \pm 2845.5$ \\
\hline $\mathrm{Mn} 257.610-\mathrm{A}$ & $4.3 \pm 0.0$ & $4.1 \pm 0.2$ & $4.6 \pm 0.2$ & $2.3 \pm 0.2$ \\
\hline Mo 202.031 - A & & & & $4.0 \pm 0.8$ \\
\hline Na 589.592 - R & $53631.8 \pm 367.5$ & $55214.0 \pm 1000.6$ & $60570.7 \pm 953.7$ & $50770.8 \pm 3394.1$ \\
\hline Ni $231.604-\mathrm{A}$ & $8.7 \pm 1.2$ & $3.3 \pm 0.2$ & $4.5 \pm 0.7$ & \\
\hline P $177.434-A$ & $164.2 \pm 7.1$ & $175.6 \pm 18.9$ & $154.6 \pm 1.4$ & $265.4 \pm 30.4$ \\
\hline \multicolumn{5}{|l|}{$\mathrm{Pb} 220.353-\mathrm{A}$} \\
\hline S $180.669-A$ & $566.0 \pm 107.0$ & $388.1 \pm 20.5$ & $177.4 \pm 3.6$ & $85.4 \pm 19.0$ \\
\hline Sb $217.582-A$ & & & & \\
\hline
\end{tabular}




\begin{tabular}{|c|c|c|c|c|}
\hline \multirow{3}{*}{ Element } & \multicolumn{4}{|c|}{ Purification With Different Mg Addition } \\
\hline & 0 ppm Mg & 400 ppm Mg & 1,000 ppm Mg & $2,500 \mathrm{ppm} \mathrm{Mg}$ \\
\hline & \multicolumn{4}{|c|}{ Average \pm Stdev in ppm } \\
\hline \multicolumn{5}{|l|}{ Se $196.026-\mathrm{A}$} \\
\hline Si 251.611 - A & $35.6 \pm 2.6$ & $25.9 \pm 11.9$ & $13.5 \pm 0.3$ & \\
\hline \multicolumn{5}{|l|}{ Sn $189.927-\mathrm{A}$} \\
\hline Sr $460.733-A$ & $1.8 \pm 0.3$ & $1.8 \pm 0.0$ & $1.7 \pm 0.0$ & $21.8 \pm 2.4$ \\
\hline \multicolumn{5}{|l|}{ Ti $334.940-\mathrm{A}$} \\
\hline \multicolumn{5}{|l|}{ TI 190.801-A } \\
\hline \multicolumn{5}{|l|}{ V $292.402-A$} \\
\hline Zn $213.857-A$ & $11.3 \pm 0.5$ & $9.8 \pm 0.5$ & $8.4 \pm 0.4$ & $5.3 \pm 0.3$ \\
\hline
\end{tabular}

The most important findings from Table 8 are that (1) the overall salt compositions (as reflected by the concentrations of $\mathrm{K}, \mathrm{Mg}$, and $\mathrm{Na}$ ) are similar when the salt is treated by different levels of $\mathrm{Mg}$ addition, and (2) there is a correlation between lower post-purification Fe, S, and Si content and higher $\mathrm{Mg}$ addition. When combined with the results from Table 7 and Figure 13, this suggests that using no $\mathrm{Mg}$ during salt purification is a possible option only in terms of $\mathrm{MgOHCl}$ reduction. Although zero-Mg purification does not have a significant impact on the overall salt composition, post-purification $\mathrm{MgOHCl}$ content, or purification time; the noticeable impact is the higher post-purification Fe, S, and Si content. There is concern with salt corrosivity if Fe is present. Theoretically, $\mathrm{Fe}^{2+}$ is able to oxidize $\mathrm{Cr}$ to $\mathrm{Cr}^{2+}$ (but not to $\mathrm{Cr}^{3+}$ ), and $\mathrm{Fe}^{3+}$ is able to oxidize $\mathrm{Cr}$ to $\mathrm{Cr}^{3+}$ based on an experimental reduction potential series in the $\mathrm{MgCl}_{2}-\mathrm{NaCl}-\mathrm{KCl}$ eutectic at $475^{\circ} \mathrm{C}$ (i.e., the most relevant experimental results to our salt system/composition [73]). Therefore, from the corrosion perspective, removal of Fe (regardless of its valency) is necessary unless $\mathrm{Fe}$ is in the elemental form. Elemental Fe is not likely because ICL's chlorination process with $\mathrm{Cl}_{2}$ gas for $\mathrm{AC}$ production should oxidize elemental Fe.

The actual valency of Fe in the salt is hard to predict, given the following theoretical and experimental information.

- In the $\mathrm{MgCl}_{2}-\mathrm{NaCl}-\mathrm{KCl}$ eutectic at $475^{\circ} \mathrm{C}$, the thermodynamic equilibrium between elemental $\mathrm{Fe}$ (i.e., the Fe electrode used in ICL's purification process with chlorination) and $\mathrm{Fe}^{3+} / \mathrm{Fe}^{2+}$, i.e., $\mathrm{Fe}+2 \mathrm{Fe}^{3+} \rightarrow 3 \mathrm{Fe}^{2+}$, has a negative Gibbs free energy, suggesting $\mathrm{Fe}^{2+}$ is the more stable form of $\mathrm{Fe}$.

- The chlorination process with $\mathrm{Cl}_{2}$ gas should oxidize $\mathrm{Fe}^{2+}$ to $\mathrm{Fe}^{3+}$. This was suggested by ICL, but no evidence was given. ICL only provided ICP results, which cannot distinguish different valences. ICL also did not provide kinetic information on the oxidation process.

- $\mathrm{FeCl}_{3}$ is known to have high vapor pressure [74]. So, we tend to believe that if Fe is in the form of $\mathrm{Fe}^{3+}$, it should evaporate quickly. However, the literature vapor pressure is measured on pure $\mathrm{FeCl}_{3}$ (i.e., with an activity of 1 ). When $\mathrm{FeCl}_{3}$ is present in a $\mathrm{MgCl}_{2}-\mathrm{NaCl}-\mathrm{KCl}$ at $\sim 100$ ppm, its activity should be much lower, the equilibrium between the $\mathrm{FeCl}_{3}$ in the salt melt and the gaseous $\mathrm{FeCl}_{3}$ above the salt melt is much easier to establish, and the complete removal of $\mathrm{FeCl}_{3}$ by evaporation is much harder to achieve. This might explain why $\mathrm{Fe}$ can be present in the raw $\mathrm{AC}$ as $\mathrm{Fe}^{3+}$. 
- An electrochemical sensor is the best tool to distinguish the valency of Fe. Communication with Dr. Hoyt at Argonne National Laboratory suggests that $\mathrm{Fe}^{2+}$ is the major species in the purified salt. ${ }^{38}$

Given the information above, we can speculate a possible chemical route of the Fe species. The major form of $\mathrm{Fe}$ cations in the raw $\mathrm{AC}$ is $\mathrm{Fe}^{2+}$ because (1) the chlorination process in ICL's purification process is not able to oxidize $\mathrm{Fe}^{2+}$ to $\mathrm{Fe}^{3+}$ with $100 \%$ efficiency, and/or (2) the converted $\mathrm{Fe}^{3+}$ (in the form of $\mathrm{FeCl}_{3}$ ) is removed from the system via vaporization until an equilibrium is established. The $\mathrm{Fe}^{2+}$ cations later can be reduced by the purification process with elemental $\mathrm{Mg}$. A few hundreds ppm of $\mathrm{Mg}$ should be sufficient to reduce either $\mathrm{Fe}^{3+}$ or $\mathrm{Fe}^{2+}$ at $\sim 100$-ppm level. The potential effects of S and Si have not been systematically investigated. The mechanism that reduces $\mathrm{S}$ and $\mathrm{Si}$ with more $\mathrm{Mg}$ is also unclear.

Corrosion tests of Alloy 600 in AC salt at ORNL revealed that the depth of penetration in the alloy samples due to corrosion is similar for AC purified with $0-0.25 \% \mathrm{Mg}$. Although this is not a direct correlation between $\mathrm{Fe} / \mathrm{S} / \mathrm{Si}$ cations and corrosion, it does provide some information about the corrosivity of the salt with different impurity levels. Note that the ORNL tests were performed isothermally at $700^{\circ} \mathrm{C}$ under static flow condition. This does not guarantee that the same will happen in a flowing system with a temperature gradient.

The findings from ORNL seem to contradict the Salt Collective's decision to use Mg during purification. However, it must be noted that the decision of using $\mathrm{Mg}$ as purification agent was made when the Salt Collective was evaluating the dehydrated carnallite salt. When using dehydrated carnallite salt with much higher initial water and $\mathrm{MgOHCl}$ content, addition of $\mathrm{Mg}$ is very necessary. ${ }^{39}$ Although this is only a speculation, it is possible that the reaction kinetics of $\mathrm{MgOHCl}$ thermal decomposition and $\mathrm{Mg}$ purification both depend on the amount of $\mathrm{MgOHCl}^{40}$, and there could be a cross-over at a certain $\mathrm{MgOHCl}$ content level. Below this cross-over, $\mathrm{MgOHCl}$ thermal decomposition alone is more effective at reducing $\mathrm{MgOHCl}$, and above this cross-over $\mathrm{Mg}$ is needed to help the overall reduction of $\mathrm{MgOHCl}$. In either case, we believe inert gas sparging will help accelerate overall reaction kinetics by more quickly removing gaseous reaction products from the salt melt.

It is very difficult to find a perfect explanation that addresses all of the contradicting information regarding $\mathrm{Mg}$ addition. However, the fact is that $\mathrm{Mg}$ is consumed during purification. Although the primary function of $\mathrm{Mg}$ is still unclear (e.g., removal of $\mathrm{MgOHCl}$ or metal cations), we believe consumption is due to purification. NREL's experiments show that there is some excess $\mathrm{Mg}$ in purifications using $\geq 1,000 \mathrm{ppm}$ of $\mathrm{Mg}$, while there is barely any in a purification using $400 \mathrm{ppm}$ of $\mathrm{Mg}$. So our recommendation of $\mathrm{Mg}$ addition is $500-1,000 \mathrm{ppm}$ (preferably closer to $1,000 \mathrm{ppm}$ to ensure that $\mathrm{Mg}$ is in excess), as shown in Table 6. Strategically, the final decision must be made based on the corrosion behavior of the purified salt, instead of Fe/S/Si content, $\mathrm{MgOHCl}$ content, or $\mathrm{HCl}$ generation. NREL's corrosion tests on Haynes 230 (discussed later)

\footnotetext{
38 The measured concentration is unknown.

${ }^{39}$ The dehydrated carnallite salts purified with and without Mg even had different colors (i.e., white vs. pink), and there is a strong correlation between low corrosion rates and $\mathrm{Mg}$ addition.

${ }^{40}$ Reference [40] shows that $\mathrm{MgOHCl}$ thermal decomposition is a first-order process on high purity $\mathrm{MgOHCl}$ amount at a $0.1-1 \mathrm{~g}$ scale (i.e., without effects from chloride components such as $\mathrm{NaCl}, \mathrm{KCl}$, and $\mathrm{MgCl}_{2}$ ).
} 
are similar for salts purified at 1,000 ppm and 2,500 ppm $\mathrm{Mg}$. However, the results are questionable and confusing for salts purified at $400 \mathrm{ppm} \mathrm{Mg}$. Therefore, driven by the corrosion results, we should abandon the idea of zero-Mg purification. Then the challenge is how to find an alternative that can balance $\mathrm{Mg}$ 's benefits and risks.

For large-scale industrial salt melter design, a compromise could be made between minimizing $\mathrm{H}_{2}$ risk and providing corrosion control by separating the thermal purification process (i.e., purification without $\mathrm{Mg}$ to reduce most $\mathrm{MgOHCl}$ ) and chemical purification process (i.e., purification with $\mathrm{Mg}$ to primarily remove harmful metallic cations such as $\mathrm{Fe}^{2+}$ and $\mathrm{Fe}^{3+}$ ). This compromise is made possible by the material selection of the melter design. The melter chambers are usually lined with ceramic-based materials and the off-gas lines are lined with reinforced plastics. Both types of materials are more resistant to attacks from a $\mathrm{HCl} / \mathrm{H}_{2} \mathrm{O}$ mixture than common and affordable structural metals such as stainless steels. ${ }^{41}$ Hence, minimization of $\mathrm{HCl}$ generation via thermal decomposition of $\mathrm{MgOHCl}$ is less of a priority in these melters than minimizing potentially flammable $\mathrm{H}_{2}$ due to the addition of $\mathrm{Mg}$. The thermal purification process is proven to remove most $\mathrm{H}_{2} \mathrm{O}$ and $\mathrm{HCl}^{42}$ Therefore, addition of $\mathrm{Mg}$ into a salt after thermal purification should not produce $\mathrm{H}_{2}$ due to reaction between $\mathrm{Mg}$ and $\mathrm{H}_{2} \mathrm{O} / \mathrm{HCl}$. The most likely source of $\mathrm{H}_{2}$ generation is the reaction between $\mathrm{MgOHCl}$ and $\mathrm{Mg}$ (Eq. 9). However, data in Table 7 suggest that the effect of $\mathrm{Mg}$ addition on post-purification $\mathrm{MgOHCl}$ content is relatively small (i.e., using $\mathrm{Mg}$ at 0 ppm, $400 \mathrm{ppm}, 1,000 \mathrm{ppm}$, and 2,500 ppm all achieve a postpurification $\mathrm{MgOHCl}$ content of 0.1-0.15 wt\%). Hence, we tend to believe that addition of $\mathrm{Mg}$ after a zero- $\mathrm{Mg}$ thermal purification will not be able to further reduce $\mathrm{MgOHCl}$ to a much lower level, and the risk of $\mathrm{H}_{2}$ generation due to reaction with $\mathrm{Mg}$ at such low level of $\mathrm{MgOHCl}$ is also low.

\section{MgO Particle Settling}

The salt purification will produce $\mathrm{MgO}$ particles via two chemical pathways: (1) thermal decomposition of $\mathrm{MgOHCl}$ (Eq. 7) and (2) reduction of $\mathrm{MgOHCl}$ by $\mathrm{Mg}$ (Eq. 9). One method to remove these $\mathrm{MgO}$ particles is via particle settling. The following Stokes' Law provides a rough estimate of how fast a particle settles in a liquid.

$$
v=\frac{2}{9}\left(\rho_{1}-\rho_{2}\right) g r^{2} / \mu
$$

where $v$ is the settling speed, $\rho_{1}$ is the density of the particle (assumed to be spherical), $\rho_{2}$ is the density of the liquid, $g$ is the gravitational acceleration, $r$ is the radius of the particle, and $\mu$ is the dynamic viscosity of the liquid.

\footnotetext{
${ }^{41} \mathrm{Ni}$-based alloys are expected to be chemically resistant too, but their affordability is a major issue.

${ }^{42}$ Continued $\mathrm{HCl}$ monitoring after a zero- $\mathrm{Mg}$ purification does not show any additional $\mathrm{pH}$ drop. Re-melting of the same purified salt also does not show $\mathrm{HCl} / \mathrm{H}_{2} \mathrm{O}$ generation.
} 


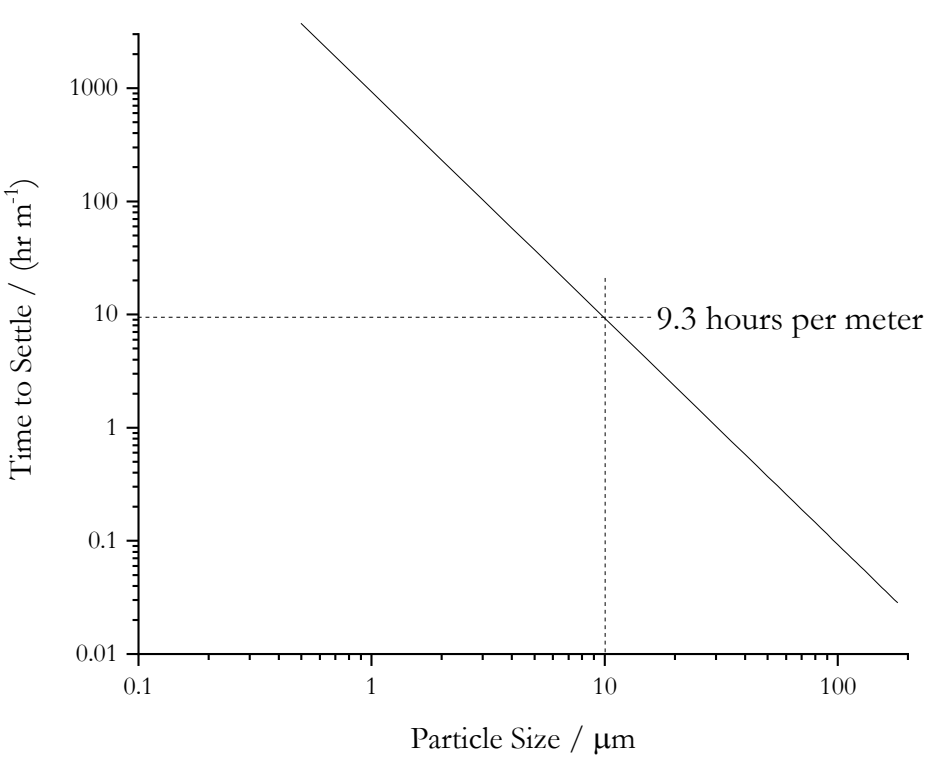

Figure 15. Calculated unit distance settling time of $\mathrm{MgO}$ particles in the ternary chloride salt at $500^{\circ} \mathrm{C}$ using Stokes' Law
Figure 15 shows the estimated unitdistance settling time of $\mathrm{MgO}$ particles at $500^{\circ} \mathrm{C}$ based on Eq. 10 . The $\mathrm{MgO}$ particle density is given by FactSage database [62], and the salt density and viscosity are given by later sections. The settling distance is defined as the shortest vertical distance that the particles travel during settling. Hence, it is only a rough estimate without considering other complications such as liquid convection effect. The peak particle size in the salt after purification is around 10-30 $\mu \mathrm{m}$ (see \#1 and "Sludge from Baseline" in Figure 32). Figure 15 suggests that about 910 hours is needed for particles at $>10 \mu \mathrm{m}$ to settle/travel each meter. The liquid height in our purification experiments is only $10-15 \mathrm{~cm}$, which suggests that $1-2$ hours are sufficient for particles in the size range of $>10 \mu \mathrm{m}$ to settle. This is only an estimate because the settling condition can be dynamic (i.e., furnace cooling from $670^{\circ} \mathrm{C}$ to $\sim 400^{\circ} \mathrm{C}$ at $1{ }^{\circ} \mathrm{C} / \mathrm{min}$, which means about 4.5 hours of settling) rather than isothermal. The lag between furnace temperature and salt temperature as well as possible non-uniform temperature distribution in the molten salt can lead to liquid convection. However, the bottom line is that our lab-scale settling was effective, as suggested by the fact that a clear salt phase with less than $0.05 \mathrm{wt} . \%$ of particles was formed at the top $\sim 95$ vol\% of the solidified salt, while a sludge phase with an estimated 20-30 wt.\% particles was formed at the bottom 3-5 vol\% of the solidified salt. Similarly, we can estimate the settling time in a large-scale settling chamber. For a large-scale cubic melter designed to process $1 \mathrm{Mt}$ of salt per hour (i.e., with a chamber size of $85 \mathrm{~cm}$ by $85 \mathrm{~cm}$ by $85 \mathrm{~cm}$ ), particles need to travel at 85 $\mathrm{cm} / \mathrm{hr}$ to keep up with the salt processing rate. This $85 \mathrm{~cm} / \mathrm{hr}$ settling velocity translates to that particles $>20 \mu \mathrm{m}$ in size can settling in an hour. Therefore, we believe that if temperature distribution and liquid convection can be precisely controlled in a real-scale settling chamber, settling can be an effective method to remove large particles. This is important because if most of the particles cannot be removed by settling, filtration with filters is likely not able to handle a salt stream with 20-30 wt\% particles for a prolonged period of time without clogging. If settling is effective, the filtration should expect to treat a salt stream with only $\sim 0.05 \mathrm{wt} . \%$ of particles. For particles that are smaller than $10 \mu \mathrm{m}$, Stokes' Law in Eq. 10 suggests that the settling time increases exponentially. It is practically difficult (i.e., extremely time consuming) to settle particles in the $<10 \mu \mathrm{m}$ size range even under the perfect conditions. But the risks of damages for bearings and bushings in the salt pumps from smaller particles (i.e., $<20 \mu \mathrm{m}$ ) might be lower. And the filters (i.e., $10 \mu \mathrm{m}$ pore size) could also capture some of these smaller particles. So ideally, the particles that escape both the settling and filtration processes will be small enough and present little risks to the downstream mechanical components. 


\section{Purification Summary}

After extensive experiments with various purification parameters, our final recommendations are:

1. Pre-drying of the raw salt materials is important, especially when the moisture content of the materials is high. There might not be a guarantee that the salt supplier(s) will store the salt in an ultra-dry environment after production. If the salt is not properly contained during storage and shipping, it can absorb significant moisture.

2. The amount of Mg used during purification should be determined based on the salt quality prior to purification (e.g., moisture/hydrate content). When the salt has a higher amount of hydrate (e.g., dehydrated carnallite from ICL), using no $\mathrm{Mg}$ can cause major corrosion problems, as seen during our early purification investigation. When the salt has lower amount of hydrate (e.g., AC from ICL), using lower amount of Mg (such as 500-1,000 ppm) is possible because the relatively small amount of $\mathrm{HCl}$ generated by thermal decomposition of $\mathrm{MgOHCl}$ is not detrimental to the hardware. The major function of this amount of $\mathrm{Mg}$ is to reduce other impurities, such as $\mathrm{Fe} / \mathrm{S} / \mathrm{Si}$, as much as possible.

3. It is key to implement an in-situ $\mathrm{MgOHCl}$ sensor to monitor the $\mathrm{MgOHCl}$ content during purification and determine the residence time of the salt at purification temperature. The sensor can also provide feedback and inform the operator to adjust the $\mathrm{Mg}$ addition amount.

4. Sparging of the salt melt with dry gas (e.g., $\mathrm{N}_{2}$ ) is important. Sparging during both pre-drying and purification can facilitate fast evolution of $\mathrm{H}_{2} \mathrm{O}$ and $\mathrm{HCl}$, which is essential to preventing back-reactions, reducing the time needed for both processes, and improving the overall salt processing rate and cost-effectiveness.

\subsection{Purified Salt Composition and Thermophysical Properties}

\section{Final Salt Composition}

Detailed ICP-AES results of post-purification salts were presented in Table 8. Because the ICPAES only measures cations (i.e., no report on $\mathrm{Cl}^{-}$), we must assume that $\mathrm{Mg}, \mathrm{K}$, and $\mathrm{Na}$ are in the form of $\mathrm{MgCl}_{2}, \mathrm{KCl}$, and $\mathrm{NaCl}$ in order to calculate the overall chloride salt composition. Note that other cations such as $\mathrm{Ca}$ (at $\sim 1,000 \mathrm{ppm}$ or $0.1 \%$ ), $\mathrm{P}$ (at $<300 \mathrm{ppm}$ ), and $\mathrm{S}$ (at $<600 \mathrm{ppm}$ ) were not included in the calculation because (1) their concentrations were too low to have a significant effect on overall salt composition and (2) their exact form (i.e., chlorides vs. phosphate vs. sulfate vs. sulfides) was unknown. The measured average concentrations and standard deviations of elements in ppm translate to the composition of the purified salt shown in Table 9. This composition is referred to as the "baseline salt" throughout the rest of the report. It should be noted that the composition in Table 9 was obtained by calculating the average and standard deviation of all salts (10 samples from 7 purification batches) listed in Table 8 . 
Table 9. Average Composition and Standard Deviation (Stdev) of Purified AC + Halite Based on ICP-AES Measurements of 10 Samples from 7 Purification Batches

\begin{tabular}{|c|c|c|c|}
\hline & $\mathbf{M g C l}_{\mathbf{2}}$ & $\mathbf{K C l}$ & $\mathrm{NaCl}$ \\
\hline Composition & \multicolumn{3}{|c|}{ wt.\% } \\
\hline Average & 45.31 & 38.70 & 15.99 \\
\hline Stdev & 1.40 & 1.46 & 1.27 \\
\hline Composition & \multicolumn{3}{|c|}{ mol. $\%$} \\
\hline Average & 37.51 & 40.92 & 21.57 \\
\hline Stdev & 1.16 & 1.54 & 1.72 \\
\hline
\end{tabular}

Figure 16 provides a graphical representation showing the compositions of AC, SPK halite, and purified baseline. The colored region shows the entire composition range where the liquidus temperature is below $500^{\circ} \mathrm{C}$ based on FactSage calculation. The radius of the red dot corresponds to the highest standard deviation in Table 9, indicating the range of potential composition

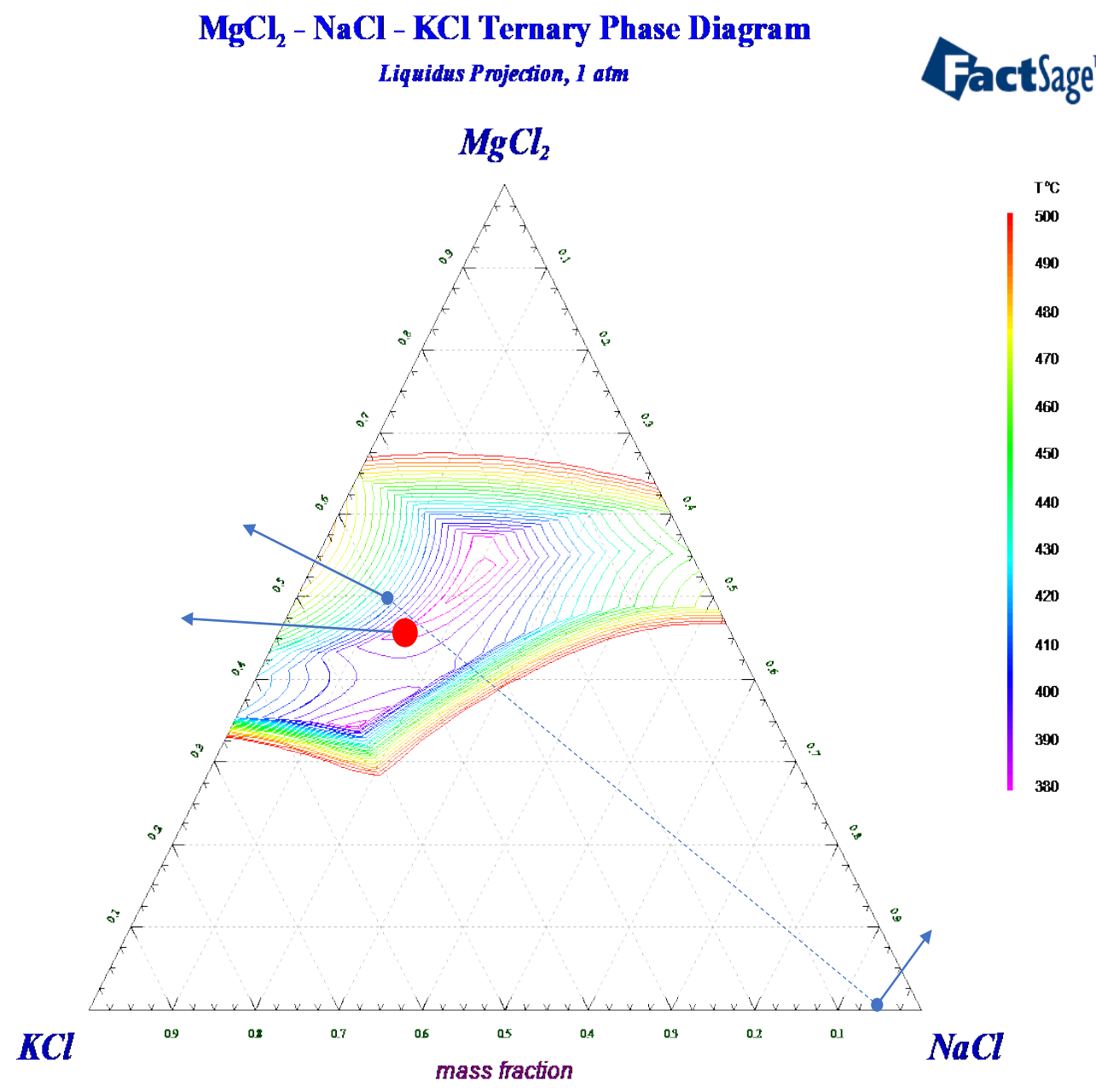

Figure 16. NaCl-KCl- $\mathrm{MgCl}_{2}$ phase diagram calculated by FactSage showing the compositions of the purified baseline salt, AC, and SPK halite. The colored contours indicate the liquidus temperatures up to $500^{\circ} \mathrm{C}$ calculated by FactSage. The radius of the red dot corresponds to the highest standard deviation in Table 9. 
variation. Note that the locations for AC and SPK halite are plotted using the compositions reported by the suppliers in Table 2 and Table 3 . Theoretically, simple mixing of AC and SPK halite should result in a salt composition that lies on the dashed line connecting AC and SPK halite. The fact that the baseline salt is slightly off such line is likely due to (1) inaccuracy and/or variation of raw salt compositions reported by the suppliers, ${ }^{43}$ or (2) permanent loss of $\mathrm{MgCl}_{2}$ to $\mathrm{MgOHCl}$ and eventually to $\mathrm{MgO}$ due to hydrolysis (Eqs. 6, 5 and 8) and thermal decomposition (Eq. 7) and/or reduction of $\mathrm{MgOHCl}$ (Eq. 9).

\section{Liquidus Temperature and Sensitivity to Composition}

The liquidus temperature of the ICL AC is around $450^{\circ} \mathrm{C}$, as reported by ICL, whereas the lowest liquidus temperature that can be achieved in the $\mathrm{MgCl}_{2}-\mathrm{KCl}-\mathrm{NaCl}$ ternary system is $385^{\circ} \mathrm{C} \pm 1^{\circ} \mathrm{C}$ [7]. Hence, the major objectives of adding SPK halite are to (1) lower the liquidus temperature of the ICL AC and provide an extra safety margin for CSP loop operation between $500^{\circ}$ and $720^{\circ} \mathrm{C}$, and (2) reduce overall cost of the salt inventory because SPK halite is significantly cheaper than ICL AC by more than an order of magnitude.

Differential scanning calorimetry (DSC) was used to investigate the temperatures of phase transitions (e.g., solidus and liquidus temperatures during melting, and freezing temperature during solidification ${ }^{44}$ ) on the purified AC (following the purification process without halite addition) and purified baseline salt.

The isotherms in Figure 16 show that the liquidus temperature of the purified baseline salt

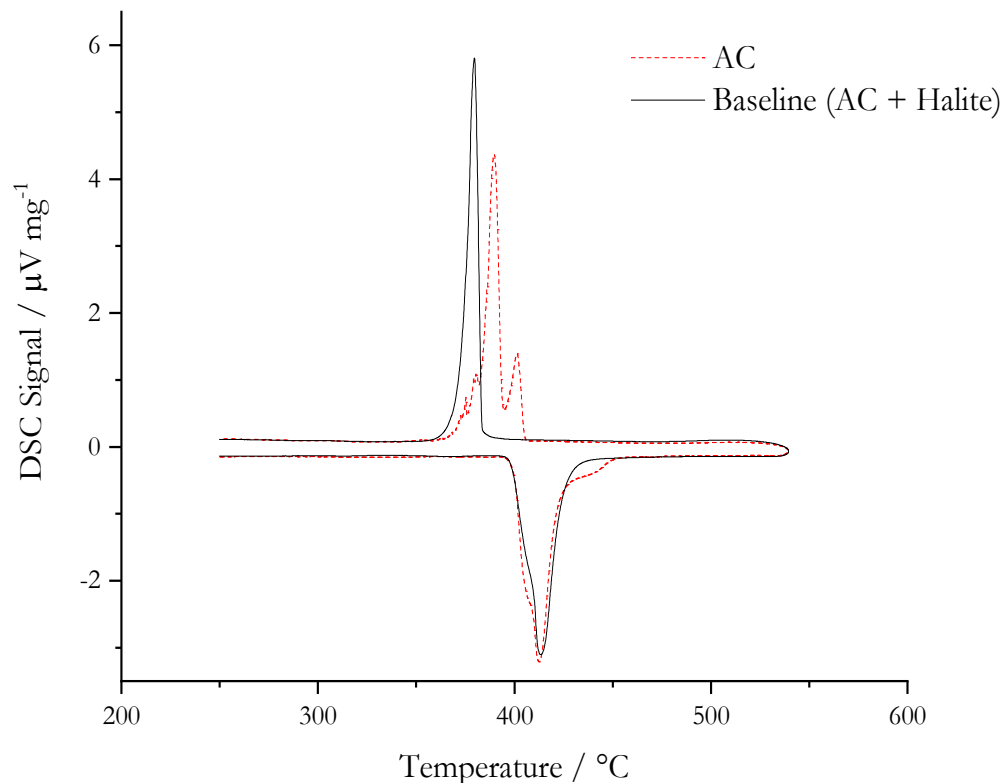

Figure 17. DSC heating and cooling traces for purified AC and baseline (purified AC with SPK halite); heating and cooling are both at $5^{\circ} \mathrm{C} / \mathrm{min}$ composition is around $400^{\circ} \mathrm{C}$. The DSC results on $\mathrm{AC}$ and baseline salt (Figure 17) confirm the effectiveness of halite addition on reducing liquidus temperature. The heating traces (i.e., the lower half with negative DSC signals) of both samples show an onset of melting (or eutectic temperature) at $\sim 400^{\circ} \mathrm{C}$, which means that their compositions are likely on the same eutectic system. The onset of $400^{\circ} \mathrm{C}$ also semi-quantitively confirms that the composition of the purified baseline salt is indeed close to the composition range measured by ICP-AES (i.e., the red dot in Figure 16). The heating trace for AC exhibits a subtle minor secondary peak (or a broad hump) on the order of $-0.3 \mu \mathrm{V} / \mathrm{mg}$ below the baseline signal at

43 There is some discrepancy between suppliers' numbers and NREL's number in Table 2 and Table 3.

${ }^{44}$ Freezing temperature is expected to be different than liquidus temperature because of undercooling. 
around $425^{\circ}-450^{\circ} \mathrm{C}$, which suggests that the composition of purified $\mathrm{AC}$ without halite has an off-eutectic behavior. Because no such secondary peak is observed for the baseline salt, this suggests that the mixture is very close to the eutectic composition in the AC-halite "pseudobinary" system.

Inspection of the cooling traces (the upper half with positive DSC signals) more clearly demonstrates the eutectic behavior of the baseline salt (i.e., only one phase transformation during solidification) vs. the off-eutectic behavior of AC (i.e., at least two phase transformations during solidification). It also reveals that the temperature at which the baseline salt solidifies is around $380^{\circ} \mathrm{C}$. It is lower than the eutectic temperature due to undercooling. This solidification temperature is a critical design parameter for CSP because HTF solidification close to the outlet temperature of the primary heat exchanger risks damaging this key component. One major objective of the salt composition optimization is to reduce the solidification of the ternary chloride salt to at least below $450^{\circ} \mathrm{C}$, giving a $>50^{\circ} \mathrm{C}$ safety margin because the lowest temperature of the primary heat exchanger for the supercritical $\mathrm{CO}_{2}$ power cycle is around $500^{\circ} \mathrm{C}$. Therefore, our DSC measurements lead to an important conclusion: addition of SPK halite following our recipe is effective at producing a local eutectic composition with a low liquidus temperature of $\sim 400^{\circ} \mathrm{C}$ and a solidification temperature of $\sim 380^{\circ} \mathrm{C}$. Even without any undercooling effect, solidification of the purified salt should not exceed the true liquidus temperature of $400^{\circ} \mathrm{C} .{ }^{45}$

After confirming that the baseline salt has a desired low liquidus temperature of around $400^{\circ} \mathrm{C}$, or more importantly, a low solidification temperature of no more than $400^{\circ} \mathrm{C}$, it is important to understand the sensitivity of liquidus temperature by potential composition shift. Therefore, similar DSC measurements were performed on baseline salt with additional $5 \mathrm{wt} . \%$ and $10 \mathrm{wt} . \%$ of $\mathrm{MgCl}_{2}, \mathrm{KCl}$, or $\mathrm{NaCl}$. Figures 18 and 19 show the DSC heating and cooling traces for baseline salts with additional $\mathrm{MgCl}_{2}$ and $\mathrm{NaCl}^{46}$ Table 10 summarizes the measured phase-transition temperatures during heating of six salt compositions off the baseline salt composition.

Table 10. Summary of Phase Transition Temperatures During Heating for Six Salt Compositions Orange cells indicate solidus temperatures and green cells indicate liquidus temperatures. Empty cells indicate that no clear transitions have been observed.

\begin{tabular}{|c|c|c|c|c|c|}
\hline $\begin{array}{c}\text { Added } \\
\text { Salt }\end{array}$ & $\begin{array}{c}\text { Added } \\
\text { Amount }\end{array}$ & $\begin{array}{l}\text { Transitio } \\
\text { During 1s }\end{array}$ & $\begin{array}{l}\text { perature } \\
\text { ing }\left({ }^{\circ} \mathrm{C}\right)\end{array}$ & $\begin{array}{l}\text { Transitio } \\
\text { During } 2\end{array}$ & $\begin{array}{l}\text { perature } \\
\text { ting }\left({ }^{\circ} \mathrm{C}\right)\end{array}$ \\
\hline $\mathrm{MgCl}_{2}$ & \multirow{3}{*}{5 wt.\% } & $400-410$ & 422.7 & $400-410$ & 421.5 \\
\hline $\mathrm{KCl}$ & & 400.5 & & 400.4 & 417.5 \\
\hline $\mathrm{NaCl}$ & & 400.7 & & 400.6 & \\
\hline $\mathrm{MgCl}_{2}$ & \multirow{3}{*}{10 wt. $\%$} & $400-410$ & 433.1 & $400-410$ & 433.6 \\
\hline $\mathrm{KCl}$ & & 400.7 & & 400.5 & 424.3 \\
\hline $\mathrm{NaCl}$ & & 400.7 & & 400.4 & \\
\hline
\end{tabular}

\footnotetext{
${ }^{45}$ Research partners at the University of South Australia independently verified our results with DSC after performing the prescribed salt purification using the same raw materials.

${ }^{46} \mathrm{DSC}$ traces for salts with additional $\mathrm{KCl}$ were not shown because their behaviors were between those of $\mathrm{MgCl}_{2}$ and $\mathrm{NaCl}$ additions.
} 
Several observations are summarized below.

- All six compositions had similar solidus temperature (i.e., onset of melting) around $400^{\circ} \mathrm{C}$.

- Neither 5 wt.\% nor 10 wt.\% $\mathrm{NaCl}$ addition showed an obvious split between solidus and liquidus during heating. There was only a minor split of the $1^{\text {st }}$ cooling trace in Figure 19(b). The onset of solidification was consistently around $380^{\circ}-385^{\circ} \mathrm{C}$.

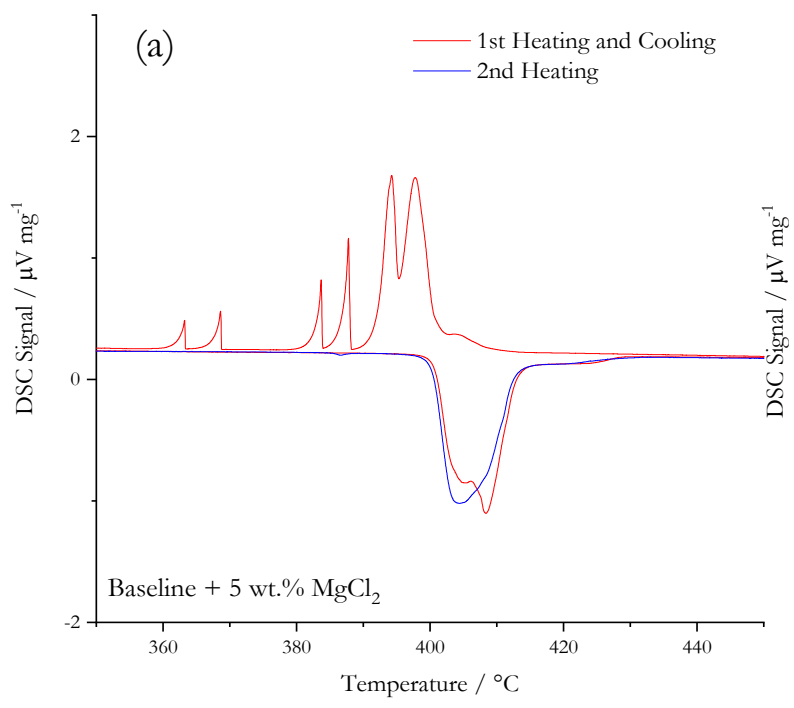

(b)

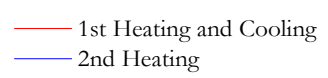

Figure 18. (a) DSC heating and cooling traces for baseline $+5 \mathrm{wt} \% \mathrm{MgCl}_{2}$; (b) DSC heating and cooling traces for baseline $+10 \mathrm{wt} \% \mathrm{MgCl}_{2}$
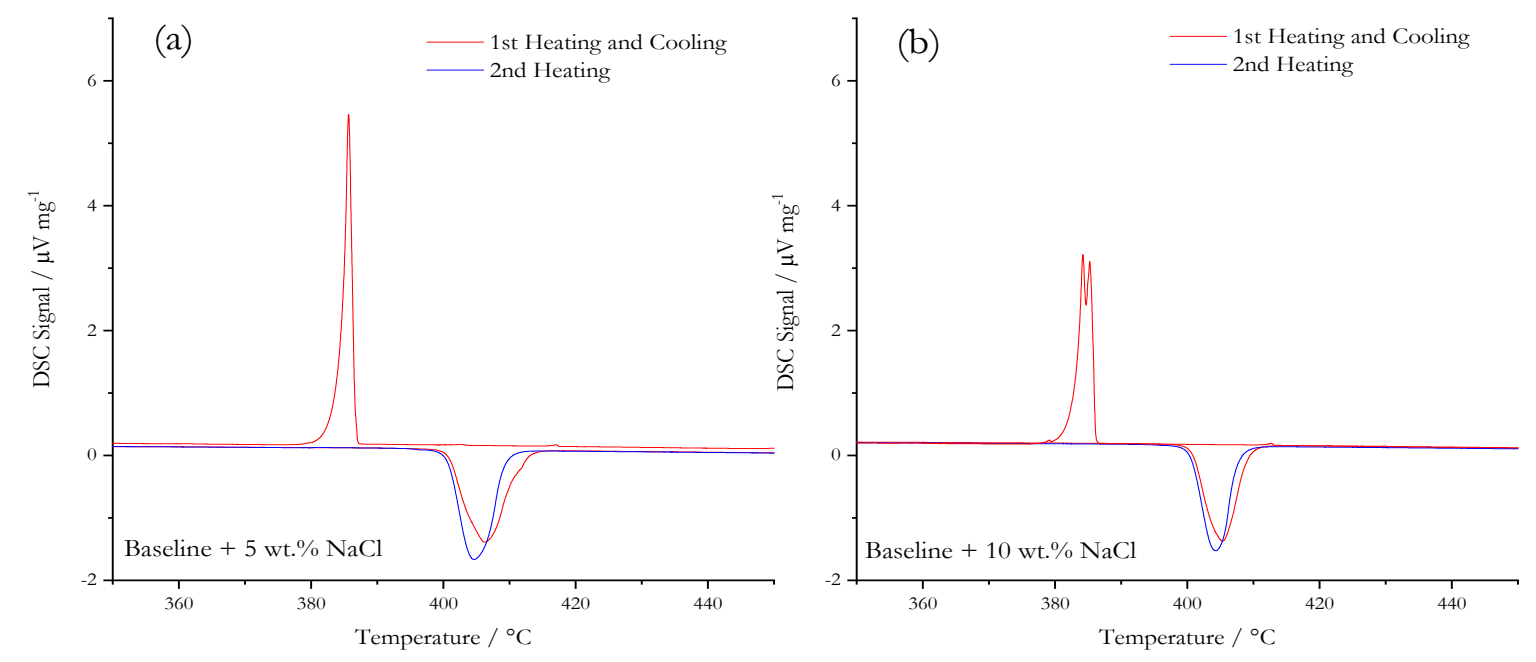

Figure 19. (a) DSC heating and cooling traces for baseline $+5 \mathrm{wt} \% \mathrm{NaCl}$; (b) DSC heating and cooling traces for baseline $+10 \mathrm{wt} . \% \mathrm{NaCl}$

- $\mathrm{MgCl}_{2}$ addition had a more significant effect. During heating, both $5 \mathrm{wt} . \%$ and $10 \mathrm{wt} . \%$ addition introduced a second peak with peak position around $410^{\circ} \mathrm{C}$. The exact onset of the second peak was difficult to locate because of overlapping with the first peak. Although there was a clear peak split, we cautiously speculate that both peaks were associated with the solidus transition. In addition, there was a weak and broad third peak around $420^{\circ}-$ $440^{\circ} \mathrm{C}$, which was more likely the liquidus temperature because of the nature of the liquidus 
transition: a second-order phase transition should be much weaker compared to a firstorder phase transition such as melting. The location of this third peak (liquidus) also increased from $\sim 422^{\circ} \mathrm{C}$ to $\sim 433^{\circ} \mathrm{C}$ (shown in Table 10) with more $\mathrm{MgCl}_{2}$, which agrees with the prediction that more $\mathrm{MgCl}_{2}$ should increase the liquidus temperature. The cooling traces of baseline salts with $\mathrm{MgCl}_{2}$ corroborated the heating traces because multiple cooling peaks were present, indicating that the material system was further away from a eutectic behavior. The first cooling also occurred at a much higher temperature of $\sim 400^{\circ} \mathrm{C}$ and $\sim 420^{\circ} \mathrm{C}$ in 5 wt. $\% \mathrm{MgCl}_{2}$ addition and 10 wt. $\% \mathrm{MgCl}_{2}$, respectively.

- The behaviors of $\mathrm{KCl}$ added salt were between those of $\mathrm{MgCl}_{2}$ and $\mathrm{NaCl}$ added salt. The liquidus during the second heating trace increased with $\mathrm{KCl}$ content and was lower than that in the case of $\mathrm{MgCl}_{2}$ addition, as shown in Table 10.

Therefore, our experimental evaluation qualitatively confirms the phase diagram prediction in Figure 16 that (1) $\mathrm{MgCl}_{2}$ addition should have the biggest influence on the liquidus temperature, as indicated by the highest density of isotherms in the direction toward the top corner of pure $\mathrm{MgCl}_{2}$, followed by $\mathrm{KCl}$ and $\mathrm{NaCl}$, and (2) even with $10 \mathrm{wt} . \%$ addition, the maximum increase of liquidus temperature is less than $50^{\circ} \mathrm{C}$. Figure 20 provides visualization of the experimental

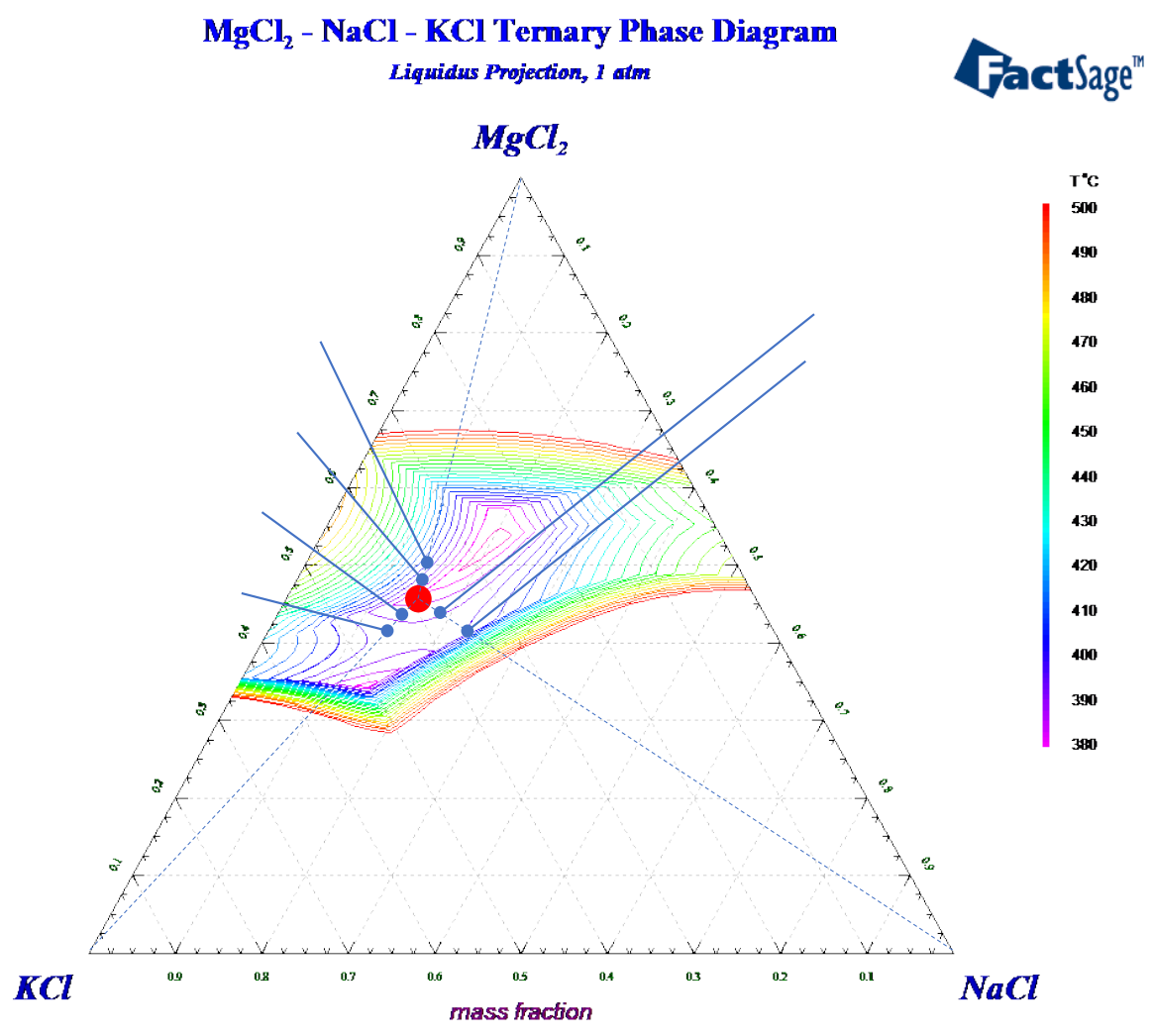

Figure 20. $\mathrm{NaCl}-\mathrm{KCl}-\mathrm{MgCl}_{2}$ phase diagram showing the locations of the baseline salt (red dot) and the six off-baseline compositions (blue dots) with their approximate liquidus temperature based on DSC measurements. The colored contours indicate the liquidus temperatures calculated by FactSage. 
liquidus temperature ${ }^{47}$ of the tested compositions in Table 10 in the ternary phase diagram. It points out that in terms of safe plant operation without salt freeze, we need to avoid significant increase of $\mathrm{MgCl}_{2}$, which practically should not be a big concern because no well-known mechanism will lead to enrichment of $\mathrm{MgCl}_{2}$ in the ternary chloride system. But we may need to keep track of any significant loss of $\mathrm{NaCl}$ and/or $\mathrm{KCl}$ in case $\mathrm{NaCl}$ and/or $\mathrm{KCl}$ preferentially react with the thermal energy storage tank liner.

\section{Thermophysical Properties}

A major project objective is to measure the thermophysical properties of the baseline salt composition in the molten state that are relevant to CSP system and component design (e.g., heat capacity, density and density change during melting, viscosity, vapor pressure, thermal conductivity, and thermal diffusivity). The University of Arizona and NREL were the leading institutes performing these measurements.

\section{Heat Capacity}

Heat capacity of the baseline salt in the molten state was successfully measured by three labs (NREL, U. Arizona, and Georgia Tech). Figure 21 summarizes the measurement results. The results from NREL and U. Arizona agree on both magnitude and standard deviation. Georgia Tech's result is $2 \%-4 \%$ off. The FactSage prediction stays well within one standard deviation of

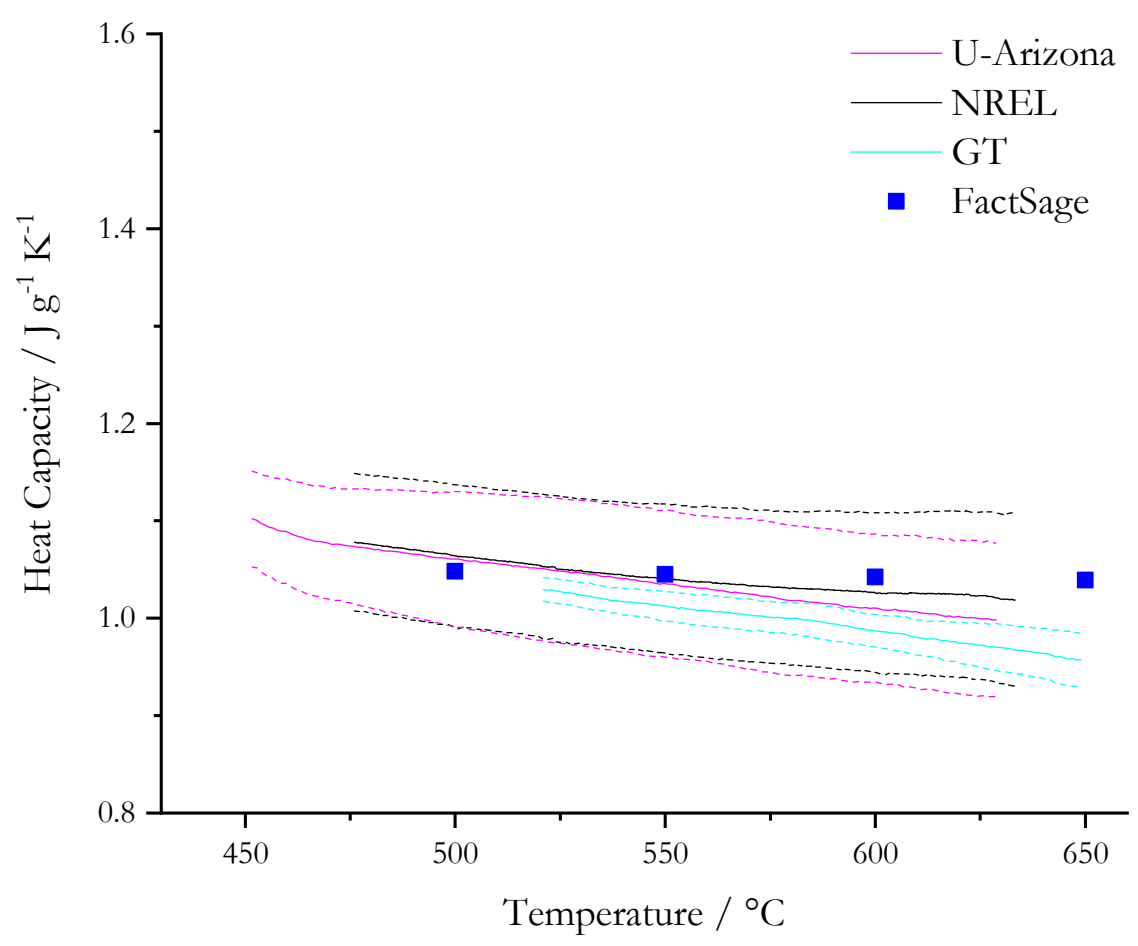

Figure 21. Molten-state heat capacity of the baseline salt measured by NREL, U. Arizona, and Georgia Tech; dashed lines indicate average \pm 1 standard deviation

\footnotetext{
${ }^{47}$ Caution should be used when comparing the experimental value to FactSage prediction because, as stated before, the liquidus signal from the DSC is usually very weak, and it is difficult to identify the onset temperature of the peaks due to peak overlapping. Therefore, the numbers presented should only be used as an estimate.
} 
the average value. The final heat capacity was calculated by weight-averaging the results from NREL, U. Arizona, and Georgia Tech (see Table 11). The overall standard deviation is about $7 \%-8 \%$ of the average value. Caution must be used when performing extrapolation of heat capacity values significantly beyond the experimental temperature range of $475^{\circ}-625^{\circ} \mathrm{C}$ because the second-order equation provided for the average heat capacity in Table 11 is only a numerical fit and does not reflect the true physics of liquid heat capacity.

Table 11. Second-Order Polynomial Fit for the Heat Capacity Measured by NREL, U. Arizona, and Georgia Tech and the Calculated Weighted-Average Heat Capacity Based on Number of Measurements from Each Lab

$\mathrm{C}_{\mathrm{p}}$ and fitting parameters $\mathrm{A}, \mathrm{B}$, and $\mathrm{C}$ are in $\mathrm{J} \mathrm{g}^{-1}{ }^{\circ} \mathrm{C}^{-1}$ and $\mathrm{T}$ is in ${ }^{\circ} \mathrm{C}$.

\begin{tabular}{|c|c|c|c|c|c|c|c|c|c|}
\hline \multirow{2}{*}{ Lab } & \multicolumn{7}{|c|}{ 2nd-Order Polynomial Fit for Measured Heat Capacity } & \multicolumn{7}{c|}{ Average Heat Capacity } \\
\cline { 2 - 9 } & \multicolumn{8}{|c|}{$\mathrm{C}_{p}=\mathrm{A} \times \mathrm{T}^{2}+\mathrm{B} \times \mathrm{T}+\mathrm{C}\left[\mathrm{J} / \mathrm{g}{ }^{\circ} \mathrm{C}\right]$} \\
\cline { 2 - 9 } & $\mathrm{A}$ & $\mathrm{B}$ & $\mathrm{C}$ & $\mathrm{R}^{2}$ & \# of Data & Weight & $\mathrm{A}$ & $\mathrm{B}$ & $\mathrm{C}$ \\
\hline NREL & $1.85 \times 10^{-6}$ & $-2.42 \times 10^{-3}$ & 1.81 & 0.999 & 29 & $60.4 \%$ & & & \\
\hline U. Arizona & $7.25 \times 10^{-7}$ & $-1.31 \times 10^{-3}$ & 1.54 & 0.995 & 15 & $31.3 \%$ & $1.284 \times 10^{-6}$ & $-1.843 \times 10^{-3}$ & \multirow{2}{*}{1.661} \\
\hline GT & $-7.53 \times 10^{-7}$ & $3.35 \times 10^{-4}$ & 1.06 & 0.997 & 4 & $8.33 \%$ & & & \\
\hline
\end{tabular}

\section{Density}

Molten-state density of the baseline salt was measured by two labs (U. Arizona and U.

Wisconsin-Madison). Figure 22 shows the results. U. Arizona had nine data points: six from three salt samples prepared from AC salt, and three from three salt samples prepared from

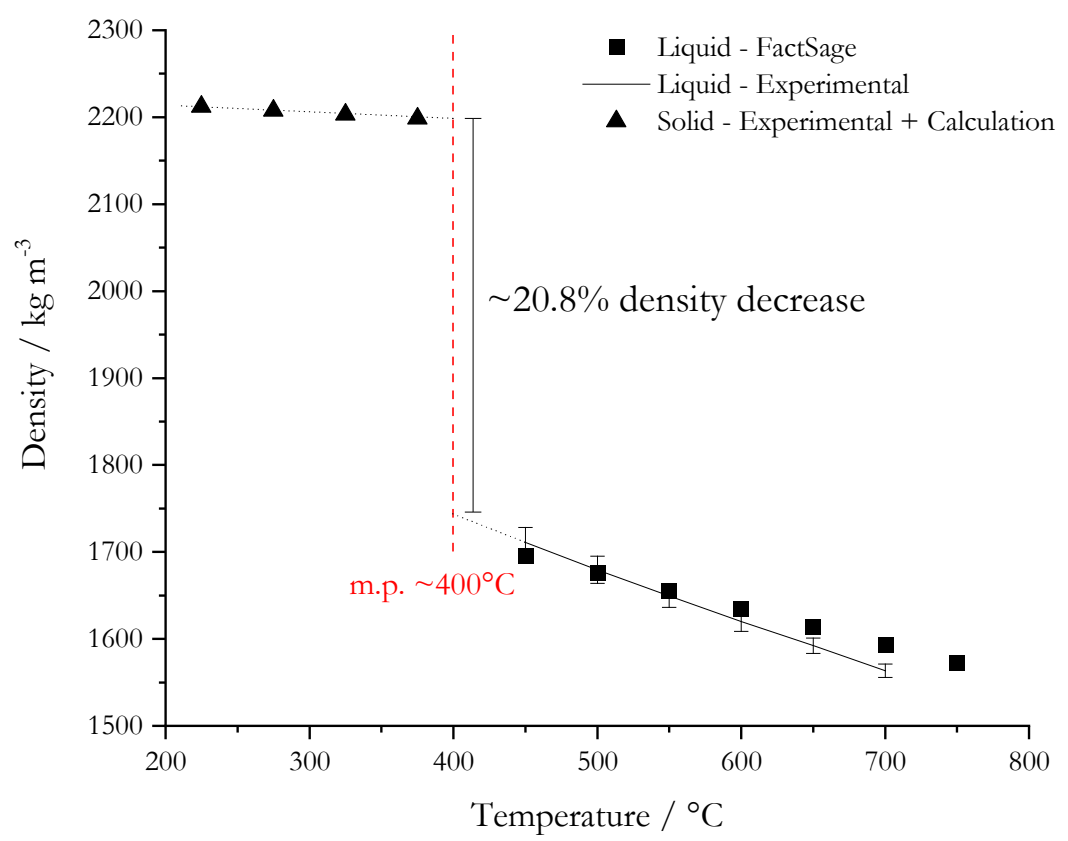

Figure 22. Molten-state density of the baseline salt measured by $U$.

Arizona and U. Wisconsin, and by FactSage thermodynamic calculation;

The error bars indicate average \pm 1 standard deviation 
dehydrated carnallite salt (all salt samples had similar composition). U. Wisconsin had two data points from one sample prepared from AC salt. The standard deviation is within $1 \%$ of the average value across the entire measurement temperature range. The difference between the experimental average and FactSage prediction is at a maximum level of $2 \%$. Given U. Arizona's experience in density measurement for $\mathrm{MgCl}_{2}-\mathrm{KCl}$ binary salt [8] and the agreement with thermodynamic calculation, we believe that the experimental results are accurate.

In theory, liquid or molten-state density for most high-temperature materials (e.g., molten salt $[75,76]$, molten oxides/slag [77]) can be described by a linear equation. Therefore, the measured density data were fitted to the linear equation below:

$$
\rho=-0.5878 T+1974.0, R^{2}=0.9996,
$$

Where temperature $T$ is in ${ }^{\circ} \mathrm{C}$ and density $\rho$ is in $\mathrm{kg} / \mathrm{m}^{3}$.

The solid-state density was experimentally measured ${ }^{48}$ as $2,229.75 \mathrm{~kg} / \mathrm{m}^{3}$ at room temperature by U. Arizona. The coefficient of thermal expansion (CTE) for the baseline salt composition in the solid-state is unknown. But an average CTE of $1-5 \times 10^{-5} /{ }^{\circ} \mathrm{C}$ can be roughly assumed given literature measurements on similar chlorides in the temperature range of $25^{\circ}-400^{\circ} \mathrm{C}[78-80]$. The solid-state density at about $400^{\circ} \mathrm{C}$ then can be roughly calculated by solving the following differential equation

$$
\alpha_{V}=-\frac{1}{\rho}\left(\frac{\partial \rho}{\partial T}\right)_{P}
$$

given the measured volumetric CTE, $\alpha_{V}$, at room temperature assuming that the CTE is temperature independent at $4 \times 10^{-5} /{ }^{\circ} \mathrm{C}$. The result is about $2,194.4 \mathrm{~kg} / \mathrm{m}^{3}$. By linearly extrapolating the liquid density to the salt melting point using Eq. 11 (i.e., $1,738.9 \mathrm{~kg} / \mathrm{m}^{3}$ ), the density change when transitioning from solid to liquid is estimated to be about $20.8 \%$.

\section{Dynamic Viscosity}

Dynamic viscosity (referred to as viscosity below) of the baseline salt was measured by U. Arizona on five samples. Figure 23(a) summarizes the viscosity data showing the average and standard deviation. The standard deviation is within $2 \%-6 \%$ of the average value across the entire measurement range.

In theory, the viscous flow of a substance made of atoms (e.g., molten metals) and simple molecules (molten oxides and molten salts) can usually be approximated by a thermally activated process using classic mechanics. At a high level, the relative motion of atoms (i.e., flow of atoms) needs to overcome a potential barrier imposed by the neighboring atoms, which can be facilitated by higher temperature. Therefore, a common Arrhenius-like equation can be used to describe the temperature dependence of viscous flow and viscosity $\mu$,

\footnotetext{
${ }^{48}$ The uncertainty of the measurement was not reported.
} 


$$
\mu=A e^{B / T},
$$

where $A$ is a pre-exponential coefficient and $B$ is the parameter related to the energy barrier to the viscous flow with a unit of temperature. A straightforward transformation of Eq. 13 gives

$$
\ln \mu=\ln A+B \cdot T^{-1} \text {. }
$$

Therefore, if a liquid follows the thermally activated model for viscous flow, a linear relationship can be established between the natural log of the measured viscosity and the inverse of absolute temperature. Figure 23(b) re-plots the viscosity data from U. Arizona in the form of $\ln (\mu)$ vs. $T^{-1}$, where $T$ is the absolute temperature. The plot is found to be fairly linear (equation given in Figure 23(b)) with a $\mathrm{R}^{2}$ value of 0.9913 . Therefore, the viscosity of baseline salt, as with most other molten salts, indeed follows the thermally activated model and can be described by the following equation,

$$
\mu=0.689 e^{\frac{1224.73}{T}},
$$

where viscosity $\mu$ is in $\mathrm{cP}$ and $T$ is in Kelvin.
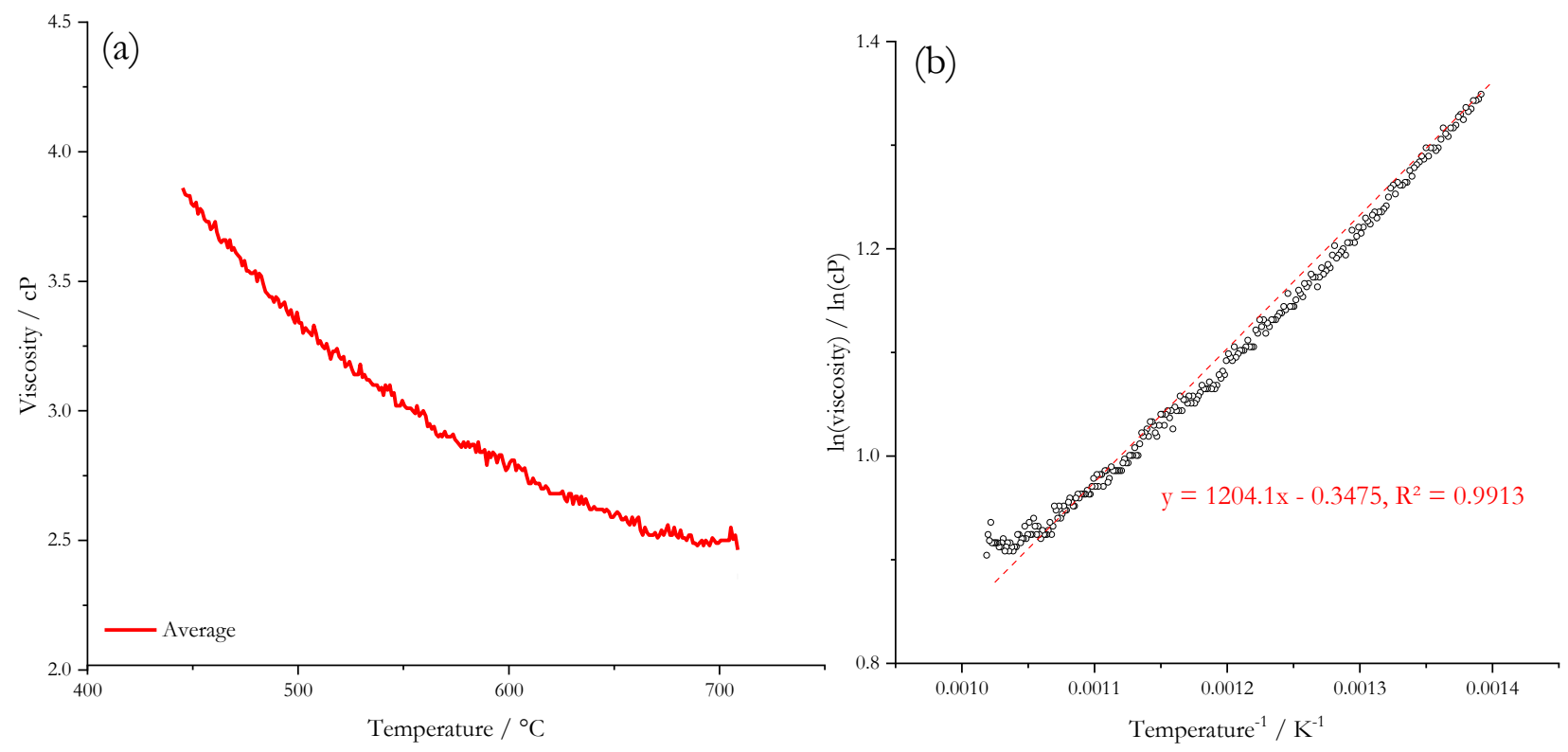

Figure 23. (a) Temperature variation of viscosity measured by U. Arizona. The red line indicates the average viscosity, and the gray shaded area indicates average \pm 1 standard deviation. (b) Re-plot of In(viscosity) vs. temperature ${ }^{-1}$, which shows a linear relationship with $R^{2}$ value of 0.9913 .

Insoluble $\mathrm{MgO}$ can form when moisture ingress occurs into the salt loop, so its effects on thermophysical properties should be understood. The insoluble and unreactive nature of $\mathrm{MgO}$ in molten $\mathrm{MgCl}_{2}-\mathrm{KCl}-\mathrm{NaCl}$ suggests that the effects on thermophysical properties such as liquid density (and density change during solid-liquid transition), melting point, vapor pressure, and thermal stability should be small; the same applies to liquid heat capacity and thermal conductivity if particle mass loading is low. The most probable impact could be the increase in viscosity. Most available models [81] predict a non-linear increase of viscosity with the particle fraction - viscosity increases much faster above $30 \%-40 \%$ particle fraction. The mass fraction of 
$\mathrm{MgO}$ particles in the purified salt after settling is measured ${ }^{49}$ at much lower level (at $\sim 0.05 \%$, see Table 15). But there is still a need to understand the effect under the most extreme case- the complete failure of particle settling in the purification process, which will introduce $\mathrm{MgO}$ particles into the loop at a much higher mass fraction at $\sim 1 \mathrm{wt} . \%{ }^{50}$

Figure 24 shows the viscosity of the purified salt as a function of $\mathrm{MgO}$ mass loading (0-3 wt.\%). The $\mathrm{MgO}$ particles used were commercially available (magnesium oxide, $99.95 \%$ metals basis, product \#14684, Alfa Aesar) with particle size of less than $44 \mu \mathrm{m}$. The goal was to simulate the real situation when $\mathrm{MgO}$ particles generated from salt purification-with most particles around 10-30 $\mu \mathrm{m}$ based on NREL's particle size analysis (to be discussed later) - are not effectively removed from salt purification or are introduced due to moisture ingress. ${ }^{51} \mathrm{We}$ can see that there is no significant difference between viscosities with all $\mathrm{MgO}$ mass loadings. Figure 23(a) shows that the magnitude of \pm 1 standard deviation is about $0.25 \mathrm{cP}$ after measuring the baseline salt five times. This is similar to the maximum vertical data spread in Figure 24 among the average viscosities with different $\mathrm{MgO}$ additions. Therefore, the spread of viscosity data in Figure 24 seems to simply originate from statistical scatter of viscosity measurements. In addition, as

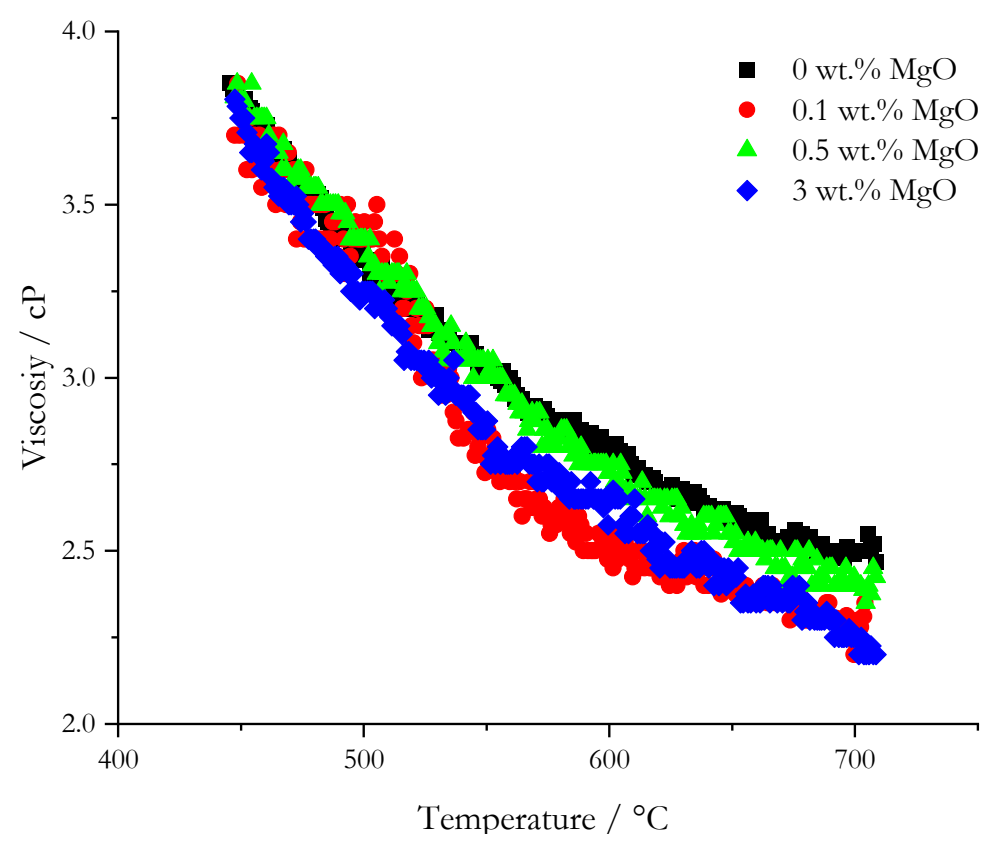

Figure 24. Viscosity as a function of temperature for different $\mathrm{MgO}$ mass loading. The $\mathrm{MgO}$ particles used were commercially available with particle size less than $44 \mu \mathrm{m}$.

shown by Konijn et al. [81], the effect of such small mass loading (0-3 wt.\%) of small particles

\footnotetext{
${ }^{49}$ Salt samples were weighed and completely dissolved in deionized water. The insoluble particles were vacuum filtered through a 450-nm filter and weighed to calculate the mass fraction.

${ }^{50}$ Based on similar mass measurements of insoluble particles in the entire volume of purified salt, including the sludge phase.

${ }^{51}$ Investigation of $\mathrm{MgO}$ particle size and distribution seems to indicate that there is no significant difference in size distribution between particles in the sludge phase and the ones that can be present in the "clean" salt phase.
} 
$(<44 \mu \mathrm{m})$ on liquid viscosity, in theory, should be negligible. So, the risks of sudden viscosity changes of the salt due to $\mathrm{MgO}$ generation which makes it difficult to circulate salt in the salt loop should be low. With proper design of other sensor systems, ${ }^{52}$ it is unlikely for $\mathrm{MgO}$ particle fraction to increase to a level at $1-5 \mathrm{wt} . \%$ (when a detectable viscosity change is likely to happen) before other loop performance indicator(s) gives a warning-e.g., (1) pressure build-up in the loop due to $\mathrm{MgO}$ particles clogging filters, (2) sudden spikes of $\mathrm{HCl}$ gas concentration due to unwanted hydrolysis reactions, and/or (3) thermal decomposition of $\mathrm{MgOHCl}$, which should generate $\mathrm{HCl}$ as well as $\mathrm{MgO}$.

\section{Vapor Pressure}

Vapor pressure of the baseline salt was measured by U. Arizona with nine tests on three samples. The first test cycle of each sample was excluded because visible water condensate was observed. The small amount of water was most likely due to handling of the salt at the U. Arizona lab, where the salt must be exposed to ambient atmosphere before loading into the test apparatus. The measured higher vapor pressure in these first test cycles (typically 3-5 kPa higher than the rest of the subsequent cycles) suggests that it was due to water vapor pressure at the cold section where the water condensate was formed. ${ }^{53}$ Therefore, only the data from the second, third, and/or fourth test cycles of each sample were taken after the water vapor was removed by evacuating the test apparatus before the second cycle (i.e., the first test can be considered a dehydration process in vacuum and at high temperature).
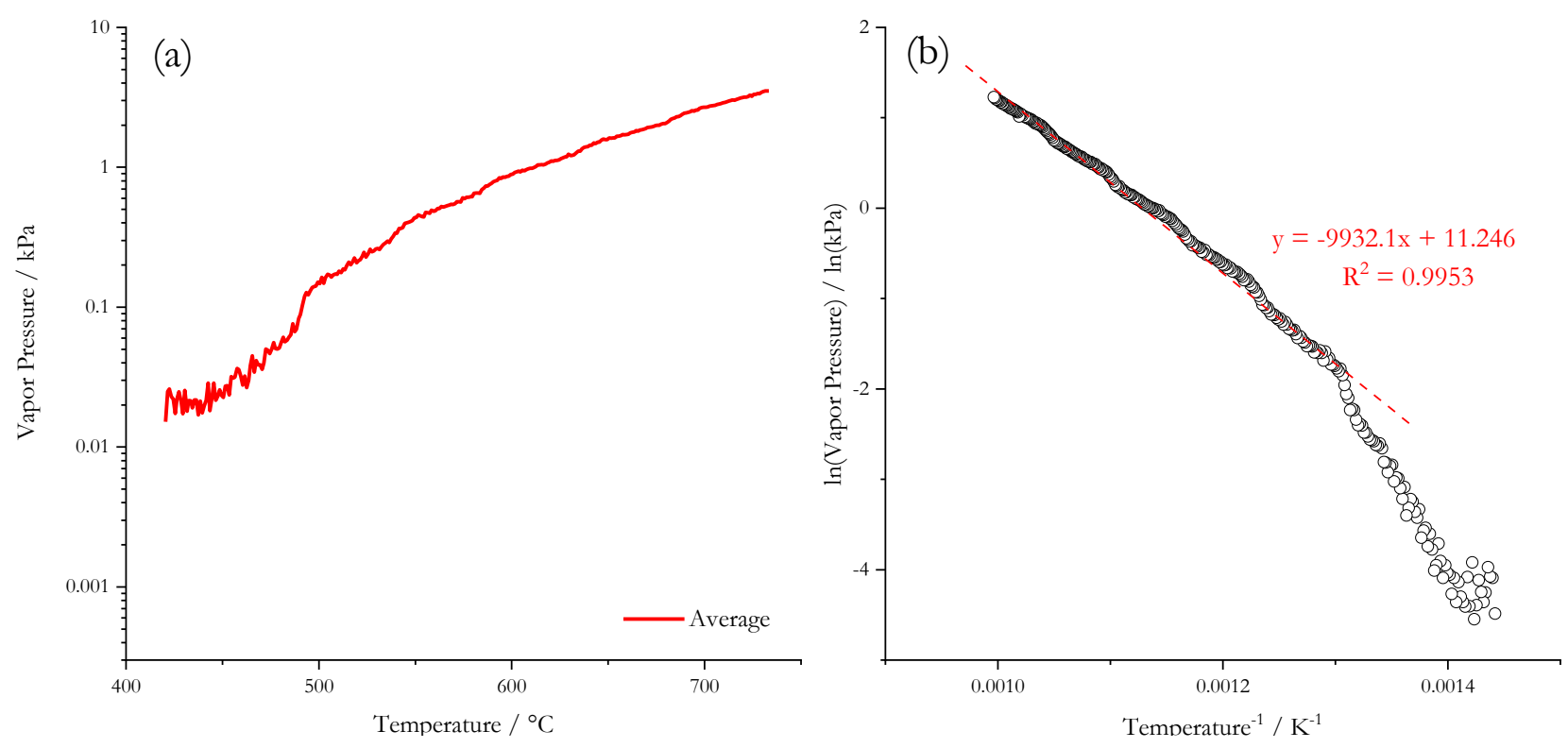

Figure 25. (a) Temperature variation of total vapor pressure measured by $U$. Arizona. The red line indicates the average vapor pressure and the gray shaded area indicates average \pm 1 standard deviation. (b) Re-plot of In(vapor pressure) vs. temperature ${ }^{-1}$ as suggested by the ClausiusClapeyron relation. The red dashed line is used to help visualize the rough linear behavior in the range of

\footnotetext{
${ }^{52}$ For example, electrochemical sensors for corrosion monitoring, gas sensors for $\mathrm{HCl}$ detection, or particle size sensors.

53 The cold section of the vapor pressure test apparatus was maintained around or slightly higher than room temperature. For reference, the water vapor pressure at $25^{\circ} \mathrm{C}$ and $35^{\circ} \mathrm{C}$ is $3.2 \mathrm{kPa}$ and $5.6 \mathrm{kPa}$, respectively.
} 
Figure 25(a) shows the temperature variation of the measured total vapor pressure. It can be seen that below $500^{\circ} \mathrm{C}$, the data are noisier and the standard deviations are larger (i.e., as a percentage of the average value). The percentage is $30 \%-80 \%$ between $430^{\circ} \mathrm{C}$ and $500^{\circ} \mathrm{C}$ and decreases from $\sim 30 \%$ to $15 \%$ from $500^{\circ} \mathrm{C}$ to $730^{\circ} \mathrm{C}$. The large variation is most likely due to the inherent difficulty of pressure measurement, especially at low pressure (e.g., below $0.1 \mathrm{kPa}$ ).

Note that the vapor pressure is plotted in log scale in Figure 25(a). Similar treatment of data as used in the viscosity section is used for vapor pressure in Figure 25(b), where $\ln$ (vapor pressure) is plotted against temperature ${ }^{-1}$. According to the Clausius-Clapeyron relation, vapor pressure $P$ increases non-linearly with temperature following

$$
\ln P=-\frac{L}{R} T^{-1}+c,
$$

where $L$ is the specific latent heat of the liquid-gas transition (i.e., latent heat of evaporation), $R$ is the gas constant, $c$ is a constant, and $T$ is absolute temperature. The red dashed line in Figure 25(b) shows that $\ln P$ and $T^{-1}$ are roughly linear when $T^{-1}<0.0013 \mathrm{~K}^{-1}$. This range corresponds to $T>500^{\circ} \mathrm{C}$, where experimental measurement was more reliable. Therefore, we can cautiously conclude that the total vapor pressure of the ternary baseline salt indeed follows theoretical expectation. The following polynomial (Eq. 17) can be used to describe the measured vapor pressure within the experimental temperature range.

$$
\begin{gathered}
P=6.63 \times 10^{-11} T^{4}-8.19 \times 10^{-8} T^{3}+5.19 \times 10^{-5} T^{2}-1.96 \times 10^{-2} T+3.07 \\
\text { where } R^{2}=0.9992, \text { for } 420^{\circ} \mathrm{C}<\mathrm{T}<730^{\circ}, P \text { in } \mathrm{kPa}
\end{gathered}
$$

However, because a polynomial does not reflect the true physics of vapor pressure (or the phenomenon of vaporization), caution must be used when performing extrapolation outside the specified temperature range. If extrapolation beyond the temperature range is needed, a linear equation between $\ln P$ and $T^{-1}$ is given below (based on experimental data above $500^{\circ} \mathrm{C}$ ),

$$
\ln P=-9932.1 T^{-1}+11.246, R^{2}=0.9953
$$

where $P$ is in $\mathrm{kPa}$ and $T$ is in Kelvin. Note that this Clausius-Clapeyron relation will introduce certain errors in the temperature range below $500^{\circ} \mathrm{C}$ compared to experimental data. Now, we can calculate the parameter $L$ from Eq. 18 (i.e., $L=9932.1 K \times R$, where $R$ is the gas constant at $8.3145 \mathrm{~J} / \mathrm{mol} \mathrm{K}$ ). The result is $82.6 \mathrm{~kJ} / \mathrm{mol}$, which is on the same order of magnitude compared to the latent heat of evaporation of some other chlorides (e.g., $51.7 \mathrm{~kJ} / \mathrm{mol}$ for $\mathrm{KCl}$ [82] and 60$70 \mathrm{~kJ} / \mathrm{mol}$ for $\mathrm{BiCl}_{3}$ [83]). Without trustworthy experimental data, no quantitative conclusion should be made here. In addition, the calculated $L$ should be an effective number for all possible vapor species including $\mathrm{KMgCl}_{3}, \mathrm{MgCl}_{2}, \mathrm{NaCl}$, and/or $\mathrm{KCl}$ based on FactSage calculations. Therefore, direct comparison with $L$ for pure salts from the literature is not very informative. The FactSage calculation also suggests much lower vapor pressure ( $\sim 30$ times lower) compared to the experimental values. However, experimental work [84,85] suggests that the vapor pressures of molten $\mathrm{NaCl}$ and $\mathrm{KCl}$ at $\sim 100^{\circ} \mathrm{C}$ above melting point ${ }^{54}$ are $\sim 0.5 \mathrm{kPa}$, which is on the same

\footnotetext{
${ }^{54}$ It makes more sense to compare vapor pressures of two molten salts with different melting point at the same temperature above melting point (i.e., using the melting point as the reference for comparison), instead of at an arbitrary temperature.
} 
order of magnitude compared to $\sim 0.15 \mathrm{kPa}$ for the baseline salt at $\sim 100^{\circ} \mathrm{C}$ above melting point. Therefore, the calculation above serves the purpose of showing that the experimentally measured vapor pressure reflects known physics and can be reliable.

The effect of impurities on total vapor pressure was investigated next because we anticipated that some compounds that the salt may be in contact with in the salt loop (e.g., refractory liners in the TES tanks) can adversely impact the total vapor pressure by forming a volatile product(s). Our FactSage calculation showed that $\mathrm{Fe}_{2} \mathrm{O}_{3}$ can have significant impact on vapor pressure, and $\mathrm{Fe}_{2} \mathrm{O}_{3}$ is usually present in commercially available refractory products at various mass fraction. Figure 26 shows the vapor pressure of purified salt with 0.2 wt. $\%$ of reagent-grade $\mathrm{Fe}_{2} \mathrm{O}_{3}$. Figure 49 in the Appendix shows the vapor pressure of purified salt with $1 \mathrm{wt} . \%$ and $3 \mathrm{wt} . \%$ of reagentgrade $\mathrm{Fe}_{2} \mathrm{O}_{3}$, respectively. Commercial $\mathrm{Fe}_{2} \mathrm{O}_{3}$ was used-iron (III) oxide, 99.9 metals basis, product \#47247, Alfa Aesar - to minimize introduction of other unknown impurities that may also cause reactions and affect vapor pressure. A clear increase of vapor pressure is observed as a function of $\mathrm{Fe}_{2} \mathrm{O}_{3}$ addition, indicating that the presence of $\mathrm{Fe}_{2} \mathrm{O}_{3}$ is indeed generating certain high-vapor species. This should raise enough caution that other oxides (e.g., $\mathrm{TiO}_{2}$ that can also be present in refractory liners) may have similar effect.

Within each $\mathrm{Fe}_{2} \mathrm{O}_{3}$ addition, a clear decrease of vapor pressure as a function of cycle number is observed. The hypothesis is that the volatile species due to $\mathrm{Fe}_{2} \mathrm{O}_{3}$ addition were slowly depleted

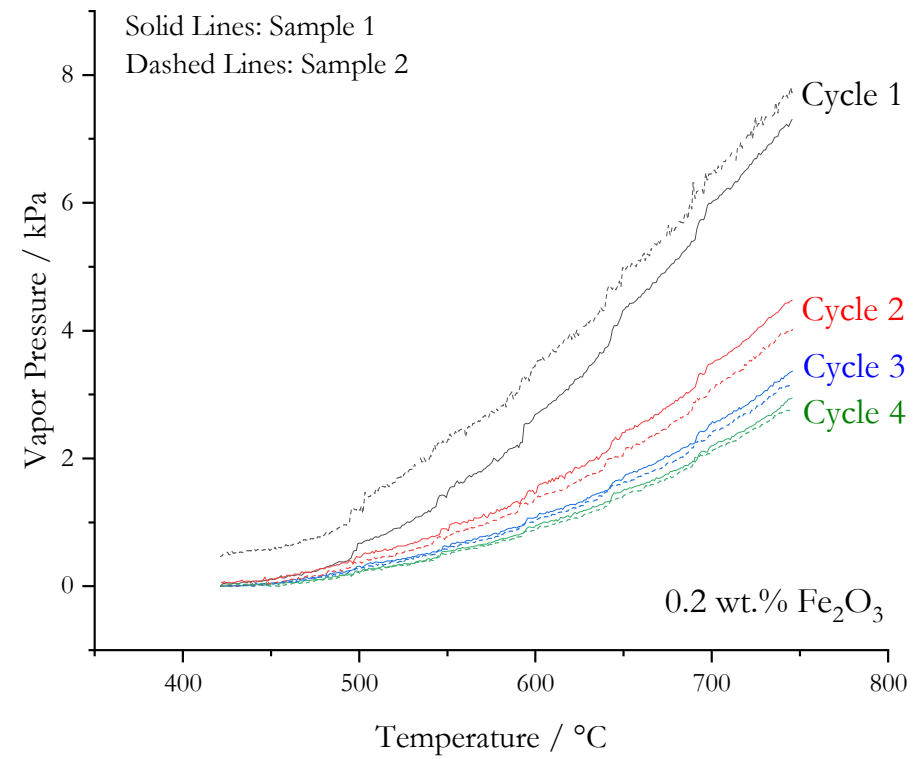

Figure 26. Vapor pressure for purified salt with $0.2 \mathrm{wt} . \%$ of $\mathrm{Fe}_{2} \mathrm{O}_{3}$. Two samples were measured given by the solid and dashed lines. Cycles 1-4 were separated by manual removal of volatile species under vacuum. because, between test cycles, the system was evacuated. Because there was a limited amount of volatile species given the amount of added $\mathrm{Fe}_{2} \mathrm{O}_{3}$, the total vapor pressure should theoretically approach that of the salt with 0 wt.\% $\mathrm{Fe}_{2} \mathrm{O}_{3}$ addition as more vacuum cycles were used. This is supported by the following calculation. The vapor pressure of the baseline salt (e.g., 0 wt. $\% \mathrm{Fe}_{2} \mathrm{O}_{3}$ addition) at $700^{\circ} \mathrm{C}$ is $\sim 2.8$ $\mathrm{kPa}$ based on Eq. 18. The vapor pressure of the 3rd and 4th cycles with 0.2 wt. $\% \mathrm{Fe}_{2} \mathrm{O}_{3}$ addition in Figure 26 falls into the same range, suggesting that $\mathrm{Fe}_{2} \mathrm{O}_{3}$ addition has been depleted to a very low level after 3 vacuum cycles. ${ }^{55}$ Similarly, Figure 27 shows the vapor pressure of the 4th cycle (average of two individual tests) of each salt. We can see that the vapor pressure of the 4th cycle of salt with 0.2 wt.\% $\mathrm{Fe}_{2} \mathrm{O}_{3}$ is very close to that of the purified salt without $\mathrm{Fe}_{2} \mathrm{O}_{3}$. Three vacuum cycles seem to remove all volatile species, and the salt is likely depleted of $\mathrm{Fe}_{2} \mathrm{O}_{3}$

\footnotetext{
${ }^{55}$ Unfortunately, no chemical analysis was performed to confirm such hypothesis.
} 
at the end. $\mathrm{As}_{\mathrm{Fe}_{2}} \mathrm{O}_{3}$ addition increases, it is more difficult to remove those volatile species with three vacuum cycles. The results provide at least two implications:

1. Optimistically, the interaction of $\mathrm{Fe}_{2} \mathrm{O}_{3}$ with the purified salt will not permanently change the chemistry for the majority of the salt (at least at 0.2 wt. $\%$ of $\mathrm{Fe}_{2} \mathrm{O}_{3}$ addition). The vapor pressure should decrease gradually and approach that of the purified salt as multiple vacuum cycles are used.

2. Pessimistically, if the reaction products cannot be effectively removed from the system, then they will remain at their high vapor pressure regardless of their absolute amounts, because the equilibrium established between the vapor and the liquid (or solid) does not depend on the absolute amount of the liquid (or solid). ${ }^{56}$ Therefore, two approaches can help avoid unwanted high vapor pressure in the CSP plant: (1) avoid using materials that can generate unwanted species, and (2) remove the unwanted vapor with a cover gas/purging gas system and/or a scrubber system.

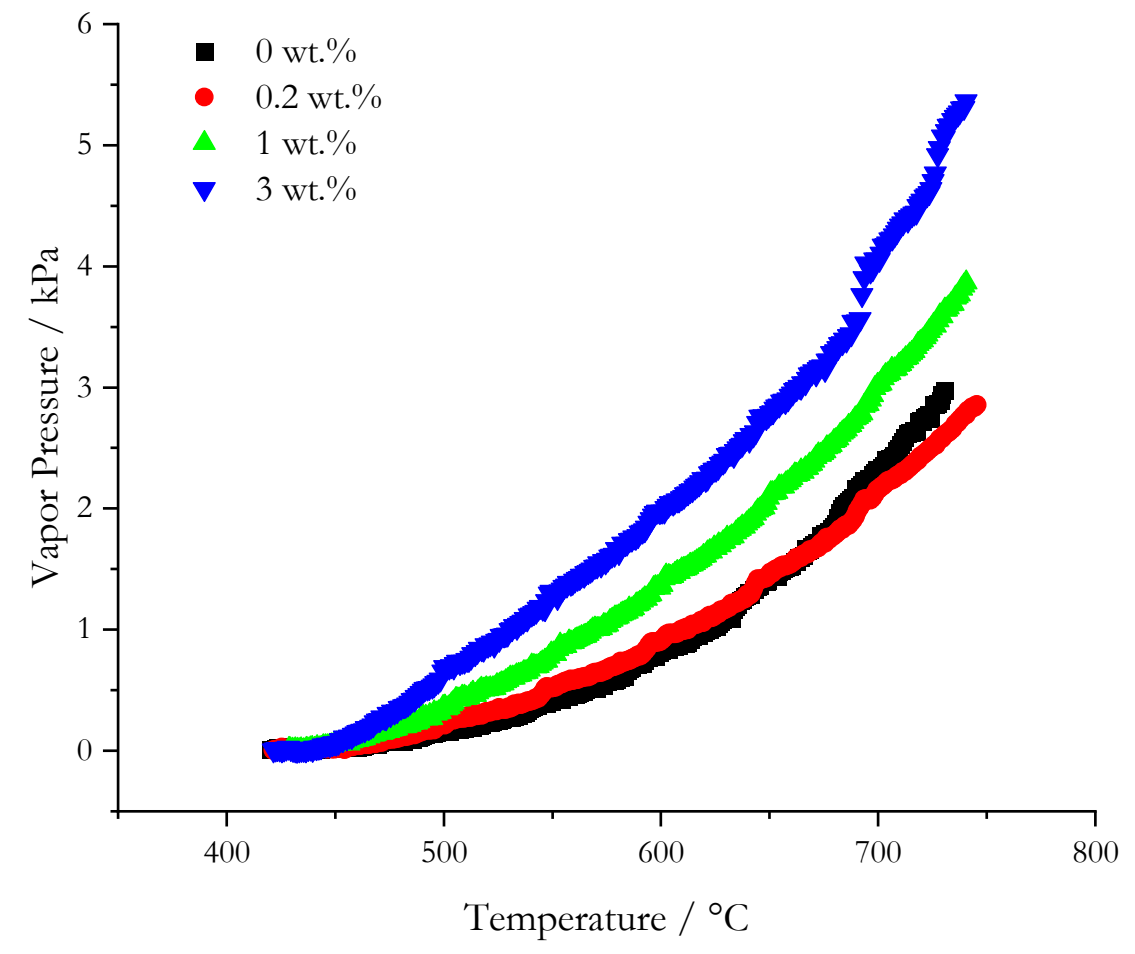

Figure 27. Vapor pressure of salts with different levels of $\mathrm{Fe}_{2} \mathrm{O}_{3}$ addition; the vapor pressure at each $\mathrm{Fe}_{2} \mathrm{O}_{3}$ addition was measured after at least three vacuum cycles to remove volatile species.

The results should raise more concerns with the vapor pressure in the TES tanks where refractories and mortars may contain various oxides. To our best knowledge, significant salt loss ( $>50 \mathrm{wt} . \%)$ due to excessive salt evaporation has been observed during a few long-term $(\sim 1,000$ hour) compatibility tests with refractories under the Topic 1 Liquid Pathway project. We believe that there is a similarity between our tests with $\mathrm{Fe}_{2} \mathrm{O}_{3}$ and those long-term tests.

\footnotetext{
${ }^{56}$ For a given material, the vapor pressure is a function of temperature instead of quantity. For example, $1 \mathrm{~g}$ and $1,000 \mathrm{~g}$ of water will both generate $1 \mathrm{~atm}$ of vapor at the boiling point under atmospheric pressure.
} 


\section{Thermal Diffusivity and Thermal Conductivity}

Thermal diffusivity of the baseline salt was directly measured on eight samples by U. Arizona using a laser flash instrument. Thermal conductivity $\kappa$ was calculated with the following equation:

$$
\kappa=\alpha \rho C_{p},
$$

where is $\alpha$ thermal diffusivity, $\rho$ is density, and $C_{p}$ is specific heat. Figure 28(a) shows the measured thermal diffusivity, and Figure 28(b) shows the calculated thermal conductivity. The large standard deviations in Figure 28(a) is an indicator of challenging experimental measurements. The crucible material available for the laser flash instrument is Pt-based which tends to allow salt to wet and creep outside the crucible causing experimental errors. ${ }^{57}$ The large standard deviations in Figure 28(b) is a result of the large standard deviations of the thermal diffusivity $(\sim 10 \%)$ and heat capacity $(\sim 5 \%)$ following the error propagation calculation in Eq. 22.
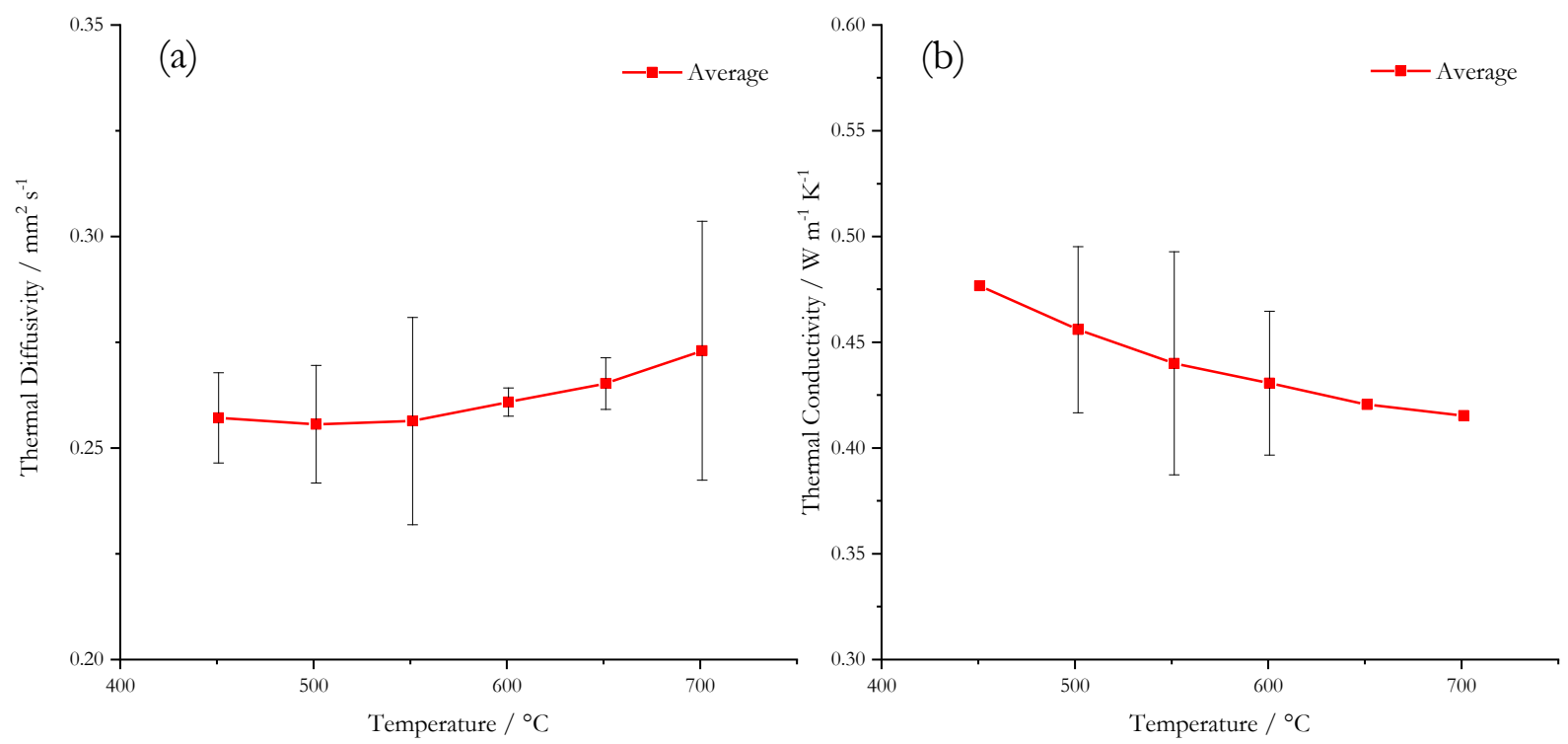

Figure 28. (a) Temperature variation of experimental thermal diffusivity measured by U. Arizona. Error bars indicate average \pm 1 standard deviation. (b) Thermal conductivity calculated from Eq.8. Error bars are only available at $500^{\circ} \mathrm{C}, 550^{\circ} \mathrm{C}$, and $600^{\circ} \mathrm{C}$ because of lack of experimental measurement of heat capacity at $450^{\circ} \mathrm{C}, 650^{\circ} \mathrm{C}$, and $700^{\circ} \mathrm{C}$.

Eqs. 20 and 21 give the fitted 2nd-order polynomial for these two properties,

$$
\begin{aligned}
& \alpha=4.338 \times 10^{-7} T^{2}-4.353 \times 10^{-4} T+0.365, R^{2}=0.9955 \\
& \kappa=7.151 \times 10^{-7} T^{2}-1.066 \times 10^{-3} T+0.811, R^{2}=0.9984
\end{aligned}
$$

\footnotetext{
${ }^{57}$ Both U. Arizona and ANL had the salt creeping issue. Only U. Arizona was able to obtain reasonable data after purchasing a brand-new Pt crucible.
} 
where $\alpha$ is in $\mathrm{mm}^{2} \mathrm{~s}^{-1}, \kappa$ is in $\mathrm{W} \mathrm{m}^{-1} \mathrm{~K}^{-1}$, and $\mathrm{T}$ is in ${ }^{\circ} \mathrm{C}$. The maximum standard deviation in Figure $28(\mathrm{a})$ is $11.2 \%$ of the average value (at $700^{\circ} \mathrm{C}$ ). The standard deviation of thermal conductivity was calculated using the principle of error propagation,

$$
\frac{\delta \kappa}{\kappa}=\sqrt{\left(\frac{\delta \alpha}{\alpha}\right)^{2}+\left(\frac{\delta \rho}{\rho}\right)^{2}+\left(\frac{\delta c_{p}}{C_{p}}\right)^{2}},
$$

where $\delta$ is the standard deviation of each quantity specified in Eq. 19. The calculated standard deviation of thermal conductivity is between $8 \%$ and $12 \%$ of the average value. As a comparison, $\mathrm{Xu}$ et al. [8] reported the thermal diffusivity and the thermal conductivity of the $\mathrm{MgCl}_{2}-\mathrm{KCl}$ eutectic melt, which agree fairly well with our results. This is expected because the molten-state structure of the binary $\mathrm{MgCl}_{2}-\mathrm{KCl}$ should be similar to the ternary $\mathrm{MgCl}_{2}-\mathrm{KCl}$ $\mathrm{NaCl}$, and the salt composition used in $\mathrm{Xu}$ et al. is not too far from the composition of the baseline salt.

\section{Thermophysical Property Summary}

Table 12 summarizes all measured thermophysical properties for the baseline salt composition as a function of temperature, if available. The applicable temperature range is $450^{\circ} \mathrm{C}$ to $700^{\circ} \mathrm{C}$. Caution should be used when extrapolating beyond this range. The energy density of the salt $\rho C_{p}$ can be calculated (Figure 29). The error bars are calculated using the same error propagation principle in Eq. 22 and are only available at three temperatures because of limited measurement range of heat capacity $\left(475^{\circ}-625^{\circ} \mathrm{C}\right)$ and limited measurement interval of density (every $50^{\circ} \mathrm{C}$ ). The standard deviations are about $6-7 \%$ of the average values.

Table 12. Summary of Measured Thermophysical Properties of the Baseline Salt Composition; Applicable Temperature Range is $450^{\circ} \mathrm{C}$ to $700^{\circ} \mathrm{C}$

\begin{tabular}{|c|l|c|}
\hline Property & \multicolumn{1}{|c|}{ Function } & Unit \\
\hline Liquidus temperature & $\approx 400$ & ${ }^{\circ} \mathrm{C}$ \\
\hline Heat capacity & $1.284 \times 10^{-6} T^{2}-1.843 \times 10^{-3} T+1.661\left[T\right.$ in $\left.{ }^{\circ} \mathrm{C}\right]$ & $\mathrm{J} / \mathrm{g}^{\circ} \mathrm{C}$ \\
\hline Density (solid state) & $\approx 2229.7$ at room temperature & $\mathrm{kg} / \mathrm{m}^{3}$ \\
\hline Density (molten state) & $-5.878 \times 10^{-1} T+1974.0\left[T\right.$ in $\left.{ }^{\circ} \mathrm{C}\right]$ & $\mathrm{kg} / \mathrm{m}^{3}$ \\
\hline Dynamic viscosity & $0.689 e^{\frac{1224.73}{T}}[T$ in K] & $\mathrm{cP}$ \\
\hline Total vapor pressure & $76573.01 e^{\frac{-9932.1}{T}}[T$ in $\mathrm{K}]$ & $\mathrm{kPa}$ \\
\hline Thermal diffusivity & $4.338 \times 10^{-7} T^{2}-4.353 \times 10^{-4} T+0.365\left[T\right.$ in $\left.{ }^{\circ} \mathrm{C}\right]$ & $\mathrm{mm} / \mathrm{s}$ \\
\hline Thermal conductivity & $7.151 \times 10^{-7} T^{2}-1.066 \times 10^{-3} T+0.811\left[T\right.$ in $\left.{ }^{\circ} \mathrm{C}\right]$ & $\mathrm{W} / \mathrm{m} \mathrm{K}$ \\
\hline
\end{tabular}




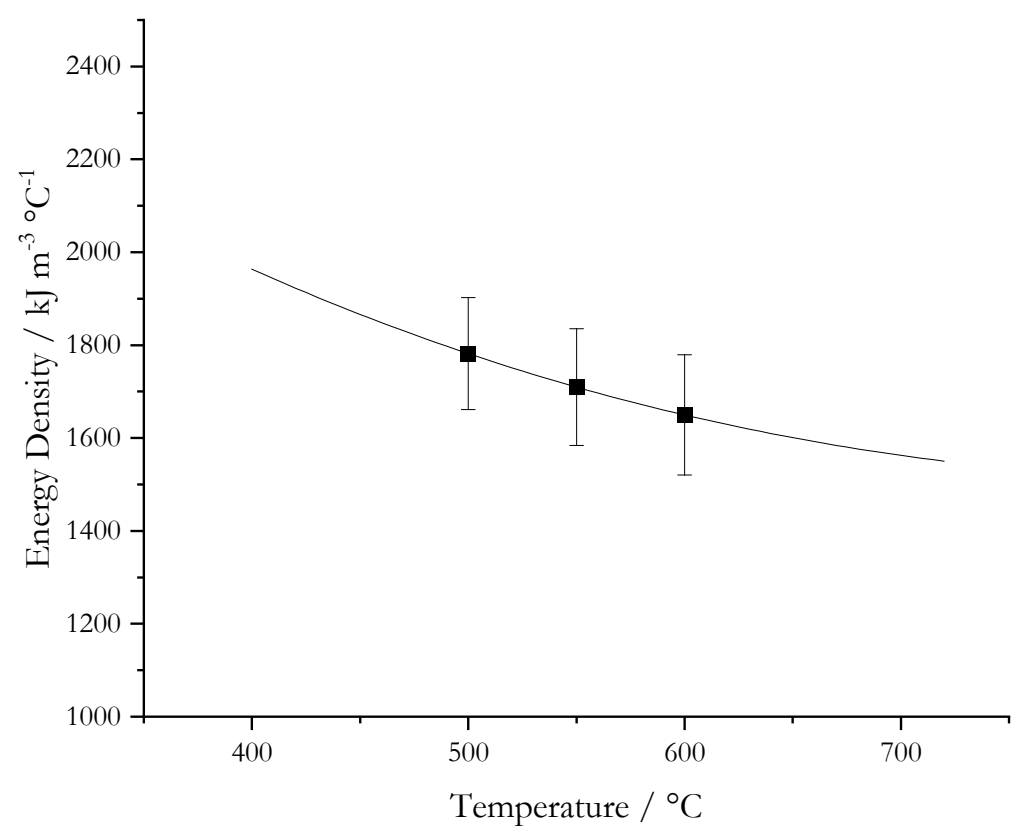

Figure 29. Calculated energy density of the baseline salt. Error bars indicate average \pm 1 standard deviation.

\section{Vapor Condensate Characterization}

Although the total vapor pressure of the baseline salt has been measured, the results cannot provide useful information about the chemical identities of the species present in the vapor. There are at least three reasons to identify the species in the vapor phase above the molten chloride salt:

1. Identify potential contaminations ${ }^{58}$ and prevent formation of high-vapor species.

2. Monitor salt composition. Thermodynamic calculation ${ }^{59}$ shown in Figure 30 suggests that $\mathrm{KMgCl}_{3}$ has the highest vapor pressure in the ternary $\mathrm{MgCl}_{2}-\mathrm{KCl}-\mathrm{NaCl}$ system, followed by pure $\mathrm{MgCl}_{2}, \mathrm{NaCl}$, and $\mathrm{KCl}$. Because of the difference of vapor pressure for these species, the loss through vaporization (at a few $\mathrm{kPa}$ of total vapor pressure) might not be at the exact stoichiometry of our ternary chloride melt. Over time, there is a risk of composition shift, leading to changes of melting/solidification temperature and/or other thermophysical properties.

3. Monitor salt degradation. If the ternary salt reacts with moisture, then it will release $\mathrm{HCl}$, which can be used as an indicator of salt degradation.

A set of salt evaporation tests were performed where the vapor condensate was collected. DSC measurements were conducted on the collected vapor condensate.

\footnotetext{
${ }^{58}$ The molten salt could react with refractory bricks in the TES and/or metallic pipeline materials.

${ }^{59}$ It is acknowledged that FactSage calculation did not correctly predict the magnitudes of the vapor species compared to experimental measurements. Hence, the calculation here serves as a qualitative, not quantitative, purpose.
} 
Tests with stainless-steel 316 (SS316) vessel: Three DSC experiments were performed on the

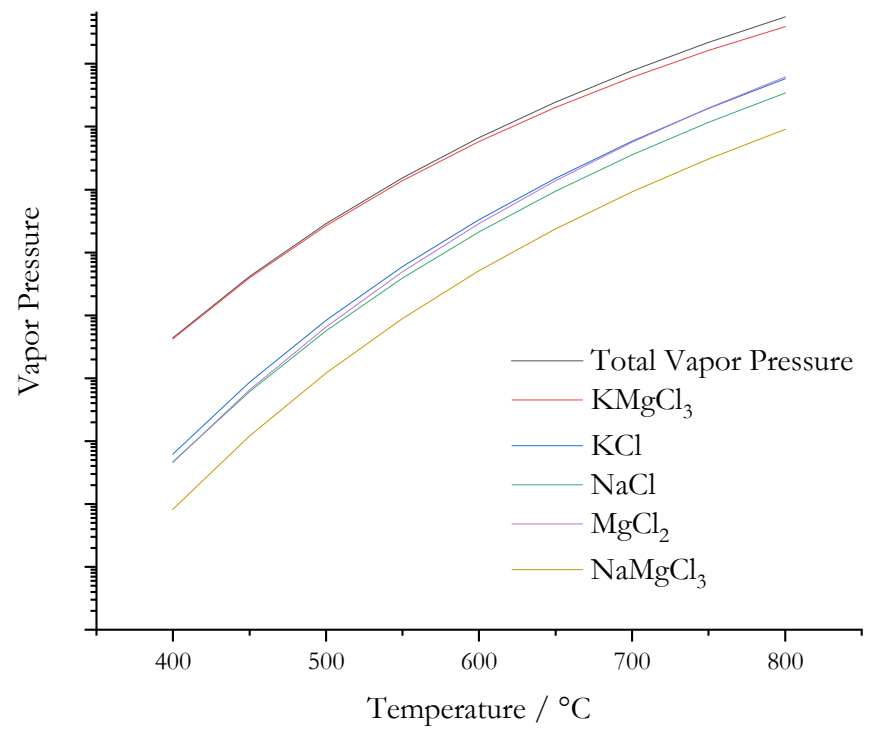

Figure 30. Total vapor pressure of $40 \mathrm{MgCl}_{2} / 40 \mathrm{KCl} / 20 \mathrm{NaCl}$ (mol\%) and the individual species with the highest vapor pressures calculated by FactSage. The y-axis is in log scale. No unit is given because the calculation should only serve a qualitative, not quantitative, purpose. collected salt vapor condensate when SS316 was used as the furnace vessel material. ${ }^{60}$ It was found that the vapor condensate has a much lower melting point (i.e., first DSC peak around $330^{\circ} \mathrm{C}$ ) than the purified salt. The true eutectic temperature of the ternary $\mathrm{MgCl}_{2}-\mathrm{KCl}-$ $\mathrm{NaCl}$ was found to be $385^{\circ} \mathrm{C} \pm 1^{\circ} \mathrm{C}$ [7]. Therefore, the collected vapor condensate is not any of the compositions in the $\mathrm{MgCl}_{2}-\mathrm{KCl}-\mathrm{NaCl}$ system. Very likely it is in a form of contaminated chloride salt with additional elements from the SS316 vessel (i.e., addition of other elements via contamination should generally lower the melting point of the salt). In addition, another separate test was performed for the Topic 1 Liquid Pathway project, where a porous refractory was used inside the SS316 vessel to collect the vapor condensate (to simulate the vaporcondensation effect on the roof of the

TES). The DSC results of the collected vapor were highly similar. Therefore, it is very likely that the contamination was due to "clean vapor"- - from evaporation of purified salt — in contact with the SS316 vessel wall in the furnace hot zone that generated Fe-containing chloride salt with high vapor pressure. ${ }^{61}$ Table 13 shows the elemental analysis from ICP-AES of the collected vapor condensate and the remaining salt in the quartz crucible. It can be seen that the vapor condensate is indeed very different from either the baseline salt or the remaining salt in the quartz crucible after the evaporation test. There are significant increases of metal elements such as $\mathrm{Fe}, \mathrm{Cu}, \mathrm{Cr}, \mathrm{Mn}, \mathrm{Ni}$, and $\mathrm{Zn}$ (most of which are alloying elements of SS316), and there are decreases of $\mathrm{Mg}$ and $\mathrm{Ca}$. Although some discrepancies exist between the baseline salt right after purification and after evaporation tests, some are due to sample preparation and some are due to contamination in the furnace atmosphere full of the same contaminants mentioned above (i.e., increase of $\mathrm{Cu}, \mathrm{Fe}, \mathrm{Ni}$, and $\mathrm{S}$ ). However, these changes seem minor, and we expect the effects to be even smaller if a more inert furnace vessel (e.g., In625 with quartz liner as additional protection) is used, which will again help validate that simple re-melting of salt in proper containment and under inert atmosphere will not significantly change the salt chemistry (i.e., the underlying assumption for long-term safe operation of the salt loop and TES). DSC on the remaining salt in the quartz crucible confirmed that its melting and solidification behavior is very

\footnotetext{
${ }^{60}$ Results from all three experiments were similar. The DSC traces can be obtained upon request.

${ }^{61} \mathrm{We}$ are confident that the vapor pressure data from the University of Arizona are free of similar effects because a full quartz set was used as salt containment in the vapor pressure measurement apparatus.
} 
similar to that of the purified baseline salt. X-ray diffraction (XRD) analysis also confirmed that the vapor condensate is not a simple chloride such as carnallite $\left(\mathrm{KMgCl}_{3}\right)$ and halite $(\mathrm{NaCl}) .{ }^{62}$

Table 13. Elemental Analysis Results (by ICP-AES) of Collected Vapor Condensate and the Remaining Salt in the Quartz Crucible

The result for the purified baseline salt (purified by $2,500 \mathrm{ppm} \mathrm{Mg}$ ) is also given for easier comparison. "BDL" means that the result is below detection limit.

\begin{tabular}{|c|c|c|c|c|c|}
\hline \multirow{2}{*}{ Analyte } & $\begin{array}{c}\text { Baseline } \\
\text { Salt }\end{array}$ & \multicolumn{2}{|c|}{$\begin{array}{c}\text { Remaining Salt in } \\
\text { Quartz Crucible }\end{array}$} & \multicolumn{2}{c|}{ Vapor Condensate } \\
\cline { 2 - 6 } & \multicolumn{5}{|c|}{ ppm } \\
\hline Al 396.153 - A & BDL & 3.9 & BDL & 52.9 & 31.6 \\
\hline Ca 317.933 - A & 1011.3 & $1,382.8$ & $1,246.3$ & 293.8 & 242.1 \\
\hline Cu 324.752 - A & BDL & 7.9 & 3.2 & $2,087.8$ & $2,039.1$ \\
\hline Cr 205.560 - A & BDL & BDL & BDL & 89.7 & 77.5 \\
\hline Fe 238.204 - A & 7.4 & 68.2 & 50.0 & $182,339.1$ & $181,694.4$ \\
\hline K 766.490 - R & 176108.0 & $227,439.1$ & $204,330.4$ & $173,440.8$ & $167,259.6$ \\
\hline Mg 285.213 - R & 102474.0 & $113,284.8$ & $100,471.7$ & $3,335.9$ & $2,413.3$ \\
\hline Mn 257.610 - A & 2.3 & 4.0 & 3.4 & $7,939.5$ & $7,803.9$ \\
\hline Na 589.592 - R & 10770.8 & $88,250.5$ & $88,231.2$ & $67,191.0$ & $62,039.5$ \\
\hline Ni 231.604 - A & BDL & 48.1 & 34.3 & 626.8 & 610.9 \\
\hline S 180.669 - A & 85.4 & $1,161.8$ & $1,142.0$ & $1,659.9$ & $1,565.0$ \\
\hline Sn 189.927 - A & BDL & BDL & BDL & $1,791.2$ & $1,706.1$ \\
\hline Zn 213.857 - A & 5.3 & 6.8 & 6.2 & $5,059.5$ & $4,941.7$ \\
\hline Co 228.616 & 0.9 & 1.0 & 1.3 & 37.7 & 35.9 \\
\hline
\end{tabular}

Tests with Inconel 625 vessel and quartz liner: The level of vaporization was noticeably lower when using the Inconel 625 vessel with a quartz liner at $700^{\circ} \mathrm{C}$, which made it very difficult to collect enough salt sample in the gas outlet tube and furnace cap for DSC and IPC-AES.

Therefore, a second evaporation at $725^{\circ}-730^{\circ} \mathrm{C}$ with gas sparging inside the salt melt at 150 sccm was used to promote salt evaporation, which eventually produced enough vapor condensate for analysis $(\sim 30 \mathrm{mg})$. Such qualitative observation corroborates our hypothesis that an inert containment system should prevent gas-phase contamination and help identify the real species in the salt vapor.

Figure 31 shows the typical DSC heating and cooling traces of the vapor condensate collected by using a Inconel 625 vessel and a quartz liner as additional protection. ${ }^{63}$ The first thermal phenomenon during heating is around $396^{\circ}-400^{\circ} \mathrm{C}$. This temperature agrees with our DSC result on the purified baseline salt. The only difference is that there is a second thermal phenomenon at around $430^{\circ}-450^{\circ} \mathrm{C}$ (as indicated by the broad and low-intensity peak), which suggests that this is likely the liquidus temperature of the sample. The cooling trace corroborates the results from the heating traces. The results confirm the thermodynamic calculation mentioned earlier-that $\mathrm{KMgCl}_{3}$ (melting point of $487^{\circ} \mathrm{C}$ ) has the highest vapor pressure, followed by $\mathrm{MgCl}_{2}, \mathrm{NaCl}$,

\footnotetext{
${ }^{62}$ The XRD pattern is significantly different from that of $\mathrm{KMgCl}_{3}$ and can be provided upon request.

${ }^{63}$ The same DSC measurements were performed under ultra-high-purity $\mathrm{N}_{2}$ and Ar, which showed almost the same behavior.
} 
and/or $\mathrm{KCl}$. The difference in vapor pressures will produce an overall vapor composition that is a combination of $\mathrm{KMgCl}_{3}$ and a secondary chloride $\mathrm{M}_{\mathrm{x}} \mathrm{Cl}_{\mathrm{y}}$ (e.g., $\mathrm{MgCl}_{2}, \mathrm{NaCl}$, and/or $\mathrm{KCl}$ ). Hence, vapor composition is off-eutectic of the $\mathrm{KMgCl}_{3}-\mathrm{M}_{\mathrm{x}} \mathrm{Cl}_{\mathrm{y}}$ "pseudo-binary," leading to a liquidus temperature bounded by $487^{\circ} \mathrm{C}$ (melting point of pure $\mathrm{KMgCl}_{3}$ ) and $\sim 400^{\circ} \mathrm{C}$ (melting point of the baseline salt).

The only puzzling fact is that the vapor condensate appeared to be a black powder after DSC instead of in a form of melted droplets. Unfortunately, all samples were used for DSC measurements. Future ICPAES analysis should provide some insights on the exact chemical makeup of the vapor condensate.

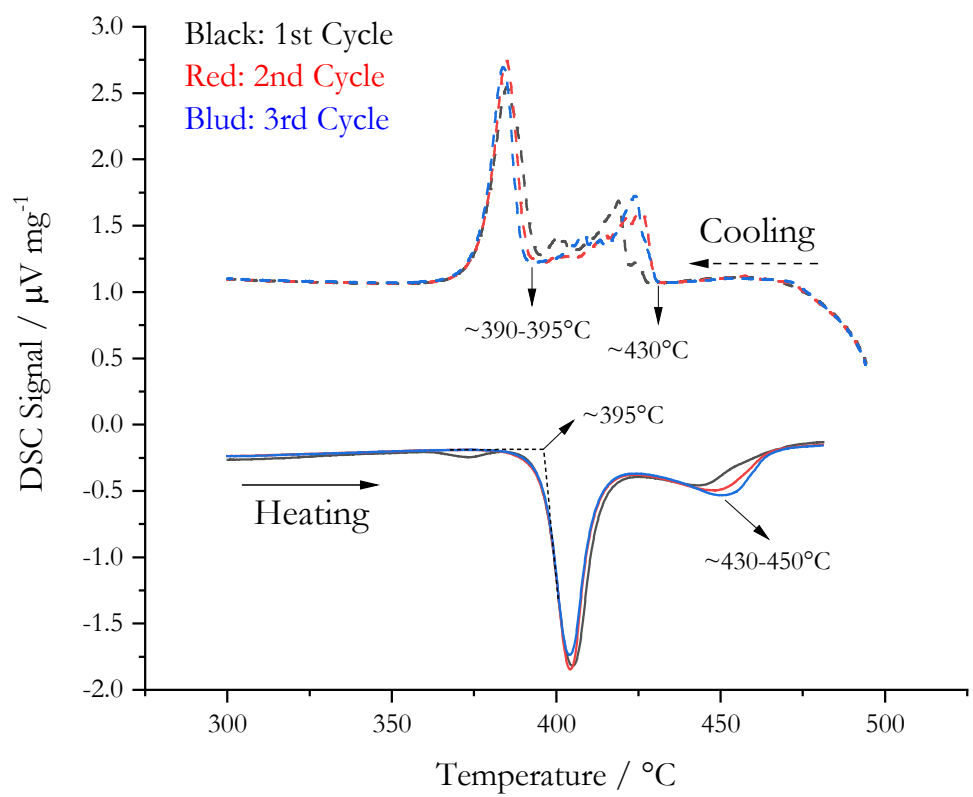

Figure 31. DSC heating and cooling traces for purified salt vapor condensate in an Inconel $\mathbf{6 2 5}$ furnace vessel. DSC was performed under ultra-high-purity nitrogen cover gas at $50 \mathrm{~mL} / \mathrm{min}$. Solid lines indicate heating traces, and dashed lines indicate cooling traces.

Here, we must emphasize the importance of the above results, concerning at least two aspects of the salt-loop design and operation:

1. Vapor treatment and salt recovery: In the TES tanks, the salt vapor should be treated to remove harmful species. It is very important to know the species to be treated and their melting points if a gas-scrubbing system (to remove harmful gases) and a condensation system (to recover useful salt components) must be designed. Ideally, the salt vapor should be condensed into liquid rather than solid so they may be guided and flow back to the TES instead of clogging the piping. Hazardous gasses such as $\mathrm{HCl}$ should pass through the condensation system and enter the scrubbing system without condensing. Hence, it is key to know at which temperature the scrubbing and condensation systems should be operated (e.g., above melting point of salt but not too high to control corrosion).

2. Salt composition control: If the salt vapor has a different composition than the salt melt, then replenishing the right salt component(s) is needed over time, unless the salt loop is an absolute closed system and no loss can occur (due to salt condensation and/or removal through scrubbing system). Based on the liquidus temperature of the vapor condensate measured, the composition difference seems small (i.e., $\sim 30^{\circ} \mathrm{C}$ increase of liquidus temperature should correspond to $<5$ wt.\% lower in $\mathrm{NaCl}$ based on Figure 23 of the Phase 1 Continuation report). Therefore, the overall impact of composition shift due to salt evaporation might be low in the short term. The long-term effect is unknown because of the lack of kinetic measurement. But the need for replenishing the salt component(s) should be underestimated. 
The biggest shortcoming of our evaporation tests is the lack of an in-situ analysis of the gas species - e.g., Fourier-transform infrared spectroscopy, gas chromatography, or mass spectroscopy - that can be connected directly to the outlet gas stream or inserted into the furnace atmosphere above the salt melt. It will be very valuable to develop such a capability for largerscale testing in the near future (e.g., FASTR loop) and eventual deployment in the field. It will help diagnose the loop and identify points of failure - for example, moisture ingress if $\mathrm{HCl}$ content is high, corrosion with refractory liners if certain Fe-O-Cl-containing ${ }^{64}$ species are high, or uncontrolled salt evaporation if $\mathrm{KMgCl}_{3}$-to- $\mathrm{NaCl}$ ratio, $\mathrm{KMgCl}_{3}$-to- $\mathrm{KCl}$ ratio, and/or $\mathrm{KMgCl}_{3}$ to- $\mathrm{MgCl}_{2}$ ratio is off. Such a capability should complement other analytical tools/sensors to detect excursions in the molten-salt loop.

\subsection{Salt Degradation During Exposure to Moisture and/or Oxygen at High Temperature}

It is expected that unwanted exposure of the molten chlorides to moisture and/or oxygen will degrade the salt based on Eqs. 5 to 8. Hence, we performed lab-scale experiments in which the purified baseline salts were exposed to controlled amounts of moisture and/or oxygen. We need to emphasize that all experiments performed were at $\sim 50$-g scale under a simplified heat $/$ mass transfer condition. ${ }^{65}$ Caution should be used when translating the results presented below to inform real-scale loop operation.

Four metrics were used to quantify and compare the degradation under different conditions.

1. Particle mass fraction: The particles were collected after complete dissolution of the salt and multiple filtrations through 450-nm filter paper that removed the soluble chlorides. The filtered particles were then dried overnight in a vacuum drying oven at $110^{\circ} \mathrm{C}$ before mass measurement.

2. Particle size and distribution: A laser-based particle-size analyzer (PSA) was used to determine the particle size and distribution of the collected particles. The dried particles after mass measurement were suspended in deionized water again before loaded into the PSA. Before each PSA measurement, the suspended particles were ultra-sonicated for 2 minutes inside the PSA to prevent agglomeration.

3. $\mathrm{MgOHCl}$ content: The analytical titration method was used to measure the $\mathrm{MgOHCl}$ content in the post-experiment salt. At least four measurements were performed on each sample.

4. Salt composition: ICP-AES was used to measure the elemental makeup of the salt and later calculate the overall salt composition.

Table 14 summarizes the details of the testing schedule. A few explanations are given below to provide the rationale behind this testing schedule:

\footnotetext{
${ }^{64}$ For illustration purpose only. The exact chemistry of concerns is unknown.

${ }^{65}$ Although the sample size was small, an aggressive gas sparging rate was used (i.e., $10 \mathrm{sccm}$ for $\sim 30 \mathrm{~cm}^{3}$ of total salt volume).
} 
1. Experiment $\# 1$ is the purified baseline salt without any exposure to moisture/oxygen for comparison. Experiments \#2-8 all used purified baseline salt (not necessarily from the same purification batch).

2. Experiments \#2-4 were designed to investigate possible effects of oxygen.

3. Experiments \#5-7 were designed to investigate possible effects of moisture.

4. Experiment $\# 8$ was designed to investigate an unlikely case where $\mathrm{Mg}$ is added to the loop operation as an emergency measure.

5. We did not design an extreme test (e.g., $>400$-ppm moisture level or $>24$-hour exposure time) because of the corrosion concern when moisture is introduced.

Table 14. Summary of Impurity Gas Exposure Tests

\begin{tabular}{|c|c|c|c|c|c|c|}
\hline Exp. \# & $\begin{array}{c}\text { Cover } \\
\text { Gas }\end{array}$ & Sparging Gas & $\begin{array}{l}\text { Sparging } \\
\text { Time } \\
\text { (min) }\end{array}$ & $\begin{array}{l}\text { Sparging } \\
\text { Rate } \\
\text { (sccm) }\end{array}$ & $\begin{array}{c}\text { Temp. } \\
\text { during } \\
\text { Sparging } \\
\left({ }^{\circ} \mathrm{C}\right)\end{array}$ & $\begin{array}{c}\mathrm{Mg} \\
\text { Coupon }\end{array}$ \\
\hline 1 & \multicolumn{6}{|c|}{ N/A (This is the purified baseline salt for comparison) } \\
\hline 2 & \multicolumn{2}{|c|}{ In-house $\mathrm{N}_{2}$ (dry) } & 180 & 10 & \multirow{7}{*}{$700-710$} & \multirow{6}{*}{ No } \\
\hline 3 & \multirow{2}{*}{\multicolumn{2}{|c|}{ In-house air (dry) }} & 180 & 10 & & \\
\hline 4 & & & 1,260 & 10 & & \\
\hline 5 & \multirow{4}{*}{$\begin{array}{c}\text { In- } \\
\text { house } \\
\mathrm{N}_{2} \text { (dry) }\end{array}$} & $\begin{array}{c}\text { In-house } \mathrm{N}_{2} \text { with } \\
\sim 40 \mathrm{ppm} \\
\text { moisture }\end{array}$ & 60 & 10 & & \\
\hline 6 & & \multirow{3}{*}{$\begin{array}{c}\text { In-house } \mathrm{N}_{2} \text { with } \\
\sim 400 \mathrm{ppm} \\
\text { moisture }\end{array}$} & 60 & 10 & & \\
\hline 7 & & & 180 & 10 & & \\
\hline 8 & & & 180 & 10 & & Yes \\
\hline
\end{tabular}

Table 15 summarizes the results of the impurity gas exposure tests. The experiment numbers in the first column match the ones in Table 14.

Table 15. Summary of the Measured Particle Mass Fraction, MgOHCl Content, and Salt Composition After All Impurity Gas Sparging Tests Performed

The experiment numbers in the first column match the ones in Table 1. "N/A" indicates that the measurement was not performed.

\begin{tabular}{|c|c|c|c|c|c|c|}
\hline & \multirow{2}{*}{$\begin{array}{c}\text { Particle } \\
\text { Mass } \\
\text { Exp. \# } \\
\text { Fraction } \\
\text { (wt.\%) }\end{array}$} & \multicolumn{2}{|c|}{$\begin{array}{c}\text { MgOHCI Content } \\
\text { (wt.\%) }\end{array}$} & \multicolumn{3}{|c|}{$\begin{array}{c}\text { Salt Composition Based on } \\
\text { ICP (wt.\%) }\end{array}$} \\
\cline { 3 - 7 } & Average & Stdev & $\mathbf{M g C l}_{\mathbf{2}}$ & $\mathbf{K C I}$ & $\mathbf{N a C l}$ \\
\hline 1 & 0.032 & 0.110 & 0.030 & 43.60 & 39.18 & 16.85 \\
\hline 2 & 0.027 & 0.138 & 0.030 & 44.69 & 36.48 & 18.41 \\
\hline 3 & 0.034 & 0.165 & 0.025 & 44.68 & 36.85 & 18.07 \\
\hline 4 & $\mathrm{~N} / \mathrm{A}$ & 0.085 & 0.017 & \multicolumn{4}{|c|}{$\mathrm{N} / \mathrm{A}$} \\
\hline 5 & $\mathrm{~N} / \mathrm{A}$ & 0.120 & 0.025 & 44.85 & 36.04 & 18.69 \\
\hline 6 & 0.043 & 0.129 & 0.016 & 45.38 & 35.74 & 18.46 \\
\hline 7 & 0.026 & 0.167 & 0.036 & 44.50 & 39.39 & 15.67 \\
\hline 8 & $\mathrm{~N} / \mathrm{A}$ & 0.151 & 0.047 & 43.03 & 41.62 & 14.99 \\
\hline
\end{tabular}




\begin{tabular}{|c|c|c|c|c|c|c|}
\hline \multirow{2}{*}{ Exp. \# } & \multirow{2}{*}{$\begin{array}{c}\text { Particle } \\
\text { Mass } \\
\text { Fraction } \\
\text { (wt.\%) }\end{array}$} & \multicolumn{2}{|c|}{$\begin{array}{l}\text { MgOHCI Content } \\
\text { (wt.\%) }\end{array}$} & \multicolumn{3}{|c|}{$\begin{array}{c}\text { Salt Composition Based on } \\
\text { ICP (wt.\%) }\end{array}$} \\
\hline & & Average & Stdev & $\mathrm{MgCl}_{2}$ & $\mathrm{KCl}$ & $\mathrm{NaCl}$ \\
\hline & & & Average & 44.39 & 37.90 & 17.31 \\
\hline & & & Stdev & 0.80 & 2.20 & 1.49 \\
\hline
\end{tabular}

Particle mass fraction: The spread of particle mass fraction in all of the measured salts is relatively small $(0.0324 \pm 0.0068 \mathrm{wt} . \%)$. All particle mass fraction values fall within one standard deviation away from the average, except $0.043 \mathrm{wt} . \%$. One sample t-test shows that at the $95 \%$ confident level, $0.043 \mathrm{wt} . \%$ is statistically different from the rest of the particle mass-fraction population. However, practically speaking, the variation of particle mass fraction should not present serious concerns to the salt-loop operation because of the low absolute magnitude. At $<0.1$ wt. \% mass loading, we do not foresee significant risks.

$\mathrm{MgOHCl}$ content: A similar conclusion can be made for the $\mathrm{MgOHCl}$ content. A statistically significant difference exists if comparing the extreme values to the entire population (e.g., 0.085 wt.\% is statistically different from the rest). However, taking into account the known magnitude of variations of $\mathrm{MgOHCl}$ measurements throughout the project period (i.e., $0.1-0.2 \mathrm{wt} . \%$ ), it is not surprising to see such a difference. In addition, the analytical titration method may be close to its limit of detection ${ }^{66}(\sim 0.1 \mathrm{wt} . \%)$ [56]. Regardless of the cautions and limitations, it is intriguing to see that 24 hours of dry in-house air exposure produced a lower $\mathrm{MgOHCl}$ (if assuming the numbers are accurate by titration). With caution, we may suggest that dry gas sparging can be a practical method to keep the purified salt relatively clean of $\mathrm{MgOHCl}$ when $\mathrm{MgOHCl}$ decomposition seems to be limited by the removal of $\mathrm{HCl}$ generated. Such speculation also aligns with our observation that with sufficient gas sparging, salt purification is easier and corrosion is less severe. Recent communication with research partners at the University of Wisconsin-Madison and MIT confirms the important role of gas sparging at the 5- to 10-kg scale of salt purification in terms of preventing furnace/test vessel corrosion.

Salt composition: Another metric used to determine the salt degradation is the shift of salt composition. The $\mathrm{MgCl}_{2}$-contaning salt chemistry suggests a decrease in $\mathrm{MgCl}_{2}$ content by producing $\mathrm{MgO}$ if the salt mixture is exposed to moisture (Eqs. 5 to 8). Therefore, we would like to confirm (1) if the magnitude of this decrease is detectable (at lab scale) and (2) if the decrease will risk safe salt-loop operation given our knowledge of the sensitivity of melting/liquidus temperature to composition shift (Figure 20). As shown by the last three columns of Table 15, there is not a significant variation of salt composition (the overall statistics of Experiments \#1 to $\# 8$ is given by the average and stdev values below the table). It should be remembered that only one ICP-AES was performed for each sample in Experiments \#1-\#8 (except Experiment \#4). Although there seem to be some noticeable variations, such as the higher $\mathrm{KCl}$ content and lower $\mathrm{NaCl}$ content in Experiment \#8, the difference from the average is only about 1.5 standard deviation. Without more data points, we need to be cautious about ruling out the possibility of pure data scatter. The conclusion that the data variation is due to exposure to moisture/oxygen is premature. In addition, the statistical variations of the baseline salt (Table 9) must be considered

${ }^{66}$ This has not been experimentally confirmed because of the lack of a second tool to individually verify the true $\mathrm{MgOHCl}$ content. 
too. It can easily be shown that the composition difference between the baseline salt and the salts after exposure to moisture/oxygen is not statistically significant, which gives one more reason to believe that the composition variation in Table 15 could be statistical.

Figure 20 suggests that the liquidus temperature of the purified salt should not change by more than $30^{\circ} \mathrm{C}$ if the composition shift stays within 5-10 wt.\% in all directions. Therefore, the composition variation we observed should not be too concerning to safe loop operation.

$\mathrm{MgO}$ particle size and distribution: Figure 32 shows the measured particle-size distributions with a laser-based particle size analyzer (PSA). It suggests that most salt samples have very similar particle-size distribution (i.e., broad peak around 10-30 $\mu \mathrm{m}$, with a tail diminishing at around $100 \mu \mathrm{m})$. Kashani-Nejad et al. [40] reported that the $\mathrm{MgO}$ particle size can be below $1 \mu \mathrm{m}$ via thermal decomposition of $\mathrm{MgOHCl}$, a major mechanism that reduces $\mathrm{MgOHCl}$ during

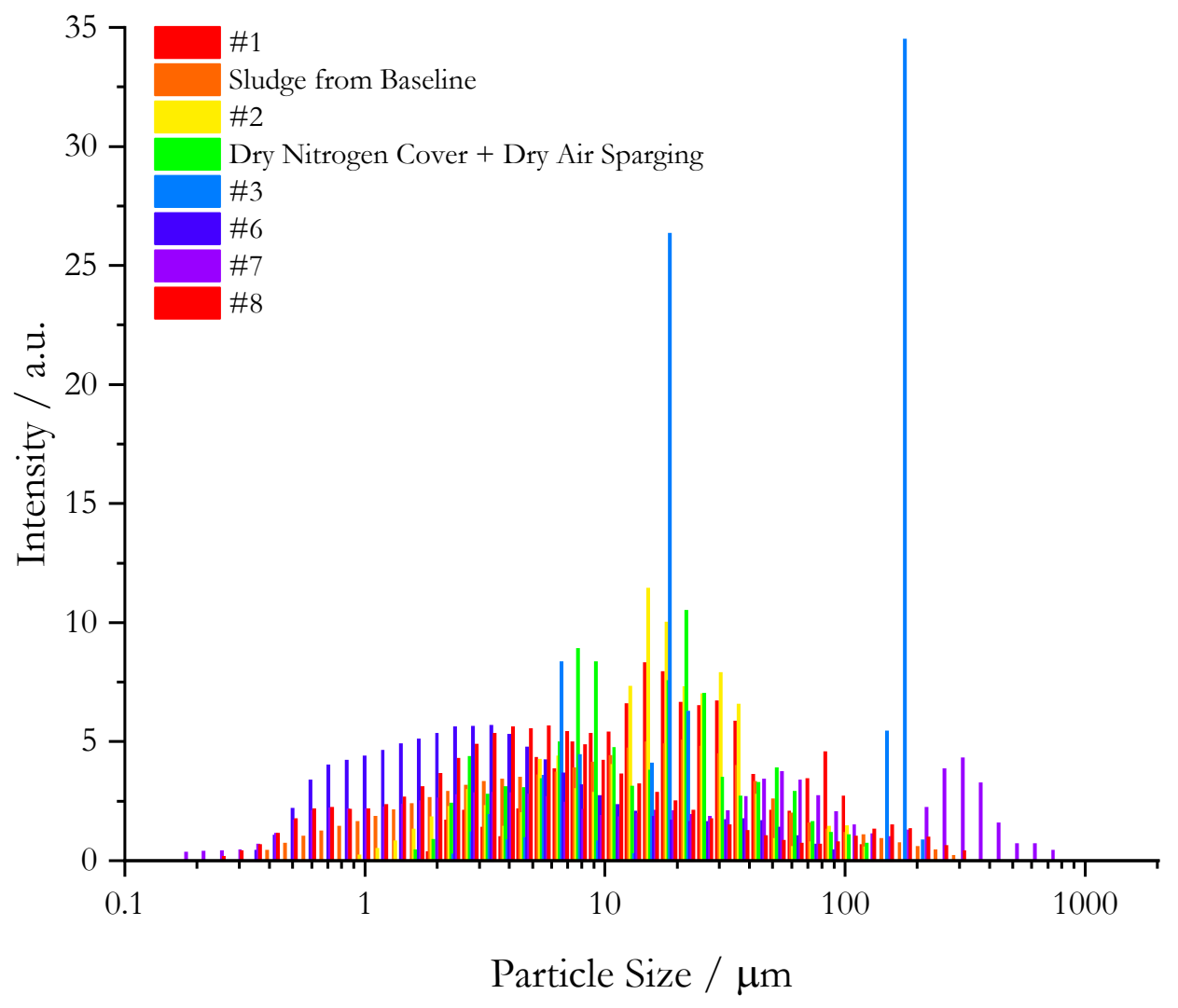

Figure 32. Particle size and distribution measured for most salt samples present in Table 1 and a few additional salts. The numbers in the legend match the ones in Table 1. Note: the peaks

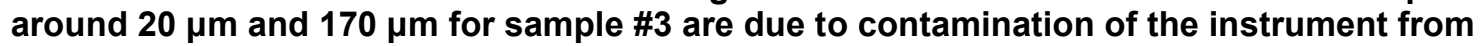
unrelated experiments and should be discounted.

purification. Note that the accuracy of the PSA could be affected by particle agglomeration, which might explain the difference with [40]. A few observations and explanations are given below:

- Particles in the purified salt phase without sparging (i.e., baseline salt) and particles in the sludge phase seem to have similar distribution. This appears to contradict our expectation 
that the sludge particles are bigger because they settle more easily. But, we need to acknowledge that when we were loading the suspended sludge particles to the PSA, the bigger particles would settle more easily; hence, the sampling process might have not been representative. From a practical point of view, such similar particle distributions may not be a problem, especially considering the vastly different mass fraction of particles (i.e., $<0.05 \mathrm{wt} . \%$ in the clear salt phase vs. $>50 \mathrm{wt} . \%$ in the sludge phase).

- The spikes of sample \#3 at 15-22 $\mu \mathrm{m}$ and $176 \mu \mathrm{m}$ are most likely due to contamination of previous users. ${ }^{67}$

- Sample \#7 shows some particles at 200-400 $\mu \mathrm{m}$. It should be noted that this was the most aggressive sparging experiment ( $400 \mathrm{ppm}$ of moisture for $180 \mathrm{~min})$. It is alarming but also anticipated given our understanding of salt interaction with moisture. Sample \#8 (same sparging condition as sample \#7 but with added elemental $\mathrm{Mg}$ ) does not show this peak around 200-400 $\mu \mathrm{m}$, which agrees with the expected function of $\mathrm{Mg}$ addition (as an oxygen and moisture scavenger).

Our opinion regarding these particle analyses is that (1) the bulk of the data can be trusted (i.e., no particles are of a size significantly greater than 100-200 $\mu \mathrm{m}$ ), and (2) the details of the data, (e.g., exact peak location at $20 \mu \mathrm{m}$ vs. $50 \mu \mathrm{m}$ ) are less trustworthy because we did notice that the particle distribution seems sensitive to previous samples (either from other users or from our own samples). The bottom line is that the $\mathrm{MgO}$ particles generated under the conditions in Table 14 should retire some risks to the pumps and bearings because (1) a significant fraction of $\mathrm{MgO}$ particles are below $25 \mu \mathrm{m}^{68}$ and do not present a high risk to the pumps and bearings, and (2) a series of filters $(10 \mu \mathrm{m}, 20 \mu \mathrm{m}$, and $25 \mu \mathrm{m})$ could be used to filter out harmful large $\mathrm{MgO}$ particles.

The next section discusses a particle size analysis after a filtration experiment at University of Wisconsin-Madison. This particle size analysis seems to indicate that the particles in the purified salt can be much smaller. Although without solid evidence to exclude the particle size analysis in this section, we want to ensure that readers understand that possible agglomeration may have happened during the PSA analysis (although ultra-sonication for $2 \mathrm{~min}$ was used to minimize agglomeration before each analysis).

\footnotetext{
${ }^{67}$ Similar peaks were found in the sample data by the previous PSA user.

${ }^{68}$ Particles above $25 \mu \mathrm{m}$ could damage the salt pumps and bearings based on communication with the pump manufacturers.
} 


\subsection{MgO Particle Filtration}

The University of Wisconsin-Madison (UW), as a subrecipient of the project, performed salt purification at larger scale $(\sim 7 \mathrm{~kg})$ following the purification recommendations ${ }^{69}$ with a mass spectroscopy connected to the exhaust gas to monitor the $\mathrm{H}_{2} \mathrm{O}$ and $\mathrm{HCl}$ release, in order to determine the end of the purification process. Figure 33 shows the schematic of the experimental setup.

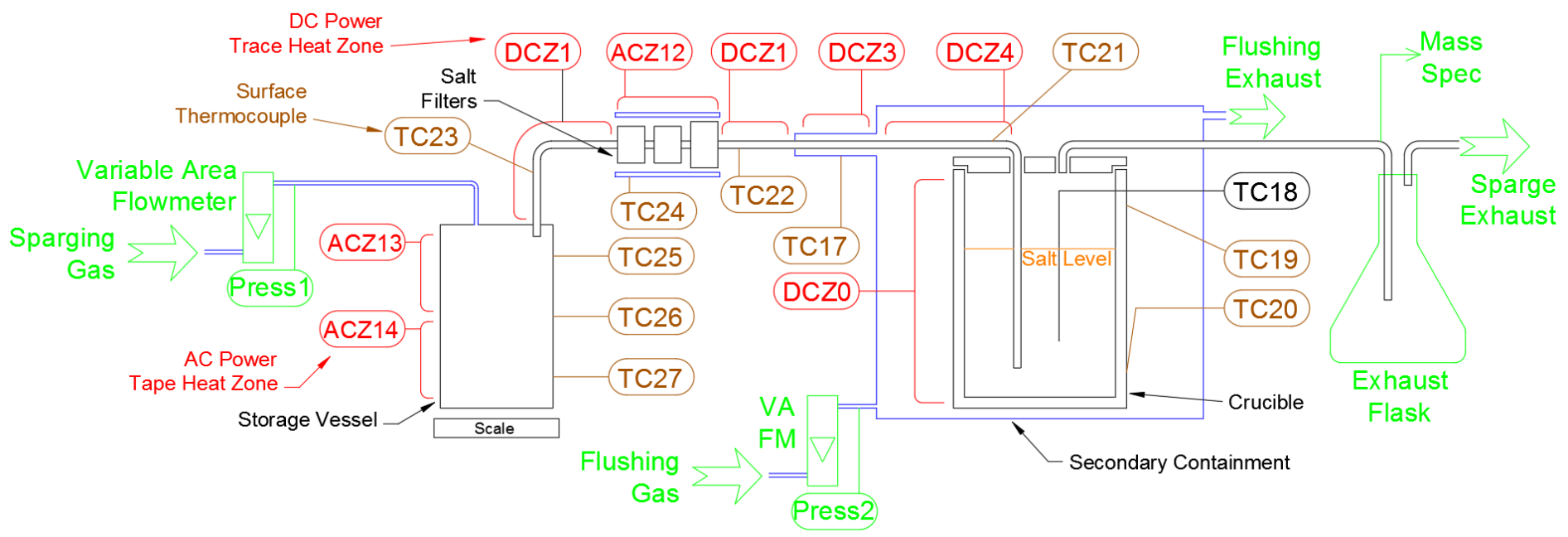

Figure 33. Schematic of the UW salt purification and filtration setup

After salt purification, the salt was cooled down to $\sim 570^{\circ} \mathrm{C}$ and filtered through a series of stainless-steel filters (Figure 34). Following the direction of the salt flow, the filters are:

1. A $25-\mu \mathrm{m}$ filter with filter area of $25.55 \mathrm{~cm}^{2}$ and thickness of $1.59 \mathrm{~mm}$.

2. A $20-\mu \mathrm{m}$ filter with filter area of $11.42 \mathrm{~cm}^{2}$ and thickness of $1.59 \mathrm{~mm}$.

3. A $10-\mu \mathrm{m}$ filter with filter area of $11.42 \mathrm{~cm}^{2}$ and thickness of $1.59 \mathrm{~mm}$

${ }^{69}$ With a few exceptions to accommodate the different experimental hardware available at larger scale, such as a $\mathrm{SiC}$ crucible. 
DE-EE00033870

Molten Chloride Thermophysical Properties, Chemical Optimization, and Purification National Renewable Energy Laboratory
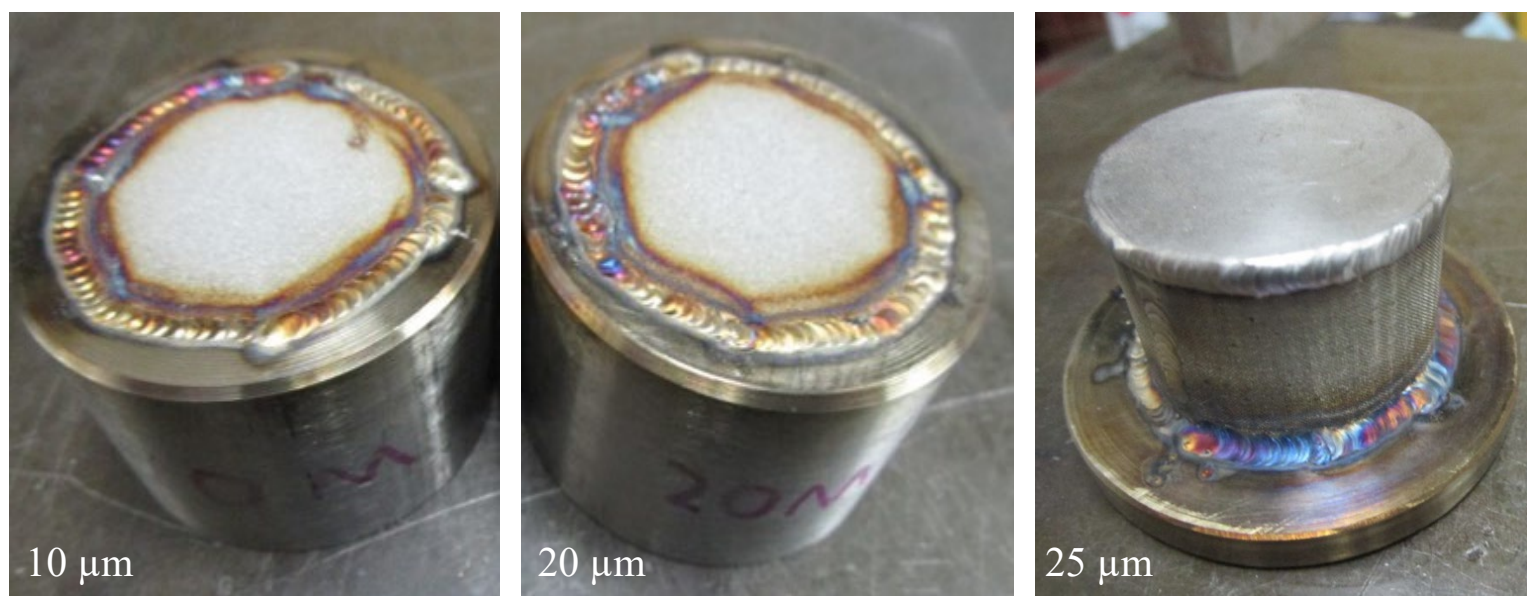

Figure 34. Stainless-steel filters used in UW's filtration experiment

Figure 35 shows a picture of the connected filters and the schematic of the setup.
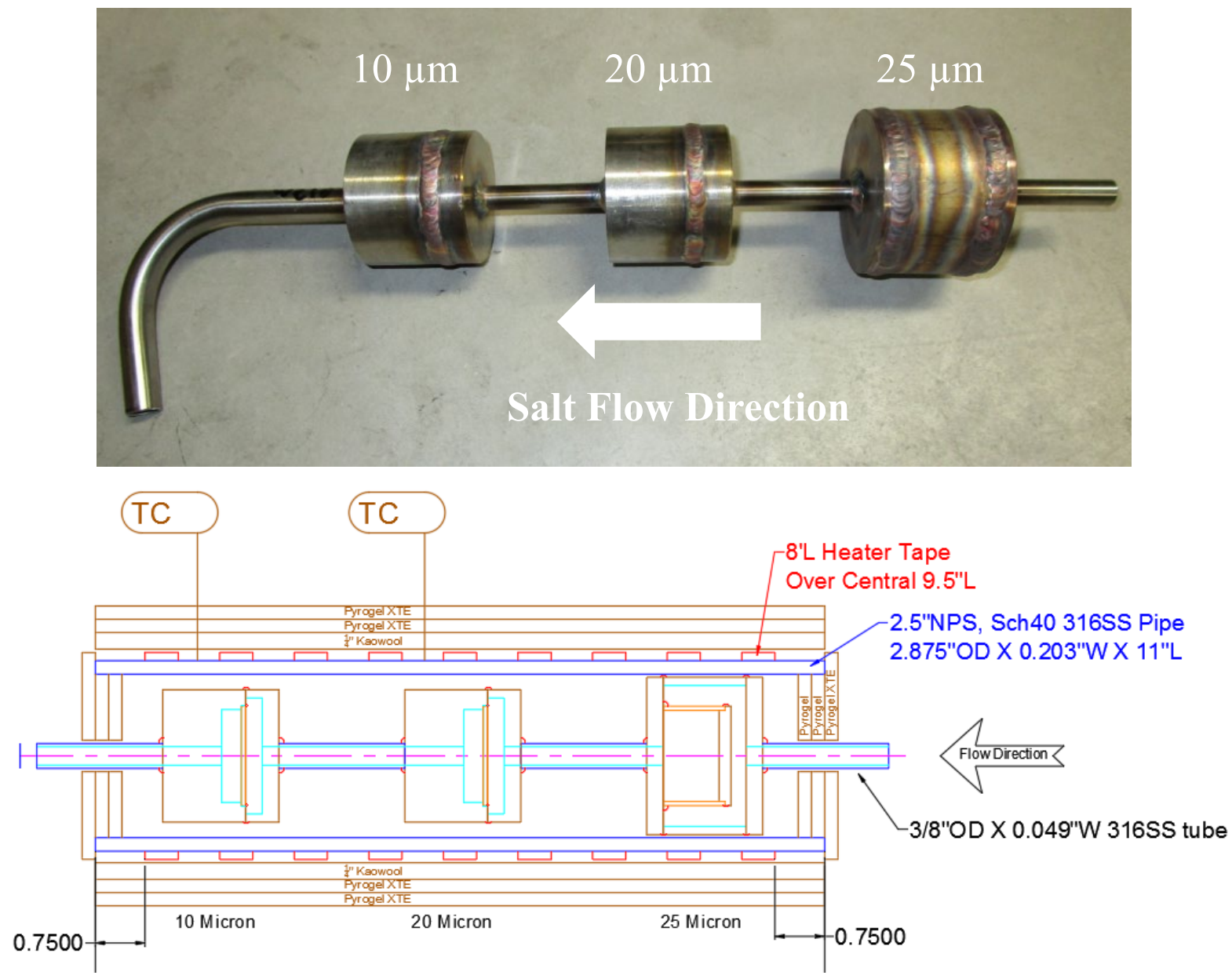

Figure 35. Schematic of the stainless-steel filters used during the filtration experiment 


\section{Salt Purification Time at Larger Scale}

A mass spectroscopy was used with the intention to monitor $\mathrm{H}_{2} \mathrm{O}$ and $\mathrm{HCl}$ release and determine the completion of salt purification. However, the purification process was interrupted by multiple hardware issues related to the heating element and gas purging. So, the salt heating was not as planned (e.g., holding at $250^{\circ} \mathrm{C}$ for salt pre-drying until $\mathrm{H}_{2} \mathrm{O}$ and $\mathrm{HCl}$ release stops and then ramping up to and holding at $670^{\circ} \mathrm{C}$ temperature until $\mathrm{H}_{2} \mathrm{O}$ and $\mathrm{HCl}$ release stops). Therefore, the $\mathrm{H}_{2} \mathrm{O}$ and $\mathrm{HCl}$ release monitored by the mass spectroscopy should be used as a qualitative indicator only. The release time was roughly 20 hours at $500^{\circ}-600^{\circ} \mathrm{C}$. Considering that the purification scale is $\sim 15 \mathrm{x}$ higher than NREL's 500 -g scale when $\sim 2$ hours of $\mathrm{H}_{2} \mathrm{O}$ and $\mathrm{HCl}$ release was observed, 20 hours seems reasonable.

\section{Flow Rate and Pressure Difference During Filtration}

During the salt transfer/filtration process, the salt flow rate was monitored based on the weight change of the salt storage vessel (including the salt), and the internal pressure difference between the salt purification vessel and the salt storage vessel (i.e., the salt entered the storage vessel for storage after filtration) was recorded. Stable values of both quantities during salt transfer indicate salt filtration without significant clogging.

Figure 36 shows the recorded salt flow rate and pressure difference between the salt purification vessel and storage during filtration. The salt flow rate is relatively stable after $\sim 25 \mathrm{~s}$ and the pressure differential reaches the maximum value in about $15 \mathrm{~s}$ and very slowly decrease with time until a sudden drop at the end of filtration. The slow decrease of pressure differential seems to indicate easier salt flow without significant clogging. The total salt transfer time was about 80

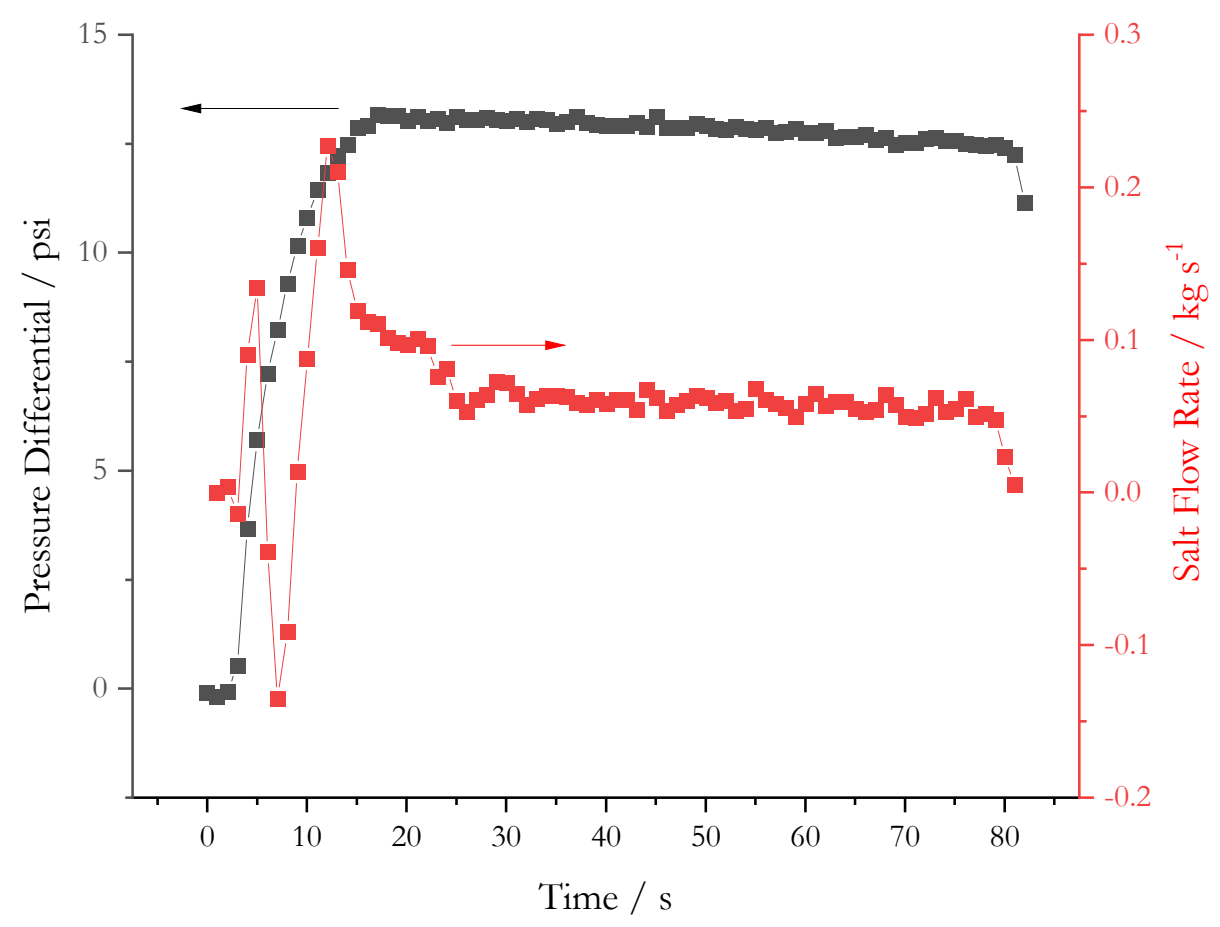

Figure 36. Salt flow rate and pressure differential between the salt purification vessel and storage vessel during salt transfer/filtration 
$\mathrm{s}$ for $\sim 5 \mathrm{~kg}$ of salt. The time period for stable (or steady-state) salt filtration/transfer (i.e., as indicated by a stable flow rate and pressure difference) was about 50-60 s. Given the salt density of $1.64 \mathrm{~g} / \mathrm{cm}^{3}$ at $570{ }^{\circ} \mathrm{C}$, the average flow rate during stable transfer (i.e., from $30 \mathrm{~s}$ to $75 \mathrm{~s}$ ) is about $0.05876 \mathrm{~kg} / \mathrm{s}$ or $35.8 \mathrm{ml} / \mathrm{s}$.

\section{Particle Weight Fraction, Size, and Chemistry}

The particles trapped by each stainless-steel filter were dissolved in deionized water and filtered through a 100-nm filter paper at UW. Figure 37 shows the collected particles, i.e., the brown film on the white filter paper (the white background). Note that there were metal shards on the outer rim of the collected particles, which were due to cutting of the stainless-steel filter casing. Table 16 shows the rough weights of the collected particles on each filter paper. ${ }^{70}$ It can be seen that the first filter ( $25 \mu \mathrm{m}$ filter) captured 6-8 times more particles.
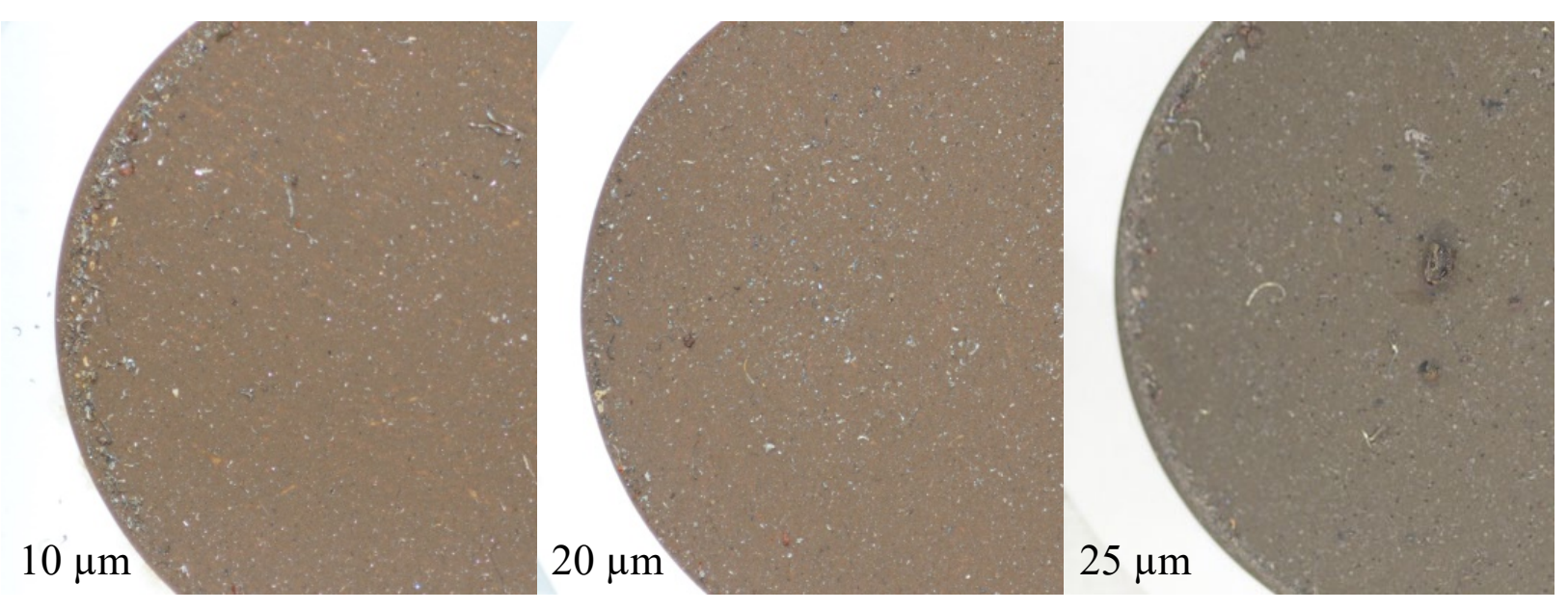

Figure 37. Particles collected on each stainless-steel filter (after deionized water dissolution to remove most chloride salt residual and drying)

Table 16. Estimation of the Collected Particles by Each Stainless-Steel Filter

\begin{tabular}{|l|c|c|c|}
\hline & \multicolumn{3}{|c|}{ Filter Size } \\
\cline { 2 - 4 } & $\mathbf{1 0} \boldsymbol{\mu m}$ & $\mathbf{2 0} \boldsymbol{\mu m}$ & $\mathbf{2 5} \boldsymbol{\mu m}$ \\
\hline Particle Weight (mg) & 13.81 & 18.67 & 108.81 \\
\hline
\end{tabular}

The total weight of particles collected on the filters was $141.29 \mathrm{mg}$ out of $\sim 5 \mathrm{~kg}$ of filtered salt, or $0.0028 \mathrm{wt} . \%$, which is a very small number. On the other hand, roughly $107.5 \mathrm{~g}$ of the filtered salt (with particles that were not captured by the filters) was collected, dissolved in deionized water, and filtered through a $100-\mathrm{nm}$ filter paper. The particles collected on the filter paper was about $48.4 \mathrm{mg}$ (or $0.045 \mathrm{wt}$ \% normalized to $107.5 \mathrm{~g}$ of filtered salt). This number-i.e., particle weight fraction in filtered salt-is in good agreement with NREL's 500-g scale experiments (see Table 14). Note that the weight fraction of particles trapped by the stainless-steel filters $(0.0028$ wt.\%) was almost 20 times lower than the fraction of particles remaining in the filtered salt,

\footnotetext{
70 The measured weights serve as upper bounds because they include the metal shards that are hard to remove manually.
} 
which seems to indicate that the filtration was not very effective. But even at $0.045 \mathrm{wt} . \%$, it is a very low level (i.e., for $5 \mathrm{~kg}$ of filtered salt, the total particle weight is $2.25 \mathrm{~g}$ ). The low level of particulates in the filtered salt is in sharp contrast to the weight fraction of particles in the sludge phase of the purified salt after settling (about $1 \mathrm{wt} . \%$ from Table 7). This suggests that the settling step during both NREL's and UW's experiments was effective by itself (i.e., both can reduce particulate weight fraction from $\sim 1 \mathrm{wt} . \%$ to less than $0.05 \mathrm{wt} . \%$ ). UW's filtration setup helped, but the overall effect in terms of particle weight fraction is much smaller.

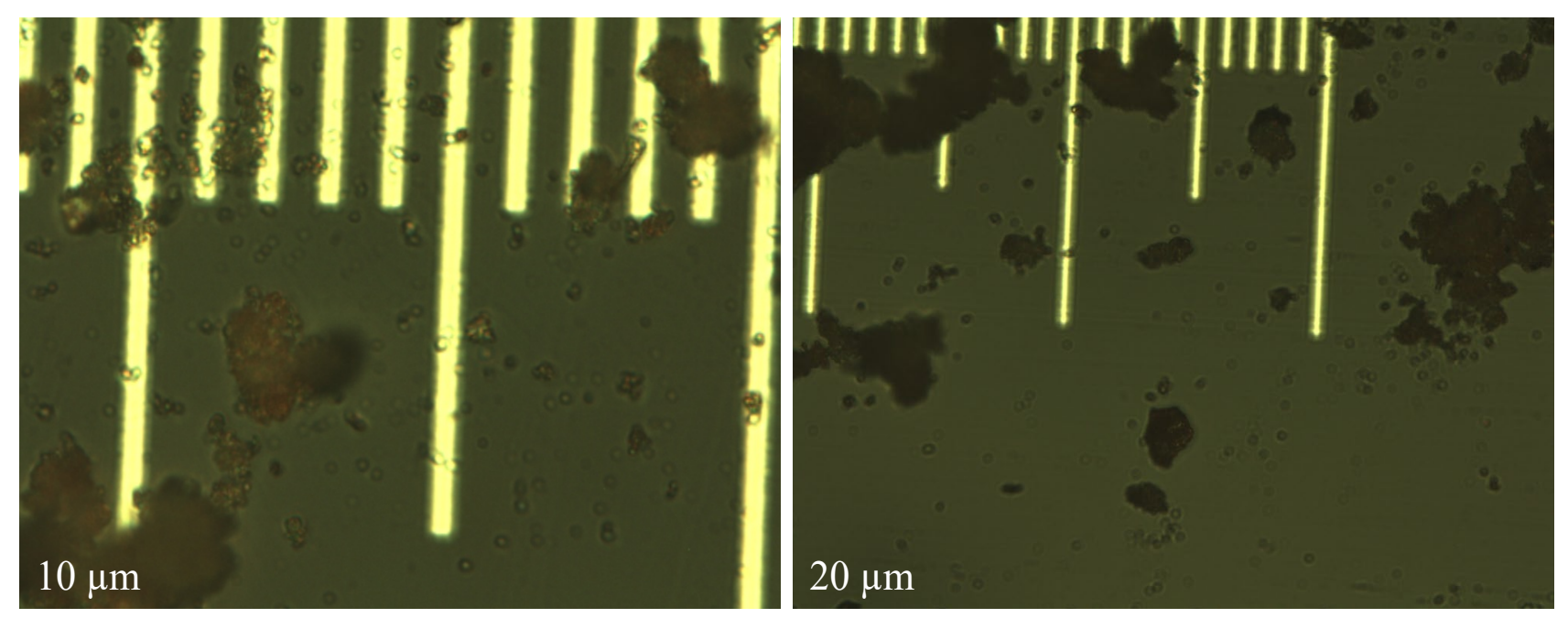

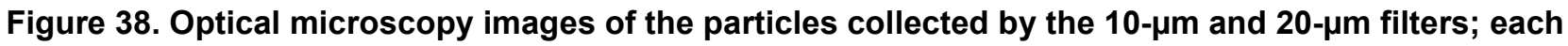 minor tick mark in the image is $1 \mu \mathrm{m}$}

The next step is to investigate the size of the particles captured by the filters and the particles remaining in the filtered salt. Figure 38 shows the particles collected on the $10-\mu \mathrm{m}$ and $20-\mu \mathrm{m}$ filters. It is intriguing to see that (1) the larger "particles" are mostly made of agglomerations of small particles at roughly 100-200 nm size, (2) the size of the small particles is fairly consistent in both optical microscopy images. The former raises the question that why $<1 \mu \mathrm{m}$ particles can be captured by $10-\mu \mathrm{m}$, $20-\mu \mathrm{m}$, and $25-\mu \mathrm{m}$ filters. A plausible explanation is that the horizontally placed filters trapped some salt liquid in the lower half of the filter casing, and the small particles simply came from the molten salt that didn't pass the filters. Given the dimension of the filter casing (see Figure 35), roughly 10-15 $\mathrm{ml}$ of molten salt can be trapped in the lower half of the cylindrical casing (see Figure 39). $10 \mathrm{ml}$ of molten salt (with density of around $1.6 \mathrm{~g} / \mathrm{cm}^{3}$ at a transfer temperature of $\sim 570^{\circ} \mathrm{C}$ ) at $0.045 \mathrm{wt} . \%$ particulate loading is $7.2 \mathrm{mg}$, which accounts for about $52 \%$ and $39 \%$ of the particle weights in Table 16 for the $10-\mu \mathrm{m}$ and $20-\mu \mathrm{m}$ filters, respectively. Considering that the metal shards also introduced errors in the weight measurement of the particles, it is possible that the 10$\mu \mathrm{m}$ filter and $20-\mu \mathrm{m}$ filter captured much fewer particles than what the weight measurement suggested. The same theory

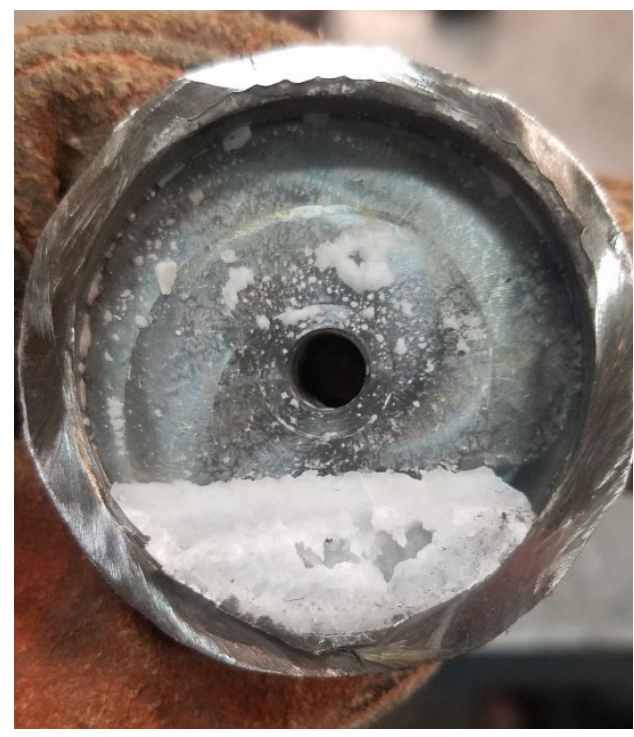

Figure 39. Trapped salt in the $20-\mu \mathrm{m}$ filter casing 
cannot be applied to the particle weight on the $25-\mu \mathrm{m}$ filter because the measured weight is much higher at $108.81 \mathrm{mg}$, suggesting that the $25-\mu \mathrm{m}$ filter is much more effective at capturing particles. UW manually counted the large particles on the $25-\mu \mathrm{m}$ filter and found that there were much more particles in the 5-10 $\mu \mathrm{m}$ range. However, we should still be very cautious to believe smaller particles can be removed by $10-\mu \mathrm{m}, 20-\mu \mathrm{m}$ and $25-\mu \mathrm{m}$ filters. Similar particle analysis in the filtered salt confirmed such concern. Figure 40 shows the particles collected from the filtered salt. The majority was the fine particles (the ones seen in Figure 38), which were compacted to a solid plate-like structure due to drying (the dark background structure). On the bright side, only a few large particles above $5 \mu \mathrm{m}$ in size were found, which indicates that the particle settling and filtration combined is effective at removing large particles from the system.
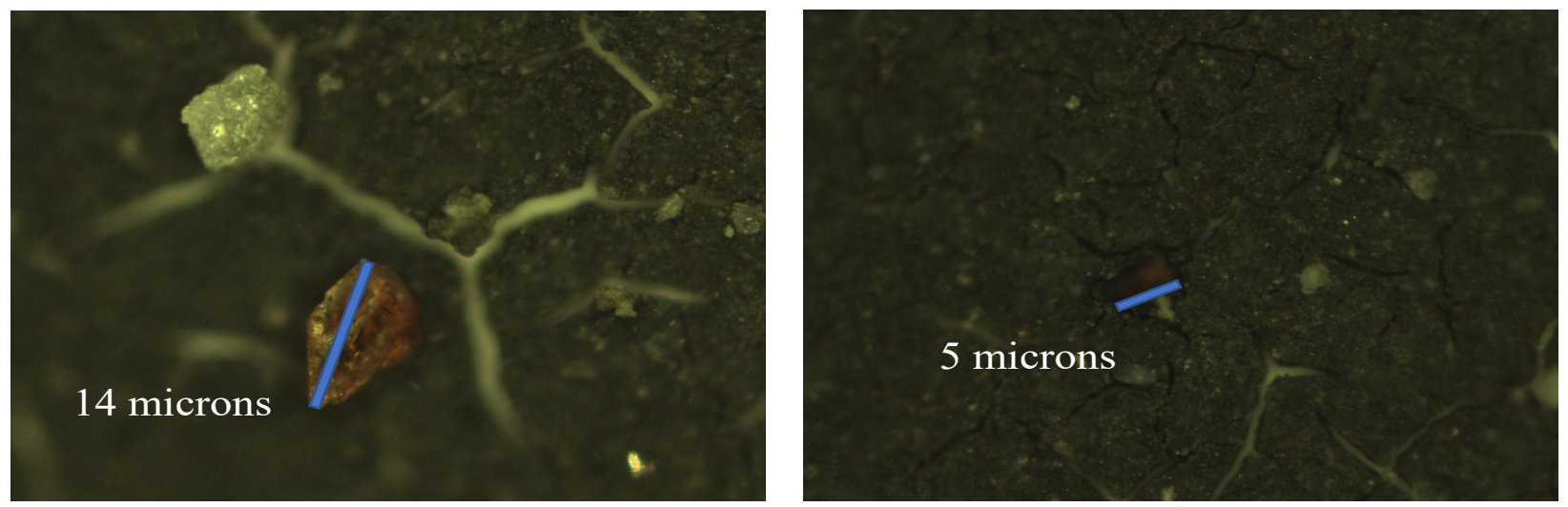

Figure 40. Optical microscopy images of the filtered salt with only a few large particles ( $\geq 5 \mu \mathrm{m}$ )

Our interpretations of the filtration experiments are summarized below.

1. A salt transfer rate of $58.8 \mathrm{~g} / \mathrm{s}$, or $35.8 \mathrm{ml} / \mathrm{s}$ assuming $1.6 \mathrm{~g} / \mathrm{cm}^{3}$ density, can be achieved at a transfer temperature of $575^{\circ} \mathrm{C}$ without filter clogging.

2. The filters are not very effective at reducing particulate loading in the purified salt, whereas particle settling is much more effective. This can be an advantage because there will be less concern with filter clogging.

3. We believe that the main function of the filters is to capture large particles as long as effective particle settling can occur beforehand. This may be achieved by using only one filter size (e.g., $25 \mu \mathrm{m}$ ).

4. The measured particle size in the filtered salt is very small, which contradicts the particle size analysis results by NREL (Figure 32). The submicron particles found in UW's optical microscope images agree better with Kashani-Nejad et al. [40], who stated that the median diameter $\mathrm{d}_{50}$ of $\mathrm{MgO}$ from $\mathrm{MgOHCl}$ thermal decomposition (one major mechanism to form $\mathrm{MgO}$ ) is $510 \mathrm{~nm}$. The discrepancy may be due to particle agglomeration in NREL's analysis, 
although a 2-min ultra-sonication was used before the particle size analysis to minimize agglomeration.

\subsection{Corrosion Testing and Effect of $\mathrm{Mg}$}

Corrosion tests were performed in two types of raw salts, dehydrated carnallite and AC, which are subject to different thermal and chemical treatments prior to corrosion.

\section{Corrosion at $800^{\circ} \mathrm{C}$ for 100 Hours in Ni Crucibles}

Haynes 230, supplied by Haynes International, was cut by a waterjet cutter into coupons with dimensions of $25.6 \mathrm{~mm}$ (length), $12.8 \mathrm{~mm}$ (width), and $1.6 \mathrm{~mm}$ (thickness). The coupon surfaces were lightly polished with 120-grit sandpaper in water prior to corrosion tests. A 3.1-mm-diameter hole was drilled at the center of the Ni crucible cover to form a mechanism to hang the Haynes coupons on a Ni wire (99.98\%, 1-mm diameter, Goodfellow NI005171) into the molten chloride salt. A 250-mL $\mathrm{Ni}$ crucible (Sigma-Aldrich Z246581) and a Ni crucible cover (Sigma-Aldrich Z245700) were used as the corrosion vessel. The crucible and cover were used as received without special treatment. The schematic in Figure 41 shows the details of the corrosion vessel setup. We used a combination of alumina tube $(3.08-\mathrm{mm}$ outer diameter, $1.53-\mathrm{mm}$ inner diameter, CoorsTek), alumina plate (2-mm thickness, CoorsTek), and quartz disc (25.4-mm diameter with a 3.2-mm-diameter center hole,

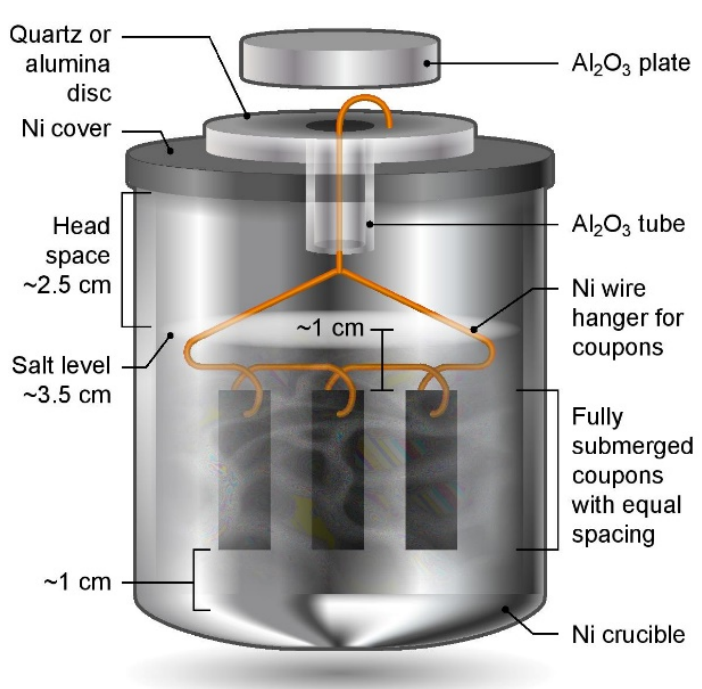

Figure 41. Schematic of the corrosion vessel setup (not to scale) showing all components and spatial arrangement of Haynes 230 coupons and salts for corrosion tests. Mg chips are blended into the salt mixture. AdValue Technology FQ-D-1N-N1/16) to prevent galvanic coupling between Haynes 230 coupons and the Ni crucible/cover. The spacing between Haynes 230 coupons was about $1 \mathrm{~cm}$ to allow ample space to minimize mass-transfer limitation during corrosion testing. The corrosion setup was then assembled according to Figure 41 . The assembly was next placed into a stainless-steel 309 (SS 309) bag (McMaster 3438K13). A piece of Ta foil (0.0127-mm thickness, certified pinhole-free, $99.95 \%$ trace metals basis, BeanTown Chemical) was inserted into the stainless-steel bag, on top of the assembly, serving as an oxygen getter. The opening of the stainless-steel bag was folded to avoid excess release of vapor from the corrosion vessel to the furnace test vessel during the corrosion test. The entire assembly was completed in the glove box under ultra-high-purity nitrogen atmosphere and then transferred into the furnace test vessel within a few minutes. The furnace test vessel was sealed from ambient atmosphere with a grafoil gasket. The furnace test vessel was pumped down to $-0.08 \mathrm{MPa}$ and refilled with nitrogen gas (ultra-high-purity, Airgas) at least three times to remove oxygen and moisture, after which ultra-high-purity nitrogen gas was flowed continuously at $150 \mathrm{sccm}$ during corrosion. The heating schedule shown in Table 17 was used for all corrosion tests. 
Table 17. Heating Schedule for the 100 -Hour Corrosion Test at $800^{\circ} \mathrm{C}$

\begin{tabular}{|c|c|c|}
\hline $\begin{array}{c}\text { Salt Temperature Range } \\
\left({ }^{\circ} \mathbf{C}\right)\end{array}$ & $\begin{array}{c}\text { Ramp Rate } \\
\left({ }^{\circ} \mathbf{C} / \mathbf{m i n}\right)\end{array}$ & $\begin{array}{c}\text { Hold Time } \\
(\text { Hour })\end{array}$ \\
\hline $25-140$ & 5 & 8 \\
\hline $140-800$ & 5 & 100 \\
\hline $800-25$ & Natural cooling & Not applicable \\
\hline
\end{tabular}

After corrosion testing, the assembly was transferred to the glove box and the corroded Haynes

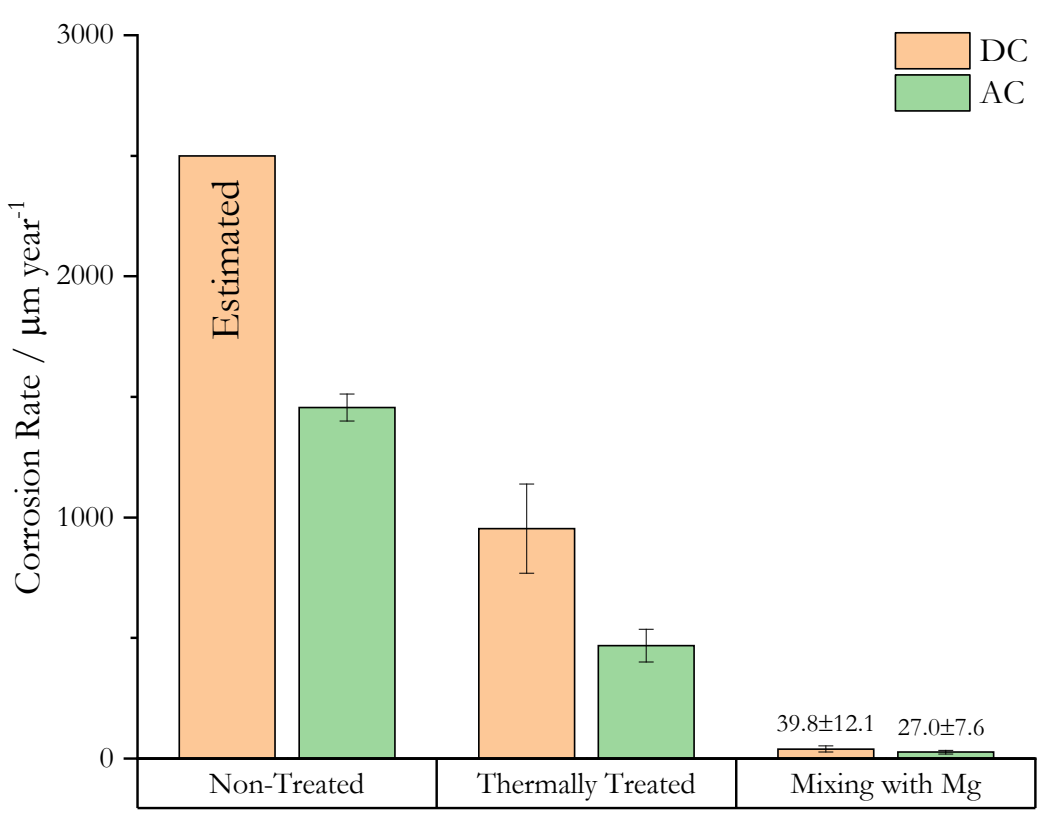

Figure 42. Corrosion rates of Haynes 230 with dehydrated carnallite (DC) and AC salts subject to different treatments. Corrosion tests were performed in a Ni crucible.
230 coupons were carefully retrieved after breaking down the solidified salt. Next, the Haynes 230 coupons were taken out of the glove box, immersed in deionized (DI) water, and ultrasonicated for $15 \mathrm{~min}$ to remove residual salt. After ultrasonication, the coupons were rinsed with ethanol, dried, and stored in a desiccator. The coupons were cut by a diamondblade saw about 6-7 $\mathrm{mm}$ from the short edge. The cut surface was mounted in phenolic resin and polished to a mirror finish for metallographic characterization with scanning electron microscopy (SEM) and energy-dispersive spectroscopy (EDS). The corrosion rates $C_{1}$

defined as the loss of metal surface thickness per unit time (e.g., $\mu \mathrm{m} /$ year) is given by Eq. 23 based on the initial metal-coupon surface area $(A)$, the weight change of the metal coupons during corrosion test $(\Delta W)$, corrosion time $(t)$, and metal density $(\rho)$ assuming that uniform corrosion occurred on the Haynes 230 coupons and that there was no change of corrosion mechanism(s).

$$
C_{1}=\Delta W / \rho A t
$$

Figure 42 shows the results of corrosion in dehydrated carnallite and $\mathrm{AC}$ with three types of treatments:

1. Raw salt with no treatment.

2. Raw salt subject to a thermal treatment by following a reported salt purification procedure [28] using a stepwise dehydration process at $117^{\circ} \mathrm{C}$ for 8 hours, $180^{\circ} \mathrm{C}$ for 8 hours, $240^{\circ} \mathrm{C}$ for 2 hours, $400^{\circ} \mathrm{C}$ for 1 hour, and $600^{\circ} \mathrm{C}$ for 1 hour.

3. Raw salt mixed with Mg chips (1.7 wt.\% for dehydrated carnallite and $0.25 \mathrm{wt} . \%$ for AC). 
It is very clear that a reported thermal salt treatment can significantly reduce corrosion rates. But note that the reported thermal treatment is not specifically developed for AC salt ${ }^{71}$; therefore, the corrosion rates shown in Figure 42 can be further improved. For example, Figure 13 shows that at least 2 hours of purification is needed at a temperature of $670^{\circ}-680^{\circ} \mathrm{C}$, which suggests that the "thermally treated" salt (at a maximum temperature of $600^{\circ} \mathrm{C}$ for only 1 hour ${ }^{72}$ ) used in the corrosion tests is not thoroughly purified, hence contributing to a higher corrosion rate.

Adding Mg chips (0.5-1 wt.\%) into the non-treated raw salt and performing a corrosion test using this salt $/ \mathrm{Mg}$ mixture also produced very low corrosion rates based on mass loss. However, there was electron microscope evidence showing that a $\mathrm{Mg}$ - and O-rich layer was formed on the metal surface when elemental Mg was present in the salt during corrosion. Therefore, we should be cautious to solely rely on mass losses to determine corrosion rates. We also acknowledge that there can be errors associated with the growth of corrosion products at the corrosion interface. Our best estimated error for the "Mixing with Mg" results in Figure 42 is up to $80 \mu \mathrm{m} /$ year based on the most likely type of corrosion product (e.g., MgO) and its thickness (e.g., 5-10 $\mu \mathrm{m}$ ). Regardless of the potential errors, elemental $\mathrm{Mg}$ is certainly reducing the corrosion of Ni-based alloys in a $\mathrm{MgCl}_{2}-\mathrm{KCl}-\mathrm{NaCl}$ ternary molten salt, as expected by its reducing power for $\mathrm{MgOHCl}$ (Eq. 9) and its ability to control the corrosion potential of the salt as reported by the literature $[19,22,23,25]$.

\section{Corrosion at $800^{\circ} \mathrm{C}$ for 100 Hours in Quartz Crucibles}

The corrosion setup was the same as the one shown in Figure 41, except a quartz crucible was used. Two sets of experiments were performed in using AC salt only: (1) corrosion with purified

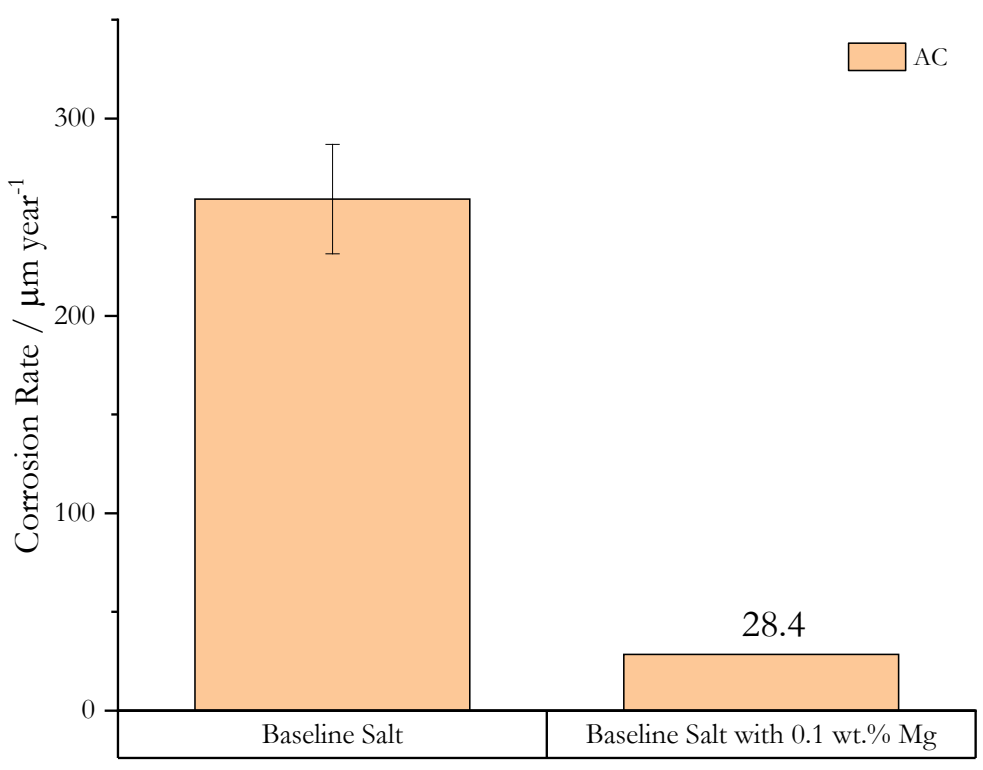

Figure 43. Corrosion rates of Haynes 230 in purified baseline salt and baseline salt with additional $0.1 \mathrm{wt} \% \mathrm{Mg}$. Corrosion tests were performed in a Ni crucible. salt and (2) corrosion with purified salt with additional elemental Mg (only at 0.1 wt.\%). The purpose was to understand the effect of the recommended purification procedure (Table 6) and a small amount of $\mathrm{Mg}$ addition.

The results are shown in Figure 43. It was clear that the baseline salt subject to the recommended purification process further improved corrosion resistance compared the thermally treated AC shown in Figure 42. The baseline salt with 0.1 wt. $\% \mathrm{Mg}$ was similar in magnitude to the best results

\footnotetext{
71 The salt purification protocol/recommendation was not fully developed prior to these corrosion tests.

72 The actual salt purification time at $600^{\circ} \mathrm{C}$ might be shorter than 1 hour because of the lag between furnace set temperature and sample temperature.
} 
in Figure 42. Note that, as mentioned above, the samples for "mixing with $\mathrm{Mg}$ " in Figure 42 did exhibit a surface build-up layer and the corrosion rates were not corrected. The result of "baseline salt with $0.1 \mathrm{wt} . \% \mathrm{Mg}$ " in Figure 43, however, was indeed corrected because a standard acid-cleaning procedure (ASTM G1-90) was performed to remove most surface buildup. The initial weight measurement indicated a mass gain of $\sim 50 \mu \mathrm{m} /$ year before acid cleaning. Note that this net change of $\sim 80 \mu \mathrm{m} /$ year (from a mass gain of $50 \mu \mathrm{m} /$ year to a mass loss around $30 \mu \mathrm{m} /$ year) is also fairly close to our estimation. Assuming a dense, zero-porosity $\mathrm{MgO}$ buildup layer formation covering $50 \%{ }^{73}$ of the coupon surface, a $5-\mu \mathrm{m}$ thickness corresponds to a mass of $6.7 \mathrm{mg}$. Then, a loss of $6.7 \mathrm{mg}$ of the build-up layer due to acid cleaning is equivalent to a change of corrosion rate by $\sim 77 \mu \mathrm{m} /$ year. Therefore, we are more confident that the number in Figure 43 is closer to the real corrosion behavior, which suggests that a very effective corrosion mitigation method is to load a small amount of $\mathrm{Mg}$ into the molten chlorides at the highest temperature allowed by the salt loop $\left(700^{\circ}-750^{\circ} \mathrm{C}\right)$. Although it will complicate the salt loop operation because of $\mathrm{Mg}$ plating on the cold sections of the loop due to lower $\mathrm{Mg}$ solubility at lower temperatures, it can at least serve as an emergency measure when significant excursion occurs in terms of salt quality, which risks the safety of the salt loop.

The other two national labs in the Salt Collective, SRNL and ORNL, performed corrosion tests on $\mathrm{H} 230$ in the baseline salt using the same purification protocol. Ideally, there should be no difference in salt quality. However, various limitations on equipment available to the three national labs may have contributed to the different corrosion rates summarized in Table 18. It is clear that the results do not agree.

Table 18. Summary of Corrosion Results by Three National Labs in the Salt Collective.

Positive corrosion rate is defined by weight loss whereas negative corrosion rate indicates weight gain.

\begin{tabular}{|c|c|c|c|c|c|c|}
\hline \multirow{2}{*}{ Lab } & \multicolumn{2}{|c|}{$\begin{array}{c}\text { Corrosion Rate } \\
(\boldsymbol{\mu m} / \mathbf{y e a r})\end{array}$} & \multicolumn{2}{c|}{$\begin{array}{c}\text { Corrosion Rate } \\
(\mathbf{m g} / \mathbf{c m} \mathbf{)})\end{array}$} & \multicolumn{2}{c|}{$\begin{array}{c}\text { Cr Depletion Depth } \\
(\boldsymbol{\mu m})\end{array}$} \\
\cline { 2 - 7 } & Average & Stdev & Average & Stdev & Average & Stdev \\
\hline NREL & 259.15 & 27.73 & 2.65 & 0.27 & 31.6 & 9.9 \\
\hline SRNL & 80.03 & 4.66 & 0.81 & 0.04 & 24.7 & 6.9 \\
\hline ORNL & -136 & 12.53 & -1.39 & 0.13 & 7.7 & 0.6 \\
\hline
\end{tabular}

The Salt Collective did not produce the same corrosion behavior. Based on information collected from all three labs, the key differences in salt purification are given below.

1. Cover gas: NREL used in-house high-purity $\mathrm{N}_{2}\left(<4 \mathrm{ppm} \mathrm{H}_{2} \mathrm{O},<10 \mathrm{ppm} \mathrm{O}_{2}\right)$. The actual ppm of impurities is lower because NREL used the same gas for a glove box and the gas purifier in the glove box never showed signs of constant increase of $\mathrm{H}_{2} \mathrm{O}$ and $\mathrm{O}_{2}$. The $\mathrm{H}_{2} \mathrm{O}$ and $\mathrm{O}_{2}$ concentrations in the glove box are rarely above $0.5 \mathrm{ppm}$. SRNL used Ar $\left(<10\right.$ ppm $\mathrm{H}_{2} \mathrm{O}$ and $\mathrm{O}_{2}$ ) and ran the gas stream through $\mathrm{H}_{2} \mathrm{O}$ and $\mathrm{O}_{2}$ traps. ORNL used ultra-high-purity (UHP) $\mathrm{Ar}\left(<1\right.$ ppm $\mathrm{H}_{2} \mathrm{O}$ and $\left.\mathrm{O}_{2}\right)$.

\footnotetext{
73 This number is a simple fudge factor that takes into account build-up layer porosity and material, percentage of coupon area covered by the build-up, thickness variation of the build-up layer, efficiency of acid cleaning, etc. For example, a $75 \%$ dense $\mathrm{MgO}$ layer that covers $75 \%$ of the coupon surface area would have a fudge factor of $56.25 \%$.
} 
2. NREL and SRNL used Mg chips (4-30 mesh size) as prescribed by the Salt Purification Protocol whereas ORNL used a single chunk of $\mathrm{Mg}$.

3. ORNL performed all post-purification handling inside a glove box including separation of clean salt from dark bottom sludge. NREL and SRNL, due to limitation of available equipment, had to open the purification furnace vessel, retrieve salt, and separate salt from sludge - all performed in ambient atmosphere before transferring salt into a glove box. The exposure time was $<2.5 \mathrm{~min}$ for SRNL and 5-10 min for NREL.

Two additional corrosion experiments with salt purified by $400 \mathrm{ppm}$ of $\mathrm{Mg}$ were performed at NREL (with $0.1 \mathrm{wt} . \%$ of $\mathrm{Mg}$ added during corrosion). The calculated corrosion rates are about $532.6 \mu \mathrm{m} /$ year and $487 \mu \mathrm{m} /$ year, which suggests that $400 \mathrm{ppm}$ of $\mathrm{Mg}$ during purification is insufficient. The results are very concerning because the corrosion rates are significantly higher even with $0.1 \mathrm{wt} . \%$ of additional $\mathrm{Mg}$ added during corrosion to serve as corrosion potential control. The $0.1 \mathrm{wt} . \%$ of additional $\mathrm{Mg}$ was all consumed, which defeated the purpose of having molten Mg as a corrosion inhibitor. ICP results of the pre-purification salt, top portion of the post-purification salt, and the bottom sludge portion ${ }^{74}$ of the post-purification salt are presented in Table 19. Table 19 provides some insight on which elements are involved in corrosion. The summary is given below:

1. $\mathrm{Al}, \mathrm{Cr}, \mathrm{Fe}, \mathrm{Mn}, \mathrm{Ni}, \mathrm{Cu}$, and $\mathrm{Si}$ are clearly involved because there is a significant concentration increase in the sludge. These elements are all listed as alloying elements for $\mathrm{H} 230$ coupon (at $>0.5 \mathrm{wt} . \%$ ).

2. $\mathrm{S}$ is also involved because there is no mass balance pre- and post-corrosion (i.e., some sulfur is lost). This is confirmed by a strong rotten egg odor after opening the corrosion setup, suggesting that some $\mathrm{S}$ is lost via $\mathrm{S}$-bearing gases such as $\mathrm{H}_{2} \mathrm{~S}$. These gases can be corrosive by themselves or their formation is a result of corrosion.

3. The relative concentration changes for $\mathrm{Ca}, \mathrm{K}, \mathrm{Mg}$, and $\mathrm{Na}$ are small suggesting that they are not involved. The results also agree with thermodynamic understanding because the chloride species with $\mathrm{Ca}, \mathrm{K}, \mathrm{Mg}$, and $\mathrm{Na}$ as cations are the most stable ones. Concentration change for $\mathrm{P}$ is also very minimal, suggesting that $\mathrm{P}$ is not involved in corrosion. ${ }^{75}$ Lastly, the concentration and concentration change for $\mathrm{As}, \mathrm{Ba}, \mathrm{Cd}, \mathrm{Li}, \mathrm{Sr}, \mathrm{V}$, and $\mathrm{Zn}$ are both small, suggesting they are less relevant to corrosion.

\footnotetext{
${ }^{74}$ Observation of sludge is usually an indicator of significant corrosion where the corrosion products rich in $\mathrm{Fe}, \mathrm{Cr}$, $\mathrm{Mn}$, and Ni settle.

75 This seems to answer the question of whether P (or phosphates) is a concern for corrosion.
} 
Molten Chloride Thermophysical Properties, Chemical Optimization, and Purification National Renewable Energy Laboratory

Table 19. ICP Analysis of Pre-Corrosion Salt Purified with 400 ppm Mg, Top Portion of the PostCorrosion Salt and Bottom Sludge of the Post-Corrosion Salt

Empty cells indicate that the measurement is below detection limit. The lack of standard deviation indicates that only one data point is available. The notation " $A$ " or " $R$ " after the name of the element means different spectrum standard used.

\begin{tabular}{|c|c|c|c|}
\hline \multirow[t]{2}{*}{ Element } & Pre-Corrosion & $\begin{array}{c}\text { Post-Corrosion } \\
\text { Top Clear Salt }\end{array}$ & $\begin{array}{l}\text { Post-Corrosion } \\
\text { Bottom Sludge }\end{array}$ \\
\hline & \multicolumn{3}{|c|}{ Average \pm Stdev in ppm } \\
\hline Al 396.153 - A & 4.2 & 3.1 & $11.8 \pm 1.4$ \\
\hline As $188.979-\mathrm{A}$ & $12.9 \pm 3.3$ & $13.5 \pm 0.2$ & $7.7 \pm 0.3$ \\
\hline \multicolumn{4}{|l|}{ B 249.677 - R } \\
\hline Ba $233.527-A$ & $0.8 \pm 0.1$ & $0.7 \pm 0.6$ & \\
\hline \multicolumn{4}{|l|}{ Be 313.107 - R } \\
\hline Ca 317.933 - A & $1119.6 \pm 24.2$ & $1080.6 \pm 141.4$ & $1090.8 \pm 50.6$ \\
\hline Cd $214.440-A$ & 0.1 & 0.1 & $0.4 \pm 0.1$ \\
\hline Cu 324.752 - A & & & $56.7 \pm 29.1$ \\
\hline Cr $205.560-A$ & $1.8 \pm 0.4$ & & $3564.6 \pm 415.3$ \\
\hline Fe 238.204-A & $47.3 \pm 11.3$ & $7.4 \pm 3.3$ & $3493.5 \pm 774.6$ \\
\hline K 766.490 - R & $179826.2 \pm 3733.0$ & $171156.3 \pm 147.0$ & $169302.8 \pm 60.6$ \\
\hline Li 670.784 - R & $6.4 \pm 6.4$ & $6.1 \pm 1.1$ & $12.5 \pm 1.0$ \\
\hline$M g$ 285.213 - R & $101115.6 \pm 32.3$ & $96001.1 \pm 4984.9$ & $108982.1 \pm 4949.3$ \\
\hline Mg 279.077 - R & $100503.5 \pm 164.5$ & $94911.9 \pm 4589.4$ & $106649.5 \pm 4188.9$ \\
\hline $\mathrm{Mn} 257.610-\mathrm{A}$ & $4.1 \pm 0.2$ & $0.6 \pm 0.0$ & $1122.4 \pm 369.7$ \\
\hline \multicolumn{4}{|l|}{ Mo $202.031-\mathrm{A}$} \\
\hline $\mathrm{Na} 589.592-\mathrm{R}$ & $55214.0 \pm 1000.6$ & $52989.6 \pm 5773.5$ & $52372.7 \pm 258.5$ \\
\hline $\mathrm{Ni} 231.604-\mathrm{A}$ & $3.3 \pm 0.2$ & $2.0 \pm 0.9$ & $612.9 \pm 140.7$ \\
\hline P $177.434-A$ & $175.6 \pm 18.9$ & $173.8 \pm 0.7$ & $188.2 \pm 8.5$ \\
\hline \multicolumn{4}{|l|}{$\mathrm{Pb} 220.353-\mathrm{A}$} \\
\hline S $180.669-A$ & $388.1 \pm 20.5$ & $218.3 \pm 27.1$ & $111.1 \pm 51.7$ \\
\hline \multicolumn{4}{|l|}{ Sb 217.582-A } \\
\hline \multicolumn{4}{|l|}{ Se $196.026-A$} \\
\hline Si $251.611-A$ & $25.9 \pm 11.9$ & $15.6 \pm 1.4$ & $231.1 \pm 9.6$ \\
\hline \multicolumn{4}{|l|}{ Sn $189.927-\mathrm{A}$} \\
\hline Sr 460.733 - A & $1.8 \pm 0.0$ & $1.8 \pm 0.2$ & $1.8 \pm 0.1$ \\
\hline Ti $334.940-\mathrm{A}$ & & & $1.5 \pm 0.3$ \\
\hline \multicolumn{4}{|l|}{ TI 190.801-A } \\
\hline V $292.402-A$ & $9.8 \pm 0.5$ & $8.3 \pm 0.5$ & $10.6 \pm 1.7$ \\
\hline Zn 213.857 - A & $11.3 \pm 0.5$ & $9.8 \pm 0.5$ & $8.4 \pm 0.4$ \\
\hline
\end{tabular}

A relevant topic of corrosion mitigation by $\mathrm{Mg}$ is the effectiveness of solid $\mathrm{Mg}$. The foreseen issues are that (1) Mg solubility should be lower when temperature decrease, although neither experimental nor theoretical evidence was available to confirm the $\mathrm{Mg}$ solubility in a ternary $\mathrm{MgCl}_{2}-\mathrm{KCl}-\mathrm{NaCl}$ salt below $\mathrm{Mg}$ 's melting point of $650^{\circ} \mathrm{C}$, and (2) reaction kinetics for reactions such as Eq. 9 should be slower. Both should lead to a less effective corrosion mitigation.

However, this is only speculation, because no kinetic information is available from the literature. Regardless of the lack of understanding, it is very necessary to consider this solution of using solid Mg in the cold section(s) of a salt loop for corrosion mitigation to avoid Mg plating. Recent results from an ORNL thermal convection loop test seem to indicate that this type of strategy is working. 


\section{Cr Depletion Depth}

Cr depletion depth of the $\mathrm{Cr}$ depletion zone was used as a second metric for corrosion because (1) there can be potential errors when relying on mass changes to calculate corrosion rates, and (2) Cr depletion has been reported by the Salt Collective as a major corrosion mechanism in $\mathrm{MgCl}_{2}-\mathrm{KCl}-\mathrm{NaCl}$ salt. Note that using $\mathrm{Cr}$ depletion also has its limitation, as illustrated in Figure 44. Because we did not observe corrosion or measure $\mathrm{Cr}$ depletion in-situ, there was not an absolute reference point to locate the initial metal surface in the post-corrosion samples. The metric is informative only when the observed base metal surface is at the same (or close) location, as in the as-received condition, which usually means light or mild corrosion. Therefore, we cautiously only reported $\mathrm{Cr}$ depletion for corrosion with baseline salt and baseline salt with $0.1 \mathrm{wt} . \%$ of $\mathrm{Mg}$ addition when corrosion is considered light to mild.

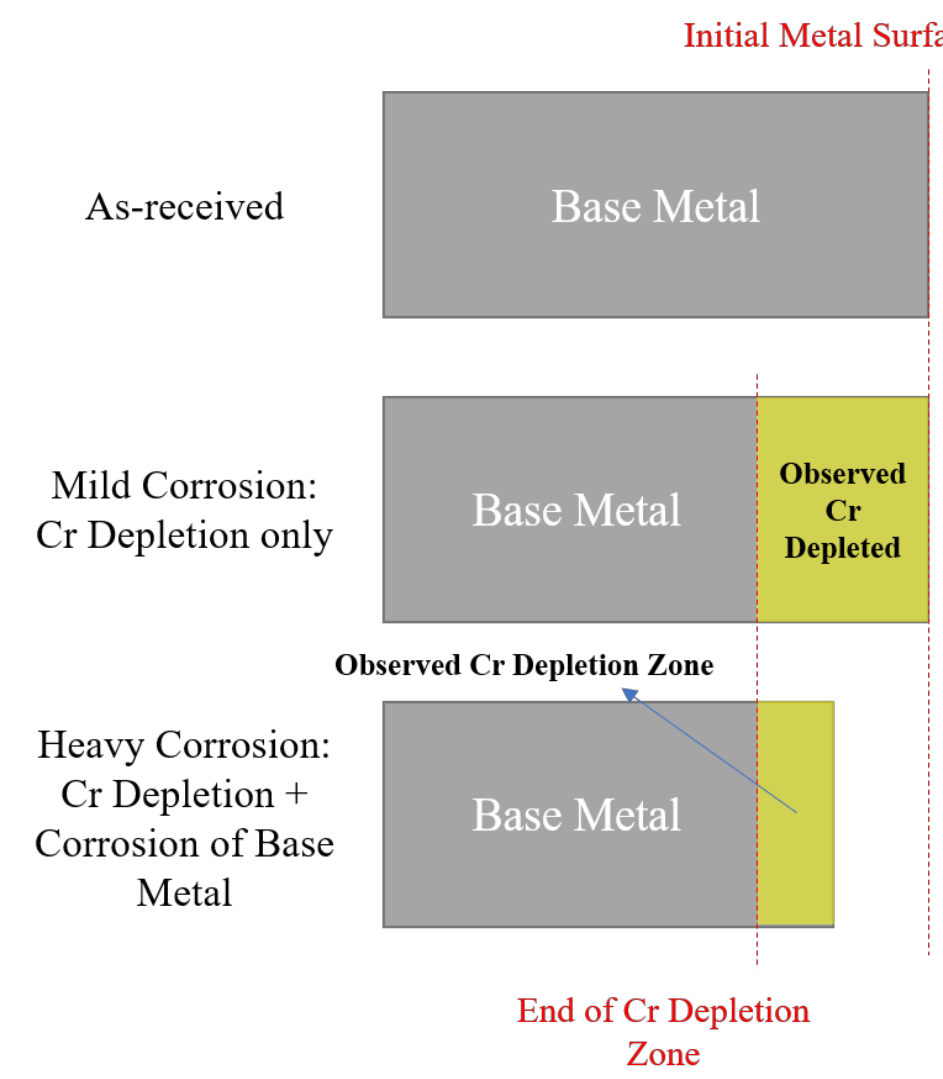

Figure 44. Illustration of corrosion surface and $\mathrm{Cr}$ depletion showing the limitation of using $\mathrm{Cr}$ depletion as a metric in the case of heavy corrosion

Table 20 summarizes $\mathrm{Cr}$ depletion depth for corrosion in baseline salt and baseline salt with 0.1 wt.\% of $\mathrm{Mg}$. The effect of even a small amount of $\mathrm{Mg}$ during corrosion at $800^{\circ} \mathrm{C}$ to reduce corrosion is reflected by a three- to four-fold reduction in $\mathrm{Cr}$ depletion depth. 
Table 20. Cr Depletion Depth for Hayne 230 Samples Corroded in Baseline Salt and Baseline Salt with $0.1 \mathrm{wt} . \%$ of Mg Addition

\begin{tabular}{|c|c|c|c|}
\hline \multirow{2}{*}{ Salt } & $\begin{array}{c}\text { Cr Depletion } \\
\text { Depth }\end{array}$ & Average & Stdev \\
\cline { 2 - 2 } & \multicolumn{2}{|c|}{$\boldsymbol{\mu m}$} \\
\hline \multirow{3}{*}{ Baseline $^{76}$} & 20.2 & \multirow{2}{*}{31.6} & \multirow{2}{*}{9.9} \\
\cline { 2 - 2 } & 37.8 & \multirow{2}{*}{8.0} & \multirow{2}{*}{0.6} \\
\hline $\begin{array}{c}\text { Baseline }+ \\
0.1 \text { wt. \% Mg }\end{array}$ & 76.8 & & \\
\cline { 2 - 2 } & 7.6 & & \\
\hline
\end{tabular}

Figure 45 shows a typical $\mathrm{Cr}$ profile across the corrosion interface in Haynes 230 corroded in baseline salt with $0.1 \mathrm{wt} . \%$ of $\mathrm{Mg}$ addition. This sample has been cleaned with acid to more

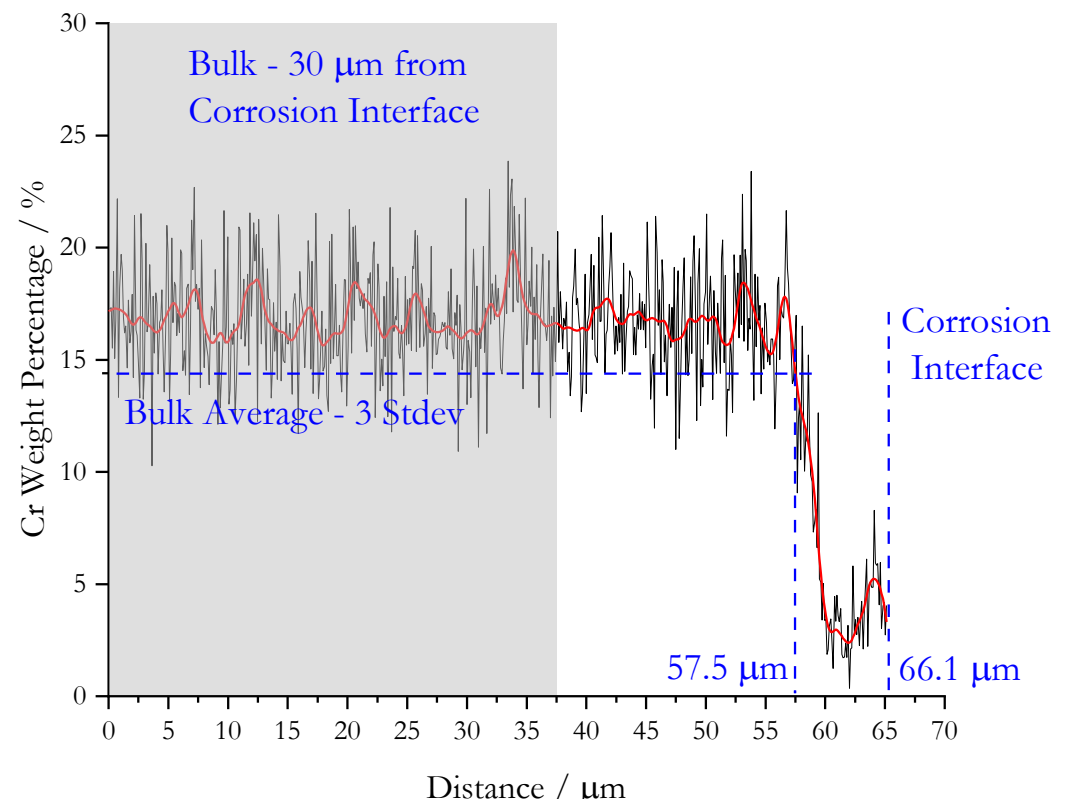

Figure 45. Cr profile across the corrosion interface of a $\mathrm{H} 230$ sample corroded in the baseline salt with $0.1 \mathrm{wt} . \%$ of $\mathrm{Mg}$ addition easily identify the corrosion interface. The $\mathrm{Cr}$ depletion depth is defined as the distance between the visually identified corrosion interface in the SEM image and the location where $\mathrm{Cr}$ concentration is 3 standard deviations below the bulk average (defined as at least 30 $\mu \mathrm{m}$ away from the corrosion interface where there is no sign of corrosion). Note that this definition also has its limitation in some extreme cases when $\mathrm{Cr}$ concentration decrease is very gradual in the $\mathrm{Cr}$ depletion zone or the magnitude of $\mathrm{Cr}$ depletion is small. This is not considered an error. It only affects our interpretation of $\mathrm{Cr}$ depletion given this definition especially when comparison across labs is needed. So, as long as all labs use the same definition and the Cr profile is similar, we don't foresee significant systematic errors.

Figures 46 and 47 show the SEM images of a Haynes 230 coupon after corrosion in baseline salt and baseline salt with $0.1 \mathrm{wt} . \%$ of $\mathrm{Mg}$ addition, respectively. We can see that both images show

\footnotetext{
${ }^{76}$ SRNL reported $24.7 \pm 6.9 \mu \mathrm{m}$ based on 8 measurements and ORNL reported $7.7 \pm 0.6 \mu \mathrm{m}$ based on 3 measurements. The corresponding mass change corrosion rates were $80.0 \pm 4.7 \mu \mathrm{m} /$ year and $-136.0 \pm 12.5 \mu \mathrm{m} / \mathrm{year}$ for SRNL and ORNL, respectively. The baseline salts were made at SRNL and ORNL following the purification procedure with necessary modifications to accommodate each lab's capability. These modifications may be the source of discrepancy among NREL, SRNL and ORNL.
} 


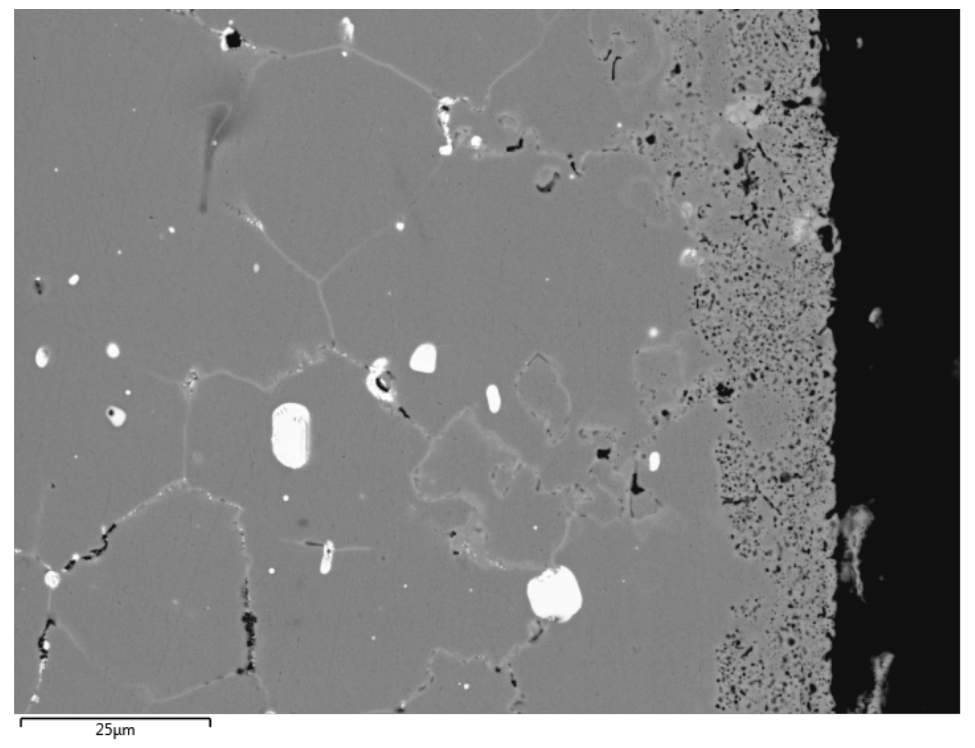

Figure 46. SEM image of the corrosion interface of a Haynes $\mathbf{2 3 0}$ coupon corroded in baseline salt a clear porous layer around the corrosion interface and there is a significant reduction of the porous layer thickness with $0.1 \mathrm{wt} . \%$ of $\mathrm{Mg}$ addition. In both cases, the thickness of the visually porous layer corresponds to the reported $\mathrm{Cr}$ depletion depth shown in Table 20. It suggests that $\mathrm{Cr}$ depletion indeed left a porous metal structure in the base metal, as suggested by the work of the Salt Collective and by recent literature [21,22]. In addition, 0.1 wt. $\% \mathrm{Mg}$ addition almost completely prevented $\mathrm{Cr}$ leaching through grain boundaries. ${ }^{77}$ The bright particles of a size about 5-10 $\mu \mathrm{m}$ in Figures 46 and 47 are found to be $\mathrm{W}$-rich carbides,

which is a signature microstructure observed in Hayne 230 corrosion in molten $\mathrm{MgCl}_{2}-\mathrm{KCl}-\mathrm{NaCl}$ reported by the Salt Collective and in the literature [21,22].

\section{Corrosion Summary}

Investigation of Hayne 230 corrosion in molten $\mathrm{MgCl}_{2}-\mathrm{KCl}-\mathrm{NaCl}$ suggests that:

1. The corrosion behavior can be sensitive to salt preparation. Although the Salt Collective intended to unify the salt purification procedure, small intentional (e.g., limited by availability of instruments and materials) or unintentional deviations (e.g., experimental errors) led to discrepancies of results from NREL, SRNL, and ORNL that cannot be easily explained.

2. The effectiveness of $\mathrm{Mg}$ addition has been proved by multiple independent corrosion tests. $^{78}$ Therefore, using Mg at high temperature can be an emergency measure when the salt degrades rapidly due to moisture ingress, etc.

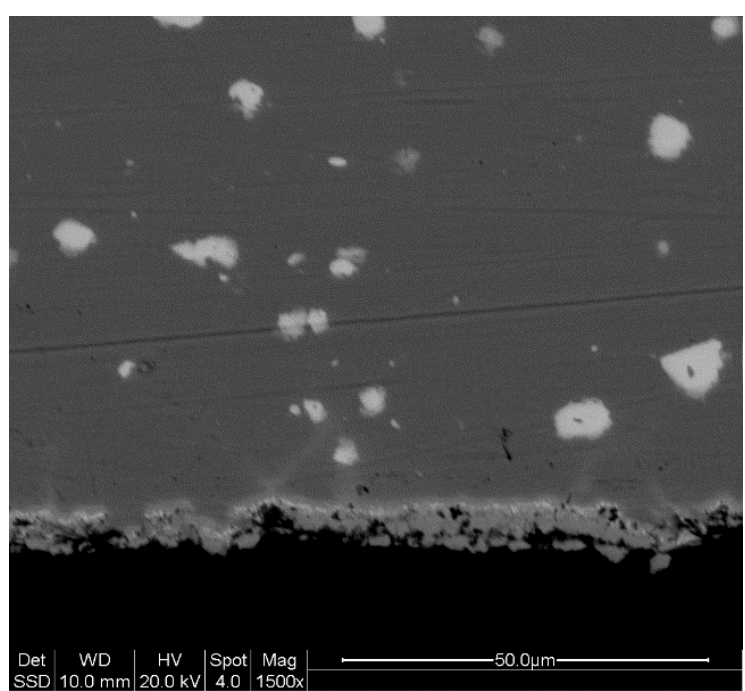

Figure 47. SEM image of the corrosion interface of a Haynes 230 coupon corroded in baseline salt with $0.1 \mathrm{wt} . \%$ of $\mathrm{Mg}$ addition

3. $\mathrm{Mg}$ solubility in similar molten chlorides is

known to decrease with temperature. Therefore, the effectiveness of using solid $\mathrm{Mg}$ as

\footnotetext{
${ }^{77} \mathrm{Cr}$ leaching through grain boundary leaching is indicated by the bright network-like lines in Figure 46. Figure 47 shows no such behavior.

${ }^{78}$ A separate NREL project investigating additively manufactured Haynes 230 (AM H230) also had very similar results. There was a normal wrought H230 coupon as control sample in all corrosion tests.
} 
corrosion mitigation at low temperature is a critical piece of information for the loop operation, considering the complications of allowing excessive molten $\mathrm{Mg}$ circulating in the entire loop and precipitating during liquid-solid transformation.

\section{Conclusions}

Using anhydrous carnallite (AC) as a more premium-grade carnallite from ICL with lower water content (as opposed to dehydrated carnallite with higher water content) is found to be essential in simplifying system and subcomponent design because of lower risks of corrosion damage during salt preparation. The project team has successfully developed a batch-style salt pre-drying and purification process at lab scale to process AC and halite. So far, the biggest batch is $\sim 8 \mathrm{~kg}$. This process has the potential to be scaled up and converted to a continuous-style process to suit industrial needs. Our ongoing relationship with an industrial salt melter designer is using the principles and measured parameters to design a melter for Topic 1 Liquid Pathway CSP that aims to process AC and SPK halite at $1 \mathrm{Mt} / \mathrm{hr}$.

The purification process also optimizes the salt to achieve a local eutectic composition with a low liquidus temperature around $400^{\circ} \mathrm{C}$. Without any composition shift, the salt freezing point should not exceed this temperature, which provides a $\sim 100^{\circ} \mathrm{C}$ safety margin for the primary heat exchanger and $\mathrm{SCO}_{2}$ power cycle that operate as low as $500^{\circ} \mathrm{C}$. The key thermophysical properties have been measured by NREL and partners from the University of Arizona and the University of Wisconsin-Madison. Thermophysical properties as a function of temperature between $450^{\circ} \mathrm{C}$ and $750^{\circ} \mathrm{C}$ are provided to the Gen 3 molten salt pathway community for system and subcomponent design. The key findings are (1) most properties (including salt freezing point) are not very sensitive to a composition shift (within a few wt.\%), which gives us more flexibility to tolerate unwanted changes in the salt, and (2) vapor pressure is considered a major source of risk because the risk has not been identified before and no more information is available.

Limited salt degradation during exposure to moisture at lab scale is surprising. Possible explanations are that (1) the level of moisture introduced is still relatively low at $\sim 400 \mathrm{ppm},(2)$ the temperature at which the moisture is introduced is high such that moisture may prefer to leave the system instead of interact with the molten salt, and/or (3) there are no metal parts in the salt melt such that there is little chance for us to directly observe salt degradation. Therefore, we need to take extreme caution when interpreting and applying the results as real-scale moisture ingress can be very different in nature (which usually occurs at a location where moisture, salt and metals all participate, leading to significant corrosion damage).

The particle size distribution is measured by NREL after salt melting/purification and by UW after similar salt melting/purification and subsequent filtration by $25-\mu \mathrm{m}, 20-\mu \mathrm{m}$ and $10-\mu \mathrm{m}$ stainless-steel filters. We found that particle settling is more effective at reducing weight fraction of particles. In addition, settling combined with filtration with $25-\mu \mathrm{m}, 20-\mu \mathrm{m}$, and $10-\mu \mathrm{m}$ filters is effective at reducing particle size too-in other words, most of the large particles $(>10 \mu \mathrm{m})$ have been eliminated. The particles that remained in the salt are mostly below $1 \mu \mathrm{m}$ as revealed by UW's optical microscopy analysis. This contradicts with NREL's particle size analysis by a laser-based analyzer, which might have been affected by particle agglomeration. But, we are optimistic that if the temperature profile and liquid flow pattern of a salt melter with a series of 
filters can be carefully designed and/or controlled, the risk of large $\mathrm{MgO}$ particles to the salt loop can be minimized.

Corrosion tests are performed on Haynes 230 at $800^{\circ} \mathrm{C}$ for 100 hours with salts subject to different purification treatments. Although the magnitude of corrosion with the purified baseline salt is not as low as the DOE's target of $<25 \mu \mathrm{m} /$ year, a viable pathway toward achieving much higher corrosion resistance is the use of elemental $\mathrm{Mg}$ as a corrosion inhibitor.

\section{Recommendations}

Although the results from this 2-year project suggest a path toward using molten $\mathrm{MgCl}_{2}-\mathrm{KCl}$ $\mathrm{NaCl}$ as the heat transfer fluid and thermal energy storage medium for next-generation CSP applications, there are a few areas for improvement in order to further de-risk the liquid pathway CSP technology.

1. Guarantee of raw material quality. One of the biggest uncertainties is the variations of salts provided by salt suppliers. The project team has devoted significant efforts to mitigate salt corrosivity, dehydrate physically absorbed moisture and chemical hydrates, minimize $\mathrm{HCl}$ and $\mathrm{H}_{2}$ generation, settle and filter $\mathrm{MgO}$ particles, etc., which are all related to the initial water content of the salt. The primary assumption that drives the research effort is that the salt tested during the 2-year period is representative of what will be used for the pilot-scale test unit and future commercial-scale plant. However, to our best knowledge, all teams in the Salt Collective use salts that have been more or less affected by moisture absorption during storage at the supplier's warehouse, shipping, and/or storage prior to experiments by each team. This makes the assumption less valid. Also, the actual behaviors can vary significantly and be sensitive to the salt quality. For example, the $\mathrm{H}_{2}$ and $\mathrm{HCl}$ generation might differ by more than $10 \mathrm{x}$ between using salts with $0.5 \mathrm{wt} . \%$ and $2 \mathrm{wt} . \%$ of initial water content. It is uncertain where the real salt will fall onto this wide spectrum. Hence, we highly recommend narrowing down the true quality of the raw materials.

2. Identification of the chemistry of the dominating species in the vapor phase.

a. We can better understand the thermodynamics of evaporation in a complex chloride salt system which should improve the modelling capability if given a new chloride salt composition.

b. We can better understand potential composition shift over time if the composition of the dominating vapor species is not very close to the composition of the salt inventory. The results will be informative to design a salt condensate recovery system.

3. Investigation of vapor phase corrosion. There was observation that vapor phase corrosion or corrosion at the liquid/vapor interface can be as damaging as molten salt corrosion. While molten salt corrosion could be mitigated by $\mathrm{Mg}$ (or possibly by an electrochemical method currently investigated by NREL), the exact extent of vapor corrosion and its mitigation strategy are unknown. With vapor chemistry information obtained in 2), we can design a theoretical and/or experimental study to understand the corrosivity in the vapor phase if we know the major (and minor) species in the salt vapor.

4. Measurement of vapor condensation rate as a function of different parameters that are relevant to the plant (e.g., temperature and geometry of a surface where condensation can 
occur). There are concerns from the system and subcomponent designers that vapor condensation may clog pipelines and valves in the gas treatment system, weigh down and collapse porous thermal insulation materials in the roof of the TES tanks, and/or damage components such as pumps.

5. Longer-term salt exposure to oxygen and moisture ingress. This is necessary to understand the real excursions that can occur in the salt loop. Ideally, this should involve corrosion testing during the exposure tests.

6. Testing of corrosion mitigation strategy in a flowing salt loop. Although our partner at ORNL had tested the use of solid Mg as a corrosion inhibitor in the cold leg of the thermal convection loop, there was still limited information on the corrosion kinetics. ${ }^{79}$ Information of corrosion vs. time with a corrosion mitigation strategy in place is critical for extrapolation to a much longer time that a Gen3 CSP plant needs to operate safely and continuously.

${ }^{79}$ Three loop tests were performed. One loop test ran for a few hundred hours and two ran for 1,000 hours or more. 


\section{Publications}

\section{Published:}

Y. Zhao, N. Klammer, J. Vidal. 2019. "Purification Stategy and Effect of Impurities on Corrosivity of Dehydrated Carnallite for Thermal Solar Applications," RSC Adv. 9, 41664-41671.

N. Klammer, C. Engtrakul, Y. Zhao, Y. Wu, J. Vidal. 2020. "Method to Determine MgO and $\mathrm{MgOHCl}$ in Chloride Molten Salts," Anal. Chem. 92, 3598-3604.

Y. Zhao, J. Vidal. 2020. "Potential Scalability of a Cost-Effective Purification Method for $\mathrm{MgCl}_{2}$ Containing Salt for Next-Generation Concentrating Solar Power Technologies," Sol. Energy Mater. Sol. Cells. 215, 110663.

\section{Submitted:}

X. Wang, J. Del Rincon, P. Li, Y. Zhao, J. Vidal. 2020. “Thermophysical properties experimentally tested for $\mathrm{NaCl}-\mathrm{KCl}-\mathrm{MgCl}_{2}$ eutectic molten salt as next generation high temperature HTF in CSP systems," Submitted to ASME J. Solar Energy Engineering. 


\section{Appendix}
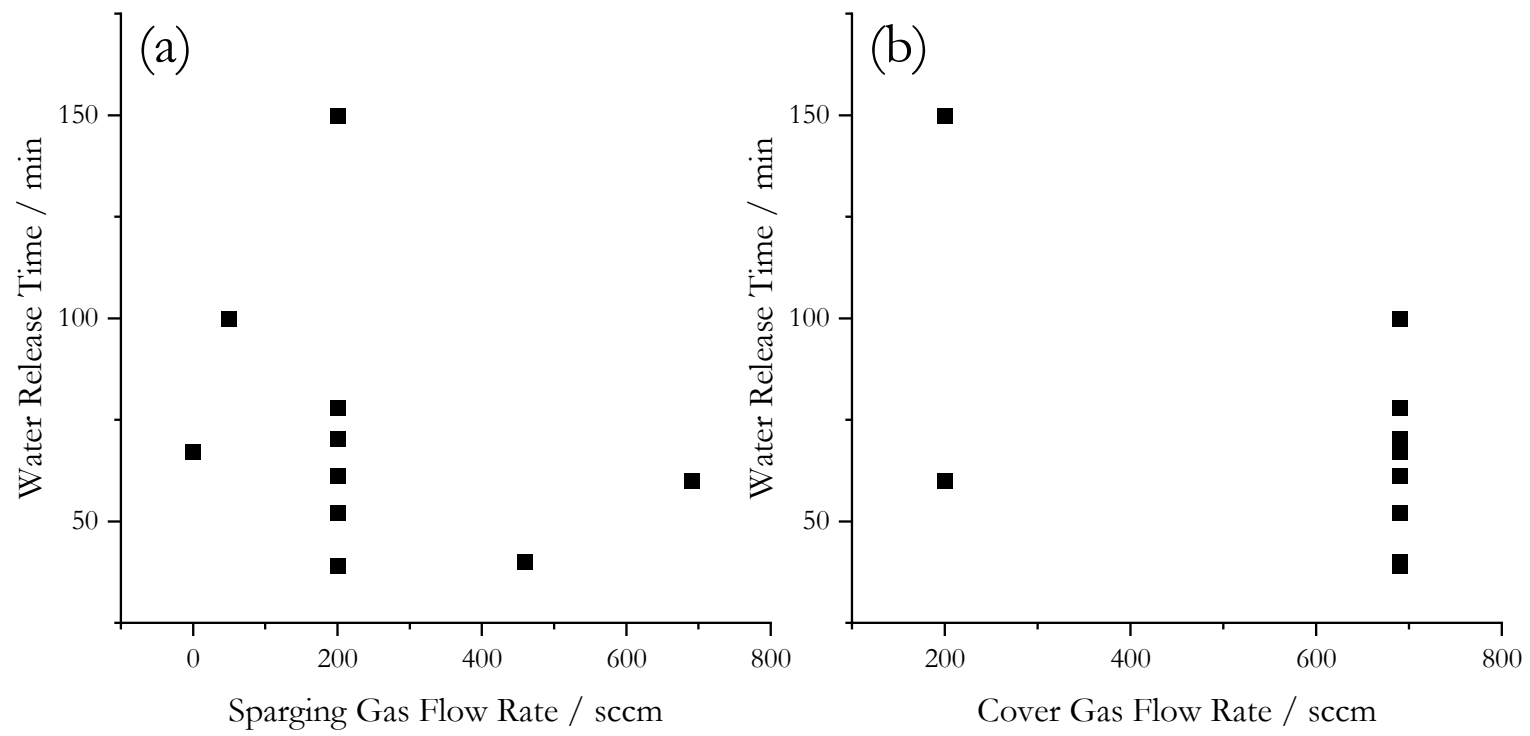

Figure 48. (a) Variation of water release time during salt pre-drying at $275^{\circ}-285^{\circ} \mathrm{C}$ as a function of sparging gas flow rate. (b) Variation of water release time during salt pre-drying at $275^{\circ}-285^{\circ} \mathrm{C}$ as a function of cover gas flow rate.
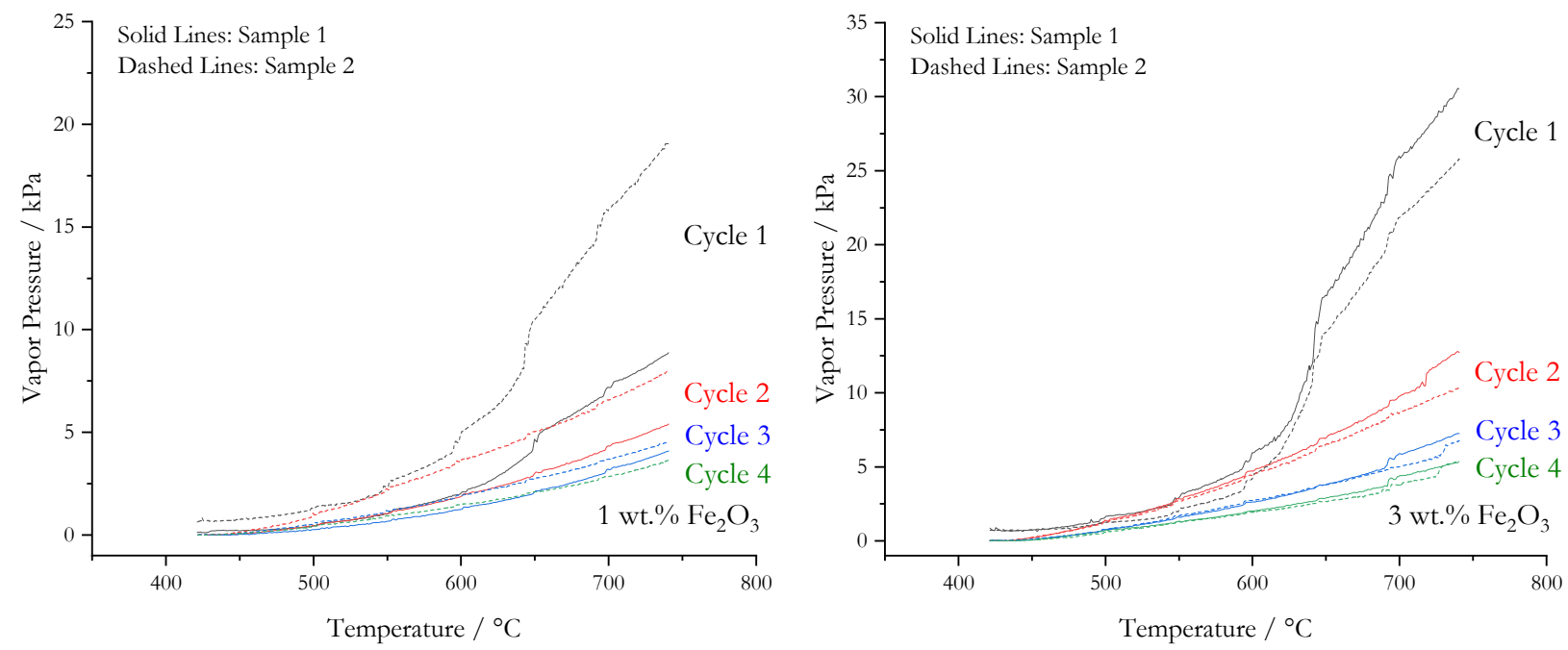

Figure 49. (Left) Vapor pressure for purified salt with 1 wt.\% of $\mathrm{Fe}_{2} \mathrm{O}_{3}$. Two samples were measured given by the solid and dashed lines. Cycles (1-4) were separated by manual removal of volatile species under vacuum. (Right) Vapor pressure for purified salt with $3 \mathrm{wt} . \%$ of $\mathrm{Fe}_{2} \mathrm{O}_{3}$. Two samples were measured given by the solid and dashed lines. Cycles (1-4) were separated by manual removal of volatile species under vacuum. 


\section{References}

[1] M. Mehos, C. Turchi, J. Vidal, M. Wagner, Z. Ma, C. Ho, W. Kolb, C. Andraka, A. Kruizenga, Concentrating Solar Power Gen3 Demonstration Roadmap, 2017. https://doi.org/10.2172/1338899.

[2] D.F. Williams, Assessment of Candidate Molten Salt Coolants for the Advanced NGNP/NHI Heat-Transfer Loop, Oak Ridge, Tennessee, 2006.

[3] P.F. Weck, E. Kim, Solar Energy Storage in Phase Change Materials: First-principles Thermodynamic Modeling of Magnesium Chloride Hydrates, J. Phys. Chem. C. 118 (2014) 4618-4625. https://doi.org/10.1021/jp411461m.

[4] G. Mohan, Development of High-Temperature Sensible Thermal Energy Storage Systems for Advanced Concentrating Solar Power Generation, The Australian National University, 2018.

[5] Y. Li, X. Xu, X. Wang, P. Li, Q. Hao, B. Xiao, Survey and Evaluation of Equations for Thermophysical Properties of Binary/Ternary Eutectic Salts from $\mathrm{NaCl}, \mathrm{KCl}, \mathrm{MgCl} 2$, $\mathrm{CaCl} 2, \mathrm{ZnCl} 2$ for Heat Transfer and Thermal Storage Fluids in CSP, Sol. Energy. 152 (2017) 57-79. https://doi.org/10.1016/j.solener.2017.03.019.

[6] K. Vignarooban, X. Xu, A. Arvay, K. Hsu, A.M. Kannan, Heat Transfer Fluids for Concentrating Solar Power Systems - A review, Appl. Energy. 146 (2015) 383-396. https://doi.org/10.1016/j.apenergy.2015.01.125.

[7] J.C. Vidal, N. Klammer, Molten Chloride Technology Pathway to Meet the U.S. DOE SunShot Initiative with Gen3 CSP, in: AIP Conf. Proc., Morocco, 2019: p. 080006. https://doi.org/10.1063/1.5117601.

[8] X. Xu, X. Wang, P. Li, Y. Li, Q. Hao, B. Xiao, H. Elsentriecy, D. Gervasio, Experimental Test of Properties of KCl-MgCl2 Eutectic Molten Salt for Heat Transfer and Thermal Storage Fluid in Concentrated Solar Power Systems, J. Sol. Energy Eng. 140 (2018) 9. https://doi.org/10.1115/1.4040065.

[9] L. Maksoud, T. Bauer, Experimental Investigation of Chloride Molten Salts for Thermal Energy Storage Applications, in: 10th Int. Conf. Molten Salt Chem. Technol., Shenyang, China, 2015.

[10] W. Ding, A. Bonk, T. Bauer, Corrosion Behavior of Metallic Alloys in Molten Chloride Salts for Thermal Energy Storage in Concentrated Solar Power Plants: A Review, Front. Chem. Sci. Eng. 12 (2018) 564-576.

[11] J.C. Gomez-Vidal, Corrosion Resistance of MCrAlX Coatings in A Molten Chloride for Thermal Storage in Concentrating Solar Power Applications, Nat. Partn. Journals Mater. Degrad. 1 (2017) 1-9. https://doi.org/10.1038/s41529-017-0012-3. 
[12] W. Ding, A. Bonk, J. Gussone, T. Bauer, Cyclic Voltammetry for Monitoring Corrosive Impurities in Molten Chlorides for Thermal Energy Storage, Energy Procedia. 135 (2017) 82-91. https://doi.org/10.1016/j.est.2017.12.007.

[13] J.M. Kurley, P.W. Halstenberg, A. McAlister, S. Raiman, S. Dai, R.T. Mayes, Enabling Chloride Salts for Thermal Energy Storage: Implications of Salt Purity, RSC Adv. 9 (2019) 25602-25608. https://doi.org/10.1039/c9ra03133b.

[14] R.T. Mayes, J. Matthew, K. Phillip, W. Halstenberg, A. McAlister, D. Sulejmanovic, S. Raiman, S. Dai, B. Pint, Purification of Chloride Salts for Concentrated Solar Power Applications, 2018.

[15] A. Gutierrez, S. Ushak, M. Linder, High Carnallite-Bearing Material for Thermochemical Energy Storage: Thermophysical Characterization, ACS Sustain. Chem. Eng. 6 (2018) 6135-6145. https://doi.org/10.1021/acssuschemeng.7b04803.

[16] A.D. Pathak, I. Tranca, S. V. Nedea, H.A. Zondag, C.C.M. Rindt, D.M.J. Smeulders, First-Principles Study of Chemical Mixtures of $\mathrm{CaCl} 2$ and $\mathrm{MgCl} 2$ Hydrates for Optimized Seasonal Heat Storage, J. Phys. Chem. C. 121 (2017) 20576-20590. https://doi.org/10.1021/acs.jpcc.7b05245.

[17] A.D. Pathak, S. Nedea, H. Zondag, C. Rindt, D. Smeulders, A DFT-based Comparative Equilibrium Study of Thermal Dehydration and Hydrolysis of $\mathrm{CaCl} 2$ Hydrates and $\mathrm{MgCl} 2$ Hydrates for Seasonal Heat Storage, Phys. Chem. Chem. Phys. 18 (2016) 10059-10069. https://doi.org/10.1039/c6cp00926c.

[18] W. Ding, H. Shi, Y. Xiu, A. Bonk, A. Weisenburger, A. Jianu, T. Bauer, Hot Corrosion Behavior of Commercial Alloys in Thermal Energy Storage Material of Molten $\mathrm{MgCl} 2 / \mathrm{KCl} / \mathrm{NaCl}$ under Inert Atmosphere, Sol. Energy Mater. Sol. Cells. 184 (2018) 2230. https://doi.org/10.1016/j.solmat.2018.04.025.

[19] W. Ding, A. Bonk, J. Gussone, T. Bauer, Electrochemical Measurement of Corrosive Impurities in Molten Chlorides for Thermal Energy Storage, J. Energy Storage. 15 (2018) 408-414.

[20] W. Ding, H. Shi, A. Jianu, Y. Xiu, A. Bonk, A. Weisenburger, T. Bauer, Molten Chloride Salts for Next Generation Concentrated Solar Power Plants: Mitigation Strategies against Corrosion of Structural Materials, Sol. Energy Mater. Sol. Cells. 193 (2019) 298-313.

[21] H. Sun, J. Wang, Z. Li, P. Zhang, X. Su, Corrosion Behavior of 316SS and Ni-Based Alloys in a Ternary NaCl-KCl-MgCl2 Molten Salt, Sol. Energy. 171 (2017) 320-329.

[22] H. Sun, J.Q. Wang, Z. Tang, Y. Liu, C. Wang, Assessment of effects of Mg treatment on corrosivity of molten NaCl-KCl-MgCl2 salt with Raman and Infrared Spectra, Corros. Sci. 164 (2020) 108350. https://doi.org/10.1016/j.corsci.2019.108350.

[23] B.L. Garcia-Diaz, L. Olson, M. Martinez-Rodriguez, R. Fuentes, H. Colon-Mercado, J. 
Gray, High Temperature Electrochemical Engineering and Clean Energy Systems, J. South Carolina Acad. Sci. 14 (2016) 11-14.

[24] B. Mehrabadi, J.W. Weidner, B. Garcia-Diaz, M. Martinez-Rodriguez, L. Olson, S. Shimpalee, Multidimensional Modeling of Nickel Alloy Corrosion inside High Temperature Molten Salt Systems, J. Electrochem. Soc. 163 (2016) C830-C838.

[25] B.A.T. Mehrabadi, J.W. Weidner, B. Garcia-Diaz, M. Martinez-Rodriguez, L. Olson, S. Shimpalee, Modeling the Effect of Cathodic Protection on Superalloys Inside High Temperature Molten Salt Systems, J. Electrochem. Soc. 164 (2017) C171-C179.

[26] H. Cho, J.W. Van Zee, S. Shimpalee, B.A. Tavakoli, J.W. Weidner, B.L. Garcia-Diaz, M.J. Martinez-Rodriguez, L. Olson, J. Gray, Dimensionless Analysis for Predicting FeNi-Cr Alloy Corrosion in Molten Salt Systems for Concentrated Solar Power Systems, Corrosion. 72 (2016) 742-760.

[27] F. Ullah, M. Ameen, K. Hasrat, Experimental Study on Optimization of Heat Storage and Melting Salts of Solar Energy, J. Food Process. Preserv. (2018) 13685. https://doi.org/10.1111/jfpp.13685.

[28] Y. Zhao, N. Klammer, J. Vidal, Purification Strategy and Effect of Impurities on Corrosivity of Dehydrated Carnallite for Thermal Solar Applications, RSC Adv. 9 (2019) 41664-41671. https://doi.org/10.1039/C9RA09352D.

[29] G.J. Kipouros, D.R. Sadoway, A Thermochemical Analysis of the Production of Anhydrous $\mathrm{MgCl}_{2}$, J. Light Met. 1 (2001) 111-117.

[30] D.L. Maricle, D.N. Hume, A New Method for Preparing Hydroxide-Free Alkali Chloride Melts, J. Electrochem. Soc. 107 (2007) 354.

[31] H.U. Rammelberg, T. Schmidt, W. Ruck, Hydration and Dehydration of Salt Hydrates and Hydroxides for Thermal Energy Storage - Kinetics and Energy Release, Energy Procedia. 30 (2012) 362-369.

[32] H. Kondo, Z. Asaki, Y. Kondo, Hydrolysis of Fused Calcium Chloride at High Temperature, Metall. Trans. B. 9B (1978) 477-483.

[33] K.M. Allal, J.C. Dolignier, G. Martin, Determination of Thermodynamical Data of Calcium Hydroxichloride, Oil Gas Sci. Technol. 52 (1997) 361-368. https://doi.org/10.2516/ogst:1997046.

[34] K.S.P. Karunadasa, C.H. Manoratne, H.M.T.G.A. Pitawala, R.M.G. Rajapakse, Relative Stability of Hydrated/Anhydrous Products of Calcium Chloride during Complete Dehydration as Examined by High-temperature X-ray Powder Diffraction, J. Phys. Chem. Solids. 120 (2018) 167-172. https://doi.org/10.1016/j.jpcs.2018.04.034.

[35] J. Partanen, P. Backman, R. Backman, M. Hupa, Absorption of HCl by Limestone in Hot 
Flue Gases. Part II: Importance of Calcium Hydroxychloride, Fuel. 84 (2005) 1674-1684. https://doi.org/10.1016/j.fuel.2005.02.012.

[36] A.K. Galwey, G.M. Laverty, The Thermal Decomposition of Magnesium Chloride Dihydrate, Thermochim. Acta. 138 (1989) 115-127.

[37] J. de Bakker, J. Lamarre, J. Peacey, B. Davis, The Phase Stabilities of Magnesium Hydroxychlorides, Metall. Mater. Trans. B Process Metall. Mater. Process. Sci. 43 (2012) 758-763. https://doi.org/10.1007/s11663-012-9673-z.

[38] J. de Bakker, J. Peacey, B. Davis, Thermal Decomposition Studies on Magnesium Hydroxychlorides, Can. Metall. Q. 51 (2012) 419-423.

[39] S. Kashani-Nejad, K.W. Ng, R. Harris, Preparation of MgOHCl by Controlled Dehydration of $\mathrm{MgCl}_{2} \cdot 6 \mathrm{H}_{2} \mathrm{O}$, Metall. Mater. Trans. B. 35 (2004) 405-406.

[40] S. Kashani-Nejad, K.W. Ng, R. Harris, MgOHCl Thermal Decomposition Kinetics, Metall. Mater. Trans. B Process Metall. Mater. Process. Sci. 36 (2005) 153-157.

[41] Q. Huang, G. Lu, J. Wang, J. Yu, Thermal Decomposition Mechanisms of $\mathrm{MgCl}_{2} \cdot 6 \mathrm{H}_{2} \mathrm{O}$ and $\mathrm{MgCl}_{2} \cdot \mathrm{H}_{2} \mathrm{O}$, J. Anal. Appl. Pyrolysis. 91 (2011) 159-164.

[42] H.-C. Eom, H. Park, H.-S. Yoon, Preparation of Anhydrous Magnesium Chloride from Magnesium Chloride Hexahydrate, Adv. Power Technol. 21 (2010) 125-130. https://doi.org/10.1007/s11663-012-9777-5.

[43] Q.-Z. Huang, G.-M. Lu, J. Wang, J.-G. Yu, Mechanism and Kinetics of Thermal Decomposition of $\mathrm{MgCl}_{2}$ × $6 \mathrm{H}_{2} \mathrm{O}$, Metall. Mater. Trans. B Process Metall. Mater. Process. Sci. 41B (2010) 1059-1066.

[44] N.B. Zhou, B.Z. Chen, X.K. He, Y.B. Li, Preparation and Characteristic Research of Anhydrous Magnesium Chloride with Dehydrated Ammonium Carnallite, J. Cent. South Univ. Technol. (English Ed. 13 (2006) 373-378. https://doi.org/10.1007/s11771-0060051-3.

[45] Z. Zhang, X. Lu, Y. Yan, T. Wang, The Dehydration of $\mathrm{MgCl} 2 \cdot 6 \mathrm{H} 2 \mathrm{O}$ by Inhibition of Hydrolysis and Conversion of Hydrolysate, J. Anal. Appl. Pyrolysis. 138 (2019) 114-119. https://doi.org/10.1016/j.jaap.2018.12.014.

[46] G.-S. Chen, I.-W. Sun, K.D. Sienerth, A.G. Edwards, G. Mamantov, Removal of Oxide Impurities from Alkali Haloaluminate Melts Using Carbon Tetrachloride, J. Electrochem. Soc. 140 (1993) 1523-1526. https://doi.org/10.1149/1.2221596.

[47] I.-W. Sun, K.D. Sienerth, G. Mamantov, The Use of Phosgene for the Removal of Oxide Impurities from a Sodium Chloroaluminate Melt Saturated with Sodium Chloride, J. Electrochem. Soc. 138 (1991) 2850-2852. https://doi.org/10.1149/1.2085328. 
[48] K. Sugimoto, R.E. Dinnebier, J.C. Hanson, Structures of Three Dehydration Products of Bischofite from in situ Synchrotron Powder Diffraction Data $(\mathrm{MgCl} 2 \cdot \mathrm{nH} 2 \mathrm{O} ; \mathrm{n}=1,2,4)$, Acta Crystallogr. Sect. B Struct. Sci. 63 (2007) 235-242.

https://doi.org/10.1107/S0108768107002558.

[49] H.H. Emons, R. Naumann, T. Pohl, H. Voigt, Thermoanalytical Investigations on the Decomposition of Double Salts - I. The Decomposition of Carnallite, J. Therm. Anal. 29 (1984) 571-579. https://doi.org/10.1007/BF01913466.

[50] R.K. Motkuri, R.S. Vemuri, D. Barpaga, H. Schaef, J.S. Loring, P.F. Martin, D.B. Lao, S.K. Nune, B.P. McGrail, An Efficient, Solvent-Free Process for Synthesizing Anhydrous MgCl2, ACS Sustain. Chem. Eng. 6 (2018) 1048-1054.

https://doi.org/10.1021/acssuschemeng.7b03366.

[51] S. Shoval, S. Yariv, The Effect of Alkali-chloride on the Thermal Hydrolysis of Hydrated Magnesium-chloride, Thermochim. Acta. 92 (1985) 819-822.

https://doi.org/10.1016/0040-6031(85)86003-2.

[52] H.E. Friedrich, B.L. Mordike, Magnesium Technology: Mettalurgy, Design Data, Applications, Springer, Berlin, Germany, 2006.

[53] S. Kashani-Nejad, K.W. Ng, R. Harris, Chlorination of $\mathrm{MgOHCl}$ with $\mathrm{HCl}$ Gas, Miner. Process. Extr. Metall. IMM Trans. Sect. C. 115 (2006) 121-122. https://doi.org/10.1179/174328506X91383.

[54] G.L. Haag, Kinetics of the Hydrolysis of $\mathrm{MgCl} 2$ and the Chlorination of Magnesia, Iowa State University, 1977.

[55] K.W. Ng, S. Kashani-Nejad, R. Harris, Kinetics of MgO chlorination with HCl gas, Metall. Mater. Trans. B Process Metall. Mater. Process. Sci. 36B (2005) 405-409. https://doi.org/10.1007/s11663-005-0069-1.

[56] N. Klammer, C. Engtrakul, Y. Zhao, Y. Wu, J. Vidal, Method to Determine MgO and $\mathrm{MgOHCl}$ in Chloride Molten Salts, Anal. Chem. 92 (2020) 3598-3604.

[57] A.D. Harris, L.H. Kalbus, Decomposition of copper(II) sulfate pentahydrate: A sequential gravimetric analysis, J. Chem. Educ. 56 (1979) 417-418. https://doi.org/10.1021/ed056p417.

[58] K. Nagase, H. Yokobayashi, K. Sone, Spectrophotometric and Thermal Analytical Studies on the Dehydration of Copper(II) Sulfate and Its Double Salts, 1Thermochimica Acta. 23 (978) 283-291.

[59] M. Suzuki, A. Uehara, Preparation, and Thermal and Electronic Properties of Double Complex Salts and Cyanide-bridged Complexes Containing Cationic Copper(II) Complexes and Hexacyanoferrate(II) Ion, Bull. Chem. Soc. Jpn. 57 (1084) 3134-3138. 
[60] C.C.M. Rindt, S. V. Gaastra-Nedea, Modeling Thermochemical Reactions in Thermal Energy Storage Systems, Woodhead Publishing Limited, 2015. https://doi.org/10.1533/9781782420965.3.375.

[61] L.C. Sögütoglu, M. Steiger, J. Houben, D. Biemans, H.R. Fischer, P. Donkers, H. Huinink, O.C.G. Adan, Understanding the Hydration Process of Salts: The Impact of a Nucleation Barrier, Cryst. Growth Des. 19 (2019) 2279-2288. https://doi.org/10.1021/acs.cgd.8b01908.

[62] C.W. Bale, E. Bélisle, P. Chartrand, S.A. Decterov, G. Eriksson, A.E. Gheribi, K. Hack, I. Jung, Y. Kang, J. Melançon, A.D. Pelton, S. Petersen, C. Robelin, J. Sangster, P. Spencer, M. Van Ende, CALPHAD: Computer Coupling of Phase Diagrams and Thermochemistry FactSage Thermochemical Software and Databases , 2010 - 2016, Calphad. 54 (2016) 3553.

[63] A. Komura, H. Imanaga, N. Watanabe, K. Nakanishi, Solubility of Magnesium in Molten Magnesium Chloride, J. Soc. Chem. Ind. Japan. 71 (1968) 1976-1979.

[64] M.A. Bredig, Mixtures of Metals with Molten Salts, 1963.

[65] M. Krumpelt, J. Fischer, I. Johnson, The Reaction of Magnesium Metal with Magnesium Chloride, J. Phys. Chem. 72 (1968) 506-511. https://doi.org/10.1021/j100848a020.

[66] J. Wypartowicz, T. Ostvold, H.A. Oye, The Solubility of Magnesium Metal and The Recombination Reaction in the Industrial Magnesium Electrolysis, Electrochim. Acta. 25 (1980) 151-156.

[67] J.W. McMurray, S.S. Raiman, Thermodynamic Modeling of the $\mathrm{K}-\mathrm{KCl}$ and $\mathrm{Mg}-\mathrm{MgCl}_{2}$ Binary Systems using the CALPHAD Method, Sol. Energy. 170 (2018) 1039-1042. https://doi.org/10.1016/j.solener.2018.06.013.

[68] K.L. Strelets, Chapter XI: Electrolysis. Physicochemical Properties of the Electrolyte, in: Electrolytic Prod. Magnes., 1977: p. 218.

[69] J. Schenin-King, G.S. Picard, Oxoacidity Effect on Metallic Oxide Dissolution Reactions in Fused Chlorides, in: Proc. First Eur. Work. Electrochem. Technol. Molten Salts, 1993: pp. 13-22.

[70] N. Cohen, Flammability and Explosion Limits of H2 and H2/Co: A Literature Review, 1992.

[71] D. John, G. Hansel James, P. Tom, Influence of Temperature on Flammability Limits of Heat Treating Atmosphere, Jinshu Rechuli/Heat Treat. Met. 36 (2011) 105-108.

[72] Z.M. Shapiro, T.R. Moffette, Hydrogen Flammability Data and Application to PWR Lossof-Coolant Accident, 1957. https://doi.org/OSTI Identifier: 4327402. 
[73] J.A. Plambeck, Electromotive Force Series in Molten Salts, J. Chem. Eng. Data. 12 (1967) 77-82.

[74] C.G. Maier, Vapre Pressures of The Common Metallic Chlorides and A Static Method for High Temperatures, 1st ed., Government Printing Office, Washing, D.C., 1925.

[75] G.J. Janz, F.W. Dampier, G.R. Lakshminarayanan, P.K. Lorenz, R.P.T. Tomkins, Molten Salts : Vol 1, Electrical Conductance, Density, and Viscosity Data, 1968. https://nvlpubs.nist.gov/nistpubs/Legacy/NSRDS/nbsnsrds15.pdf.

[76] G.J. Janz, B. Allen, Carolyn, N.P. Bansal, R.M. Murphy, R.P.. Tomkins, Physical Properties Data Compilations Relevant to Energy Storage. II. Molten Salts: Data on Single and Multi-Components Salt Systems, 1979.

[77] M. Allibert, H. Gaye, J. Geisler, D. Janke, B.J. Keene, D. Kirner, M. Kowalski, J. Lehmann, K.C. Mills, D. Neuschutz, R. Parra, C. Saint Jours, P.J. Spencer, M. Susa, M. Tmar, E. Woermann, Slag Atlas, 2nd ed., Verlag Stahleisen GmbH, Dusseldorf, 1995.

[78] N.N. Achar, G.R. Barsch, Thermal Expansion of Rocksalt, Phys. Rev. B. 3 (1971) $4352-$ 4360 .

[79] T. Rubin, H.L. Johnston, H.W. Altman, Thermal Expansion of Rock Salt, J. Phys. Chem. 65 (1961) 65-68. https://doi.org/10.1021/j100819a021.

[80] R. Srinivasan, Thermal Expansion of Sodium and Potassium Chlorides From Liquid-Air Temperatures To $+300^{\circ} \mathrm{C}$, J. Indian Inst. Sci. 37 (1955) 232-241.

[81] B.J. Konijn, O.B.J. Sanderink, N.P. Kruyt, Experimental Study of the Viscosity of Suspensions: Effect of Solid Fraction, Particle Size and Suspending Liquid, Powder Technol. 266 (2014) 61-69. https://doi.org/10.1016/j.powtec.2014.05.044.

[82] R.S. Bradley, P. Volans, Rates of Evaporation. VI. The Vapour Pressure and Rate of Evaporation of Potassium Chloride, Proc. R. Soc. London. Ser. A. Math. Phys. Sci. 217 (1953) 524-529. https://doi.org/10.1098/rspa.1953.0077.

[83] J.W. Johnson, W.J. Silva, D. Cubicciotti, E. Section, The Vapor Pressue and Enthalpy of Vaporization of Molten Bismuth Chloride to the Critical Point, J. Phys. Chem. 69 (1965) 3916-3919. https://doi.org/10.1021/j100895a046.

[84] Y. Zhang, E. Shibata, E. Kasai, T. Nakamura, Vapor Pressure Measurements for Metal Chloride Systems by the Knudsen Effusion Method, Mater. Trans. 46 (2005) 1348-1353. https://doi.org/10.2320/matertrans.46.1348.

[85] G. Mohan, M. Venkataraman, J. Gomez-Vidal, J. Coventry, Assessment of a novel ternary eutectic chloride salt for next generation high-temperature sensible heat storage, Energy Convers. Manag. 167 (2018) 156-164. https://doi.org/10.1016/j.enconman.2018.04.100. 